\title{
Anna Schmidt
}

\section{Form und Deformation}

\author{
Zum kunsttheoretischen \\ und dramatischen Werk \\ von Stanisław Ignacy Witkiewicz
}

Verlag Otto Sagner München · Berlin - Washington D.C.

Digitalisiert im Rahmen der Kooperation mit dem DFG-Projekt „Digi20“

der Bayerischen Staatsbibliothek, München. OCR-Bearbeitung und Erstellung des eBooks durch den Verlag Otto Sagner:

http://verlag.kubon-sagner.de

() bei Verlag Otto Sagner. Eine Verwertung oder Weitergabe der Texte und Abbildungen, insbesondere durch Vervielfältigung, ist ohne vorherige schriftliche Genehmigung des Verlages unzulässig. 


\title{
Slavistische Beiträge
}

\author{
BEGRÜNDET VON \\ ALOIS SCHMAUS \\ HERAUSGEGEBEN VON \\ HEINRICH KUNSTMANN \\ PETER REHDER - JOSEF SCHRENK \\ REDAKTION \\ PETER REHDER
}

Band 294

VERLAG OTTO SAGNER

MÜNCHEN 


\section{Anna Schmidt}

\section{FORM UND DEFORMATION \\ Zum kunsttheoretischen und dramatischen Werk von Stanisław Ignacy Witkiewicz}

\section{VERLAG OTTO SAGNER - MÜNCHEN}


ISBN 3-87690-533-8

(c) Verlag Otto Sagner, München 1992 


\section{VORBEMERKUNG}

Die vorliegende Arbeit wurde im Wintersemester $1991 / 92$ von der Philosophischen Fakultăt II (Sprach- und Literaturwissenschaften) der FriedrichAlexander-Universität Erlangen-Nünberg als Inaugural-Dissertation angenommen.

Ich mochte besonders meinem Doktorvater. Herrn Prof. Dr. U. Steltner fur seine Hinweise, Anregungen und die verstăndnisvolle, ermutigende Betreuung dieser Arbeit danken. Mein Dank gilt auch Herrn Prof. Dr. J. Lehmann fur seine fördernde Kritik.

Beim Endkampf mit den Korrekturen hat mich Herr G. Lindner wirksam unterstutzt. Fur seine Geduld und Sorgfalt bei der Durchsicht des Manuskripts morchte ich ihm an dieser Stelle herzlich danken.

Schließlich danke ich dem Herausgeber Herrn Prof. P. Rehder dafur, daß er diese Untersuchung in die Reihe "Slavistische Beitrăge" aufgenommen hat.

Erlangen, im September 1992

Anna Schmidt 
Anna Schmidt - 9783954791224 


\section{INHALTSVERZEICHNIS}

Vorwort 9

1. Einleitung 15

1.1. Kurzbiographie 15

1.2. Philosophie 23

1.3. Kunsthistorischer Hintergrund 30

1.4. Rezeption und Forschungslage 33

2. Die Theorie der Reinen Form 43

2.1. Allgemeine Ästhetik 43

2.1.1. Kunstbegriff 43

2.1.2. Ästhetische Erfahrung 49

2.1.3. Form- und Inhaltsbegriff 58

2.1.4. Gegenstăndlicher Inhalt. Deformation 70

2.2. Literarische Xisthetik 76

2.2.1. Theorie der kunstlerischen Sprache 76

2.2.2. "Reine Form" im Theater 91

2.2.3. Deformationsverfahren im Drama 104

2.2.4. Auffuhrungspraxis und Schauspielkunst 109

3. Dramenanalyse 112

3.1. Die Schicht der Laut- und Bedeutungseinheiten 120

3.1.1. Titel 122

3.1.1.1. Haupttitel 124

3.1.1.2. Untertitel 132

3.1.1.3. Motto und Widmung 134

3.1.2. Figurennamen 136

3.1.3. Dialogf Uhrung 148

3.2. Die Schicht der dargestellten Gegenstăndlichkeiten 162

3.2.1. Figuren 162

3.2.1.1. Figurenkonzeption 164

3.2.1.2. Figurenkonstellation $\quad 181$

3.2.2. Fabel und Geschichte 192 
5. Literaturverzeichnis 240

5.1. Primärliteratur 240

5.2. Deutsche Ubersetzungen 241

5.3. Sekundärliteratur zu Witkiewicz

5.3.1. Bibliographien 244

5.3.2. Sammelwerke 244

5.3.3. Einzeldarstellungen 245

5.4. Sonstige Sekundärliteratur 250

6. Abkurzungsverzeichnis

257 


\section{VORWORT}

"Denn dieses ganze Werk, sein Stil, seine Ideen und sein Schicksal, das ist eine seltsame Geschichte. Sehr polnisch, etwas europaisch und unerhört verwickelt. Verwickelt im vielfachen Sinn. Schon die Vielfalt der von Witkacy betriebenen Disziplinen ruft Verlegenheit hervor: Malerei, Roman, Drama, Kunsttheorie, Ontologie; alles sehr individuell, schwierig mit ein paar Worten zu umschreiben, fesselnd als ein intellektueller Vorschlag, und dabei unlösbar miteinander verbunden. Und zu der Vielgleisigkeit von Witkiewicz' Interessen kommt die innere Vielschichtigkeit seines Werkes hinzu." 1

Stanisław Ignacy Witkiewicz (1885-1939), genannt Witkacy (ein Kompositum aus dem Nachnamen und dem zweiten Vornamen, welches Witkiewicz als Pseudonym benutzte, um nicht mit seinem beruhmten Vater Stanisław Witkiewicz verwechselt zu werden), gehört zu den faszinierendsten Gestalten der europäischen historischen Avantgarde. Die im vorangehenden Zitat erwăhnte Vielseitigkeit seiner Begabung erinnert an Kunstler der Renaissance und der Aufklărung. Eine Pionierrolle kommt Witkiewicz insbesondere im Bereich des Theaters zu. In Anlehnung an die abstrakte Malerei entwickelte er nach dem 1. Weltkrieg die sog. Theorie der Reinen Form im Theater, mit der er sich gegen das naturalistische und symbolistische Drama wandte. In den 20 er Jahren verfaßte er an die 40 Dramen (davon sind etwa 20 erhalten), die das moderne grotesk-absurde Theater, welches sich in Westeuropa erst seit den 50er Jahren entwickelte, vorwegnahmen und seine relativ fruhe Entstehung in Polen entscheidend beeinflußten. ${ }^{2}$ Witkiewicz' Dramen und seine Kunsttheorie wurden zwar zu seinen Lebzeiten nicht anerkannt, dennoch sehr heftig diskutiert, und letztendlich gingen von ihnen entscheidende Impulse fur das polnische Theater und fur Autoren wie w. Gombrowicz, B. Schulz, Cz. Miłosz, T. Rozewicz aus.

1 Puzyna, K.: Vorwort. In: Werke, IV: 5.

2 Eine vergleichbare Bedeutung fur die Entwicklung des Absurden Theaters im Westen hatte die westliche Theater-Avantgarde des fruhen 20 . Jahrhunderts (A. Jarry, M. Maeterlinck, L. Pirandello, A. Artaud, Y. Goll). F. N. Mennemeier - der auch St. 1. Witkiewicz und W. Gombrowicz erwăhnt - bezeichnet in diesem Zusammenhang das Absurde Theater als eine "postavantgardistische" Bewegung. (Vgl. F.N. Mennemeier: Absurdes Theater. In: Borchmeyer/Zmegac (Hrsg.), 1987: 13.) 
Die Theorie der Reinen Form ${ }^{3}$ gehört in die Reihe der zahlreichen formalistischen Kunsttheorien im ersten Viertel des 20. Jahrhunderts, die aus einer antinaturalistischen Haltung heraus die Dominanz der Gegenstănde in der Kunst ablehnten ${ }^{4}$. Ihr Grundgedanke erinnert an den 1890 von Maurice Denis geprăgten und in den damaligen kunsttheoretischen Debatten of $\mathrm{zi-}$ tierten Satz: "ein Bild, bevor es irgend etwas darstelle, habe eine ebene Flăche zu sein, bedeckt mit Farben in einer bestimmten Ordnung. Diese Ordnung verändere das Erscheinungsbild der Gegenstände durch objektive und subjektive Deformation, d.h. zugunsten flăchendekorativer allgemeingultiger (daher objektiver) Schönheit und zum Ausdruck des besonderen (subjektiven) Gehaltes." 5 Auch Witkiewicz forderte, daß das Kunstwerk aus seinen rein formalen Elementen (Farben und Flăchen) nach einem subjektiven Formempfinden des Künstlers konstruiert werden sollte. Die Naturăhnlichkeit der dargestellten Gegenstănde sei dabei von untergeordneter Bedeutung, aus bildkonstruktiven Gründen könne sie auch aufgegeben werden, d.h. die Gegenstănde können "deformiert" werden. Interessanterweise wandte Witkiewicz die Theorie der Reinen Form nicht nur auf die bildende, sondern auch auf die sprachliche Kunst an, und zwar mit Hilfe einer für seine Zeit sehr modernen Sprachtheorie. Danach sollten die sprachlichen Zeichen in einem literarischen Kunstwerk - ăhnlich wie in der Musik und Malerei - zueinander in formalen und nicht in inhaltlichen Relationen stehen. Die referentielle Funktion des Textes könnte aus formalkonstruktiven Grüden deformiert werden.

Aus der erstaunlichen Doppelbegabung Witkiewicz' - er war sowohl Kunstler als auch ein anerkannter Philosoph - ergab sich das Faktum, daß die Theorie der Reinen Form eine der wenigen formalistischen Ästhetiken ist, die auch ein nntolngierhes. gearhirhte- und eprarhphilnenphierhoe Fundament hat.

Die hier nur kurz angerissenen Hauptaspekte von Witkiewicz' ăsthetischer

3 Eine genauere Darstellung der Theorie der Reinen Form erfolgt im 2. Kapitel. An dieser Stelle sollen nur deren wesentlichste Aspekte dargelegt werden, die für die Erörterung der Fragestellung und der methodischen Konzeption dieser Arbeit relevant sind.

4 Vgl. z.B.: Worringer, 1907/1987; Gleizes/Metzinger, 1912; Kandinskij, 1912/1952; Malevic 1927/1989.

S Hess, W.: Ursprung neuer Bildvorstellungen. In: Hess (Hrsg.), 1988: 19. 
Theorie und literarischer Praxis deuten schon die Aktualităt dieses Autors an. Die Deformationen von Sinneinheiten werden heute in der von J. Derrida ausgelösten Diskussion uber Dekonstruktion in Philosophie und Literaturtheorie vielfach erörtert. Neu erwacht ist auch das Interesse am Kunstverständnis der historischen Avantgarde, seitdem sie von J.-F. Lyotard zur Asthetik der Postmoderne erklärt wurde. 'Witkiewicz' Năhe zur Postmoderne ist ubrigens in der (v.a. amerikanischen) Forschung mehrmals festgestellt worden. 'Diese Tatsache soll hier aber nur als ein Argument fur die Aktualităt der von Witkiewicz aufgeworfenen Probleme angefuhrt werden. Das Ziel der vorliegenden Arbeit ist nicht, eine eindeutige Position hinsichtlich der literaturgeschichtlichen Zuordnung Witkacys zu beziehen. In Anbetracht des gegenwartig sehr kontrovers diskutierten und noch recht vagen Postmoderne-Begriffes wirde ein solches Ziel eine ganz andere Themenstellung und Anlage der Arbeit verlangen.

Thema der vorliegenden Arbeit ist die Konzeption und Leistung der formalistischen Xisthetik von St. I. Witkiewicz. Untersuchungsgegenstand sind die Theorie der Reinen Form und die Dramen der fruhen 20er Jahre. Von einem engen Zusammenhang zwischen den beiden Bereichen seines Schaffens, der von Witkacy immer beteuert wurde, wird zunăchst a priori ausgegangen. Er soll in der weiteren Arbeit nachgewiesen und erlăutert werden.

Die Untersuchung erfolgt in zwei Schritten. Zunăchst sollen in hermeneutischer Vorgehensweise die wesentlichen Aspekte von Witkiewicz' Xsthetik und Dramentheorie herausgearbeitet und systematisiert sowie im Kontext seiner anderen Schriften und im Vergleich mit verwandten Dramentheorien erklärt werden. Der zweite Schritt besteht in einer phănomenologischen Analyse der elnzelnen Schichten der Dramen in Anlehnung an $R$. Ingardens Schichtenmodell des literarischen Werkes ${ }^{8}$. Es werden alle Dramen untersucht, die Anfang der 20er Jahre und somit fast gleichzeitig mit den dramentheoretischen Schriften Witkacys entstanden sind. Das 1931-34 entstandene Drama "Die Schuster" soll nur als Beispiel fur eventuelle Weiterentwicklungen bestimmter Tendenzen im Dramenschaffen Witkiewicz' herangezo-

\footnotetext{
6 Lyotard, 1984: 151-164.

7 Vgl. 2.B.: Gerould, 1990; Wirth, 1985: 318; .

8 Vgl. Ingarden, 1972.
} 
gen werden. Die Dramenanalyse erfolgt in einem systematischen Querschnitt durch das gesamte Dramenwerk.

Der oben geschilderte methodische Ansatz dieser Arbeit ist also von der Dualităt zwischen ästhetischer Theorie und dramatischer Praxis geprägt. Eine derartige Konzeption darf natürlich nicht zu einer unzulässigen Verknupfung der beiden Ebenen fuhren.

Wie R. Ingarden theoretisch begrundete?, sind alle Aussagen in einem literarischen Werk sog. "Quasi-Urteile", die nur innerhalb der fiktiven Sphăre des Werkes Gultigkeit besitzen. Es wăre also unzulässig, die Aussagen aus dem Drama in die philosophische Theorie zu projizieren. Genauso falsch wäre der Versuch, die ÄuBerungen der Dramenfiguren mit Hilfe der bekannten philosophischen Erkenntnisse Witkiewicz' zu vertiefen und im Hinblick auf ein Thema oder gar die Idee des Werkes interpretativ weiterzuruhren. Gerade bei einem Autor wie Witkiewicz ist ein derartiges Vorgehen besonders verlockend, weil er in seinen literarischen Werken gerne die eigenen oder zeitgenössischen philosophischen Schriften zitiert. Allerdings - wie die genauere Strukturanalyse zeigt - nicht um die inhaltliche "Aussage" des Werkes zu vertiefen, sondern um antillusionistische Effekte a la Pirandello zu erzeugen.

Damit eine derartige Vermischung zwischen Theorie und Praxis nicht zustande kommt, werden die einzelnen Untersuchungsschritte nicht nur durch das zeitliche Nacheinander in der Darstellung getrennt, sondern auch durch die methodisch unterschiedlichen Vorgehensweisen: im Fall der ästhetischen Theorie handelt es sich um eine hermeneutische Begriffsanalyse und im Fall der Dramen um eine phänomenologische Strukturanalyse.

Ein entscheidender Vorteil einer solchen, zwischen ästhetischer Theorie und literarischer Praxis eingespannten Konzedtion liegt in der Mrglichkeit eines Wechselspiels zwischen dem Ansatz einer induktiven und einer deduktiven Untersuchung. Die deduktiv hergeleiteten ästhetischen Grundthesen Witkiewicz' können als erkenntnisleitende Arbeitshypothesen für die Textanalyse im Sinne der Feststellung von $F$. v. Kutschera dienen:

"Erst aus Hypothesen ergeben sich Fragestellungen, unter denen man die Phănomene systematisch untersuchen kann. Einzelanalysen ohne Hypothesen sind blind. Umgekehrt gilt: Sinnvolle Hypothesen lassen

9

Ebd.: $169 f f$. 
sich nur aufgrund einer gewissen Kenntnis der Phänomene entwerfen, und mussen sich an ihnen bewahren $\langle\ldots\rangle^{n^{10}}$.

Die zwei wichtigsten Untersuchungsaspekte der Dramenanalyse, die sich aus Witkiewicz' Kunsttheorie ergeben, sind: die Deformation der lebenslogischen Elemente und die Komposition rein formaler Elemente des Dramas.

Die Dramenanalyse wird sich nicht nur auf die Analyse von einzelnen Strukturelementen beschränken, sondern es soll auch die Funktion des Ganzen - der Stil und die vermittelten ästhetischen Erfahrungen - beschrieben werden. Der funktionale Aspekt der Dramenanalyse schlăgt wiederum die Brucke zur ästhetischen Theorie: bei der Untersuchung der vermittelten ästhetischen Erfahrungen soll auch die theoretisch postulierte "formistische" ăsthetische Erfahrung erörtert werden. Zum Schluß wird die Frage zu klären sein, ob und in welcher Weise die von Witkiewicz' Dramen vermittelten asthetischen Erfahrungen mit der in seiner Theorie beschriebenen Wirkungsintention Ubereinstimmen.

In Anbetracht der relativen Unbekanntheit Witkiewicz' im deutschen Sprachraum - anders als im englischen und franzøsischen" - wird der Arbeit eine kurze Darstellung des Lebens, des Werkes, der Philosophie und der Rezeptionsgeschichte Witkiewicz' (mit Hinweisen auf weiterfuhrende Literatur) vorangestellt und eine umfangreiche Bibliographie mit dem Verzeichnis aller deutschen Ubersetzungen von Witkiewicz' Werken angefugt.

Die Arbeit will ein Beitrag zur Rezeption Witkiewicz' in Deutschland sein. Daruber hinaus sollen am Beispiel der ăsthetischen Theorie und der dramatischen Praxis Witkiewicz' sowie im Vergleich mit verwandten Erscheinungen in der europăischen Literatur allgemeine literaturwissenschaftliche und dramentheoretische Fragestellungen erörtert werden: der Begriff von "Form und Inhalt" in der Literatur, die "Deformation" als Strukturelement des Dramas und die Frage nach einer "formistischen" ăsthetischen Erfahrung im Theater.

\footnotetext{
${ }^{10}$ Kutschera, 1988: 4.

${ }^{11} \mathrm{Vgl}$. Kapitel 1.4 in dieser Arbeit.
} 
Die Zitate aus dem Polnischen wurden - wenn nicht anders vermerkt - von der Verfasserin ins Deutsche ubersetzt. Theoretische, wissenschaftliche oder beschreibende Texte werden nur in deutscher Ubersetzung zitiert, wobei wichtigere oder schwer übertragbare Begriffe auch im Original angefuhrt werden. Bei Fragmenten aus fiktiven Werken, bei denen die sprachliche Form ästhetisch relevant ist, wird im allgemeinen zweisprachig zitiert. Bei einigen theoretischen Begriffen wird die von Witkiewicz verwendete Großschreibung (z.B. Reine Form) beibehalten. 


\section{EINLEITUNG}

\section{I.1. KURZBIOGRAPHIE}

Stanisław Ignacy Witkiewicz wurde als das einzige Kind von Stanisław Witkiewicz, einem in Polen bekannten Maler, Romancier und Kunstkritiker, und von Maria Pietrzkiewicz, einer Musiklehrerin, am 24. Februar 1885 in Warschau geboren. Die Familie Witkiewicz entstammt dem litauischen Landadel. Wegen des schlechten Gesundheitszustandes des Vaters zieht die Familie kurz nach der Geburt des Sohnes nach Zakopane in die Tatra. St. I. Witkiewicz verbringt dort den grösten Teil seines Lebens. Er wăchst in einer besonderen Atmosphăre auf: in einem Elternhaus, in welchem die kunstlerische und intellektuelle Elite Polens verkehrt; vergottert von seinem Vater und der gesamten Umgebung, die in ihm ein Wunderkind sieht. Der Vater, ein Nietzsche-Anhänger, ist gegen eine gewbhnliche Schulbildung, die nach seiner Uberzeugung nur MittelmäBigkeit und Anpassung bewirkt:

"In unserer Zeit $\langle. .$.$\rangle steht die Schule vollig in Opposition zu der$ menschlichen Psychologie 〈...〉, die Lehrmethoden und -ziele haben nichts mit dem lebenden Menschen und dem wirklichen Leben gemein <...>, man hat Methoden zur Zerstörung selbstăndiger Kreativităt des Verstandes, zur Zersetzung und Erweichung schöpferischer Energie erfunden und das alles mit dem einzigen und endgultigen Ziel: das Relfezeugnis! Nicht die Wissenschaft, nicht das Wissen, nicht die Entwicklung des Talents, nicht die Tugend: das Reifezeugnis! <Hervh. im Original $>^{n}$

Die Erziehung und Bildung soll nach St. Witkiewicz nur die naturlichen Neigungen, Talente und Interessen behutsam unterstutzen. Auf diesem Weg will er aus seinem Sohn eine außergewöhnliche, geniale Persönlichkeit formen.

In den etwa funfhundert Briefen, die er später an den jungen Witkacy schreibt, klingt diese Haltung an: sie sind voll idealistisch-uberzogener Ermahnungen, frei, stolz und kreativ zu sein. Diese Forderungen werden reichlich mit entsprechenden Nietzsche-Zitaten bekräftigt:

1 Witkiewicz, St.: Dziwny człowiek. Lwow 1903. S. 24f. Zit. nach: Witkiewicz (St.), 1969: 672. 
"Greife in Deinen intellektuellen Konzepten nach der Unendlichkeit, gehe in Deinen sozialen Ideen bis an die außerste Grenze der maßlosen, der universellen Liebe <...>. Lasse Dich durch keine gesellschaftlichen Schranken, keine fachspezifischen Vorurteile, keinen kleinlichen Personen- oder Klassenegoismus belasten <...>. Lebe in der Zukunft. Bleibe stets auf den Hohen stehen, von denen aus Du die weitesten Horizonte hast, und strecke die Flugel Deiner Gedanken und Taten aus, um uber sie hinwegzufliegen."

Den Idealen des Vaters gemäß wird St. I. Witkiewicz von Hauslehrern und Eltern unterrichtet, seine Neigungen werden von der Umgebung aufmerksam verfolgt und gefördert. Er malt und schreibt kurze Theaterstucke schon seit seinem achten Lebensjahr. Diese Jugenddramen weisen kunstlerische Mittel auf, die auch sein späteres Schaffen bestimmen sollen: Autoironie und Autothematismen, Uberraschende Wendungen und Lösungen, Parodie. sprachliche Erfindungskraft. D. Gerould stellt eine Nahe zu A. Jarrys "Ubu roi" und eine "Comics-ăhnliche Lebendigkeit" in ihnen fest ${ }^{3}$. Mit 17 verfaßt Witkiewicz seine ersten philosophischen Abhandlungen "Uber den Dualismus" und "Die Philosophie von Schopenhauer und ihr Verhaltnis zu den Vorgăngern"4. Er lernt Englisch, Französisch, Deutsch und Russisch, beschaftigt sich - hăufig unter Anleitung berühmter Wissenschaftler, die im Haus seines Vaters verkehren - mit Naturwissenschaften und höherer Mathematik, nimmt Musikunterricht bei seiner Mutter.

1903 macht Witkacy als Externer in Lemberg sein Abitur, und 1905 immatrikuliert er sich gegen den Wunsch seines Vaters an der Krakaver Kunstakademie. Erwartungsgemäß ist er ein nachlässiger Student, der sich wenig um die akademischen Pflichten und Regeln schert und sein Studium nicht beendet. Dafur pflegt er Kontakte zu den fuhrenden Künstlern und Intellektuellen Polens (u.a. Karol Szymanowski, Arthur Rubinstein, Bronisław Malinowski) und lernt auf zahlreichen Reisen, die ihn nach RuBland, Italien, Deutschland, Frankreich und England füren, die europăische Kunst kennen.

1911 beendet er seinen ersten autobiographischen Roman "622 Stürze Bungos

2 Witkiewicz (St.), 1969: 143f (Brief $\mathrm{Nr}$. 92 vom 27.08.1903).

3 Gerould, 1981a: 31.

4 Erschienen erst 1977 unter dem Titel "O idealizmie i realizmie" in: Schriften, III. 
oder Das dămonische Weib" (erschienen 1972), der in rudimentărer Form die wichtigsten philosophischen und stilistischen Ideen Witkiewicz' enthät. Doch sein eigentliches Debut lät auf sich warten. Sicherlich wirken die Ubersteigerten Ambitionen und die Erwartungshaltung seiner Umgebung paralysierend auf den jungen Kunstler. Hinzu kommt die Suche nach dem eigenen Stil in einer Zeit des Neben- und raschen Nacheinander mehrerer Kunstrichtungen: Naturalismus, Symbolismus, Expressionismus, Kubismus etc. In seinen Briefen aus dieser Zeit beklagt sich St. Witkiewicz hăufig über das Zigeunerleben seines Sohnes, der dabei ist, seine schöpferische Energie unnutz zu verschwenden. In der Tat scheint der junge Kunstler hin und hergerissen zu sein zwischen tiefen Studien, küstlerischen Experimenten und exzessiv ausschweifendem Leben. Besonders qualvoll war wohl seine lange, schmerzhafte Liebesaffäre"mit der beruhmten Schauspielerin Irena Solska, die in den Stücken von Ibsen und Przybyszewski die Rolle der fernme fatale spielte und in Decadence-Manier ein entsprechendes Image offensichtlich auch im Privatleben pflegte.

1913 macht St.I. Witkiewicz eine schwere psychische Krise durch:

"Ich habe ein Paar schreckliche Kompositionen gemacht und erreichte einen Zustand volliger Gereiztheit, die an Wahnsinn grenzte. Ich habe Angst, daß ich nicht mehr zurUckkehren kann. Heute dachte ich: habe ich diese Grenze schon Uberschritten? <..>Ich bin sehr krank und vielleicht werde ich nie mehr gesund. Ich fuhle deutlich den Wahnsinn und habe eine schreckliche Angst davor."

Witkiewicz' psychischer Zustand bleibt - medizinisch betrachtet - immer etwas labil. Er macht des ofteren psychische Krisen durch und ist beherrscht von der Angst, den Verstand zu verlieren. 1913 unterzieht er sich auf Anraten der Freunde einer psychoanalytischen Behandlung. Dadurch erwacht sein ernsthaftes Interesse an S. Freud und an der Psychoanalyse, obwohl er nicht an deren Erfolge bei der Behandlung seiner Krankheit glaubt: "Wenn ich aus all dem 'rauskomme, dann nicht deshalb, weil ich mir meines Embryo-Komplexes bewußt geworden bin."

5 Listy Stanisława Ignacego Witkiewicza do Heleny Czerwijowskiej, S. $36 f$. (Brief vom 27.01.1913).

6 Ebd.: 41 (Brief vom 17.04.1913). 
Im Februar 1914 begeht Witkiewicz' Verlobte Jadwiga Janczewska Selbstmord. Verzweifelt und voller Schuldgefüle nimmt Witkacy die Einladung seines Freundes, des Ethnologen Bronistaw Malinowski, an, sich dessen Expedition nach Ceylon und Australien anzuschließen. Die exotische Welt und die besonderen Licht- und Farbverhältnisse uben einen sehr starken Einfluß auf Witkiewicz' Malerei aus. Seine Eindrücke von den primitiven Kulturen schlagen sich in den Sujets vieler seiner Dramen nieder und bestimmen auch seine Welt- und Kunstanschauung: die negative Einschätzung der europäischen Zivilisation - die an ähnlich motivierte Urteile von $P$. Gauguin, J. Conrad und A. Artaud erinnert - und die Konzeption der rituellen und magischen Aufgaben der Kunst. Von der Begegnung mit dem Exotischen gingen Ubrigens entscheidende Impulse fur die moderne Kunst aus, insbesondere fur die Bewegung des Primitivismus ${ }^{7}$. Man könnte also bei Witkacy in dieser Hinsicht auch von einem internen Einfluß - Uber die zeitgenठssischen Kunstprogramme und -experimente - ausgehen.

Beim Ausbruch des Ersten Weltkrieges meldet er sich als russischer Staatsburger freiwillig (als Einzelkind war er zum Militădienst nicht verpflichtet) zur zaristischen Armee und verletzt damit seinen Vater tief: die antizaristische Haltung hatte in der Familie Witkiewicz eine lange Tradition - Stanisław Witkiewicz verbrachte die ersten vier Jahre seines Lebens in Sibirien, wohin sein Vater wegen Teilnahme am polnischen Aufstand 1863 verbannt worden war.

Die Zeit in Rußland gehört zu der wichtigsten und zugleich am wenigsten bekannten Zeitspanne seines Lebens ${ }^{8}$. Hier macht er die Erfahrungen, die ihn menschlich am meisten geprägt haben, und in dieser Zeit reifen auch seine ästhetischen und kulturgeschichtlichen Ideen.

Im September 1914 tritt er in die Offizierssrhule in Petershurg ein und dient anschlieBend in dem elităren Pavlovskij-Regiment. 1915 wird er an der Front verwundet und hält sich dann vorwiegend in Petersburg auf. Er setzt seine Malereistudien fort und arbeitet an philosophischen und ästhetischen Theorien. Wăhrend der Februar-Revolution gerät er plötzlich auf die Seite der Revolutionäre - er wird von seinen Soldaten zum Kommis-

\footnotetext{
7 Vgl. dazu: Goldwater, 1967; Zelinsky, 1983.

8 Vgl. dazu: Witkiewicz (J.S.), 1977.
} 
sar gewăhlt - eine Ehrung, die er nach seinen Worten "der schwachen Ausprăgung seiner negativen Verdienste" verdankte: er schlug und beschimpfte seine Soldaten nicht, strafte milde und war relativ hoflich. ${ }^{9}$ Witkacy erlebt also die Wirren des Krieges und der Revolution, den Zerfall der gesellschaftlichen und politischen Ordnung, die Angst, die Hemmungs- und Orientierungslosigkeit in den oberen Gesellschaftsschichten und die zunehmende Macht der hungernden und unterdruckten Massen aus unmitellbarer Năhe. In diesen Erlebnissen wurzelt sicherlich der tiefe Pessimismus Witkiewicz', der seine Philosophie und die Thematik seiner Werke beherrscht. Pessimismus gehört allerdings auch zur geistigen Haltung vieler von witkiewicz' Zeitgenossen - ein signifikantes Beispiel dafür ist die Geschichtsphilosophie von 0 . Spengler ("Der Untergang des Abendlandes", entstanden 1918-22).

Im Juni 1918 kehrt Witkacy nach Krakau zuruck und schlieBt sich der als "Formisten" bekannten Malergruppe an. Erst jetzt, mit 33 Jahren, beginnt sein eigentliches kunstlerisches Schaffen - dafur aber in einem fieberhaften Tempo. 1919-24 ist der produktivste Abschnitt seines kunstlerischen Wirkens. Er formuliert und veröffentlicht seine wichtigsten asthetischen Schriften: "Neue Formen in der Malerei und die daraus resultierenden Mißverständnisse" (1919), "Ẍsthetische Skizzen" (1922) und "Theater" (1923).

In Analogie zur Ästhetik des Kubismus entwickelt er seine Theorie der "Reinen Form" im Theater, mit der das konventionelle, naturalistische Drama abgelరst werden sollte. Das Drama soll nach seiner Theorie keine Nachahmung der realen Welt sein, sondern eine dem asthetischen Sinn des Kunstlers entsprungene Komposition von Einzelelementen: der Sprache, der Mimik und Gestik der Schauspieler, der Farben und Formen des Buhnenbildes. Die Wirklichkeitsnăhe der Ereignisse, der Handlungen oder der Figuren kann nicht vollig vermieden werden, sie soll aber nicht den wesentlichen Inhalt des Stückes ausmachen, sondern nur für die "Richtungsspannungen der kompositorischen Massen" von grundlegender Bedeutung sein. ${ }^{10}$

9 Witkiewicz, St.I.: Niemyte dusze. Studia obyczajowe i społeczne. In: Werke, I: 178.

${ }^{10} \mathrm{~V}_{\mathrm{gl}}$. dazu Kapitel 2 in dieser Arbeit. 
In dieser Zeit verfaßt Witkiewicz alle seine Dramen bis auf das StUlk "Szewcy" ("Die Schuster"), das erst 1931-34 enteht. Es sind etwa 40 Buhnenwerke (davon sind bis heute etwa 20 erhalten geblieben). Dabei wird sein Postulat der "Reinen Form" nach eigener Aussage nicht vollkommen verwirklicht, die Stücke selbst weisen aber auf das kommende abstrakte, groteske Theater eines Beckett hin.

1925 beendet Witkiewicz das letzte Stück dieser Schaffensperiode: "Die Beelzebub Sonate" und widmet sich fortan dem Roman, obwohl er ihn in seinen theoretischen Schriften als eine für die Reine Form ungeeignete literarische Gattung betrachtet." Es entstehen die Romane: "Abschied vom Herbst" (1927), "Unersăttlichkeit" (1930) und "Der einzige Ausweg" (1932 - bleibt unvollendet).

Ebenso abrupt schlieBt er 1924 seine Experimente mit der Reinen Form in der Malerei ab und betreibt nun "angewandte Kunst", indem er Portrăts zum Lebensunterhalt malt. Seine Beschäftigung inszeniert er selber als kommerzielle Farce, indem er ein witziges Reglement fur seine "Portrătfirma" aufstellt. Darin werden die Portrăts in folgende Qualităts- und Preiskategorien eingeteilt:
A - "geleckte";
B - "charakteristische";
B + D - "charakteristische; die an Karikatur grenzen";
C - "Reine- Form-Porträts" entstanden unter Verwendung von Rauschgift;
D - "Reine-Form-Porträts ohne Rauschgift;
$E$ - "intuitive";
$B+E$ - "Kinderportrăts".

Dabei gehören die "geleckten" (poln. "wylizane") Potrăts zu der niedrigsten und die "Kinderoortrăts" zil der hörhsten Preiskategnrie, Oherstes Gebot der "Portrătfirma" heißt zweckmäßigerweise: "Der Kunde muß zufrieden sein. Mißverständnisse sind ausgeschlossen. ${ }^{12}$

1918-39 ist fur Witkacy eine Zeit der fieberhaften, schöpferischen Tătigkeit und eines hektischen Lebensstils. Neben seinen künstlerischen und intellektuellen Tătigkeiten leitet er ein formistisches Laientheater in

${ }^{11} \mathrm{Vgl}_{\mathrm{g}}$. dazu Kapitel 2 und isbesondere 2.2.1. in dieser Arbeit.

${ }^{12} \mathrm{Vgl.:}$ Regulamin firmy portretowej "Stanisław Ignacy Witkiewicz". In: Schriften, II: 563. 
Zakopane und reist mit philosophischen und kunsttheoretischen Vortrăgen durchs Land. Seine Werke und Theorien finden zwar Beachtung aber keine Anerkennung.

Mehr noch als seine Kunst schockiert das gesittete, bürgerliche Publikum sein Leben: seine zahlreichen erotischen Abenteuer, seine Experimente mit Drogen, uber die er provozierend und wahrscheinlich übertreibend berichtet, $^{13}$ vor allem aber die von ihm inszenierten Happenings. Witkiewicz mystifiziert und spielt im Leben liebend gern Theater, er arrangiert z.B. Begegnungen, bei denen er buhnenreife Verwicklungen und dramatische Konflikte schafft.

"Man kann sagen, daß Witkacy um sich herum ein "Theater" aus unrealistischen Ereignissen organisierte, und daB er sich in diesem Theater wohl fuhlte, sich darin von der Realitat erholte. Er lebte sich darin aus, weil er gleichzeitig Schbpfer und Schauspieler sein konnte. Daher kommt auch sein erstaunlicher Dynamismus, sel es in der "Arbeit" oder beim "Spiel", oder beim Experimentieren - fur ihn waren das alles Modifikationen des Schaffens. Daher kommt auch, meiner Ansicht nach, nicht nur seine Begeisterung fur Selbstexperimente mit verschiedenen Mitteln, sondern auch seine - hăufig brutale - Beharrlichkeit, mit welcher er seine Bekannten und Freunde zu solchen Experimenten zwang ${ }^{\text {14 }^{4}}$

- so ein Zeitgenosse Uber Witkacy.

In den letzten Jahren seines Lebens beschäftigt er sich hauptsächlich mit Philosophie. Er veröffentlicht zahlreiche Artikel, in denen er seine philosophischen Zielsetzungen wissenschaftlich erläutert oder popularisiert und mit anderen Konzeptionen polemisiert (unter anderem mit B.A.W. Russel. R. Carnap, L. Wittgenstein und dem "Wiener Kreis"). 1935 erscheint sein Hauptwerk "Der Daseinsbegriff und die von ihm implizierten Begriffe und Behauptungen".

In den 30er Jahren verschlechtert sich der Gesundheitszustand von Wit-

${ }^{13}$ Z.B. in der Abhandlung "Nikotyna, Alkohol, Kokaina, Peyotl, Morfina, Eter + Appendix". Darin berichtet Witkiewicz von kontrollierten Rauschgift-Experimenten, in denen er den Einfluß von Rauschgift auf das küstlerische Schaffen untersuchte. In: Werke, I: 521-638.

${ }^{14}$ Birula-Białynski, 1957: 303. 
kiewicz: seine Depressionen werden immer hăufiger, es verfolgen ihn Selbstmordgedanken. Im September 1939, als er im Ausbruch des Krieges die Erfullung seiner katastrophistischen Zukunftsvisionen sieht, nimmt er sich das Leben. 


\subsection{PHILOSOPHIE}

Das philosophische und ästhetische Werk Witkiewicz' umfaßt etwa 100 Titel. Darunter befinden sich viele essayistische Artikel, aber auch etwa 40 wissenschaftliche Abhandlungen und 2 umfangreichere Arbeiten aus den 30er Jahren. 1935 erscheint Witkacys Hauptwerk ("Główniak" nannte es sein Autor) "Der Daseinsbegriff und die von ihm implizierten Begriffe und Behauptungen", an dem er, nach eigener Aussage, zwischen 1917 und 1933 gearbeitet hat. 1932-39 entsteht dann Witkiewicz' reifste und umfangreichste philosophische Schrift "Die psychophysische Frage"15, die aus drei Teilen besteht: "Allgemeine Kritik des physikalischen Materialismus", "Der Versuch, die psychophysische Frage im monadistischen System zu lösen" und "Kritik einzelner Autoren" (T. Kotarbinski, L. Wittgenstein, A. N. Whitehead, R. Carnap und andere Mitglieder des "Wiener Kreises").

Zu Witkiewicz' philosophischen Arbeiten gehören Untersuchungen zum Gegenstand, zu den Aufgaben und zur kulturell-sozialen Rolle der Philosophie; Kritik des Positivismus ("Wiener Kreis"), des Empiriokritizismus, des Physikalismus, der Analytischen Philosophie (Russell, Whitehead, Carnap und Wittgenstein) sowie eine briefliche Diskussion mit Chwistek uber $R$. Ingarden und die Phănomenologie.

Seine eigene Ontologie bezeichnete Witkiewicz als "biologische Monadologie". Witkiewicz' Monaden sind im Unterschied zu Leibniz korperlichorganische Einheiten ("Einzelexistenzen" in Witkiewicz' Terminologie), die untereinander nicht isoliert, sondern interaktiv sind. Sie befinden sich in "doppelter Dualităt"16 - erstens als psychisch-physische, raumzeitlich begrenzte Formen des Daseins, die "an und fur sich ${ }^{17}$ existieren und zweitens in ihrem Verhaltnis zum raumzeitlich unendlichen Dasein. "Der Daseinbegriff impliziert <nach Witkiewicz> den Begriff der Vielheit. Als absolute Einheit würde das Dasein mit dem absoluten Nichts gleichbedeutend sein". ${ }^{18}$

Die Frage nach der Identită lost Witkiewicz durch die Einfuhrung des

\footnotetext{
${ }^{15}$ Erschienen erst 1978 in: Schriften, III.

${ }^{16}$ Schriften, III: 543 <Deutsch im Original>.

${ }^{17}$ Ebd.: $544<$ Deutsch im Original>.

${ }^{18}$ Ebd. <Deutsch im Original>.
} 
Begriffes "Einheit in der Vielfalt", der sowohl für die Einzelexistenzen mit ihren verschiedenen Qualitäten als auch fur das unendliche Dasein gelten und ein "Mehr" als die Summe der Einzelelemente ausdrúcken soll. Die "Einheit in der Vielfalt" ist fur Witkiewicz "das Geheimnis der Existenz" und eigentlich eine metaphysische Kategorie. "Das Geheimnis der Existenz ist die Einheit in der Vielfalt und deren Unendlichkeit sowohl in der Kleinheit als auch in der Größe, bei gleichzeitiger notwendiger Begrenztheit jeder Einzelexistenz" 19

In einer deutschen Zusammenfassung von "Der Daseinsbegriff und die von ihm implizierten Begriffe und Behauptungen" beschreibt Witkiewicz sein philosophisches System folgendermaßen:

'Mein 'System' hat keinen Anspruch auf absolute Originalităt. Es ist vielmehr eine Kombination von einem 'verbesserten' Psychologismus im Sinne von Hans Cornelius und einer gleichfalls 'verbesserten' leibnizschen Monadologie. Diese Kombination durfte wohl als eine Art des 'biologischen Materialismus' (im Gegensatz zum physikalischen) angesehen werden. Ich bemerke nebenbei, dass ich ein ontologischer Realist mit einem sehr măssigen Einschlag von Idealismus bin (in dem Sinne, dass die 'leblosen Gegenstănde der Aussenwelt' nicht das sind, was sie uns sein scheinen) und auch ein mässiger Nominalist in der Theorie der Begriffe." <Deutsch im Original> (Schriften, III: 543)

Die Hauptströmung in der polnischen Philosophie der Zwischenkriegszeit war der logischer Empirismus (J. Kukasiewicz, St. Lesniewski, A. Tarski, L. Chwistek). Phănomenologie (R. Ingarden) und Konkretismus (T. Kotarbinski) fungierten damals als kaum beachtete Randerscheinungen. Das philosophische System Witkiewicz' entstand in dieser geistigen Atmosphăre. Wie B. Michalski feststellt, kann Witkacys "RUckgriff auf die individualiotionh-pluraliotionho Trodition dor Monadalogio (und oino naturaliatisch-materialistische Interpretation derselben) als ein Versuch betrachtet werden, die bedrohte Autonomie und Eigenheit des geistig-körperlichen Individuums zu retten. Sie war durch Doktrinen bedroht, die nach einer 'Auflösung' der psychophysischen Persönlichkeit entweder in der Materie oder im 'Reinem Bewußtsein' trachteten." 20

\footnotetext{
${ }^{19}$ NFM: 6. Vgl. dazu auch: Michalski, 1973.

${ }^{20}$ Michalski, 1978: 79.
} 
Wie seine Kritiken (an R. Carnap, L. Wittgenstein, A.N. Whitehead) zeigen, war für Witkiewicz die westeuropäische Philosophie wichtiger als die polnische: in ihr war sein Denken verwurzelt und an sie adressiert ${ }^{21}$.

Maßgebend fur die Einordnung und Einschätzung von Witkiewicz' Philosophie wurde für die Forschung lange Zeit das beilăufige Urteil R. Ingardens:

"Er war <...> in seiner Grundhaltung ein Existenzialist, lange bevor diese Richtung in Frankreich aufkam, und wahrscheinlich gleichzeitig mit dem Auftreten Heideggers. Doch soviel ich weiß, hat er Heidegger nie gelesen. Von der Phänomenologie kannte er nur die "Logischen Untersuchungen" Husserls, doch die Fragen der philosophischen Grundlagen der Logik waren für ihn niemals besonders wesentlich, außerdem hatte er auch kein Verständnis fur die phänomenologischen Analysen. Von den französischen Existenzialisten unterschied ihn auch trotz seines tiefen Pessimismus - sein dynamischeres Temperament und seine urwuchsige Natürlichkeit. In der Philosophie dagegen war sein Ehrgeiz, ein vollstăndiges metaphysisches System zu schaffen, großer als bei ihnen." 22

Diese Grundhaltung Witkiewicz' kommt nach Ingarden aus der Erfahrung

"einer grundsătzlichen Feindseligkeit des Seins dem Menschen gegenUber. 〈...> Verstand, Wissen, ein klarer, entschlossener Wille und ein klares Bewußtsein - das alles erschien ihm als etwas, das aus einem vollig finsteren, irrationalen Untergrund aufsteigt $\langle. .$.$\rangle .$ Dieser dem Menschen feindselige Untergrund $\langle. .$.$\rangle war fur ihn keine$ tote Materie, sondern - in seiner Terminologie - der physikalische Materialismus. Nach seinen Aussagen bildet ihn die feindselige, urwUlchsige, biologische Lebensmacht, die in einem Chaos der Vielfaltigkeit, in einer völligen Sinnlosigkeit der Entwicklung stăndig neue Lebenserscheinungen produziert ."

Obwohl sich Ingardens Urteil mehr auf die psychologische Welterfahrung als auf das philosophische System bezog, wurde das Urteil uber Witkiewicz' Existentialismus hăufig ubernommen. ${ }^{24}$

Dagegen schliebt J. Sarna Analogien in Motiven und Denkmustern zwar nicht aus, aber eine grundsătzliche Xhnlichkeit zwischen Witkiewicz' Ontologie

${ }^{21}$ Entsprechendes stellt auch B. Michalski fest (vgl. ebd.: 94).

22 Ingarden, 1957: 175.

${ }^{23}$ Ebd.

${ }^{24}$ So z.B.: Pomian, 1971: 265-280; Sokót, 1972: 63f.; Rudzinska, 1973: 71. 
und Existenzialismus lehnt er ab. ${ }^{25}$ Sarna, der seine Dissertation in der in deutscher Sprache abgefaßten Zusammenfassung als den "erste<n>Versuch einer Analyse des philosophischen Systems von Witkiewicz vom Standpunkt der marxistischen Methodologie gesehen" ${ }^{26}$ bezeichnet, fürt als Argumente gegen die existentialistische Interpretation Witkiewicz' Rationalismus, Determinismus und sein dialektisches Verstăndis der Seins-Kategorie an. ${ }^{27}$

B. Michalski, der Herausgeber der philosophischen Schriften und wohl der beste Kenner der Philosophie Witkacys ${ }^{28}$, weist auch als erster darauf hin, daß das philosophische System Witkiewicz' - entgegen den bisherigen Feststellungen - sehr uneinheitlich ist und offensichtlich eine Entwicklung durchmacht. Die Konzeption des metaphysischen Gefuhls und des geschichtsphilosophischen Katastrophismus, die man aus den asthetischen Schriften der fruhen 20er Jahre kennt, gibt Witkiewicz in seinem letzten philosophischen Werk "Die psychophysische Frage", das erst 1978 erschienen ist, auf $^{29}$.

Seine wichtigsten kultur- und geschichtsphilosophischen Reflexionen ăuBerte Witkiewicz in der Abhandlung "Uber den Untergang der metaphysischen Gefuhle im Zusammenhang mit der gesellschaftlichen Entwicklung", die 1919 in dem Band "Neue Formen in der Malerei" erschienen ist.

Analog zu der Dualităt zwischen der Einzelexistenz und dem unendlichen Dasein in seiner Ontologie geht Witkiwicz in seiner Geschichtsphilosophie von der Opposition Individuum - Gesellschaft bzw. menschliche Gattung aus.

Ein Maßstab fur die Humanităt, fur den Wert eines Individuums ist, nach Witkiewicz, die Fåhigkeit, metaphysische Gefuhle ${ }^{30}$, d.h. das Geheimnis der Existenz. der Einheit in der Vielfalt zu erleben. Dagegen ist das Ziel der menschlichen Gattung die Selbsterhaltung und das Ziel einer Gesell-

${ }^{25}$ Sarna, 1978: 188.

${ }^{26}$ Ebd.: 232.

${ }^{27}$ Ebd.: $194 f$.

${ }^{28}$ Vgl. Michalski, 1979.

29 Michalski, 1977: 410-447.

${ }^{30}$ Zum "metaphysischen Gefuhl" als Grundlage der asthetischen Erfahrung vgl. Kapitel 2.1.2. in dieser Arbeit. 
schaft eine für alle möglichst bequeme und beglückende Lebensform. Diese divergierenden Ziele des Individuums und der Gattung bzw. Gesellschaft bilden die Grundlage für Witkiewicz' geschichtsphilosophischen Pessimismus.

Man spürt das Lebensgefuhl der Decadence-Epoche und die Philosophie Nietzsches in Witkiewicz' Darstellung der starken Persönlichkeiten, groBen Individuen und Subjekte (Priester, Könige), die in frühen, unterentwickelten Kulturen die Fähigkeit hatten, das Geheimnis der Existenz zu erleben und denen sich das Volk, das in Angst vor der noch unerforschten Natur lebte, unterwarf. Fur diese groBen Individuen fielen die Religion, Philosophie und Wissenschaft in einer einheitlichen geistig-intuitiven Erkenntnis der Welt zusammen, in der sie die metaphysische Gefuhle erlebten. Kraft ihres Charisma und ihres Intellekts, mit dem sie gewisse Erleichterungen fur das Volk vollbrachten und somit die Zivilisation vorantrieben, beherrschten diese großen Persönlichkeiten die Massen.

Das Erleben der metaphysischen Gefuhle ist nach Witkiewicz nicht nur durch die Kontemplation möglich, sondern auch in Form eines berauschenden Lebenserlebnisses. Dieses konnten die früheren genialen Existenzen dank ihrer Macht uber die Massen verwirklichen:

"Der fruhere Herrscher schickte wegen einer Laune, um seine inneren
Erlebnisse zu bereichern oder um sich seine Macht zu bestătigen
ganze Scharen von Menschen in den Tod. Er setzte dabei manchmal auch
sein eigenes Leben aufs Spiel, um umso stärker dessen unendlichen
Wert zu empfinden. Doch damit gab er der Menschenmenge, die er fuhr-
te Stärke und Gestalt. Seine Kraft strahlte wie die Sonne und weckte
in den Menschen neue Werte, indem sie in die Seele eines jeden Skla-
ven Samen dieser Ubermacht warf <...>." (NFM: 106f)

Doch durch bestimmte soziale und wissenschaftliche Entwicklungen verlagerte sich die Macht allmăhlich auf das Volk, die Masse mit ihrem gattungserhaltenden Trieb. $\mathrm{Zu}$ diesen Entwicklungen gehorten unter anderen die Entstehung der Naturwissenschaften und der einhergehenden Möglichkeiten der Naturbeherrschung; die Ethik des Christentums; insbesondere aber die Entstehung des Handels und der damit verbundenen materiellen Macht, mit der sich die großen Fuhrer arrangieren mußten. Der materielle Wohlstand aller entstand aber, laut Witkiewicz, auf Kosten der metaphysischen Făhigkeiten der Ausnahmepersönlichkeiten. "Die Unterordnug der In- 
teressen des Individuums unter die der Allgemeinheit - das ist die allgemeinste Beschreibung dessen, was ich Vergesellschaftung <uspołecznienie> nenne" (NFM: 100). Diese Vergesellschaftung fuhrte kontinuierlich zum Untergang metaphysischer Gefuhle (was Witkiewicz an einem Diagramm veranschaulicht - NFM: 103), des großen Individuums und eigentlich auch der Menschlichkeit:

"Die großen altruistischen Ideen, groß aus der Sicht der Unterdrückten und Schwachen, die durch sie ein neues Leben und neue Rechte bekommen, die sie sich alleine nicht erkămpfen könnten, sind ein Ausdruck der Dekadenz und des Niedergangs des menschlichen Individuums als solchen <...〉." (NFM: 109)

und somit auch ein Untergang von Kunst, Philosophie und Religion, die eine Objektivation des metaphysischen Gefuhls seien. In der kommenden wohlhabenden und glucklichen Massengesellschaft mit ihrem Utilitarismus und Materialismus ist, laut Witkiewicz, kein Platz fur Schønheit, Wahrheit und metaphysische Erlebnisse eines Individuums.

Der Wertmaßstab fur den modernen Menschen ist allein seine gesellschaftliche Rolle. Er wird zur Ausfuhrung festumrissener Teilaufgaben erzogen, so daß weder seine Bildung noch seine Arbeit es ihm erlauben, sich mit dem Absoluten zu beschăftigen.

Den Wissenschaften sind zwar enge Erkenntnisgrenzen gesetzt, sie liefern aber immer mehr Begriffe, mit denen man uber den Grenzbereich des absoluten Geheimnisses sprechen kann, das dadurch seine beunruhigende Attraktivităt verliert.

Die Erschlaffung der metaphysischen Unruhe in der Gesellschaft äußert sich nach Witkiewicz' in dem Aufkommen positivistischer und pragmatischer Strömungen. Die Philosophie gibt damit ihr ursprungliches Ziel, sich mit Begriffssystemen dem Geheimnis der Existenz zu nahern, auf. Das Streben nach diesem letztendlich unerreichbaren Ziel ist ein Wert fur sich und dessen Aufgabe, der Verzicht auf die Metaphysik, kommt einem "Selbstmord der Philosophie ${ }^{\text {31 }}$ gleich.

In analoger Weise fuhrt der Untergang der metaphysischen Unruhe auch zum Untergang der Kunst.

${ }^{31} \mathrm{Vgl}$. NFM: $116 \mathrm{ff}$. 
Die Geschichtsphilosophie Witkiewicz' erinnert nur ăuBerlich an den romantischen Gegensatz zwischen Kunstler und Philister. Die Analogie zu Witkacys Ontologie läßt die Opposition Individuum - Gesellschaft als ein tieferliegendes Problem erscheinen. Die Unterordnung der Einzelexistenz unter das Ganze ist fur Witkiewicz ein ontologisches Gesetz:

"<...> der Untergang der metaphysischen Gefuhle zugunsten des allgemeinen Glucks. Dies ist $\langle. . .>$ eine feste Formel fur alle Einzelexistenzen, die in Gruppen leben und die in der Hierarchie der Existenzen auf der Stufe stehen, auf der das Denken und die kunstlerische Tătigkeit möglich sind." (NFM: 102)

Witkiewicz' Kunstverstăndnis und seine Geschichtsphilosophie erweisen sich als sehr problematisch, wenn man sie unter ethischen Gesichtspunkten betrachtet: $\mathrm{Da}$ in dem grundsătzlichen Gegensatz Individuum - Gesellschaft die Kunst auf der Seite des Individuums steht und von dessen metaphysischen Gefuhlen abhăngt, ist sie nicht nur mit ihm zum Untergang verurteilt, sondern es gibt für sie offensichtlich keine Möglichkeit, in der Gesellschaft einen Platz zu finden. Der radikale Subjektivismus und die absolute Kunstautonomie, die Witkiewicz in seiner Xsthetik ${ }^{32}$ vertritt, sind also in seiner Geschichtsphilosophie schon latent angelegt.

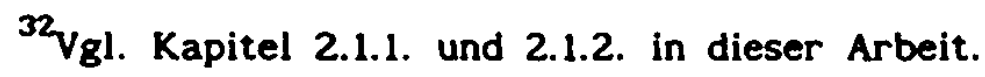




\subsection{KUNSTHISTORISCHER HINTERGRUND}

Es ist nicht das Ziel dieser Arbeit, Witkiewicz' Werk im Hinblick auf die moglichen Analogien zu anderer Literatur zu untersuchen und die Arten der festgestellten interliterarischen Beziehungen und Parallelităten sowie Fragen der Wirkung und Aneignung, Originalităt und Tradition zu erörten.

Da aber ein literarisches Phänomen immer nur vor dem Hintergrund der jeweiligen ästhetischen und weltanschaulichen Haltungen sowie literarischer Traditionen $\mathrm{zu}$ verstehen ist, sollen hier skizzenhaft die externen und die eventuellen internen Kontakte ${ }^{33}$ Witkiewicz' aufgezeigt werden.

In der biographischen Forschung wird die große Bedeutung des Vaters und Uberhaupt des Elternhauses fur Witkacy betont. Sein Vater spielte zweifellos in seiner Kindheit und Jugend eine - psychologisch sicher nicht unbedenklich - dominierende Rolle. Trotz seiner liberalen Erziehungsideale ubte St. Witkiewicz allein durch seine lebhafte Anteilnahme, mit der er jeden Schritt seines Sohnes verfolgte und mit Ratschlagen und Hinweisen begleitete, einen großen Elnfluß aus. Die umfangreiche Korrespondenz dokumentiert diese Art von sanfter Tyrannei in anschaulicher Weise. ${ }^{34}$

St. Witkiewicz wie auch die meisten berümten Gäste (H. Sienkiewicz, $\mathbf{S}$. Zeromski), die in seinem Haus verkehrten, waren dem Realismus und dem Naturalismus verpflichtet. Zunächst folgte Witkacy wenigstens in der Malerei diesem Vorbild. Doch die metaphysische Untermauerung der ăsthetischen Erfahrung und die rituell-religiöse Begründung der Rolle des Theaters in seiner späteren Ästhetik sind vielleicht auch als eine Opposition zum Vater zu verstehen.

In seiner Krakauer Studienzeit lebte Witkacy in einem Milieu von Kunstlern und Intellektuellen (T. Szymberski, B. Malinowski, L. Chwistek), die nach neuen Wegen in der Kunst und Philosophie suchten, dabei aber noch sehr stark in der Xsthetik und Geisteshaltung der Jahrhundertwende befangen waren. Der künstlerische Weg dieser Mănner, die J. Błoński als "die dritte Generation des Jungen Polen" bezeichnet, war voll uberraschender

${ }^{33}$ Die Begriffe stammen von D. Durišin, der unter externen Kontakten persönliche Begegnungen, Briefe oder nachweisbare Kenntnisnahme und unter internen Kontakten die innere literarische Wechselwirkung versteht. Vgl: Durišin, 1968: 47-59.

${ }^{34}$ Witkiewicz (St.), 1969. 
Wendungen und Entwicklungen: von Décadence und Symbolismus zum Futurismus, Expressionismus etc. ${ }^{35}$ In diesem Kontext muß auch das Schaffen Witkiewicz' gesehen werden: sein relativ spätes Debüt, das schnelle Wechseln von Stil und betriebenen Disziplinen und nicht zuletzt die ungeworhnliche Synthese von Décadence-, Formalismus- und Avantgarde-Elementen in seiner Ästhetik. Witkiewicz' Verwurzelung in der Ästhetik der Jahrhundertwende bemerkten schon seine Zeitgenossen, z.B. K. Irzykowski, der Parallelen zu Przybyszewski zog:

\begin{abstract}
"So wie für den einen das 'Metawort' ein Exponent der 'nackten Seele' war, so ist fur Witkiewicz die 'reine Form' ein Symbol der 'Elnheit in der Vielfalt'. Beide betreiben das, was ich als Philosophle des verlorenen Paradieses <Hervh. im Orig.> bezeichne: sie betrachten die Kunst als ein Mittel, um metaphysische und kulturelle Risse zu stopfen. Sie beneiden beide als Dichter die Musik. Şjie hăngen beide mit einigen Wurzeln in der Philosophie Schopenhauers."
\end{abstract}

Auf seinen zahlreichen Reisen lernt Witkiewicz die moderne Malerei ( $P$. Gauguin, P. Picasso) kennen, besucht fauvistische und kubistische Ausstellungen in Paris, studiert während seines Moskauaufenthaltes 1917/18 in der Scukin-Galerie die Werke P. Picassos.

Uber die vier Jahre, die er in RuBland verbrachte, weiB man recht wenig ${ }^{37}$. Es ist bekannt, daß er sehr viel malte, und daß er seine asthetischen und geschichtsphilosophischen Theorien dort entwickelte - sie wurden kurze Zeit nach seiner RUckkehr veroffentlicht. Es ist anzunehmen, daB er mit den Strömungen des Konstruktivismus und Suprematismus (M. Larionov, K. Malevi() in Beruhrung gekommen ist, und daß ihm die Programme und das

${ }^{35}$ "Sie waren sozusagen die dritte Generation des Jungen Polen, die sich entweder gar nicht auszudrücken vermochte oder sich ganz anders, als das die Jugendversuche versprachen, ausdrückte. Der Ubergang vom Sezessionismus zum Kubismus, von Wagnerbegeisterung zur Dodekaphonie, von der "nackten Seele" zur "Reinen Form" oder "Stadt, Masse und Maschine" gehört zu den rätselhaftesten und schwerstverstăndlichen Momenten in der Kultur des 20. Jahrhunderts." (Błonski, 1983: 11.)

${ }^{36}$ Irzykowski, K.: Walka o tresc. Zit. nach: Puzyna, K.: Vorwort. In: Werke, IV: 11. Puzyna fugt noch hinzu: "Man muB hier noch die auffallendste Ahnlichkeit hinzufüen: die dämonische Erotik des Jungen Polen." (Ebd.)

${ }^{37}$ Vgl.: Witkiewicz (J.S.), 1977. 
Schaffen der Kubofuturisten ${ }^{38}$ (V. Chlebnikov, A. KruCenych, V. Majakovskij) nicht unbekannt geblieben waren. Die Theatermanifeste F. T. Marinettis und anderer italienischer Futuristen kannte er sicherlich auch.

Zu erwahnen wäre auch der Einfluß des in diese Jahre fallenden Expressionismus, der deutliche Parallelen zur pessimistischen Geschichtsphilosophie von Witkiewicz zeigt.

In einem Brief an Wiercinski schreibt Witkiewicz recht ausfuhrlich uber seine literarischen Vorlieben. Außer einigen polnischen AvantgardeAutoren (A. Stern, J. Przybos, T. Peiper, J. Kurek, J. Brzekowski) nennt er A. Strindberg ("Gespenstersonate"), Y. Goll, W. Hasenclever, G. Kaiser, F.v. Unruh, A. Bronnen, P. Kornfeld, J.M. Synge, E. O'Neill und A. Jarry ("Ubu roi"). 39

${ }^{38}$ Die Hohepunkte dieses Schaffens fanden kurz vor Witkiewicz' Ankunft in Rußland statt: 1912 verfaßte V. Majakovskij zusammen mit D. Burljuk das futuristische Manifest "Poscexina obscestvennomu vkusu". Im Herbst 1913 wurde in Petersburg im Luna-Park-Theater V. Majakovskijs "Vladimir Majakovskij" und A. Krucenych "Pobeda nad solncem" auf gefuhrt.

${ }^{39} V_{g l}$. Puzyna, K.: Wstęp. In: Werke, IV: 14. 


\subsection{REZEPTION UND FORSCHUNGSLAGE}

$\mathrm{Zu}$ seinen Lebzeiten teilte Witkiewicz das Schicksal vieler AvantgardeDichter: er war in Künstler- und Intellektuellenkreisen zwar nicht unbekannt, aber großere Popularităt und Anerkennung blieben ihm versagt. Von seinen etwa vierzig Theaterstucken wurden nur füf veroffentlicht: "Pragmatysci" (dt.: "Die Pragmatiker") - in: Zdrój (1920), H.3; "Tumor Mózgowicz" (dt.: Tumor Hirnmann") - Krakau 1921; "Neue Wyzwolenie" (dt.: "Neue Befreiung") - in: Zwrotnica (1923), H. 5; "Wariat i zakonnica" (dt.: "Narr und Nonne") - in: Skamander (1925), H.. 5. In den 20er Jahren gab es etwa 20 Inszenierungen von 12 seiner Stucke, davon vier in dem "Formistischen Theater" in Zakopane ${ }^{10}$, welches Witkiewicz 1925 grundete und als Regisseur und Buhnenbildner leitete. Einige der Auffuhrungen lösten leidenschaftliche Diskussionen in der Presse aus, und Witkacy polemisierte in zahlreichen Artikeln mit den Rezensenten. ${ }^{41}$

Die Theorie der Reinen Form entfesselte einen wahren Sturm an Kontroversen. Die konservative Kritik betrachtete sie als eine Art Manifest der avantgardistischen Strömungen und polemisierte - selten mit sachlichen Argumenten - gegen die vermeintliche Propagierung des Unsinns in der Kunst. Man bezichtigte Witkiewicz des Nihilismus und Anarchismus mit dem Argument, daß die Realisierung seiner ăsthetischen Kategorien zur Zerstઠ̈rung der Nationalkultur und zur Verdummung der Gesellschaft fuhren wurde, oder man zweifelte gar an seinem Verstand. ${ }^{42}$

Aber auch in der Avantgarde fand Witkacy wenig Zustimmung. Die Futuristen warfen ihm seine Befangenheit in der Xsthetik der Jahrhundertwende vor, störten sich an der Metaphysik und an seiner scharfen Ablehnung der Produktion von programmatischem Nonsens. Die metaphysische Begrundung der asthetischen Erfahrung und die irrationalen Elemente des Schopfungsprozesses in Witkiewicz' Theorie der Reinen Form lehnten auch die Krakauer Formisten ab, allen voran Witkiewicz' Freund L. Chwistek.

\footnotetext{
${ }^{40}$ Witkiewicz inszenierte funf Stucke: "Narr und Nonne" (WLZ), "Neue Befreiung" (NW), "Das kleine Landhaus" (WMD)" Pragmatiker" und Strindbergs "Gespenstersonate". Die Tătigkeit des Theaters endete im Jahre 1927.

${ }^{41}$ Vgl. dazu: Degler, 1973.

${ }^{42}$ gl. dazu: Degler, 1986: 6.
} 
Eine positive Aufnahme und Würdigung fand Witkacys Ästhetik eigentlich nur bei Tadeusz Peiper ${ }^{43}$, aber auch er äußerte Zweifel an der Möglichkeit einer Verwirklichung der Reinen-Form-Theorie in der Praxis. Dieser Einwand wurde nach den ersten Auffuhrungen von Witkiewicz' Dramen das wichtigste Diskussionsthema, und die Frage nach dem Verhăltnis von Witkiewicz' Theorie und seinen Dramen bildet bis heute ein bevorzugtes Untersuchungsobjekt.

In den Diskussionen um die Theorie der Reinen Form, die etwa bis Ende der 20er Jahre andauerten, polarisierte sich die Auseinandersetzung zwischen der konventionellen und der avantgardistischen Kunst in Polen. K. Irzykowski widmete der Polemik mit Witkiewicz' Asthetik sogar ein ganzes Buch "Kampf um den Inhalt" ("Walka o tresc", erschienen 1929).

Nach dem Krieg herrschte in Polen zunächst Schweigen um den AvantgardeKunstler und -Denker, und erst ab 1956, in der "Tauwetterperiode", begann die positive Rezeption. Das Eis wurde durch die Inszenierung des "Tintenfisches" (M) von Tadeusz Kantor im Krakauer Theater "Cricot 2" gebrochen. Kantor knupfte mit seinem Theater bewußt an das Experimentiertheater "Crikot" und dessen Auffuhrung des "Tintenfisches" in den 30er Jahren an. Nach eigener Aussage leitete er seinen surreal- revueartigen Theaterstil hauptsächlich von Witkiewicz' Theorie ab.

1962 erschien die erste, von Konstanty Puzyna herausgegebene, zweibăndige Dramenausgabe. Es folgte eine Welle von Inszenierungen und Urauffuhrungen in Polen und im Ausland. Das Absurde Theater Ionescos, Becketts, Hildesheimers hatte in diesen Jahren seine "Hochkonjunktur" und auf dieser Welle schwamm auch Witkiewicz ganz oben. Zunächst inszenierten polnische Regisseure Witkacys Stücke im (vorwiegend deutschsprachigen) Ausland: Zbigniow Stock "Die Muttor" (Matka) in Saarbruakon; Tadouoz Kantor "Nao kleine Landhaus" (WMD) unter dem Titel "Der Schrank" in Baden-Baden; Jan

${ }^{43}$ "Man muß einmal die Wahrheit sagen: Witkiewicz' Werk ist bis jetzt der einzige nennenswerte Beitrag Polens zur Theatertheorie. In jedem anderen Land hătte in solches Werk eine Reihe leidenschaftlicher Proselyten bekommen, die fest entschlossen gewesen wăren, alle möglichen Mittel zur Verwirklichung seiner Ideen anzuwenden. Doch entgegen dem Schein behaupte ich, daß auch bei uns Witkiewicz' Losungen nicht spurlos verschwinden, und daB vieles von dem, was auf unseren Buhnen jetzt geschieht, unmöglich wäre, wenn der Boden dafür nicht durch seine Muhe vorbereitet worden wäre." <Peiper odpowiada Witkiewiczowi. In: Almanach Nowej Sztuki (1925), Nr. 1, S.45. Zit. nach: Degler, 1986: 5.> 
Biczynski "Narr und Nonne" (WiZ) in Wien. 1967 fand im "Main Theater" in San Francisco State College die amerikanische Urauffuhrung von "Narr und Nonne" statt und begründete Witkiewicz' Popularităt in den USA. Die französische Erstauffuhrung der "Mutter" am 3. November 1970 in Paris brachte Witkiewicz' Schaffen in das Bewußtsein der Theaterfachleute in Frankreich. Die Inszenierung von Claude Régy mit der großen Schauspielerin Madelaine Renauld in der Hauptrolle wurde ein vielbeachteter Erfolg, und anlåßlich der Premiere im Theátre Récamier wurde eine Sondernummer der Zeitschrift "Cahiers Renauld-Barrault" (73, 1970) Witkiewicz gewidmet. Auch im skandinavischen Raum wurde Witkacy bekannt. Zwischen 1966 und 1984 folgten - hauptsächlich an Universitäts- und Experimentiertheatern etwa 150 Premieren in 18 Lädern. In den USA gab es 44, in Frankreich 24, in Italien 11 und in der Bundesrepublik 9 Inszenierungen von Witkiewicz' Werken, vor allem der beiden beruhmtesten Stucke "Narr und Nonne" sowie "Die Mutter". In Polen gehört Witkacy inzwischen zu den meistgespielten Autoren. $^{44}$

In den 60er Jahren beginnt in Polen eine intensive editorische Arbeit an den Werken von Witkiewicz. Der 1962 erschienen Dramenausgabe folgen: 1972 die Erstveroffentlichung von "622 Stüze Bungos, oder Das Dămonische Weib"45; die Narkotika-Abhandlung "Nikotyna, Alkohol, Kokaina, Peyotl, Morfina, Eter + Appendix" und die sozial-geschichtlichen Essays "Ungewaschene Seelen" (poln.: "Niemyte dusze") - ebenso eine Erstveroffentlichung ${ }^{46}$; 1974-75 die vierbăndige Ausgabe der philosophischen Schriften ${ }^{47}$ (darin "Die psychophysische Frage" als Erstveroffentlichung); Anfang der 80 er Jahre die drei Romane ${ }^{48}$. Noch nicht abgeschlossen ist die Edition der

'A4 Wu Witkiewicz' Inszenierungen in der Welt vgl. Degler, 1985.

Zu Witkiewicz' Dramen im deutschsprachigen Raum vgl. Bauer, 1988.

${ }^{45}$ Hrsg. v. A. Micinska. Warszawa 1972.

${ }^{46}$ Witkiewicz, St. I.: Narkotyki. Niemyte dusze. Hrsg. v. A. Micinska. Warszawa 1975

${ }^{47}$ Witkiewicz, St. I.: Pisma filozoficzne i estetyczne. Hrsg. von J. LeszCzyński und B. Michalski. Warszawa 1974-1978.

${ }^{48}$ Jedyne wyjscie. Hrsg. v. T. Jodetka-Burzecki. Warszawa 1980. (Erstveroffentlichung)

Nienasycenie. Warszawa 1982

Pozegnanie jesieni. Warszawa 1982 
umfangreichen Korrespondenz Witkiewicz', ebenso das Katalogisieren und Systematisieren seiner Gemälde und Zeichnungen.

Seit Mitte der 60er Jahre beginnt auch die Rezeption Witklewicz' in Ausland. Den Erfolgen seiner Werke auf der Buhne folgen im allgemeinen die Ubersetzungen. Witkiewicz' Dramen und Romane wurden inzwischen in 19 Sprachen ubersetzt (darunter Japanisch und Arabisch). Die Bundesrepublik hat dabei dank Heinrich Kunstmann und Tadeusz Kantor sogar eine Pionierrolle gespielt: Kantors Inszenierung von "Der Schrank" in Baden-Baden (1966) ist die erste Auffuhrung Witkacys im Ausland; H. Kunstmanns Ubersetzungen von zwei Dramen die erste Buchausgabe ${ }^{49}$. H. Kunstmann ist ebenfalls der Autor der ersten wissenschaftlichen Kurzdarstellung uber Witkacy in Deutschland ${ }^{50}$ und der Herausgeber seiner Korrespondenz mit dem deutschen Philosophen Hans Cornelius ${ }^{51}$. In der folgenden Zeit bleiben die Publikationen uber Witkiewicz eher spärlich und beschrănken sich auf kurze Aufsătze zu Spezialthemen oder Erwăhnungen in Gesamtdarstellungen zum modernen Drama. Ähnlich verhălt es sich mit den Ubersetzungen der Primărtexte: Zwar sind fast alle der uberlieferten Stucke von Witkiewicz ins Deutsche ubersetzt, aber sie liegen hauptsăchlich als Theatermanuskripte vor. Im Buchhandel ist im Moment nur der Roman "Unersăttlichkeit" ${ }^{\mathbf{5 2}}$ und der Sammelband "Verruckte Lokomotive" ${ }^{53}$ erhăltlich, der neben dem Titelstuck das Drama "Die Schuster", die "Einfuhrung in die Theorie der Reinen Form des Theaters" und Fragmente aus Witkiewicz' Prosa beinhaltet. Einige Dramen enthält auch der in Ost-Berlin erschienene Sammelband "Stucke". 54

${ }^{49}$ Witkiewicz, St. I.: Das Wasserhuhn. Narr und Nonne. Deutsch von Heinrich Kunstmann. Frankfurt a.M. 1965.

${ }^{\text {So }}$ Kunstmann, H.: Stanisław Ignacy Witkiewicz (Witkacy). In: Kunstmann, 1965: 48-82.

${ }^{51}$ Stanisław Ignacy Witkiewicz im Briefwechsel mit dem deutschen Philosophen Hans Cornelius. In: ZfSIPh 39 (1976), H. 1 S.60-156 und 40 (1978), H. 1. S. 150-213.

${ }^{52}$ Unersattlichkeit. Ubers. v. W. Tiel. Mit einem Nachwort von W. Gombrowicz. München 1966

${ }^{53}$ Verruckte Lokomotive. Ein Lesebuch mit Bildern des Autors. Hrsg. v. A. Wirth. Frankfurt a.M. 1985

${ }^{54}$ Stucke. Ubersetzt und mit einem Nachwort versehen von H. Bereska. Berlin (Ost) 1982. 
Anders verhält es sich im angelsächsischen und französischen Sprachraum. Ein Zentrum der Witkiewicz' Rezeption ist Lausanne. In dem Verlag Editions l'Age d'Homme (Collection "Slavica") erschienen 1969-76 die Gesamtausgabe der Dramen und in den folgenden Jahren auch die vier Romane sowie ein Teil der theoretischen Schriften und Briefe. Die franzorsische Ubersetzung besorgte zum großen Teil der Slawist A. van Crugten, der an der Université Libre de Bruxelles mit einer Monographie Uber Witkiewicz promovierte ${ }^{55}$. Seit 1976 erscheinen in dem Verlag Editions l'Age d'Homme Jahrbucher, die Witkiewicz' Schaffen gewidmet sind (Cahiers Witkiewicz).

Große Beachtung findet Witkiewicz in den USA. Hier gilt er als ein Klassiker des 20. Jahrhunderts und wird dementsprechend in Anthologien ${ }^{56}$ und Gesamtdarstellungen berucksichtigt. Fast alle seine Dramen und Romane sind ins Englische Ubersetzt und in Einzel- oder Gesamtausgaben erschienen, ebenso viele seine theoretischen Schriften. Das Vorwort zu dem zweiten Band der Theaterstucke "The Tropical Madness" schrieb Ubrigens Martin Esslin 57 , der Witkiewicz auch in der Neuausgabe seines Buches The Theatre of the Absurd" berucksichtigte ${ }^{58}$. Ein engagierter Ubersetzer, Herausgeber und Kommentator von Witkiewicz' Werken ist der Professor der City University of New York, Daniel Gerould. Er ist der Autor einer WitkiewiczMonographie ${ }^{59}$ und vieler wissenschaftlicher Beitrăge.

Die ersten wissenschaftlichen Publlkatlonen uber Witkiewicz erschienen Ende der 40er Jahre. In einem Sammelband uber moderne polnische Literatur gibt S. Zahorska (1945) die ersten ausfuhrlichen Informationen uber Leben und Werk von Witkiewicz. Seine Dramen betrachtete sie als die Verwirklichung der Theorie der Reinen Form durch die Betonung der abstraktformalen Elemente. Das Drama von Witkiewicz sei "eine musikalische Kompo-

${ }^{55}$ Crugten, A. van, 1971.

${ }^{56}$ Z.B. in: A Treasury of the Theatre. Bd. 2. Hrsg. v. J. Gassner. New York 1970.

${ }^{57}$ Witkiewicz, St. I.: The Tropical Madness. Four Plays. Introduction M. Esslin. New York 1972.

${ }^{58}$ Esslin, 1969: 343-346.

${ }^{59}$ Gerould, 1981. 
sition der Bewegungen, Stimmen, Worte, eine modernistische Symphonie ${ }^{\mathrm{60}}$. Eine Gegenposition dazu nimmt K. Puzyna (1949) ein. Er sieht einen Bruch zwischen der Theorie und der dramatischen Praxis: die Dramen von Witkiewicz - insbesondere "die Schuster" - interpretiert er als eine Analyse und Verspottung der sozial-politischen Verhăltnisse im Polen der 20er Jahre. Die grotesken Stilmittel geben eine groteske Wirklichkeit wieder insofern seien die Dramen von Witkiewicz "realistisch". Die Beiträge von Zahorska und Puzyna enthalten schon den Schwerpunkt, der die weitere Diskussion um das Schaffen Witkiewicz' bestimmen wird: die Frage nach dem Verhăltnis zwischen Theorie und Praxis. Gleichzeitig markieren sie die beiden extremsten Positionen in der Interpretation von Witkiewicz' Werken, die sich sowohl in den wissenschaftlichen Untersuchungen als auch in der Inszenierungspraxis niederschlugen. Das ist zum einen die Betonung der nichtliterarischen, visuellen oder akustischen Elemente bis hin zur plastisch-musikalischen Buhnenkompositionen in einigen Inszenierungen ${ }^{61}$ und zum anderen die Betonung der "realistischen" Momente in Witkiewicz' Stücken: die Verdeutlichung und Vertiefung eventueller Bezüge zur außerkünstlerischen Wirklichkeit. Um eine Brucke zwischen der küntlerischen und der außerkünstlerischen Welt schlagen zu können, wird hăufig zu der Philosophie, insbesondere $\mathrm{zu}$ der Geschichtsphilosophie Witkiewicz' Zuflucht genommen und die Dramen auf das vermeintliche Weltbild des Kunstlers bezogen. Beispielsweise interpretiert J. Błonski das Handlungsziel der Witkiewicz'schen Figuren als das Streben nach metaphysischen Gefuhlen. Das Geheimnis der Existenz soll durch Deformation der außeren Wirklichkeit erfahren werden. ${ }^{62}$

Die eigentliche wissenschaftliche Forschung setzt jedoch erst nach 1956 oin. 1257 oroohoint oin Eammolband ${ }^{63}$ mit Doitrkgon Ubor Witkiowiox' Philo sophie, Xsthetik und Dramatik sowie Erinnerungen von Zeitgenossen (z.B. R. Ingarden) an ihre Begegnungen mit Witkacy. Die von P. Grzegorzyk erarbeitete Bibliographie legt die Grundlage fur die Forschung der nachfol-

${ }^{60}$ Zahorska, 1945: 393.

${ }^{61} \mathrm{Vgl}_{\mathrm{g}}$ dazu die Rezension einiger Witkiewicz-Inszenierungen von J.Kłossowicz, 1964.

${ }^{62}$ Btonski, 1967a.

${ }^{63}$ Stanisław Ignacy Witkiewicz. Człowiek i twórca. 
genden Jahre. Es folgen nun mehrere Aufsätze zur literaturgeschichtlichen Einordnung Witkiewicz'. Es wird auf Gemeinsamkeiten zwischen Witkiewicz und Artaud $^{64}$, auf Witkiewicz' Verwurzelung in der Ästhetik der Jahrhundertwende sowie auf seine Berührungspunkte mit Surrealismus und Expressionismus hingewiesen ${ }^{65}$. Die zahlreichen Aufsătze zur Theorie der Reinen Form und zu den Dramen haben im allgemeinen einen Uberblickscharakter und bewegen sich um die Frage nach der Verwirklichung der Theorie in der Praxis. $^{60}$

Die große Popularităt Witkiewicz' im Ausland in den 60er Jahren beweist die Tatsache, daß die erste grobere Monographie uber seine Dramen im französischen Sprachraum erschienen ist: 1970 promovierte der Slawist A.v. Crugten an der Université Libre de Bruxelles mit mit der umfangreichen Arbeit: "St. I. Witkiewicz aux sources d'un theatre nouveau".

1973 erscheinen zwei polnische Monographien uber das Dramenschaffen von Witkiewicz. Der Theaterwissenschaftler J. Degler untersucht in der Arbeit "Witkacy w teatrze międzywojennym" die Rezeption Witkiewicz' bei seinen Zeitgenossen und stellt die Beschreibungen und Rezensionen von Inszenierungen seiner Stucke zusammen. L. Sokót analysiert in seiner Dissertation "Groteska w teatrze Stanisława Ignacego Witkiewicza" die Dramen von Witkiewicz unter dem Aspekt des Grotesken. Dabei geht er weitgehend von einem Begriff des Grotesken aus, wie ihn W. Kayser in seinem 1957 erschienenen Buch "Das Groteske. Seine Gestaltung in Malerei und Dichtung" bestimmt hat: "Das Groteske ist die entfremdete Welt" ${ }^{67}$. Xhnlich wie Kayser betrachtet Sokbt als Hauptkriterium des Grotesken die Disharmonie, die sich aufgrund von Vermischung heterogener oder vollig gegensătzlicher Elemente - Pathos und Trivialităt, Tragik und Komik, Lachen und Grauen etc. - In einem Kunstwerk einstellt. Sokot rindet in der Theorie der Reinen Form Ansătze, die als eine Theorie des Grotesken interpretiert werden konnen, und daruber hinaus weist er eine Reihe von grotesken Elementen in den Dramen von Witkiewicz nach. Sie bestehen "auf zwel Ebenen: als ein

\footnotetext{
${ }^{64}$ Falkiewicz, 1960.

${ }^{65}$ Puzyna, 1961.

${ }^{66}$ Kłossowicz, 1959/60; Błonski, 1963, 1967; Mencwel, 1965; Iwaszkiewicz, 1963.

${ }^{67}$ Kayser, 1957: 198. Zitiert nach Sok6t, 1973: 31.
} 
System kunstlerischer Techniken oder Kunstgriffe und als eine Vision der Welt und aller ihrer Probleme." 68 Ähnlich wie K. Puzyna kommt auch L. Sokół zu dem Ergebnis, daß Witkiewicz eine von ihm als grotesk empfundene Realität mit grotesken Stilmitteln in seinen Dramen dargestellt hat.

Während sich die Forschung in den 60er Jahren hauptsăchlich auf das Dramenschaffen Witkiewicz' konzentriert, beginnt ab Mitte der 70er Jahre die Beschaftigung mit der Weltanschauung ${ }^{69}$ und mit der Philosophie Witkiewicz ${ }^{70}$. Dieser neue Forschungsschwerpunkt begleitet die Edition der philosophischen Schriften Witkiewicz', die Ende der 70er Jahre - teilweise als Ersterscheinung - veröffentlicht werden.

Anfang der 80er Jahre setzt auch die Erforschung der Bildkunst von Witkacy ein ${ }^{71}$. Daruber hinaus zeichnet sich verstärkt ein komparatistischer Ansatz ab: In der polnischen Forschung nimmt er manchmal die Gestalt der Intermedialităt und Interdisziplinarităt an - es werden beispielsweise Vergleiche zwischen Witkiewicz' Ästhetik in der Sprach- und in der Bildkunst gezogen ${ }^{72}$. Im Ausland dominiert der typologische Vergleich: Witkiewicz' Kunst wird in Beziehung zu den zeitgenössischen Kunstrichtungen gesetzt. $^{73}$

In Polen und im englischen Sprachraum wird also die Witkiewicz-Forschung relativ intensiv und ertragreich betrieben. Neben zahlreichen Aufsätzen liegen inzwischen auch einige Monographien zu Einzelaspekten des künstlerischen und theorethischen Schaffens Witkiewicz' vor: zum Drama und Theater $^{74}$; zum Roman ${ }^{75}$; zur Philosophie und Weltanschauung ${ }^{76}$ sowie Malerei ${ }^{77}$. Im deutschen Sprachraum dagegen sind die wissenschaftlichen Arbeiten zu

${ }^{68}$ Sok6t, 1973: 209.

${ }^{69}$ Danek-Wojnowska 1976; Szpakowska 1976.

${ }^{70}$ Sarna 1978; Michalski 1979.

${ }^{71}$ Jakimowicz, 1978 und 1985. Sztaba, 1982.

72 Piotrowski, 1985.

${ }^{73}$ Gerould, 1981. Kiebuzinska, 1988.

74 Sokót, 1973; Crugten, 1970; Degler, 1973.

${ }^{75}$ Speina, 1965.

${ }^{76}$ Michalski, 1979; Sarna, 1978; Szpakowska, 1976.

77Jakimowicz, 1978 und 1985; Piotrowski, 1985; Sztaba, 1982. 
Witkiewicz eher spărlich und beschränken sich auf kurze Aufsătze zu Spezialthemen oder Erwăhnungen in Gesamtdarstellungen zum modernen Drama $^{78}$.

Die Forschung zu den Dramen von Witkiewicz hatte ihren Hohepunkt in den 60 er und in der fruhen 70er Jahren. Wie schon erwahnt, stand dabei die Frage nach dem Verhăltnis zwischen Theorie und Praxis im Mittelpunkt. Die Forschungsergebnisse lassen zwei Grundpositionen erkennnen: man betonte entweder den formal-abstrakten, nichtliterarischen Charakter der Stucke von Witkiewicz, oder man stellte Bezulge zur empirischen Wirklichkeit oder zu der Philosophie von Witkiewicz fest. Beide Positionen gehen eigentlich an der Konzeption der Reinen Form vorbei: Witkiewicz betonte immer wieder, daß ein Drama in erster Linie ein sprachliches Kunstwerk ist, das nicht zum Musik- oder Ballettwerk verfremdet werden darf. Gleichzeitig aber wehrte er sich in den zahlreichen Auseinandersetzungen mit seinen Kritikern gegen philosophische oder sozial-politische Interpretationen seiner Stulke und beteuerte den formalen Charakter seiner Kunst. Daß seine Sprachkunst nicht adăquat gewürdigt werden konnte, lag an der Xsthetik, die sowohl die Zeitgenossen Witkiewicz' als auch die literaturwissenschaftlichen Methoden in den 60er Jahren bestimmte. Diese Xisthetik war in erster Linie auf die gegenständliche Schicht des literarischen Kunstwerkes $^{79}$ und auf ihren Bezug zu der außerkunstlerischen Welt fixiert. Doch bei einem Autor, der vorsătzlich "Reine Form" in seiner Kunst anstrebte, sollte man nach den formalen Kriterien seiner Dramen fragen. Das notige begriffliche und methodische Instrumentarium fur Form- und Strukturuntersuchungen des literarischen Werkes entstand jedoch zur selben Zeit, in der auch Witkiewicz seine Xisthetik entwickelte und wurde erst in den 70er Jahren richtig bekannt - in einer Zeit also, als das Interesse an Witkiewicz wieder abflaute. Das düfte auch der Grund dafür sein, daß trotz der zahlreichen Publikationen uber das Dramenschaffen Witkiewicz' genauere

${ }^{78}$ Kunstmann, 1965. Wirth, 1968 und 1985. Lettenbauer, 1973. Nierle, 1975. Fieguth, 1987a, 1987b. Kosny, 1989.

${ }^{79} \mathrm{Vgl}$. dazu die Ausfuhrungen zum Form- und Inhaltbegriff im Kapitel 3. dieser Arbeit. 
textanalytische Arbeiten fehlen ${ }^{80}$. Diese Lücke zu fullen gehört zu den Zielen der vorliegenden Arbeit.

${ }^{80}$ Dieses stellt auch W. Kosny, (1989: 1) fest. 


\section{DIE THEORIE DER REINEN FORM}

\subsection{ALLGEMEINE XSTHETIK}

\subsubsection{KUNSTBEGRIFF}

"In der Ästhetik gibt es den Form-Inhalt-Dualismus und Systeme, die eines dieser Elemente stärker als das andere berllcksichtigen, d.h. realistische und formistische Systeme. Da man keinen der Faktoren negieren kann, geht es um das Schaffen eines solchen Systems, das dem Verhăltnis der beiden gerecht werden und ihnen den richtigen Platz im Kunstphănomen als Ganzes zuweisen könnte. <...> Ich betone, daß mein System formistisch sein wird." (CzF: 35f) <Hervh. d. Verf. - A.S.>

Der Begriff "formistisch" (poln.: formistyczny) ist an sich sowohl im Polnischen als auch im Deutschen ungebrăuchlich. Die găngige Vokabel in diesem Zusammenhang heißt "formalistisch" (poln.: formalistyczny). F. จ. Kutschera beispielsweise unterscheidet in seiner Ästhetik grundsätzlich zwei Gruppen von Kunsttheorien: "Formalistische Theorien und Ausdruckstheorien" ${ }^{\prime \prime}$. In Witkacys Terminologie hat der Begriff "formistisch" jedoch einen festen Platz. Als "Formisten" bezeichnete sich die Krakauer Malergruppe, der Witkacy Anfang der 20er Jahre angehorte, und "formistisch" nennt er auch sein Experimentiertheater in Zakopane. Da eine explizite Definition des Begriffes "Formismus" und eine Abgrenzung zum Begriff "Formalismus" von Witkiewicz nicht vorgenommen wurde, muB man annehmen, daß die Begriffe in ihrem Aussagekern - Betonung des formalen Elementes identisch sind. Der Begriff "Formismus" hatte fur die Krakauer Avantgarde sicherlich die Funktion einer Signalwirkung: die neue Auseinandersetzung mit dem Form-Inhalt-Problem sollte nicht mit dem abgegriffenen und negativ besetzten Begriff "Formalismus" in Zusammenhang gebracht werden.

1 Kutschera, 1988: 166ff.

2 Die entsprechenden negativen Konnotationen des Begriffes "Formalismus" thematisiert (und enthält) z.B. die Feststellung von F. v. Kutschera: "Der Formalismus ist zumeist ein Feinbild, man findet kaum Autoren, die sich selbst als "Formalisten" bezeichnen, und bei denen, die von anderen so genannt werden, finden sich keine klaren Thesen und Argumente." (Kutschera, 1988: 172). Kutschera berucksichtigt bei diesem Urteil jedoch weder den russischen Formalismus noch die zahlreichen formalistischen und strukturalistischen Schulen in der Literaturwissenschaft, die 
Darüber hinaus ist aber das Adjektiv "formistisch" die morphologisch korrekte Ableitung von dem Substantiv "Form", wăhrend "formalistisch" eine quasi sekundäre Adjektivbildung uber das Adjektiv "formal" und das Substantiv "Formalismus" ist: Form - formal - Formalismus - formalistisch ${ }^{3}$ (ăhnlich wie in: Subjekt - subjektiv - Subjektivismus - subjektivistisch). Die tatsăchliche Leistung der Begriffe "Formalismus" bzw. "Formismus" zur Bezeichnung einer ästhetischen Theorie wird letztendlich jedoch von den Definitionen der Begriffe "Form" und "Inhalt" abhängen. Die Problematik deutet sich dabei schon bei der Bildung von Antonymen an: als Gegensatz zum Formalismus werden in der wissenschaftlichen Literatur u.a. genannt: Realismus, Materialismus, Naturalismus, Mimesis, Inhaltsăsthetik, Ausdruckstheorie etc. Die Antonymbildung verdeutlicht nicht nur die Unsicherheit, sondern sogar Widerspruchlichkeit der Geisteswissenschaften hinsichtlich der Definition von Form und Inhalt: teilweise heben sich die Begriffe in ihrem Aussagewert gegenseitig auf. Beispielsweise stellt $F$. v. Kutschera dem Formalismus die Ausdruckstheorie gegenuber", wăhrend P.V. Zima, der von linguistischer Position ausgeht, den Begriff "Ausdruck" dem formalen Kriterium zuordnet und ihm gegenuber den Begriff "Inhalt" stellt. So spricht er dann auch von Ästhetiken die einseitig die Ausdrucks- oder die Inhaltsebene des Kunstwerkes privilegieren ${ }^{5}$.

In der vorliegenden Arbeit geht es daher nicht darum, den vorhandenen Begriffsbestand um den neuen Begriff des "Formismus" zu erweitern, sondern um die systematische Darstellung und geschichtliche Einordnung der wesentllichen $^{6}$ Momente der ästhetischen Positionen Witkiewicz'. Sie sollen in den năchsten Kapiteln an den Grundfragen und -begriffen der Ästhetik wie ästhetische Erfahrung, Form, Inhalt, Weltbezug und Struktur des

seit den 20er Jahren entstanden sind.

3 Poln.: forma - formistyczny bzw. forma - formalny - formalizm - formalistyczny.

4 Vgl. Kutschera, 1988: 172.

5 Vgl.: Zima, 1991: 13.

6 Eine ausfuhrliche Analyse der Ästhetik Witkiewicz' wirde nicht nur den Rahmen dieser - als literaturwissenschaftlich angelegten - Arbeit sprengen, sondern auch die philosophischen Kompetenzen der Verfasserin ubersteigen. Leider steht eine Monographie zu Witkiewicz' Ästhetik von philosophischer Seite noch aus, obwohl Einzelaspekte der Theorie der Reinen Form des ofteren untersucht worden sind. 
Kunstwerks expliziert werden.

Witkiewicz' "formistischer" Kunstbegriff impliziert bestimmte Grundthesen. Wenn die Form nicht nur als Ubertragungsmittel eines kognitiven Gehaltes, sondern als der alleinige Träger der ästhetischen Erfahrung betrachtet wird, so folgen daraus zum einen die Autonomie der Kunst und der ästhetischen Erfahrung und zum anderen die Irrelevanz des Inhalts (verstanden als eines Weltbezugs') fur die Komposition des Kunstwerks und fur.die ăsthetischen Erfahrungen und Urteile.

Witkiewicz geht davon aus, daß die Kunst einen Wert hat, der auch außerhalb jeglicher Nüzlichkeitserwăgung besteht, und daß dieser Wert durch die Form des Kunstwerks begrundet ist:

"<...> das Wesen der Kunst ist die Form. Der Begriff des Schönen divergiert in den Begriff des Lebensschönen, der mit der Lebensnutzlichkeit des Gegenstandes oder der Erscheinung verbunden ist und in den Begriff des Formschonen, welcher ausschlieBlich auf der Ordnung, Form, Konstruktion des Gegenstandes oder der Erscheinung beruht. Es handelt sich dabei im engeren Sinn um das Kunstschöne." ( $C_{z} F$ : 38f)

Der Autonomiegedanke wird aber nicht nur auf den Seinsmodus und den Wert der Kunst angewendet, sondern auch auf ästhetische Erfahrungen und Urteile:

"Ein jedes lebendige Geschøpf, einen jeden Einzelgegenstand oder einen Gegenständekomplex, kann man als etwas betrachten, dessen Anblick uns Vergnugen (oder auch VerdruB) bereitet, und uns als solcher gefallt, d.h. uns schön erscheint aus Grüden, die man auf rein lebensadăquate Elemente (Nüzlichkeit, ZweckmaßBigkeit, Angst, welche er erzeugt oder Beruhigung, die er gibt) zurückfuhren kann. Oder er gefallt uns unabhăngig von allen Ursachen dieser Art, allein durch sich selbst, ohne jegliche wirklichkeitsnahen Assoziationen, allein durch seine reine Form als solche. Diese letzte Art des Gefallens nenne ich ein kunstlerisches Gefallen, und Dinge mit der Fähigkeit, eine solche, vom Standpunkt des Lebens grundlose, Bewunderung hervorzurufen, nenne ich küstlerisch schöne Gegenstände." (SzE: 157)

Ein kantianischer Anstrich ist bei diesen Äußerungen nicht zu Ubersehen:

7 Zur einer differenzierten Analyse der Begriffe "Inhalt" und "Form" bei Witkiewicz vgl. Kapitel 2.1.3. in dieser Arbeit. 
man erkennt nicht nur Kants Idee der Autonomie des Geschmacksurteils wieder, sondern es scheint sogar als ob einzelne Formulierungen und Begriffe aus der "Kritik der Urteilskraft" direkt übernommen worden wären. So etwa die These: "Das Wohlgefallen, welches das Geschmacksurteil bestimmt, ist ohne alles Interesse" ${ }^{8}$ oder "Das Geschmacksurteil hat nichts als die Form der Zweckmäßigkeit eines Gegenstandes <...> zum Grunde".

Die Autonomieăsthetik erlebt in der ersten Hălfte des 20. eine Renaissance. Sie beeinflußt B. Croce und uber ihn den amerikanischen New Criticism, Uber B. Christiansen den Russischen Formalismus und uber J.F. Herbart den Prager Strukturalismus ${ }^{10}$. So ist es nicht weiter erstaunlich, kantianische Positionen auch bei Witkiewicz wiederzufinden. Doch bei den vollig unterschiedlichen ontologischen und anthropologischen Ansätzen der beiden Philosophen wäre es sicher unangebracht, die Konsequenzen des gemeinsamen ästhetischen Ansatzes zu weit $\mathrm{zu}$ führen. Tatsächlich zeigen sich bei Witkiewicz' Konzeption der ästhetischen Erfahrung deutliche Unterschiede zu Kant."

Ein Unterschied zu Kant besteht z.B. in der Frage der Gultigkeit der ästhetischen Urtelle. Kant postulierte in diesem Zusammenhang die vielzitierte "Antinomie des Geschmacks" und behob sie in der Konzeption eines zwar unbestimmten aber allgemeingultigen Begriffes, der dem Geschmacksurteil zugrunde liege. ${ }^{12}$

Witkiewicz dagegen nimmt in bezug auf die ăsthetischen Urteile die Position des "extremsten Subjektivismus" 13 ein. In seiner Auffassung ist die ästhetische Erfahrung so tief in psychisch-physischen Gegebenheiten des Rezipienten verwurzelt, hat einen derartig individuellen Charakter, daß eine intersubjektive, geschweige denn objektive Gultigkeit der ästhetioohon Urtollo augoonhlocoon iot.

"Eine objektive Kunstkritik kann es nicht geben, denn wir haben

8 Kant, (KdU) 1974: 116

9 Ebd.: 136.

${ }^{10} \mathrm{Vgl}$. dazu: Zima, 1991: 48ff.

${ }^{11} \mathrm{Vgl}$. Kapitel 2.1.2. in dieser Arbeit.

${ }^{12}$ Kant, (KdU) 1974: $280 \mathrm{ff}$.

${ }^{13}$ Kowalik, 1973: 131. 
keine konstanten Kriterien zum Beurteilen kunstlerischer Werke. Die Annahme, daB es solche Kriterien gebe, ist eine lllusion von Menschen, die in naturalistischen WertmaBstäben erzogen worden sind. Kunst war, ist und wird sein das persönlichste der menschlichen Werke und sie kann nur aufgrund von Ähnlichkeit zwischen Menschen der gleichen Epoche und Schicht, kleinen Gruppen, und dann durch sie breiteren Bevolkerungsschichten aufgezwungen werden. Bei diesem sekundăren ProzeB spielt jedoch das eigentliche Kunstverstăndnis eine verschwindend geringe Rolle, stattdessen wirken hauptsächlich der Snobismus und die Kulturansprulche ungebildeter Personen." ( $T$ : 380)

Diese polemischen Äußerungen, die in einem Artikel Uber zeitgenठ̈ssische Kunstkritik erschienen sind, haben natürlich nicht den Aussagewert einer wissenschaftlichen Beweisfuhrung. Leider hat sich Witkiewicz in seinen philosophischen Schriften nicht direkt zu diesem Problem geăuBert. Doch seine zahlreichen publizistischen Äußerungen lassen erkennen, daß der rigorose Subjektivismus hinsichtlich ästhetischer Urteile zu den assthetischen Hauptthesen Witkacys gehørt. Vor dem Hintergrund der Konzeption der ästhetischen Erfahrung ist er auch durchaus nachvollziehbar: die formistische asthetische Wirkung entfaltet sich, laut Witkiewicz, indem der Rezipient durch die strukturelle Einheit des Kuntwerkes auf die eigene Identităt und Existenzform verwiesen wird ${ }^{14}$ :

"Die Kunst ist so etwas wie eine subjektive Droge, deren Wirkung sowohl fur den Schöpfer als auch den Empfänger von Eindrucken darauf beruht, das Gefuhl der Einheit und Einzigartigkeit ihrer Persönlichkeit zu potenzieren durch das unmittelbare Schaffen und Begreifen von formalen Konstruktionen, d.h. des Abstraktschbnen." ( $T$ : 380)

Als letzter Aspekt des formistischen Kunstbegriffes von Witkiewicz soll hier noch die Frage des Weltbezugs kurz angerissen werden. ${ }^{15}$ Es wurde schon darauf hingewiesen, daß ein Kernpunkt von Witkiewicz' Asthetik die Trennung des Begriffes des Schönen vom Gegenstand in der Malerei oder vom Sinn in der Literatur ist, und damit die Trennung zwischen einer lebenslogisch motivierten Beurteilung und einer asthetischen Erfahrung, die nur auf dem Erleben der Form beruht. Daraus ergibt sich aber auch die ästhe14Eine detaillierte Darstellung von Witkiewicz' Konzeption der astheti-
schen Erfahrung erfolgt im Kapitel 2.1.2.

${ }^{16} \mathrm{Vgl}$. auch Kapitel 2.1.4. in dieser Arbeit. 
tische Irrelevanz der Inhaltsebene des Kunstwerkes: weder eine Wirklichkeitstreue in der Darstellung noch die Vermittlung von kognitiven Wahrheiten gehen, so Witkiewicz, in die ästhetische Erfahrung ein. Lebenslogische Aspekte sollen in einem Kunstwerk daher den formalen Erfordernissen untergeordnet werden. Die Konsequenz einer solchen "Umkehrung der Werte" besteht in der Freiheit des Künstlers, die Ähnlichkeit seiner Darstellung mit den Gegenständen der äußeren Welt und die referentiellen Normen der Sprache nach formalen Gesichtspunkten des Kunstwerkes zu deformieren. Dabei sollten aber die formalen Erfordernisse als einheitsstiftende Elemente unbedingt bewahrt bleiben. Witkiewicz verurteilt immer wieder den "programmatischen Unsinn" der Futuristen und Dadaisten, 16 die Sinneinheiten beliebig deformieren und formlos aneinanderfügen. Daß seine Kritik unscharf und unsachlich bleibt, ist in dem extremen Subjektivismus der Theorie der Reinen Form angelegt. Da die ästhetischen Erfahrung der Reinen Form ein völlig subjektives Erlebnis ist, kann es auch keine objektiven Urteilskriterien in der Kunst geben. Es erhebt sich jedoch die Frage, ob es nicht materialspezifische Kompositionsstrukturen gibt, die den Einzelelementen eines Kunstwerkes auch ohne referentielle Bezüge eine Einheit verleihen Diese Frage soll bei der Analyse der Dramen ${ }^{17}$ von Witkiewicz beantwortet werden.

${ }^{16} \mathrm{Z}$.B. in dem Aufsatz mit dem signifikanten Wortspiel als Titel: "Manifest (Fest-mani)" /dt.: Manifest (Fest der Manie)/. In: Werke, V: 675-680.

${ }^{17} \mathrm{Vgl}$. Kapitel 3 in dieser Arbeit. 


\subsection{2. ÄSTHETISCHE ERFAHRUNG}

Witkiewicz' Ästhetik und insbesondere seine Konzeption der ästhetischen Erfahrung ist tief in seiner monadologischen Ontologie verwurzelt. Deshalb beginnt er auch seine erste Schrift zur Ästhetik "Neue Formen in der Malerei und die daraus entstehenden Mißverständnisse" mit einer "Philosophischen Einfuhrung", in der er eine kurze Zusammenfassung seines ontologischen Systems gibt. Diese Einfuhrung soll hier in knapper Form wiedergegeben werden.

Witkacy geht von der Dualităt der Existenz aus: der Existenz als solcher, "eins und identisch mit sich selbst" (NFM: 5) und der Existenz als Vielfalt von Einzelexistenzen, die einerseits als Teil des Ganzen und anderseits für sich bestehen. Die Einzelexistenzen sind wiederum eine zeitlich-räumlich begrenzte Vielfalt von Qualităten, die als Einheit unmittelbar erfahren werden können.

Der Vielfalt der Einzelexistenzen und Qualităten steht eine Einheit dieser Vielfalt gegenuber, ein Zusammenhang, der die Identităt des Ganzen garantiert. Witkiewicz füht dafür den Begriff "Geheimnis der Existenz" ein. Er unterscheidet zwischen dem Gesetz der Einheit der Einzelexistenzen (die sog. Einzel-Faktische Identităt - Tozsamosc Faktyczno Poszczególna) und dem Gesetz der Einheit der Existenz (sog. Absolute Wahrheit). Beide entziehen sich einer vollständigen Erkenntnis, man kann ihnen aber auf bestimmten Wegen nahe kommen. Der Einzel-Faktischen Identităt kann man sich - laut Witkiewicz - auf genetisch-wissenschaftlichem Wege năhern, und sie findet ihren Ausdruck in Kunst und Religion. Die absolute Wahrheit kann mit Hilfe eines philosophischen Systems an begrifflichen Impllkatlonen "mehr oder weniger vollkommen ausgedruckt" (NFM: 6) werden. Die metaphysische Kategorie des "Geheimnisses der Existenz", d.h. der Einheit in der Vielfalt, ist die Brucke zwischen Witkiewicz' Ontologie und seiner Ästhetik. Das vage Empfinden dieser Einheit ist jedem Menschen gegeben. Obwohl er - in Witkiewicz' psychologistischer Sichtweise - eine biologische Monade, d.h. eine raum-zeitlich begrenzte Vielfalt an biologisch-psychischen Qualităten ist, empfindet er die Identităt seiner Persönlichkeit und die Einmaligkeit seiner Existenz.

"Die Einzigartigkeit, Einheit und Identität einer jeden Einzelexistenz und ihre Begrenztheit in Dauer und Ausdehnung ist die Ursache 
dafür, daß sogar fur den Dämon, von dem wir annehmen, daß er alle Zusammenhănge der ganzen Existenz kennt, sein eigenes "Ich" als ein eben solches und kein anderes im unmittelbaren Erleben ein Geheimnis bleiben mußte. Die aus einem solchen Gefuhl entstehenden Fragen: 'Warum bin ich gerade diese und keine andere Existenz? an diesem Ort des unendlichen Raumes und in diesem Augenblick der unendlichen Zeit? in dieser Gruppe der Existenzen, auf gerade diesem Planet? warum existiere ich uberhaupt? ich könnte auch nicht existieren; warum ist uberhaupt etwas da? es könnte ja auch das Absolute Nichts da sein, das man sich nicht einmal als einen leeren Raum vorstellen darf, da der Raum schon eine von den zwei Seiten der dualistischen Form der Existenz ist? wie konnte ich vor meinem Anfang uberhaupt nicht existiert haben.' usf. - muBten trotz seines ganzen Wissens ohne endgultige Antwort bleiben." (NFM, 7)

Das unmittelbare Erleben der Einheit der Persönlichkeit in einer Vielfalt von psychischen und biologischen Qualităten nennt Witkiewicz "das metaphysische Gefuhl". Das Adjektiv "metaphysisch", das Witkiewicz selber als unglucklich gewăhlt, doch im wesentlichen zutreffend bezeichnete ( $\mathrm{vgl}$. Schriften, II: 29), soll das Grundsätzliche, Existentielle dieser Erfahrung ausdrucken (vgl. CzF: 42). Entgegen der eigentlichen Wortbedeutung und dem von einer christlichen oder idealistischen Weltanschauung implizierten Sinn, bezieht sich das metaphysische Gefuhl bei Witkiewicz keinesfalls auf etwas hinter oder außerhalb des Physischen Liegendes, etwa einen Geist, Gott, eine Idee etc., sondern auf eine diesseitige, existentielle Grunderfahrung, die im Erleben der Identităt und Einzigartigkeit der eigenen Existenz besteht.

Eng mit dem "metaphysischen Gefuhl" ist die "metaphysische Unruhe" verbunden: "ein Zustand, in welchem die Opposition zwischen der Persönlichkeit eines Lebewesens und der äußeren Welt sich im Bewußtsein scharf und deutlich als solche abzeichnet." (Schriften, II: 53)

"Metaphysisches Gefuhl" und "metaphysische Unruhe" deuten die "Quellen" des Einheitserlebnisses an: einerseits gleichsam von innen kommend als ein Erleben der eigenen Identităt, und anderseits von außen als ein Bewußtwerden des Andersseins, der Abgrenzung des Ich von der AuBenwelt. Aus letzterem folgt aber auch das "Lebensgefuhl" der Einsamkeit und Verlorenheit in der Welt ${ }^{18}$ bzw. wenn man es auf die metaphysische Ebene setzt, das Gefuhl des "metaphysischen Entsetzens" (poln.: "przerazenie") angesichts

${ }^{18}$ Ahnlich interpretieren auch: Rogatko, 1971. und Kowalik, 1973: 125. 
des Nichts - denn in Witkiewicz' Ontologie ist ja die Absolute Einheit mit dem Absoluten Nichts gleichbedeutend. ${ }^{19}$

In Witkiewicz' Terminologie druckt das Adjektiv "metaphysisch" ("metaphysisches Gefuhl". "metaphysische Unruhe", "metaphysisches Entsetzen") eine existentielle Grunderfahrung aus, die objektiven Charakter hat, im Unterschied zu den subjektiven und vergänglichen Lebensgefuhlen wie Freude, Liebe etc. bzw. der Lebensunruhe in Form von Existenzsorgen und -ăngsten.

Das Gefuhl der Einheit in der Vielfalt bzw. der "metaphysischen Unruhe" stellt sich in verschiedenen Lebenssituationen ein. Witkiewicz zăhlt dazu z.B. den Zustand der Kontemplation, der dann eintritt, wenn "das Gleichgewicht <zwischen Dauer und Ausdehnung> vollkommen ist, und kein äußeres Handeln oder inneres, stärkeres Empfinden unser Verharren stören" (NFM: 8). Da die Kontemplation in modernen Zeiten der hektischen Betriebsamkeit immer seltener möglich ist und nur in einer schwachen Ausprägung auftritt $^{20}$, erscheint die "Qualität der Einheit" nur unbewußt vor dem Hintergrund anderer Erlebnisse als ein kurzes Aufblitzen, das die Alltăglichkeit fur einen Augenblick verdrängt. Des weiteren erscheint das Erlebnis der Einheit des "Ichs" in Augenblicken besonders starker Gefuhlserlebnisse oder des "Reinen Zustands" unseres BewuBtseins, wenn es frel von Lebensplänen oder -problemen ist, wie das z.B. gelegentlich kurz vor dem Einschlafen oder nach dem Aufwachen geschieht.

Die metaphysische Unruhe kann auch durch die intellektuelle Arbeit hervorgerufen werden, indem man versucht, komplizierte Konzeptionen zu verstehen, sich z.B. bei der Beschäftigung mit Astronomie in die Unendlichkeit des Raumes hineindenkt und versucht, die aktuelle Unendlichkeit der Existenz zu verstehen. (vgl. NFM, 9)

Eine Möglichkeit, metaphysische Gefuhle zu vermitteln, stellt schlieBlich die Kunst dar.

${ }^{19}$ Vgl.: "Der Begriff der Existenz impliziert die Vielfalt, ohne die die einzige Existenz des Absoluten Nichts da wäre. Die Vielfalt der Einzelexistenzen ist das grundlegende Gesetz der Existenz." (NFM: 15)

${ }^{20}$ Dies ist ubrigens ein Ansatzpunkt fur Witkiewicz' geschichtsphilosophische Reflexionen uber den "Untergang der metaphysischen Gefuhle im Zusammenhang mit der sozialen Entwicklung" (vgl. NFM: 119-172). 
"Im allgemeinen können wir das Kunstwerk als die Konstruktion beliebiger einfacher und komplexer Elemente bezeichnen, die von einem Individuum als Ausdruck der Einheit seiner Persönlichkeit geschaffen wurde und allein durch ihre Konstruktivität in unmittelbarer Weise wirkt." (CzF, 43)

Die Form eines Kunstwerks, die ein Ausdruck der Einheit der Kunstlerexistenz ist, kann auch vom Kunstrezipienten als ein Symbol der Einheit in der Vielfalt empfunden werden:

"Die einzige Einheit fur sich sind wir allein, aber gewisse Verbindungen der Qualităten in der Zeit oder im Raum können fur uns durch ihre Beständigkeit oder Folgerichtigkeit Symbole unserer eigenen Einheit und der Einheit der ganzen Existenz werden: sie können die Quelle der metaphysischen Unruhe werden. Deshalb sprechen wir von den äuBeren Formen der Einheit in der Vielfalt, die aus der Einheit von deren Schopfer, als ein unmittelbarer Ausdruck seiner metaphysischen Gefuhle entstehen, und durch ihre Einwirkung auf andere diese Gefuhle hervorrufen können." (NFM: 9)

Die Vermittlung der metaphysischen Gefühle erfolgt auf den zwei Ebenen des Kunstwerkes, der Produktion und der Rezeption, in unterschiedlicher Weise. Fur den Rezipienten hat die Einheit der Einzelelemente eines Kunstwerkes die Bedeutung eines Zeichens, das inn auf die Einheit der eigenen Persönlichkeit verweist, und somit assoziativ das metaphysische Gefuhl in ihm auslost. Für den Kunstler selber bedeutet das Werk die Objektivierung seiner metaphysischen Unruhe:

"<...> diese zwei Kunstarten <Malerel und Musik> haben das Ziel, deren Schöpfer vom Gefuhl der Einsamkeit und des metaphysischen Entsetzens $z u$ befreien durch eine Objektivierung der Einheit in der Vielfalt, die von der Persönlichkeit losgetrennt und von der objektiven Nützlichkeit unabhängig ist. Dieses ist nur durch das Schaffen unter dem Einfluß einer virtuellen Vision möglich, d.h. einer bestimmten Folge oder Gleichzeitigkeit von abstrakten Qualitäten, einer Konstruktion von einfachen Qualităten, die zu einer Einheit zusammengefugt werden, in einer Art, die nicht mit Logik-oder Nutzlichkeitskategorien erklärt werden kann." (NFM: 15)

Der Preis der menschlichen Existenz ist für Witkiewicz die Einsamkeit, und die metaphysische Unruhe ist die Vergegenwärtigung dieser Einsamkeit. Ebenso verhălt es sich mit dem künstlerischen Schaffen: 
"Das künstlerische Schaffen ist die unmittelbare Bestätigung des Gesetzes der Einsamkeit als der Bedingung der Existenz uberhaupt, und zwar die Bestätigung nicht nur für den Künstler sondern auch fü andere Einzelexistenzen, die in ahnlicher Weise einsam sind, es ist die Bestatigung der Existenz in ihrer metaphysischen Grausamkeit".

(NFM, 11)

In diesen Äußerungen wird eine deutliche Parallele zur Existenzphilosophie und insbesondere zu $M$. Heidegger sichtbar, auf die schon $R$. Ingarden hingewiesen hat ${ }^{21}$ : die Einsamkeit des Menschen vor dem Nichts, aus der sich die Grundbefindlichkeit der Angst ergibt, ist auch der Grundgedanke der existenzialistischen Anthropologie. Doch anders als bei Heidegger fehlen in Witkiewicz' philosophischem System Hinweise auf die positive Konsequenz der existentiellen Angst, die uber das Offenbarwerden des Seins und das bewuBte Ertragen der Angst zur Freiheit des Menschen fuhren kann. Diese Moglichkeit wird von Witkiewicz in seinem geschichtsphilosophischen Katastrophismus indirekt negiert. In der sozial-historischen Entwicklung glaubt er zu sehen, daß nicht das Individualitătsprinzip des Menschseins, nămlich das Erleben der eigenen Identităt, für die Entwicklung der Menschheit bestimmend sei, sondern das Prinzip der gattungstypischen Vereinheitlichung. Die Menschheit steuert laut Witkiewicz - auf eine Massengesellschaft $2 u$, in der die Einzelexistenz durch die Erfordernisse des allgemeinen Wohlstands und Glucks fremdbestimmt ist, und die individualitătsbezogenen "metaphysischen Gefuhle" sowie deren Objektivierung in Kunst, Philosophie und Religion zum Untergang bestimmt sind.

Kunst, die aus dem metaphysischen Gefuhl - dem "das Erscheinen der Qualităt der Einheit in der Zeit" (NFM: 12) zugrundeliegt - entsteht und Entsprechendes auch beim Rezipienten auslost, nennt Witkiewicz die Relne Kunst.

Zur Veranschaulichung des Zusammenhangs zwischen dem metaphysischen Gefuhl, den restlichen psychischen Gegebenheiten des Menschen und dem künstlerischen Schaffen benutzt Witkiewicz ein Modell (NFM: 13). Darin bildet das metaphysische Gefuhl den innersten von konzentrischen Kreisen,

${ }^{21}$ Ingarden, 1957: 175. 
gefolgt von lebensadăquaten ${ }^{22}$ Gefuhlen und Vorstellungen sowie der Kontroll-Sphäre des Intellekts. Den äußersten Kreis bildet die Sphäre der Reinen Form, die "potentielle Sinneselemente und einfache Qualitäten in dem speziellen Koeffizienten des entsprechenden Individuums" (NFM: 12) enthält. Das künstlerische Schaffen stellt sich Witkiewicz wie eine Welle vor, die vom innersten Kreis des metaphysischen Gefuhls ausgeht, von den individuellen Sinnes-, Intellekts- und Erfahrungswerten beeinflußt wird, und in der Sphäre der Reinen Form seine Ausprägung findet. Der RezeptionsprozeB verläuft in umgekehrter Richtung.

Wichtig ist, daß Witkiewicz für die Kunstproduktion und -rezeption nicht allein die metaphysischen Gefuhle als grundlegend betrachtet, sondern auch die lebensadäquaten Empfindungen, Erfahrungen und das Denken des Individuums miteinbezieht. Das metaphysische Gefuhl kann nur uber eine Polarisierung in der psychischen Sphäre des Individuums zum Ausdruck gelangen, und die Form des Kunstwerkes ist weitgehend von dieser Sphäre abhängig:

"Obwohl metaphysische Gefuhle eine notwendige Bedingung fur die Entstehung des idealen Kunstwerks sind, so können auch andere psychische Sphăren eine entscheidende Rolle spielen. Was nützt nämlich einem Kunstler die Intensităt seiner metaphysischen Erlebnisse, wenn seine Gefuhle schwach polarisiert in der durftigen Sphäre der Empfindungen und Vorstellungen auf ein entsprechend durftiges Material in der Reinen Form treffen. Es entsteht dann etwas, was man kaum als ein Kunstwerk bezeichnen kann. Nehmen wir an, daß diese Sphäre relativ reich ist, und das Gefuhl der Einheit sehr schwach; es wurde etwas entstehen, was kompliziert, aber nicht einheitlich ist, obwohl wir vom Standpunkt der Sinnesbefriedigung aus, den Kombinationen der Reine-Form-Elemente nichts anlasten könnten. Nehmen wir eine groBe Intensität des ursprünglichen Gefühls bei einer geringen Komplikation der Sphăre der lebensadăquateñ Gefuhle und Vorstellungen und einem relativ stark entwickelten intellekt an. vie vernalunismaniy geringe Komplikation kann durch die intellektuelle Arbeit ergănzt werden, und es wird eine verworrene Sache entstehen. Doch diese Verworrenheit, d.h. der Grad der Vielheit, die in der ästhetischen Erfahrung zu einer Einheit zusammengefugt werden sollte, wird von uns nicht unmittelbar als Einheit verstanden, sondern zuerst intellektuell begriffen. Als solche ist sie nicht in der Lage, unmittelbar ein metaphysisches Cefuhl in uns auszulösen - dessen Bedingung ist năm-

22Das polnische Adjektiv "zyciowy" von "zycie" (das Leben) kann ins Deutsche nicht eindeutig ubersetzt werden und muB mit Komposita wie "lebenslogisch", "lebensadäquat", "realitäts- bzw. wirklichkeitsnah" wiedergegeben werden. 
lich das Verstehen der Einheit ohne vorherige Analyse" (NFM, 14)

Ahnlich wie die visionäre Kunstproduktion ist auch die Rezeption eine unbewuBte und irrationale Handlung:

"<...> Bedingung einer tiefen, ästhetischen Befriedigung ist die Unmøglichkeit einer bewußt-begrifflichen Antwort auf die Frage, warum die gegebene Kombination der Qualităten eine Einheit sei." (vgl. NFM, 16)

Zusammenfassend kann man nun folgendes feststellen: In Witkiewicz' Xsthetik ist die ästhetische Erfahrung ein Auslöser von metaphysischen Gefuhlen. Der Begriff "metaphysisches Gefunl" ist nicht eindeutig definiert und wird in mehreren Bedeutungsabstufungen verwendet. B. Szymanska unterscheidet acht Bedeutungen:

"1) der Sinn fur die eigene Einheit und Identităt,

2) der Sinn für das eigene Ausgegrenzt- und Anders-Sein vom restlichen Sein,

3) der damit verbundene Sinn fur die Individualităt,

4) das damit verbundene Gefuhl der Einsamkeit,

5) das Erahnen des 'Geheimnisses der Existenz',

6) der Sinn fur die Einheit mit der Welt,

7) das Gefuhl der Angst und Bedrohung.

8) die ästhetische Befriedigung.

Witkiewicz' Konzeption der ästhetischen Erfahrung beinhaltet eine Antinomie. Einerseits schildert er das formistische ästhetische Erlebnis und Urteil als vollig subjektiv: im KunstgenuB erlebt das Ich, als Monade, die Einheit und Identităt seiner Existenzform. Witkiewicz' Xsthetik der Reinen Kunst erschelnt hier wie die Forderung nach einer Innerlichsubjektiven, gegenuber äußeren Einflüssen, sei es historisch-poetischer Normen oder gesellschafts-politischer Funktionserwartungen, autonomen Kunst. Gleichzeitig aber hat die formistische, åsthetische Erfahrung eine Erkenntnisfunktion. Dieser Denkansatz löste in der Forschung eine Diskussion aus, die den Formalismus bei Witkiewicz in Frage stellte. ${ }^{24}$ Man wies

${ }^{23}$ Vgl. Szymanska, 1971: 175f. Das polnische Wort "poczucie" wurde in der Ubersetzung mit "Sinn fü" oder "Gefuhl" + Genitiv wiedergegeben.

${ }^{24}$ Vgl. z.B. Linkowski, 1975. 
darauf hin, daß Witkiewicz der Kunst eine symbolische Erkenntnisfunktion zumesse: das Kunstwerk Ubermittele durch bzw. in seiner Form das Wesen des Kosmos. ${ }^{25}$ Die kognitive Leistung der Kunst, die Witkacys Ästhetik sicherlich enthält, darf jedoch nicht zu weitreichend gesehen werden. Witkiewicz' ontologische Konzeption des menschlichen Individuums und des "metaphysischen Gefuhls" widerspricht der Auffassung, daß es ihm um ein intersubjektives oder gar objektives Wissen als Ergebnis der ästhetischen Erfahrung gehen könnte. Das Kunstwerk enthält keinesfalls Symbole der einzelnen Wirklichkeitsgesetze im Sinne einer idealistischen intuitiven "Anschaung" der Idee hinter der Welt der Erscheinungen oder eines Schlusses vom Besonderen auf das Allgemeine. Witkiewicz' "Metaphysik" bezieht sich zwar auf die Fundamentalbedingungen alles Seienden, doch sie liegen fur ihn in einer einzigen Wirklichkeitsdimension. In seiner Vorstellung soll das Kunstwerk als eine Existenzform - eben die rein subjektive Konstruktion von Einzelelementen - eine Existenzerfahrung sowohl beim Kunstler im Schaffensprozeß als auch beim Rezipienten während der Aufnahme hervorrufen. Und das Erleben dieser grundlegenden Existenzerfahrung ist fur Witkiewicz ein metaphysisches Erlebnis. Es geht ihm also weder um eine induktive noch um eine deduktive Erkenntnisart, sondern um das unmittelbare Erleben ("przezywanie") einer bestimmten Existenzerfahrung. Das "metaphysische Gefuhl" bei Witkiewicz ist qualitătsmäßig völlig subjektiv und allenfalls in seiner Funktion - die mit der eines religiosen Gefuhls vergleichbar ist - objektivierbar.

In seinen Schriften findet man zahlreiche Aussagen, in denen er jeglichen Verweisungs- und Symbolcharakter der Gegenstände ablehnt und das KonkretSinnliche, die Unmittelbarkeit der ästhetischen Erfahrung und die Subjektivităt des Frlebens (orzetvwanie) der metaphvsischen Gefuhle betont.

"Der ganze seltsame Wert des kunstlerischen Werkes beruht auf seinem konkretem Dasein <poln: konkretnosc> als ein Komplex der Qualitäten (Farben, Laute), die eine völlig konkrete Befriedigung geben, in ihrem Konkretum analog $2 u$ der rein sinnlichen Befriedigung <...>." (SzE, 161)

Der Aspekt des Konkret-Sinnlichen in der ästhetischen Erfahrung wird auch

${ }^{25}$ So z.B.: Piotrowski, 1985: 52; Wolicka, 1969. 
in Witkiewicz' Theorie der Malerei deutlich. Besonders in der Farbenlehre zeigt es sich, daß Witkiewicz das Moment des Zusammenfügens der Einzelelemente zunächst nur auf die formalen Elemente des Kunstwerkes bezieht. Er untersucht und beschreibt detailliert die Wirkungen der verschiedenen Zusammenstellungen von Farben, die Rolle der Komplementärfarben ("kolor rozwiazujący") und entwickelt daraus eine Typologie der Harmonie- und Disharmoniearten ( $v g l$. NFM: 58ff). Anders als V. Kandinskij - der mit Witkiewicz hăufig in Zusammenhang gebracht wird - versucht er nicht, die Wirkung der Farben zu psychologisieren und damit die formistische ăsthetische Erfahrung mit assoziativen Gehalten zu fullen. ${ }^{26}$

In ahnlicher Weise verfährt er bei der Differenzierung der Kompositionen von farblich gefullten Formen. Auch hier setzt sich Witkiewicz mit den einzelnen Kompositionsgesetzen wie Symmetrie, Wiederholung, Kontinuităt und Kompositionsformen wie z.B. dem Thema auseinander.

Auf der gleichen Linie liegen Witkiewicz' Untersuchungen zu der evokativen Funktion der Sprache und den konkret-sinnlichen Wirkungen der Handlungen im sprachlichen Kunstwerk oder im Theater. ${ }^{27}$

\footnotetext{
${ }^{26}$ Vor dem Hintergrund seines theosophischen Natur- und Weltverstăndnisses versuchte Kandinskij formale künstlerische Mittel, insbesondere Farben, mit expressiven oder kognitiven Gehalten zu fullen und eine "Malgrammatik" aufzustellen. (Grü verkorpere "volle Unbeweglichkeit und Ruhe" S. 90; "Gelb ist die typisch irdische Farbe" S. 91 etc.). Seine abstrakte Kunst war also - anders als bei Witkiewicz - eigentlich als mystischesymbolische Ausdruckskunst ("das Mystischnotwendige zum Ausdruck zu bringen" S. 84) gemeint. (Vgl. Kandinsky, 1952).

${ }^{27} \mathrm{Vgl}$. Kapitel 2.2.1. und 2.2.2. in dieser Arbeit.
} 


\subsubsection{FORM- UND INHALTSBEGRIFF}

Wie schon erwahnt, ist die Leistung und das Wesen einer Ästhetik, die von ihrem Schöpfer als "formistisch" bezeichnet wird, weitgehend von der Definition der Begriffe "Form" und "Inhalt" abhängig. Dabei ist in dem gleichzeitig systemgrundlegenden und unbestimmten Charakter ihrer Bedeutung die Problematik der Begriffsbestimmung schon angelegt. Wie W. Heilmann richtig feststellt, ist Form "kein konkretes Einzelobjekt, ja uberhaupt kein eigentliches Substantiv", sondern das substantivierte Prädikat vom Verb "formen" 28. Der Begriff "Form", der in seiner Verbalform "formen" transitiv ist, beinhaltet die Bedeutung einer "Bestimmung" von etwas durch etwas. Die Determination des Formenden und Geformten gehört daher zu den ersten Axiomen eines ontologischen oder ästhetischen Systems. Hinzu kommt, daß die Begriffe korrelativ sind, d.h. sich gegenseitig als ein Antonymenpaar definieren. Die Relativităt und Unbestimmtheit des Begriffspaares Form/Inhalt fuhrte bei unterschiedlichen philosophischen Ansätzen (etwa bei Aristoteles und Platon; F. Th. Vischer und B. Croce) teilweise zu völlig gegensätzlichen Determinationen.

Eine sehr differenzierte und scharfsinnige Analyse der Form-InhaltProblematik sowohl in der Ontologie als auch in der Ästhetik stammt von R. Ingarden ${ }^{29}$. Sie dient im folgenden als Folie bei der Systematisierung und Darstellung des Form- und Inhaltsbegriffes bei Witkiewicz.

In seinem Aufsatz "Âsthetische Skizzen" unterscheidet Witkiewicz zwischen vier Bedeutungen des Formbegriffes:

${ }^{28}$ Heilmann, 1984: 23.

${ }^{29}$ In seinem philosophischen Hauptwerk "Der Streit um die Existenz der Welt" (poln.: "Spor 0 istnienie swiata", 1947/48) unterscheidet Ingarden zwischen neun grundlegenden Form-Materie-Begriffen in der Ontologie (II/2, 1965: 1-59). Parallel dazu analysiert er die Form-InhaltProblematik in der Ästhetik. Die Untersuchung wurde von R. Ingarden als Fortsetzung seiner Ontologie des literarischen Werkes ("Das literarische Kunstwerk") und Ubergang zur Untersuchung der Beurteilungskriterien ("Vom Erkennen des literarischen Kunstwerkes") geplant. Sie entsteht in Umrissen noch vor dem 2 . Weltkrieg und wird vollständig erst 1958 (nur in polnischer Sprache) veroffentlicht. (Ze studiow nad zagadnieniami formy i tresci dzieła sztuki. In: Ingarden, 1958, Il: 319475).

Vgl. dazu auch Kapitel 3 in dieser Arbeit. 
1. die Form der Gegenstände der äußeren Welt, die in sinnlichen Erfahrungen grüdet;

2. die sog. Silhouetten-Form, d.h. die flache, einem zweidimensionalen Sehen (mit einem Auge) entsprechende Form, die in der Malerei nachgebildet wird;

3. die "wirkliche" mehrdimensionale Form, die in einem mehrdimensionalen Sehen und durch die Beruhrung von allen Seiten erfahren wird und in der Bildhauerei ihre Verwendung findet;

4. die ästhetische Form. (SzE, 164ff)

Witkiewicz differenziert also einerseits nach Arten der sinnlichen Wahrnehmung (optische, akustische, taktile), und andererseits unterscheidet er zwischen sinnlich-materiellen Gegenstandsformen (1.) sowie Abblldungsformen (2. und 3.), in denen die răumlichen Relationen im Vergleich zu den entsprechenden Gegenstănden verändert und zu neuen Gesetzmäßigkeiten geordnet worden sind.

Eine Unterscheidung nach Formen der Anschauung wird nicht explizite vorgenommen, aber sie deutet sich an in der Differenzierung zwischen Kunstwerken, die in der Zeit dauern z.B. Musikstücke, Gedichte und Theaterstucke (Zeitformen, sog. Erscheinungen), und Kunstwerken, die im Raum existieren, z.B. Bilder und Skulpturen (Raumformen, sog. Gegenstände) (vgl. CzF, 33).

Sind also die Raumformen bzw. Gegenstande als optisch und taktil wahrnehmbare, sinnlich materielle Gestalten (polnisch "kształty") zu verstehen, so entspricht dem auf der Ebene der Zeitformen bzw. Erscheinungen eine unsinnlich-immaterielle Komposition von Phasen: "Die Form <...einer Erscheinung> kann man als eine bestimmte Ordnung der Aufeinanderfolge in der Zelt bezeichnen." ( $C z F, 35)$ Die Erscheinungen werden akustlsch wahrgenommen (z.B. eine Melodie als rhythmisch geordnete Klangfolge). In Witkiewicz' Theorie der Begriffe wird eine weitere Wahrnehmungsart der Zeitformen angedeutet, und zwar bei sprachlichen Zeichensystemen: sie werden nicht nur als Klangformen aufgenommen, sondern auch in Form eines Verlaufs von schnellwechselnden Antizipationen, die von Wortbedeutungsfolgen hervorgerufen werden. 30

Den sinnlich bzw. anschaulich wahrnehmbaren Formen steht der Begriff der

${ }^{30} \mathrm{Vgl}$. Kapitel 2.2.1. in dieser Arbeit. 
"Den Begriff der ästhetischen Form, der Form des gegebenen Kunstwerkes, definieren wir als eine bestimmte Einheit der Vielfalt, die die Elgenschaft der Einheit für sich selbst besitzt, und zwar die Einheit in der Vielfalt der Silhouette-Formen, unabhängig davon, an welche Gegenstände-Silhouetten uns diese Bestandformen erinnern und unabhängig davon, ob vom Standpunkt der Sicht des Lebens und der äuBeren Welt, diese Formen deformiert sind oder nicht.

Die ästhetische Form ist, anders gesagt, Konstruktion <...〉. (SzE, 166) <Kursiv im Original>.

Die Differenzierung zwischen den Begriffen Komposition, Konstruktion, ästhetische und Reine form ist recht schwierig. Witkiewicz selber trägt viel zu den Unklarheiten bei, indem er sich einerseits in seinen wissenschaftlichen Schriften um eine Differenzierung und Abgrenzung seiner Begriffe bemüt, und anderseits in den publizistischen Aufsätzen die Begriffe scheinbar beliebig gleichsetzt und vermischt.

Das Unterscheidungskriterium zwischen ästhetischer Form (4.) und den anderen Formen (1., 2. und 3.) besteht wohl in der Art ihres Gegebenseins und ihrer Rezeption und kann mit dem (Ober-) Begriffspaar: äußere und innere Form bezeichnet werden.

Sind die außeren Formen materielle Gegenstănde oder zeitlich-răumliche Erscheinungen, die sinnlich bzw. "anschaulich" wahrgenommen werden, so bezieht sich der Begriff der inneren Form auf ein Ordnungs- oder Funktionsprinzip, das intellektuell, intuitiv oder ăsthetisch erkannt werden kann.

Im Polnischen gibt es dafur das Begriffspaar "forma" und "kształt". letzteres etymologisch mit dem deutschen Wort "Gestalt" verwandt. Doch ulullich wio im Doutochon wordon dio Wortbodoutungon in dor Vorwondung nicht immer klar unterschieden, und "forma" wird häufig (auch von Witkiewicz) fur "kształt" verwendet. Da die synonymische Verwendung jedoch nicht in umgekehrter Richtung ("kształt" fur "forma") erfolgt, liegt der Schluß nahe, daß "forma" ein Oberbegriff von "kształt" ist.

Das Interesse des Rezipienten richtet sich bei ăußeren Formen hauptsăchlich auf das Material und bei inneren Formen auf die Art und Weise seines Gegebenseins in einem Formganzen.

Während die Unterscheidungskriterien für Witkiewicz' Differenzierung des Formbegriffes in den "Ästhetischen Skizzen" relativ plausibel und nach- 
vollziehbar erscheinen, wird der Sachverhalt wesentlich schwieriger, wenn es um die Differenzierung innerhalb des Oberbegriffes der inneren bzw. ästhetischen Form geht, nämlich bei den Begriffen Komposition, Konstruktion und Reine Form.

Die Begriffe "Komposition" und "Konstruktion" darf man wohl als gleichbedeutend betrachten:

"<...> die Konstruktion, bzw. Komposition. Mit diesem Ausdruck wollen wir das Wort Konstruktion ersetzen: er ist mit dem vorigen fast gleichbedeutend, doch erinnert er zu stark an Brucken, Maschinen, die Leiber von Lebewesen und andere Gegenstănde". (SzE, I71)

Dagegen scheint eine Unterscheidung zwischen Komposition, Reiner Form oder der Formerfassung ("ujęcle formy") notwendig, auch wenn Witkiewicz diese Begriffe manchmal gleichsetzt: "dieser neue Begriff der Form" (...> "ist gleichbedeutend mit der Konstruktion der Form in der Ebene, d.h. der Komposition, d.h. der Reinen Form." <Kursiv im Original> (SzE, 178). Wie oben schon erwăhnt, wird das Verständnis fur die "Theorie der Reinen Form" nicht zuletzt durch Witkiewicz Darstellungsweise erschwert, der in der Begriffsverwendung hăufig wechselhaft und widersprilchlich war, sei es auf grund der Schwierigkeit des Gegenstandes oder infolge seines Schwankens zwischen dem Bemuhen um wissenschaftlich-begriffliche Klarheit und der polemisch-rhetorischen Uberzeugungskraft seiner Darstellungen.

In dem Werk "Neue Formen in der Malerei" fallt schon bei der Kapiteleinteilung eine Unterscheidung zwischen "Komposition" und "Formerfassung" auf. Folgende Definition beweist indirekt die, zumindest theoretisch vorhandene, Differenzierung:

'<...> eine 'Erfassung (ujęcie>) der Form' als solcher, losgetrennt von Komposition und Farbe, existiert nicht - es ist eine Abstraktion um der leichteren Orientierung willen. Es ist schwierig, sie auf einfache Weise zu definieren. Man kann sie als eine konstante Bauweise der Einzelheiten des Ganzen in der Konstruktion der Reinen Form bezeichnen; als den Charakter der geringsten, auf den ersten Blick in dem allgemeinen Eindruck unmerklichen Unterschiede oder Gemeinsamkeiten zwischen den kleinsten Elementen, oder auch den Charakter des Ubergangs der einzelnen größeren Teilflăchen des Bildes, die Art, sie zu verbinden und zu trennen." (NFM, 74)

"<...> fur die Formerfassung ist es entscheidend, ob in dem gegebenen Bild alle Formen, die den Kompositionsstoff abgrenzen, immer den gleichen Charakter haben, unabhängig davon, welchen Gegenständen sie ähneln. Also: ob sie spitz, kantig oder rundlich sind; ausgefranst 
oder glatt; ob die Konturen fließend sind, oder ob sie ihre Kurven verăndern <...." (NFM, 75)

Komposition in der Malerei definiert Witkiewicz folgendermaßen:

"Als Komposition, d.h. Aufbau (układ) des Bildes, bezeichne ich die Verhältnisse der Bestandteile dieses Bildes untereinander und ihr Verhaltnis zu der indifferenten Form, die in die Zusammensetzung der inneren Formen nicht eingeht, sondern das Bild von den restlichen Gegenstănden abgrenzt, d.h. zum Rahmen." (NFM, 32)

Die wesentliche Funktion der Komposition in der Malerel besteht also in der Abgrenzung der sichtbaren Formen/Gestalten voneinander und vom Hintergrund sowie in einer bestimmten Anordnung der Einzelformen in der vorgegebenen Flăche. Die wichtigsten Elemente der Komposition sind neben den schon erwähnten Richtungsspannungen die verschiedenen Abstufungen der Symmetrie. Unter den Einzelformen der Bildflăche unterscheidet Witkiewicz zwischen Haupt- und Nebenformen, die er in Analogie zu Musik und Literatur Haupt- und Nebenthemen nennt. Seine Schilderung der Komposition des Bildes als ein Ausfullen einer begrenzten Flăche mit Formen und Farben, die eine bestimmte Richtungsspannung haben und nach formalen Kriterien geordnet sind, ruft, trotz des unterschiedlichen Mediums, Assoziationen zu seiner späteren Theorie des Dramas hervor, das er als ein formalăsthetisch bestimmtes "Werden in der Zeit" bezeichnet. Wenn man die Abgrenzungsfunktion der Komposition auf die Wortkunstwerke uberträgt, so kann man an das Bewnßtmachen der Fiktionalităt denken und im Bereich des Theaters an die Ablehnung der Identifikations- und lllusionsăsthetik, die mit den antinaturalistischen Strömungen am Anfang des 20. Jahrhunderts wiodor aurlobt.

Die Literarizităt von Witkiewicz' Theorie der Malerei ist wahrscheinlich auch P. Piotrowski bewußt, wenn er vom "Aufbau einer visualen Aktion" durch "das Hierarchisieren der Bildflăche" und von einer "plastischen Narrativik" spricht. 31

Die angedeuteten intermedialen Parallelen in Witkiewicz' Theorie sollen fur das Weitere die Gultigkeit seiner Begriffe auch fur sprachliche Kunstwerke legitimieren.

${ }^{31}$ Piotrowski, 1985: 38. 
Die Hauptfunktionen der Komposition bestehen, nach Witkiewicz, in der Abgrenzung von der außerküntlerischen Sphäre und in der Organisation der Elemente eines Kunstwerkes. Es handelt sich um wahrnehmbare GesetzmäBigkeiten (2.B. Rhythmus, Symmetrie), die von der Art der Elemente, d.h. des Materials, abhängen.

Komposition bzw. Konstruktion ist also eine Artefakt-Kategorie. Dagegen scheinen die Begriffe Formerfassung und Reine Form Kategorlen des ästhetischen objekts zu sein. ${ }^{32}$

Für diese Interpretation spricht z.B. die Tatsache, daß in der Zeichnung, die modellhaft "die Einheit der Psyche des Individuums" darstellen soll (vgl. NFM, 12f), die Reine Form als der außerste der konzentrischen Kreise erscheint, d.h. auf dem gleichen Niveau angesiedelt ist wie die metaphysischen und realitätsnahen Gefuhle sowie der Intellekt. Es handelt sich also um eine besondere Produktions- oder Rezeptionskraft der individuellen Psyche, die ihre Wurzel in dem schon beschriebenen Erleben der Einheit in der Vielfalt hat.

Die Komposition bzw. Konstruktion allein ist noch kein Maßstab fur die Kunst. Erst in der Konkretisation - um mit Ingarden zu sprechen - vollzieht sich das Kunstwerk:

"Konstruktion ist kein Kriterium, denn das Kunstwerk ist keine Brulcke, die als gut gelten kann, wenn sie unter dem ersten Zug nicht zusammenbricht. Die Meinung, die ein gewisser Bildhauer äußerte, daß das Werk wie irgendein Lebewesen die Făhigkeit zum Eigenleben haben sollte, ist nur eine schöne Xußerung. Denn die Fahigkeit eines Werkes zum Leben ist die Fahigkeit, in elner begrenzten Anzahl anderer Personen (und sei es nur in einem oder zweien außer dem Schbpfer) dieses Gefuhl der Einheit zu wecken, woruber wir in den vorigen Ka-

${ }^{32}$ Witkiewicz verwendet die Begriffe Artefakt und asthetisches objekt nicht, obwohl sie in seiner Zeit Gegenstand ästhetischer Diskussion waren. Sie treten zum ersten Mal 1909 in dem Buch "Phllosophie der Kunst" von B. Christiansen auf. In die $20 \mathrm{er}$ Jahre fallt die Beschäfigung mit dieser Problematik in der russischen (G. Spet, S. Bernstein, M. Bachtin), und in der tschechischen (O. Żich) Àsthetik. Bei Mukałovsky taucht die Konzeption von einer Polaritat von "materiellem" Werk und ästhetischen Objekt zum ersten Mal im Jahre 1934 auf. Man kann bei Witkiewicz keinen direkten Kontakt mit diesen Arbeiten nachweisen, doch wahrscheinlich ein adăquates Kunstverstăndnis und eine offenheit fur diese Problematik aufgrund des zeitgenössischen Gedankenguts und Geistesströmungen voraussetzen.

Vgl.: Civikov, 1987. 
piteln gesprochen haben. Ein gutes Bild ist ein Bild, das wenigstens in einem Menschen das metaphysische Gefuhl durch seine Reine Form weckt." <Hervh. im Original> (NFM, 88f)

-

Das angefuhrte Zitat beweist, daß Witkacy in bezug auf die Ontologie des Kunstwerkes einen ăhnlichen Standpunkt einnimmt wie $R$. Ingarden und andere zeitgenössische Kunsttheoretiker (B. Croce, Ch. Morris, M. Bachtin): das Kunstwerk existiert nicht als ein realer Gegenstand, sondern als ein geistiger $\mathrm{Akt}^{33}$. Es realisiert sich erst im ästhetischen Erlebnis des $\mathrm{Re}-$ zipienten.

Nur vor diesem Hintergrund bekommt der Begriff "Reine Form" Uberhaupt Sinn, denn eine Form ohne Inhalt - und das betonten sowohl die Kritiker Witkiewicz' als auch er selber - ist als realer Gegenstand unmöglich. Die Interpretation der Reinen Form als einer Kategorie des ästhetischen Objekts erklärt auch solche vermeintlichen Widersprüche wie z.B. die Aussage: "die Form des Kunstwerkes ist sein einziger wesentlicher Inhalt" (NFM, 11). "Reine Form" liegt einer ästhetischen Erfahrung zugrunde, die auf einem unbewuBten und unmittelbaren Wahrnehmen der Struktur eines Kunstwerkes beruht, die dem Rezipienten die Grunderfahrung der Identităt der eigenen Person und des Grundprinzips der Existenz - der Einheit in der Vielfalt - vermittelt. Wie im vorangehenden Kapitel ausgefuhrt, ist es eine konkret erlebbare existentielle Grunderfahrung. Eine untergeordnete Rolle spielen dabei die abgebildeten oder dargestellten realitätsnahen Gegenstände und die von ihnen ausgelösten Gedanken oder Gefuhle, die sich auf das Leben beziehen.

Zusammenfassend kann man also folgendes feststellen: Witkiewicz' Auffassung der ästhetischen form entspricht in etwa dem von Ingarden unter Punkt 3 beschriebenen Formbegriff ${ }^{34}$. Bei einer Auffassung des Gegenstandes (der Dinge oder des Seins) als einer Menge an Einzelelementen - so Ingarden - werden als Inhalt eben diese Elemente und als Form die Beziehungen

${ }^{33}$ Zur perzeptuellen Auffassungen des ăsthetischen Objektes in der modernen Ästhetik vgl. Kutschera, 1988: 83ff.

${ }^{34} \mathrm{Vgl}$. Ingarden, 1958, II: $350 \mathrm{ff}$ und den Beginn des Kapitels 3 in dieser Arbeit. 
zwischen den Elementen betrachtet. ${ }^{35}$ Heute wUrde man darauf den Begriff "Struktur" anwenden: die von J. Mukałovsky $1929^{36}$ vorgeschlagene Definition der Struktur als einer funktionalen Wechselbeziehung zwischen den Elementen hat sich inzwischen in den Geisteswissenschaften etabliert.

Witkiewicz hat sich uber seinen Formbegriff hăufig in analoger Weise geäußert: "Form ist das, was komplexen Gegenstănden und Erscheinungen eine gewisse Einheit verleiht." (CzF.: 39). Eine entsprechende Formauffassung legt auch seine monadologische Ontologie nahe. Wie schon mehrmals erwahnt, betrachtet er die Dinge und das Sein als unterschiedlich strukturierte Monaden und das "Geheimnis der Existenz" als "Einheit in der Vielfalt". Ähnlich wie er die Einzelexistenz, den Menschen, als eine abgeschlossene, individuelle Einheit von biologisch-psychischen Einzelqualitäten versteht, ist für ihn auch das Kunstwerk eine unbewußt konstruierte Einheit von Einzelelementen. Die Beziehungen, die zwischen den Elementen eines Kunstwerkes bestehen, haben ihre Entsprechung in der Psyche des Menschen und in der Welt. ${ }^{37}$ Aus einem solchen Formbegriff leitet Witkiewicz auch die metaphysische Qualităt der ästhetischen Erfahrung ab:

"Als ästhetisches Wohlgefallen, im Unterschied zu anderen Annehmlichkeiten lebensnutzlicher Art, bezeichne ich ein unmittelbares, ohne den Filter begrifflicher Kombinationen erfolgendes Verstehen dieser Einheit. Anders ausgedruckt als Verganzheitlichung (scałkowanie) der Vielfalt der Elemente in eine Einheit. <...>

Eine solche, durch sich selbst wirkende Form, die ein asthetisches Wohlgefallen auslరst, bezeichne ich als Reine Form. Dies ist also keine Form ohne Inhalt, denn eine solche kann kein Lebewesen schaffen, sondern eine Form, in der realitătsnahe Elemente eine untergeordnete Rolle spielen. 〈...> nur die unmittelbar wirkende, d.h. gefuhlte Form, nenne ich Reine Form." (CzF, 39)

Wenn die Form als eine funktionale Beziehung, welche die Einzelteile eines Gegenstandes zu einer Einheit zusammenfugt, definiert wird, so impli-

${ }^{35}$ Ebd.: 350.

${ }^{36}$ Mukałorsky, J.: Der Begriff des Ganzen in der Kunsttheorie. In: Mukałovsky, 1974: 20-30.

${ }^{37}$ Vgl.: "Dieses Gefuhl der Einheit in der Vielfalt ist uns unmittelbar in der Gestalt der Einheit unserer Persönlichkeit, unseres "Ichs" gegeben, und deshalb habe ich die Kunst als den Ausdruck der Einheit der Persönlichkeit bezeichnet." ( $C z F: 42)$ 
ziert das noch eine andere, verwandte Formauffassung, die $R$. Ingarden unter Punkt 9 beschreibt ${ }^{38}$. Form wird in diesem Fall als "GesetzmäBtgkeit" oder "Regel" (Ingarden: "prawidłowosc") verstanden, und als Opposition stehen ihr nicht direkt der Inhalt, sondern die "Formlosigkeit" bzw. "Regellosigkeit" gegenuber. Eine solche Formauffassung ist eigentlich ein Beurteilungs- und Rangkriterium in der Kunst und liegt den meisten normativen Poetiken (etwa von Aristoteles oder Baumgarten) zugrunde ${ }^{39}$. Einheitlichkeit und Ausgewogenheit des Stils, Zusammengehörigkeit der Elemente sind Kriterien, die in den meisten klassizistischen Ästhetiken vorkommen und den Ausgangspunkt fü die Konzeption des Schönen als Harmonie bilden. Es wäre erstaunlich, etwas Entsprechendes bei einem Autor wie Witkiewicz zu finden. In der Tat ubernimmt Witkacy zwar aus diesen Ẍsthetiken die grundlegende Auffassung der formalen Einheitlichkeit als Beurteilungskriterium des Kunstwerkes, wehrt sich aber gleichzeitig gegen die normativen Einzelforderungen und gegen den traditionellen Harmoniebegriff. Beides geschieht nicht als eine explizite Auseinandersetzung mit den Positionen anderer Philosophen, sondern ist implizit in der Thematik und Art seiner Theorie enthalten. Gegen die normativen Forderungen des Harmoniebegriffes postuliert Witkacy den Begriff der "subversiven Komposition" ${ }^{40}$. Eine solche Komposition ist durch Asymmetrie, Arrhythmie, Disharmonie gekennzeichnet und wirkt trotzdem - sofern es ein Werk der Reinen Kunst ist einheitlich und ganzheitlich:

"Wenn uns das Ungleichgewicht der Kompositionsmassen oder große Differenzen in ihrem Charakter nicht als ein Fehler erscheinen, der die Kunstlerintention negiert, sondern wir gerade diese beunruhigenden Gestalten oder ihr Ungleichgewicht als ein notwendiges Element der Einheit in der Ganzheit des Bildes anerkennen mussen; wenn die leeren Stellen und die Häufung der Gestalten von solcher Art sind, dass das Ganze trotz seines ursprünglich unangenehmen Charakters, seinen

${ }^{38}$ Ingarden, 1958, II: $355 f$.

${ }^{39} \mathrm{Vgl}$. Kutschera, 1988: 236ff.

${ }^{40}$ Im Original wird die Komposition mit den Adjektiven "perwersyjna" (dt. wörtl.: pervers) und "przewrotna" (dt. wörtl.: perfide. treulos) bezeichnet (NFM: 46). Da eine wörtliche Ubertragung ins Deutsche das Bezeichnete verfälscht hätte, wurde das Wort "subversiv" verwendet, das die von Witkiewicz geschilderten Sachverhalte gut ausdruckt und auch indirekt mit dem Wort "przewrotna" (von "przewracac" - dt.: umstürzen) etymologisch verwandt ist. 
wesentlichen Sinn durch deren Entfernen verlieren wurde - eine Komposition, in der solche Verhältnisse vorkommen, werden wir als subversiv bezeichnen". (NFM, 46f)

Zu einer solchen Kompositionsart gehört auch die Aufnahme von, nach allgemeingultigem Geschmack, unangenehmen bzw. häBlichen Elementen in das Kunstwerk:

"Fur Kunstwerke ist es auch charakteristisch, daß an sich unangenehme Elemente: eine unbehagliche Farbzusammenstellung; Dissonanzen in der Musik; seltsame, unangenehme und beunruhigende, oder sogar widerwătige Wort- und Handlungskombinationen, in der Summe, im Ganzen des Werkes notwendige Elemente seiner Einheit, d.h. der kunstlerischen Schönheit sein können. Diese Zusammensetzung der Einheit aus Elementen, die an sich unangenehm sind, und deren Uberwiegen im Kunstwerk nenne ich die kilnstlerische Subversion. <Hervh. im Original> $(C 2 F, 43)$

Bei der Definition des Inhaltsbegriffes unterscheidet Witkiewicz zwischen dem gegenständlichen Inhalt ${ }^{41}$ (d.h. wirklichkeitsăhnliche Gestalten in der Malerei, Gefuhle und Stimmungen, die durch Musik ausgelost werden, Sinneinheiten in der Dichtung), der ästhetisch irrelevant sein soll, und dem klinstlerischen Inhalt (d.h. die Form bzw. die Konstruktion von Einzelelementen).

"<...> der Inhalt der Reinen Kunst ist die Reine Form (wie wir die Konstruktion der Qualităten, die eine Einheit in der Vielfalt bildet, nennen wollen) <...>." (NFM, 16)

Den eigentlichen kunstlerischen Inhalt machen also die Kunstelemente aus. Dem Form-Inhalt-Dualismus gemäB unterscheidet Witkiewicz streng zwischen roin-formalen und realitgtsnahen Elementen. In einem wahren (reinen) Kunstwerk soll die Komposition der formalen Elemente im Vordergrund stehen. Die realitätsnahen Elemente sollen den Erfordernissen der Komposition angepaßt und gegebenenfalls in ihrer imitatorischen Realitatsnahe beliebig verändert, deformiert werden. Doch anders als fur die Futuristen besteht fü Witkiewicz das Ziel des Kunstwerkes nicht darin, die Realitătsnăhe grundsătzlich zu vermeiden bzw. programmatisch die Deformation

${ }^{41} \mathrm{~V}_{\mathrm{gl}}$. Kapitel 2.1.4. in dieser Arbeit. 
anzustreben.

Die Einzelelemente, insbesondere die formaler Art, sind je nach Kunstart verschieden. ${ }^{42}$ Die "reinste" Kunstart ist die Musik: die Töne als formale Grundelemente sind nahezu frei von einem lebensadăquaten Inhalt. Doch geordnet in bestimmte Formen: Rhythmus, Themen, Melodie können sie beim Zuhörer Gefuhle (Freude, Ruhe, Angst usw.) oder auch realitätsnahe Assoziationen auslösen. Dieses wäre der lebensadăquate Inhalt der Musik, der jedoch in die eigentliche ăsthetische Erfahrung nicht eingehen sollte.

In der Malerei und in der bildenden Kunst werden die Unterscheidungen komplizierter. Die formalen Elemente sind hier Farben, Gestalten ("kształty") bzw. das Material (Marmor, Holz etc). Doch im Kunstwerk erscheinen diese Elemente als Gegenstände, die an die äußere Welt erinnern können. Die formalen und die realitătsnahen Bestandteile treten also als zusammengesetzte Elemente auf, und fur das wahre Kunstwerk ist es von Bedeutung, daß die formalen und nicht die realitätsnahen Elemente die Komposition bestimmen.

Noch komplizierter wird es in der Sphäre der Poesie und des Theaters. Die Sprache ist ein zusammengesetztes Element. "Zu dem lautlichen Wert des Wortes kommt seine Bedeutung und das Vorstellungsbild, das es hervorruft, hinzu". Wie schon erwăhnt, will Witkiewicz die in spezieller Weise eingesetzte Wortbedeutung und Elemente des Inhalts ${ }^{43}$ als rein formale, d.h. künstlerische Elemente verstanden wissen. Die Folge der sprachlich ausgelösten Vorstellungen soll als eine Anschauungsform wahrgenommen werden und mit der Folge der Wortlaute eine Komposition bilden, die das metaphysische Gefuhl auslöst ( $v g l . C z F, 40 f)$.

"Darauf beruht die Wirkung guter Gedichte. Wenn wir sie hören, wissen wir selber nicht genau, wo wir uns befinden: in der Welt der Bilder, Laute oder Wortbedeutungen. Wir verstehen dieses Gemisch unmittelbar in der allgemeinen Konstruktion des Poems, und wenn das Gedicht zu Ende ist, wachen wir wie aus einem Traum auf, als ob wir in einer unbekannten Dimension gewesen wären." (CzF, 41)

Im Bereich der Theaterkunst kommt zu den Sphären der Vorstellungsbilder, der Wortlaute und -bedeutungen noch ein viertes Element hinzu: die Hand-

\footnotetext{
${ }^{42} \mathrm{Für}$ das Folgende vgl. CzF, 40ff

${ }^{43} \mathrm{Vgl}$. Kapitel 2.2.1. in dieser Arbeit.
} 
lung. Doch auch die Handlung wird von Witkiewicz auf ihren formalen Charakter hin untersucht. Er findet inn in der real-optischen und, ahnlich wie bei der Sprache, in der evokativen Komponente. Die Handlung hat also neben dem "lebenslogischen Inhalt" auch eine formale Funktion - durch ihren visuellen und evokativen Gehalt:

"Die Handlung ist ein Teil des verănderlichen realen Bildes, mit welchem sich die durch Wörter suggerierten Bilder verbinden. Dabei können die Lautkombinationen der Wörter abwechslungsreich ergänzt werden." (CzF, 41)

Zusammenfassend kann man folgendes feststellen: Der ästhetisch relevante Inhalt eines Kunstwerkes sind seine rein formalen Elemente: Laute, Farben. Gestalten, Wortbedeutungen (in ihrer evokativen Funktion) und Handlungen (in ihrer evokativ-visuellen Funktion). Diese künstlerischen Mittel haben fur Witkiewicz einen autonomen Wert ${ }^{44}$. Ästhetisch irrelevant, obgleich untrennbar mit den rein formalen Elementen verknupft, ist der gegenstăndliche Inhalt: Wirklichkeitsähnlichkeit in der Darstellung, Gefuhle, Stimmungen, Sinneinheiten und kognitive Gehalte. Die Funktion des gegenstăndlichen Inhalts soll im folgenden Kapitel untersucht werden.

44 Damit entspricht Witkiewicz den Auffassungen der historischen Avantgarde, die eine "Freisetzung der Kunstmittel" anstrebte. (Vgl. Burger, 1974: 22ff). 


\subsubsection{GEGENSTÄNDLICHER INHALT. DEFORMATION.}

Wie schon erwähnt, trennt Witkiewicz den Begriff der Schönheit vom Begriff des Gegenstandes und unterscheidet zwischen einem gegenstăndlichen und einem kunstlerischen Inhalt ( $v g l . C z F: 38 f$ ). Witkiewicz polemisiert zwar immer wieder gegen eine realitätsbezogene Rezeption. Die durch einen gegenständlichen Inhalt, z.B. die dargestellten Gestalten, das Thema oder gar den Titel ausgelösten lebenslogischen Assoziationen, weiterfürenden Interpretationen oder Stimmungen und Gefühle hătten mit dem künstlerischen Eindruck nichts gemeinsam. Ähnliches gilt auch fü die Kunstkritik: der Maßstab fur die Kunstqualität ist allein dessen Fähigkeit, metaphysische Gefuhle hervorzurufen. Lebensbezogene Elemente wie Gefuhle, Psychologie, Weltanschauung, Ethik, oder die Gelungenheit der Wirklichkeitsnachahmung sollten nicht als Maßstab für die Kunstkritik herangezogen werden. (NFM, 19f). Doch gleichzeitig wendet er sich gegen ein programmatisches Entfernen der Gegenstände aus der Kunst, wie das die Suprematisten und Futuristen forderten ( $v g l . N F M, 79$ ).

Der gegenständliche Inhalt hat zwar - laut Witkiewicz - fur die ästhetische Erfahrung keine Bedeutung, doch er spielt eine wichtige Rolle bei der Komposition des Artefaktes und in der Psychologie des Schaffensprozesses.

Als ein Kompositionsmittel ist der gegenständliche Inhalt notwendig, um dem Stoff die sog. "Richtungsspannungen" (poln.: "napięcia kierunkowe") zu geben. Durch eine gewisse Naturăhnlichkeit der dargestellten Gegenstănde werden die Wahrnehmungen und Antizipationen des Rezipienten in einer bestimmten Weise gelenkt: es werden Anfang und Ende, oben und unton, roohto und linko, oto. im Dild markiort,

"Die Bedeutung bestimmter Stoffe und Themen hängt auch davon ab. welche der möglichen Stoffachsen uns als Hauptachse erscheint; wie wir deren Richtung deuten, und welche Stellen wir als den Anfang und das Ende betrachten. Dieses Element nennen wir "Richtungsspannung" des Stoffes; es hăngt vom Charakter des ganzen Stoffes und seiner Einzelelemente $a b$, die unseren Blick in eine ganz bestimmte Richtung fuhren oder uns dazu zwingen sollen, die gegebene Masse als unbeweglich oder als scheinbar von links nach rechts beziehungsweise nach unten oder nach oben strebend 24 begreifen. <...> Es geht nur um die Bestimmung der Hauptachse des Stoffes, seines Anfangs und Endes. Diese Akzentuierung der Elemente der Reinen Form erfolgt jedoch vor dem Hintergrund der Assoziationen mit der äußeren Welt, wo aufgrund 
der Nichtgleichgultigkeit des Raumes ein Oben und ein Unten und bestimmte Richtungen der Ortsveränderung von Qualităten im Raum auftreten." (NFM, 51)

Mit dem Begriff der Richtungsspannung reduziert Witkiewicz also die Bedeutung der Gegenstănde, d.h. der wirklichkeitsbezogenen Elemente in der Kunst, auf eine formal-kompositionelle Funktion.

"Mit Hilfe dieses Begriffes <der Richtungsspannung> können wir den Begriff des Gegenstandes und dessen Deformation aus der Xsthetik eliminieren. Dieser Begriff <des Gegenstandes> impliziert den Begriff der Imitation des Gegenstandes und ferner den Begriff der Wirklichkeit uberhaupt, der die einfache Kunstauffassung so verdunkelt." (NFM: 50)

Eine Eliminierung des gegenständlichen Inhalts ist neben kompositionellen Erwăgungen auch aufgrund der Psychologie des Schaffensprozesses nicht vertretbar: Das Kunstwerk entsteht nicht durch "kaltes" intellektuelles Ausdenken, sondern als "Polarisierung und Individualisierung des metaphysischen Gefuhls in der Welt der Gefuhle und Vorstellungen" (SzE, 181) des Kunstlers ${ }^{45}$. Die Produktion und -rezeption von Reiner Kunst betrachtet Witkiewicz als eine extrem subjektive und persönliche Erfahrung, in die nicht nur die existentiellen metaphysischen Gefuhle eingehen, sondern auch die lebensadăquaten Empfindungen, Erinnerungen und das Denken des Individuums. Das metaphysische Gefuhl kann nur Uber eine Polarisierung in der psychischen Sphăre des Individuums zum Ausdruck gelangen. ${ }^{46}$ Daher ist es auch verstăndlich, daß der gegenstăndliche Inhalt auch in die Reine Kunst eindringt.

Als Objekt einer ăsthetischen Erfahrung soll der gegenstăndliche Inhalt jedoch eine untergeordnete Rolle spielen. Hierin soll nur das Erleben der formalen Einheit des Kunstwerkes ausschlaggebend sein.

Ein wichtiger Problemkreis in der Ästhetik Witkiewicz', der mit dem gegenstăndlichen Inhalt des Kunstwerkes zusammenhăngt, bildet das Phănomen

\footnotetext{
${ }^{45} V_{g}$ l. dazu Witkiewicz' Konzeption des metaphysischen Gefuhls und der ăsthetischen Erfahrung, dargestellt in Kapitel 2.1.2. in dieser Arbeit.

${ }^{46} \mathrm{Vgl}$. dazu insbesondere NFM: $22 \mathrm{ff}$.
} 
der Deformation.

Der Begriff der Deformation spielte in den postnaturalistischen kunsttheoretischen Debatten zu Beginn des 20. Jahrhunderts eine zentrale Rolle. Die Abkehr vom Nachahmungsideal in der Darstellungstheorie warf gleichzeitig die Frage nach dem neuen Darstellungsgegenstand auf. Die Rechtfertigung der Deformation, d.h. des Verzichtes auf Ähnlichkeit mit den Gegenstănden der äußeren Welt, erfolgte dabei von zwei Hauptpositionen aus: einer abstrakt-neuplatonischen und einer formalistischen. Man betrachtete die Deformation entweder als einen Weg zur Vermittlung einer das Sichtbare transzendierenden Realităt ${ }^{47}$ (z.B. V. Kandinskij, K. Malevix, P. Mondrian) oder als ein Nebenprodukt formaler Experimente im Zeichen der Autonomie künstlerischer Mittel ${ }^{48}$.

Auch für Witkiewicz wurde die Auseinandersetzung mit der Deformationsproblematik in Anbetracht der zeitgenössischen Malerei und der kunsttheoretischen Debatten unumgänglich. Der Begriff der Deformation nimmt in seiner Ästhetik eine zentrale Stellung ein. $\mathrm{Er}$ ist fur ihn jedoch nicht als ein werkkonstitutives, sondern als ein kulturgeschichtliches Phănomen interessant.

Witkiewicz wendet den Begriff der Deformation zunăchst einmal auf die bildende Kunst an und definiert ihn als eine Abweichung bzw. Verănderung von bekannten Formen der äußeren Welt in der künstlerischen Darstellung:

'Der Begriff der 'Deformation' druckt aus, daß etwas, was eine bestimmte, auf irgendeine Art geheiligte form hat, verunstaltet <zniekształcone> wird. Das betrifft hauptsăchlich alle Einzelgegenstănde der äußeren Welt, die konstant sind oder einen abgesteckten Bereich der Formvariabilităt haben." (SzE: 189)

Die Deformation ist eine besondere Ausprägung des gegenständlichen In-

${ }^{47}$ Als Beispiel fur eine solche Haltung kann die Theorie von $W$. Worringer (1908) dienen. Worringer prägt den Begriff des "Abstraktionsdranges" für ein Bedurfnis, das Wesentliche, Gesetzmaßige der Erscheinungen in der Kunst auszudrücken. Die nicht-klassische Kunst, die im Abstraktionsdrang gründet, bezeichnet er als "transzendente" Kunst. (Vgl. Worringer, 1987: 180f).

${ }^{48}$ Insbesondere im synthetischen Kubismus. Die Beschreibung einer derartigen formalistischen Haltung der Deformation gegenuber liefert beispielsweise J. Gries. In: Hess (Hrsg.), 1988: 99-105. 
halts und insofern für die Konstitution des ästhetischen Objektes unerheblich. Sie ist eine Folge der Autonomie künstlerischer Mittel und der Formdominanz in einem Kunstwerk der Reinen Form: aufgrund kompositioneller Erfordernisse können lebenslogische, realitătsăhnliche Inhalte beliebig verändert werden. Die Deformation entspringt also nicht etwa einer bestimmten Weltsicht des Künstlers, sondern der kompositionellen Notwendigkeit.

'Die 'Deformation' auf Gemălden ist nicht etwa das Ergebnis einer primitiven, im Grunde genommen, perversen Lust auf Mißgestaltung als solche, sondern sie wird durch die Notwendigkeit hervorgerufen, den Horizont der kompositionellen Möglichkeiten zu erweitern." (SzE, 194)

Bei der Ausweitung des Gegenstandes seiner Ästhetik auf sprachliche Kunstwerke weist Witkiewicz der Deformation aber auch eine indirekte ăsthetische Funktion zu: durch die Destruktion der gegenständlichen Inhalte werden die küstlerischen Inhalte eigentlich erst freigesetzt. Diese indirekte ästhetische Funktion der Deformation wird an kUnstlerischen Elementen sichtbar, die nicht rein formal, sondern mit "Lebenslogik" durchsetzt sind, wie beispielsweise die Sprache. In seiner Theorie der kunstlerischen Sprache ist die Deformation ein Mittel dazu, Wortbedeutungen als rein formale, d.h. künstlerische Elemente $z u$ etablieren. ${ }^{49}$ Durch diesen Ansatz bekommt Witkiewicz' Begriff der Deformation eine ahnliche Bedeutung wie der Begriff der Verfremdung im Russischen Formalismus: er wird als eine Differenzqualităt erfaßt, die den Kunst- vom Lebensbereich abgrenzt. ${ }^{50}$

Das Hauptgewicht der theoretischen Untersuchung WItklewicz' zur Deformation betrifft jedoch ihre kultur- und sozialgeschichtlichen Grundlagen.

Für die Erklărung des Auftretens der Deformation in der modernen Malerei greift Witkiewicz auf seine Anthropologie und Geschichtsphilosophie zu-

\footnotetext{
${ }^{49} \mathrm{Vgl}$. Kapitel 2.2.1. in dieser Arbeit.

${ }^{50}$ Zum Begriff der Verfremdung im Russischen Formalismus und zu seinen Analogien mit der Theorie der modernen Malerei vgl. Hansen-Love, 1978. 1.Teil.
} 
ruck. Kunst ist eine individuelle Objektivierung des metaphysischen Gefühls für die Einheit in der Vielfalt. Eine Erklärung für das Auftreten der deformierenden bzw. abbildenden Darstellungsverfahren leitet Witkiewicz von der historisch unterschiedlichen Psyche der Schöpfer ab.

Die Kunstler in frUheren Zeiten lebten angeblich im Einklang mit der sie umgebenden Welt, waren weniger kompliziert, geistig nicht so zerrissen wie die modernen Künstler, die die fortschreitende Mechanisierung und Vergesellschaftung subtil registrierten.

"Fruher hatten die Menschen ein besseres Gefuhl fur die Größe, Symmetrie und höhere Ordnung der Welt als wir. Bei uns ist dieses Gefuhl durch die Erkenntnis wissenschaftlicher Wahrheiten und die Bestimmung der Erkenntnisgrenzen zwar in der Sphäre der Begriffe gleichsam gesteigert, doch gerade deshalb nicht Gegenstand eines unmittelbaren, alltäglichen Erlebens. Wir haben dieses Wissen in entsprechend beschrifteten Schubladen abgelegt. Bei ihnen war es vielleicht unbestimmt, doch voller, es steckte gleichsam im Blut, außerte sich in jedem Augenblick des Lebens." (W, 71$)$

Fur den Kunstler der Antike fiel sein metaphysisches Gefuhl der Einheit in der Vielheit mit seinen religibsen Vorstellungen zusammen und er konnte sie auch in einfachen, an die außere Welt erinnernden Formen ausdrucken. Ahnliches geschah auch unter dem Einfluß christlicher Mystik z.B. in der russischen Ikonenmalerei. Die realitătsnahen Gegenstănde ihrer Kompositionen haben außer einer leichten Stilisierung und Verflachung keine Deformation erfahren und ihre Rolle in der Komposition bestand trotzdem nur darin, dem Stoff Richtungsspannungen zu geben.

Ganz anders ist das äußere Leben und somit auch die Erlebnis- und Gefuhlsfăhigkeit des modernen Menschen:

"Die Psyche heute ist differenzierter und vielseitiger als früher, doch auch die Geschwindigkeit des außeren Lebens ist weit größer, sein Charakter fieberhafter - dagegen sind die individuellen Lebensaußerungen schwăcher. Wenn fruher der Puls des Lebens gleichmäßig. langsam und kräftig war, so ist er heute beschleunigt, schwach, und in einigen Sphären zeichnet er sich durch eine starke Arrhythmie aus. (NFM, 141)

Mit unserem schnellen und fieberhaften Leben finden sich zwar Personen $a b$, deren metaphysische Gefuhle bis zu einem gewissen Grad erloschen sind - es wird von ihnen ruhig und normal durchlebt. Doch auf Individuen, in deren Seele eine unbestimmte Unruhe brennt, die Fragen nach den Letzten Dingen und zu dem Geheimnis der Existenz entspringt, wirkt diese fieberhafte und nach AuBen in ihrer Mechanisie- 
rung scheinbar ruhige Atmosphäre in der Weise, daß ihre Ausdrucksform zugellos und rasend werden muß" (NFM, 142)

Die komplizierte Psyche des modernen Kunstlers wirkt sich auf sein Schaffen in zweifacher Weise aus: einerseits wird seine Anschauung der Welt, der Menschen und Gegenstände verzerrt; anderseits drückt sich das komplizierte, fieberhafte Dasein in der kunstlerischen "Formunersättlichkelt" aus. Der moderne Mensch braucht immer kompliziertere Gestalt- und Farbkompositionen, um ein befriedigendes Gefuhl der Einheit zu empfinden, und er sucht in seinem Innovationsstreben nach immer neuen Formen. Die Möglichkeiten an Richtungsspannungen, die wirklichkeitsnahe Gegenstände besitzen, erweisen sich dabei als zu gering - daher müssen die Gegenstände der äußeren Welt deformiert werden. Als Beispiel nennt Witkiewicz die kubistische Malerei, die weitgehend. mit einfachen geometrischen Formen auskommt, welche durch geringfügige Ähnlichkeitsmomente mit realen Gegenstănden ihre Richtungsspannungen und damit ein strukturierendes Element erhalten ( $v g l . S z E, 191)$.

Der "Formunersăttlichkeit" sind jedoch Grenzen gesetzt. Eine zu komplizierte Komposition erscheint als ein Chaos und kann weder seinem Schopfer noch dem Rezipienten das metaphysische Gefuhl der Einheit vermitteln. Diese Tatsache im Zusammenhang mit der zwanghaften "Formunersăttlichkeit" des modernen Kunstlers ist nach Witkiewicz mit ein Grund fur den herannahenden Untergang der Kunst. 


\title{
2.2. LITERARISCHE ẌSTHETIK
}

\subsubsection{THEORIE DER KUNSTLERISCHEN SPRACHE}

Witkiewicz' formalistische Dramentheorie und -praxis sowie seine Ubertragung der ungegenständlichen Ästhetik von der bildenden auf die sprachliche Kunst gewinnt vor dem Hintergrund seiner Sprachphilosophie an Klarheit und Stringenz.

Die von Witkacy ironisch als "mäBiger Nominalismus" bezeichnete Sprachtheorie entstand im Zusammenhang mit seinem philosophischen Hauptwerk "Der Daseinsbegriff und die von ihm implizierten Begriffe und Behauptungen" zwischen 1917 und 1933. Hinsichtlich ihres zeichentheoretischen Ansatzes und erkenntnistheoretischen Relativismus erscheint sie aus heutiger Sicht als erstaunlich aktuell und fur ihre Entstehungszeit als ungewöhnlich modern. Witkiewicz selber gibt in einer prăgnanten Zusammenfassung in deutscher Sprache die wichtigsten Thesen seiner Sprachtheorie folgendermaßen an:

\begin{abstract}
"Meine Theorie der Begriffe ist, als nominalistisch, sehr einfach: gewisse Tiere 'kleben' identische Zeichen auf ăhnliche Gegenstănde 'auf'. Der Begriff des Begriffes zerfallt in die Unterbegriffe: in den des Zeichens und den der Bedeutung. Der Begriff ist eben ein Bedeutung besitzendes Zeichen; der Begriff der Bedeutung zerfallt auch in Unterbegriffe: 1) in den des "Privatbedeutungskomplexes" gemeint ist hier alles, was man mit irgend einem Zeichen beim Erlernen seiner Bedeutung assoziiert hatte - und 2) in den des dem Zeichen 'Entsprechenden', das sowohl in der Form einer Menge reeller Entităten oder Gegenstände, als auch nur in der Form einer Definition existieren kann. Ganze Massen von Assoziationen können durch die blosse Vorstellung des Zeichens repräsentiert werden, und es brauchen nicht alle Inhalte des 'Privatbedeutungskomplexes' als solche zum Bewusstsein kommen." <Deutsch im Original> (Schriften, III: 550)
\end{abstract}

Die angefuhrten Grundthesen zeigen, daß Witkiewicz mit einem Begriff des sprachlichen Zeichens operiert, der weitgehend dem - auch heute aktuellen - triadischen Zeichenmodell von Ch.S. Peirce oder C.K. Ogden und I.A.

1 Schriften, III: 543. <Deutsch im Original>. 
Richards ${ }^{2}$ entspricht. Von ästhetik- und sprachtheoretischer Relevanz erweisen sich dabei zwei Grundvorstellungen. Das ist zum einem die These der - um mit Saussure zu sprechen - Arbitrarităt des sprachlichen Zeichens: Witkiewicz betrachtet die Zuordnung der Lautformen zu den Bedeutungen als beliebig bzw. gesellschaftlich-konventionell geregelt (vgl.: 'gewisse Tiere 'kleben' <...> Zeichen 'auf' <...>"). Zum anderen ist Witkacy offensichtlich bewußt, daß zwischen dem Zeichen und dem außersprachlichen Gegenstand keine direkten und relevanten Beziehungen bestehen, sondern daß Zeichen und Objekt/Referent ("reelle Entităten", "Definitionen") nur uber die Vermittlung durch eine Interpretation, eine psychischindividuelle Vorstellung ("Privatbedeutungskomplex") aufeinander bezogen werden.

Die Arbitrarität des Zeichens und die Differenzierung innerhalb der Zelchenbedeutung zwischen dem "Privatbedeutungskomplex" und dem auBersprachlichen Referent bzw. Denotat sind axiomatische Voraussetzungen fur die Ǎsthetisierung der Wortbedeutung in formaler und nicht - wie im Realismus oder Naturalismus - in inhaltlicher Hinsicht. "Das Neue an meiner Theorie besteht eben darin, daß ich das Bedeutungselement des Wortes als ein kunstlerisches Element betrachte" (CzF: 40) stellt Witkiewicz fest. Dabei versteht er erklärtermaßen unter "küstlerischen Elementen" die "rein formalen", von keiner "Lebenslogik" beeinträchtigten Elemente, wie etwa Farben in der Malerei oder Töne in der Musik. Wortbedeutungen bekommen derartige Qualităten, indem das Gewicht von ihrer Darstellungs- auf die Evokationsfunktion ${ }^{3}$ verlagert wird. Durch ihre Făhigkeit, einen Strom von Vorstellungen und Assoziationen zu evozieren, werden die sprachlichen Zeichen fur Witkiewicz zu konstruktiven Einheiten, die, herausgelöst aus den am Wirkllchkeitsmodell orientierten Sinnstrukturen, abstrakte Formen in der Zeit bilden können.

"<...> Begriffe <sind> optische oder akustische Zeichen, d.h. bestimmte Folgen oder Gleichzeitigkeiten von Qualităten in der Zeit,

2 Entsprechende Kontakte und direkte Einflußnahmen sind - meines Wissens - nicht bekannt.

3 Uber Evokation als psychologisch-individueller Aspekt der Bedeutung und als Gesamtheit der Sprachfunktionen, die sich nicht auf die Darstellungsfunktion reduzieren lassen, referiert E. Coseriu, 1981: $89 f f$. 
denen andere Folgen oder Gleichzeitigkeiten von Qualităten in der Zeit bzw. deren mehr oder weniger bestimmte Komplexe entsprechen <Hervh. im Original>." ( $T: 269)$

In seinem Aufsatz "O Czystej Formie" trifft Witkiewicz eine grundlegende Unterscheidung zwischen Formen, die im Raum existieren (sog. Gegenstănde - poln.: przedmioty) und Formen, die in der Zeit erfolgen (sog. Erscheinungen - poln.: zjawiska). Zu den Raumformen zăhlen Werke der bildenden Kunst, und zu den Zeitformen musikalische Kompositionen, Dichtung und Drama ( $C z F$ : 33). Das oben angefuhrte Zitat zeigt, daß Witkiewicz sprachllche Zeichen als Zeitformen auffaßt ("Folgen oder Gleichzeitigkeiten von Qualitäten in der Zeit"), sie also in formal-ăsthetischer Hinsicht auf die gleiche Stufe stellt wie Töne in der Musik. Doch werden die sprachlichen Laute mit den musikalischen Tönen nicht gleichgesetzt. Als bedeutungstragende Elemente haben sie auch in formaler Hinsicht eine ganz andere Qualităt und ein anderes Medium: sie entfalten sich nicht in der sinnlichen Sphäre der Akustik sondern in der psychischen der Vorstellung. Witkiewicz geht nicht so weit wie die Dadaisten und versucht nicht, Signifikant und Signifikat zu trennen und mit phonetischen Effekten zu experimentieren. Sprachliche Laute bleiben fur ihn bedeutungstragende Zeichenformen - aber als solche eben auch formale Elemente. Die dadaistischen Sprachexperimente verurteilt er in seinen polemischen Schriften mit giftigen Kommentaren:

"Eine solche Zügellosigkeit der Sprache, in der die Dichtung aufhort, Dichtung zu sein, d.h. nicht mehr mit Begriffsbedeutungen als kunstlerischen Elementen operiert, sondern so etwas wie Pseudomusik, ein unartikuliertes und bedeutungsloses Gelalle wird, so etwas ist noturlioh oohrooklioh. In donko, taR dioco thorgangokinatartan. Nia als Grenzerscheinungen zwischen den verwandten und streng determinierten Kunstgattungen auftreten, niemals so wertvoll sein werden wie Kunstgattungen, die in Jahrhunderten fundiert wurden, und die nicht vor dem Hintergrund der Verarmung und Degeneration, sondern aus der Fulle, dem Reichtum und der Blüte entstanden sind. $\mathrm{Zu}$ den ersteren kann man sicherlich den dadaistischen 'Bruitismus' zählen, der weder Dichtung noch Musik ist." (T: 313)

Auf Witkiewicz' Haltung in diesen Fragen ist der Begriff des "Diskretismus" anwendbar, den A. Hansen-Löve zur Bezeichnug der intermedialen Vorgehensweise der historischen Avantgarde geprăgt hat. Danach sieht die 
Avantgarde die Verwirklichung ihres Ideals einer Vermischung und gegenseitigen Durchdringung der einzelnen Kunstformen nicht, wie der Symbolismus, auf metaphorischer Ebene, sondern in der metonymischen Variation der formalen Verfahren. Bei der Projektion dieser Verfahren von einer Kunstgattung in eine andere wird dabei die medienspezifische "Differenzqualităt" der künstlerischen Mittel respektiert und theoretisch reflektiert." Fur Witkiewicz scheint ein derartig definierter Diskretismusbegriff im hohen Maße zutreffend zu sein: bei der Ubertragung seines "formistischen", gegenstandslosen, ästhetischen Ansatzes von Malerei und Musik auf Literatur versucht er auch dem sprachlichen Medium dieser Kunstgattung gerecht zu werden.

Zusammenfassend kann man feststellen, daß fur eine formale Ästhetisierung des sprachlichen Zeichens der konnotative und nicht der denotative Aspekt der sprachlichen Bedeutung und die Evokations- und nicht die Darstellungsfunktion der Sprache relevant sind.

Witkiewicz' nächster Schritt bei der "Entgegenstăndlichung" und Xsthetisierung der sprachlichen Bedeutung besteht in der Feststellung, daß im Moment der Bedeutungszuweisung nicht etwa das Bezelchnete in seiner vollen Bedeutung, sondern nur eine seiner Qualitäten erfast wird, und die restlichen Qualităten als ein unbewußter Hintergrund ${ }^{5}$ existieren,

"Dabei existiert im Moment der Dauer nur eine einzige zeitliche Qualităt (z.B. der Laut) oder nur ein Komplex eher răumlicher Qualităten (2.B. die Farbe), Vorstellungen oder Erinnerungen als ein solcher, und die anderen bilden einen 'gemischten Hintergrund'. Mit diesem Begriff drüken wir in psychologischen Termini die Einheit und Kontinuităt unserer Persర̈nlichkeit aus." ( $T$ : 269f)

Eine solche Differenzierung innerhalb der Wortbedeutung entspricht weitgehend den Auffassungen der zeitgenössischen und auch der heutigen Lin-

Hansen-Löve, 1983: $292 f$.

5 Im Original: "tło zmieszane" (gemischter Hintergrund). In seinen philosophischen Schriften beruft sich Witkiewicz dabei auf den Begriff "unbemerkter Hintergrund" (Deutsch im Original) des deutschen Philosophen H. Cornelius. In: Schriften, III: 545. 
guistik". R. Ingarden, der seine Arbeit "Das literarische Kunstwerk" etwa zeitgleich mit Witkiewicz entwarf, prägte für diesen Sachverhalt die Begriffe "aktueller und potentieller Bestand der Wortbedeutung".?

Für Witkiewicz ist die Erkenntnis, daß nur ein Teil der Bedeutung im Moment der Bedeutungszuweisung aktualisiert wird, ein weiterer Schritt in seinem Bemuhen, die Wortbedeutung auf ihre kleinsten Elementarteilchen zu reduzieren und von einem Weltbezug $z u$ isolieren. Ähnlich wie in der bildenden Kunst soll auch das sprachliche Kunstwek als eine formale Einheit jenseits der lebenslogischen Zusammenhänge wirken. Um eine derartige Âsthetisierung und Formalisierung der Wortbedeutung zu erreichen, gilt es, eine automatische Einbindung der Bedeutung in referentielle Strukturen zu unterbinden und dafür einen Strom von fluchtigen, undeutlichen Vorstellungen und Assoziationen auszulosen, die in der Psyche des Rezipienten abstrakte Formen in der Zeit entstehen lassen. Witkiewicz beschreibt diesen Zustand als:

"ein gewisses physisches Gefuhl (eine zeitliche Folge innerer Qualităten, d.h. solcher, die sich innerhalb unseres Körpers befinden). Zunächst allein dieses Gefuhl und später auch das sichtbare oder hörbare Zeichen selbst werden zum Symbol eines ganzen Komplexes möglicher Gedanken, Einfuhlungen, Vorahnungen und Erwägungen. All diese 'Akte' lassen sich auf gewisse Abfolgen der gegenwärtigen oder vergangenen Qualităten in der Dauer reduzieren." (T: 273)

Wichtig erscheint dabei die Tatsache, daß die Ästhetik der Zeichen von deren unmittelbarer Einwirkung abhăngig ist, d.h. nur in Kunstwerken, die Erscheinungen sind (sich in der Zeit realisieren wie Musik, Dichtung und Drama), auftreten kann. Das ist wahrscheinlich der Grund dafur, daß Witkiowlic don Ruman alo rur dio Wirkung dor Roinon Form ungooignot ab lehnte, und in der Malerei das Kriterium der Planităt zur Voraussetzung der Reinen-Form-Erfahrung machte: Dreidimensionalităt, sei es wirkliche wie in der Bildhauerei oder nachgeahmte wie in der Malerei, stört die Wirkung des unmittelbaren Eindrucks' der Formen. ${ }^{8}$ Die künstlerische Wir-

6 Vgl.: Lewandowski, 1990, I: 139ff, s.v. "Bedeutung".

7 Ingarden, 1972: 86.

8 Damit entspricht Witkiewicz aber auch der Xisthetik der modernen europäischen Malerei. Die Forderung nach einer planen, zweidimensionalen 
kung der Begriffe entwickelt sich unmittelbar in der Zeit, die ja nur eine Dimension und eine Richtung hat, wie ein schneller und spannungsgeladener Strom von sich verăndernden undeutlichen Bildern, Assoziationen und Lautkombinationen.

Nachdem er grundsătzlich das formal-ăsthetische Potential der sprachlichen Bedeutung festgestellt und begrundet hat, untersucht Witkiewicz die Wirkungsweise einzelner Wörter und Wortgruppen und versucht, Kategorien und Beurteilungskriterien der künstlerischen Sprache zu explizieren.

Der ästhetlsche Wert eines Begriffes wird Uber seine konnotative Lelstung definiert:

"Die klunstlerische Bedeutung eines Begriffes hăngt von seiner Kapazităt ab, d.h. von der Größe seines Umfangs an Möglichkeiten <...〉." (T: 271)

Gemeint ist die Kapazităt an Vorstellungen und Assoziationen, die ein Begriff hervorufen kann. Im folgenden untersucht Witkiewicz die konnotative bzw. ăsthetische Kapazităt einzelner Begriffsgruppen. Dabei stellt er folgende Hierarchie auf:

1) "absolut abstrakte Begriffe", die mit realen Vorstellungen nicht ausgefullt werden können, z.B. "die abstrakte Zeit" .

2) "real abstrakte Begriffe", die man mit gewissen realen Ereignissen assozlieren kann, z.B. "die Tugend".

3) "perzeptible Begriffe", die den Qualităten entsprechen, z.B. "rot"

4) "empirische Begriffe", die den realen Qualitätskomplexen entsprechen, 2.B. "das Pferd". (vgl.: T: 270f)

Das ăsthetische Potential eines Begriffes ist also quasi umgekehrt pro-

Darstellungsweise und die Ablehnung solcher Techniken, die răumliche Verhăltnisse auf dem Bild vortăuschen, gehorte zu den wesentlichen theoretischen Forderungen der modernen Malerei seit dem Impressionismus. Fur den Kubismus wurde die praktische Umsetzung dieser Xsthetik zum Wesensmerkmal: die kubistischen Bilder entspringen gröBtenteils den Versuchen,"die konkrete Fläche zu wahren und sie zugleich auf ganz 'metaphorische' Weise körperhaft-räumlich zu machen." <Hess, W.: Fruhe abstrakte Malerei. In: Hess (Hrsg.), 1988: 76.) 
portional zu seinem real-empirischen Bedeutungsgehalt oder, um mit Witkiewicz zu sprechen, zu den "Abfolgen gegenwärtiger Qualitäten in der Dauer" ( $T$ : 272), die dem Zeichen entsprechen. Wichtiger jedoch als die Stellung innerhalb dieser Hierarchie der Begriffe ${ }^{9}$ ist die Art der Qualitäten, auf welche sich das Zeichen bezieht. Die größte ästhetische Qualităt mißt Witkiewicz also eigentlich den real abstrakten Begriffen wie "Tugend", "Liebe" und insbesondere solchen bei, die Mrglichkeiten an menschlichen Handlungen beinhalten.

Das năchste Beurteilungskriterium des ăsthetischen Wertes eines Wortes ist die Spannung, die ein Wort auslöst oder die innerhalb einer Wortgruppe besteht:

"Jedes ausgesprochene oder geschriebene Wort ist etwas, was sozusagen eine innere Spannung besitzt, ist wie ein GeschoB, das explodieren kann. Der Moment der Explosion ist der Moment des Verstăndnisses durch den Leser oder Zuhörer." ( $T$ : 272)

In Abhăngigkeit von der Kapazităt und dem Spannungsvermögen der Begriffe trifft Witkiewicz folgende Differenzierung:

1) "unbestimmte Begriffe", 2.B. "etwas", "jemand". Sie erwecken keine bestimmten Vorstellungen, ihre innere Spannung dauert Uber den Augenblick der Bedeutungszuweisung hinaus an. Isoliert ausgesprochen, sind sie bedeutungslos, doch in Kombination mit anderen Begriffen können sie ein sehr wirkungsvolles kunstlerisches Element in der Dichtung werden.

2) "widerspruchliche Begriffe", 2.B. "lebendige Leiche" oder "quadratischer Kreis". Witkiewicz zăhlt sie zu den "relativ sinnlosen Begriffon". Olo habon ewar koino Entoproohung in dor Roalitkt, ovozioron ahar zwei realitătsnahe Bilder (z.B. eines lebendigen und eines toten Menschen), die die Tendenz haben, ineinanderzufließen (daher werden sie auch Grenz-, oder asymptotische Begriffe genannt). Auch diese Begriffe zăhlt Witkiewicz zu den eindrucksvollen artistischen Mitteln.

3) "absolut sinr.lose Begriffe" wie 2.B. "eine Leiche im Quadrat".

9 Der Vollstăndigkeit halber sei hier noch erwăhnt, daß in Witkiewicz' Hierarchie der Begriffe an oberster Stelle der Begriff des Seins steht (T: 271). 
oder "quadratische Leiche" - eine Verbindung vollig fremder Bedeutungen. Das Bemühen um das Verständnis des Begriffes fuhrt dazu, daß die zwei fremden Bilder abwechselnd ineinanderfließen, ohne sich jemals vollig zu verbinden.

4) "Worte mit unbestimmter Bedeutung", denen kein Signifikat in der außerkunstlerischen Wirklichkeit entspricht, die nur ihren rein-formalen lautlichen Inhalt haben wie z.B. "kalamarapaksa". Ihr eigentlicher Wert abgesehen von dem lautlichen - liegt in der Unbestimmtheit ihrer Bedeutung. Da sie mit beliebigen Inhalten ausgefullt werden können, besitzen auch sie eine hohe innere Spannung. Dazu gehören auch Wortschöpfungen oder verfremdende Transformationen von Fremdwörtern. (vgl. T: $273 f f$ ):

Die zuvor beschriebenen sprachlichen Phănomene (Evokation, konnotative Kapazităt, aktualisierte Bedeutung, und auch die Kriterien der Begriffshierarchie) blieben noch weitgehend auf den Bereich der "normalen", auf effektive Kommunikation ausgerichteten Sprache beschränkt. Um Spannungen auf der Ebene der Wortbedeutung zu erzeugen, setzt Witkiewicz dagegen ganz bewuBt das Mittel der Deformation der "Normalsprache" ein. So expliziert er z.B. bei der Beschreibung der Wirkungsweise der "Worter mit unbestimmter Bedeutung" die poetische Funktion der Sprache im ahnlichen Sinne wie R. Jakobson ("die Einstellung auf die Nachricht als solche ${ }^{n 10}$ ). Den ästhetischen Phänomenen der "widerspruchlichen Begriffe" und der "absolut sinnlosen Begriffen liegt wiederum das Prinzip der Verletzung von lexikalischer Solidarităt zugrunde. Dieser von E. Coseriu in die Linguistik eingefuhrte Begriff bezeichnet syntagmatische Strukturen unter den Lexemen, die eine bestimmte Kombinierbarkeit von Lexemen festlegen (z.B. "Hund" mit "bellen" und nicht mit "wiehern")". Coseriu weist auch darauf hin, daß Verstbße gegen die lexikalischen Solidaritäten stilistische Werte wie 2.B. sprachliche Metaphern ergeben können ${ }^{12}$. Für Witkiewicz hat aber eine derartige innersprachliche Struktur, die die lexikalische Kombinierbarkeit von Worten festlegt, die Funktion eines Erwartungshorizontes, dessen Enttăuschung ăsthetische Qualităten wie z.B. Spannung erzeu-

\footnotetext{
${ }^{10}$ Jakobson, 1971: 151.

${ }^{11} V_{g}$ l. Coseriu, 1974.

${ }^{12}$ Ebd.: $85 f$.
} 
gen kann. Daher ist sie auch für ihn ein Mittel zur Ästhetisierung der Wortbedeutung in formaler Hinsicht.

Die Deformation in sprachlichen Kunstwerken hat also ein wesentlich groBeres Gewicht als die Deformation in der bildenden Kunst. Wahrend sie in der Malerei sozusagen nur ein Nebenprodukt bei der Suche nach neuen Formen und Richtungsspannungen ist, wird sie in der Literatur zum konstitutiven Faktor: sie setzt bei dem komplexen, mit lebenslogischen Elementen durchsetzten kunstlerischen Mittel der Sprachbedeutung formal-ästhetische Qualităten Uberhaupt erst frei. Auf der Ebene des Satzes und der satzUbergreifenden Bedeutungsstrukturen hat die Deformation aber einen ăhnlichen Charakter wie in der Malerei: der Verzicht auf lebenslogische bzw. referentielle Bedeutungsstrukturen erweitert den Umfang formaler Gestaltungsmbglichkeiten, die wiederum die "Formunersăttlichkeit"13 des modernen Küntlers befriedigen.

Es ist verstăndlich, daß Witkiewicz mit einem derartig ästhetisierten Begriff der sprachlichen Bedeutung, wie oben beschrieben, behaupten kann: "die Bedeutungen der Begriffe sind kunstlerische Elemente, ähnlich wie reine Qualităten: Laute und Farben." ( $T$ : 279) In einem sprachlichen Kunstwerk sollen die Begriffe zu einer ästhetischen Konstruktion zusammengesetzt werden, und zwar nicht im Hinblick auf ihre referentiellen Sinngehalte, sondern auf ihr formales Potential, Spannungen zu erzeugen und Vorstellungen zu evozieren.

"In den Kombinationen aller solcher Worte zu Sătzen liegen, trotz der scheinbaren Begrenztheit in der Lautsphäre und der tatsăchlichen Begrenztheit in der Bildsphäre, unerschöpfliche kompositorische Roichtumor." (T, 276)

Bei einer solchen Konzeption der künstlerischen Sprache spielen konventionelle Beurteilungskriterien wie z.B. die Entsprechung zwischen dem sozialen Stand und dem Redestil der Figuren naturlich keine Rolle. Ebenso irrelevant sind rhetorische Kriterien. Zeitgenössische Literaturkritiker haben Witkiewicz seinen hyperbolischen, mit Neologismen, Wortspielen und ordinăren Fluchen gespickten Sprachstil häufig als sprachliches Unver-

${ }^{13} \mathrm{Vgl}$. Kapitel 2.1.3. in dieser Arbeit. 
mögen oder Geschmacklosigkeit vorgeworfen. $T$. Zelenski-Boy soll in einer Rezension uber "Tumor Mózgowicz" geschrieben haben, Witkiewicz' Sprache sei "ungewaschen und ungekămmt" gewesen (poln.: "język niemyty i nieczesany"). Das veranlaßte Witkacy, in einem lăngeren Artikel die Kriterien seiner formalistischen Sprachkonzeption zu erörtern und die Irrelevanz von konventionell-gesellschaftlich geprägten Beurteilungskriterien fur ein Kunstwerk mit metaphysischem Anspruch zu begrunden. ${ }^{14}$

Zusammenfassend kann Witkiewicz' formalistische Ästhetik im Bereich küstlerischer Sprache folgendermaßen umrissen werden:

Um das Kriterium der Gegenstandslosigkeit von der Malerei auf die Literatur ubertragen $2 u$ können, bemulhte sich Witkiewicz um eine theoretische Begründung eines formal-ăsthetischen Potentials der sprachlichen Bedeutung. Mit Hilfe eines triadischen Zeichenmodells und des Phänomens des aktuellen und potentiellen Bedeutungsbestandes konnte er die sprachliche Bedeutung aus den referentiellen Sinnstrukturen isolieren und sie auf das kleinste Bestandteil, nămlich eine Qualităt in der Vorstellung reduzieren. Dadurch war es möglich, die sprachliche Bedeutung als ein reines künstlerisches Element zu betrachten, das in der Lage ist, abstrakte Formen in der Zeit zu bilden, die durch Spannungen strukturiert und zusammengehalten werden.

Das literarische Kunstwerk konnte demnach als ein sprachliches Gebilde aufgefaßt werden, das nach formalen Kriterien konstruiert ist.

"Der Sinn als solcher verliert sich, Begriffe, die Gegenstände und Handlungen benennen, werden unnotig. Es wirken ganze Komplexe durch ihre innere Spannung, die sich verăndert in Abhăngigkeit vom Charakter der vorangehenden Satze und Bindeglieder." ( $T$ : 277 )

Auf diese Weise entstehen Sphăren, "wo sich der lebenslogische Unsinn in den høchsten formalen Sinn wandelt." (T: 279)

Die Dichtung ist nach Witkiewicz dreidimensional und besteht aus:

1) der lautlich-rhythmischen Schicht;

2) aus der Schicht der hervorgerufenen optischen Bilder (poln.:

\footnotetext{
${ }^{14}$ "Kwestia jezyka w sztukach scenicznych w czystej formie." (Das Sprachproblem in Buhnenwerken der Reinen Form). In: $T$ : 309-328.
} 
obrazy wzrokowe) und

3) aus der Schicht der Begriffsbedeutungen.

Daruber hinaus können die drei Schichten bestimmte realitătsnahe Qualităten (z.B. Lebensgefuhle wie "Freude" und "Angst" bzw. Wahrheiten und Erkenntnisse uber die Welt) hervorrufen (vgl. T: 279). ${ }^{15}$

Bei der Rezeption und Beurteilung eines Gedichtes ist es freilich wichtig, die Begriffe in ihrem künstlerischen Wert und nicht in ihrem außersprachlichen Bezug zu betrachten. Das sprachliche Kunstwerk soll die asthetische Erfahrung der Reinen Form vermitteln, d.h. Uber das Erleben der künstlerischen Form soll dem Rezipienten das metaphysische Gefuhl der Identităt seiner Persönlichkeit und der Einheit des Seins suggeriert werden. $^{16}$ Als eine Realisation der Reinen Form erscheint die Dichtung aber nur in unmittelbarer Wirkung, d.h. nur wenn sie gelesen bzw. deklamiert wird, und zwar in einer abstrakt-formalen Synthese von Laut, Vorstellung, Gedanke, Gefuhl und vom begrifflichen Sinn einzelner Sătze oder des ganzen Werkes. ( $T: 280$ )

Die formalistische Betrachtung der Wortbedeutung entspricht weitgehend dem allgemeinen Trend in der historischen Avantgarde, eine Autonomie der künstlerischen Mittel zu etablieren. Seit dem Impressionismus stehen in der Malerei die theoretische und experimentelle Beschäftigung mit Wirkung und Kompositionsweisen von Farben und Formen im Vordergrund und nicht wie fruher die Techniken einer "naturtreuen" Darstellung" . Analog dazu bemult

${ }^{15}$ Es ergibt sich hier ein interessanter Vergleich zu dem VierschichtenModell des literarischen Werkes von $R$. Ingarden (1972). Wahrend die veldaı Kunstlicut celkas bal dor Dowortung don oroton drol Cohiohton offensichtlich im wesentlichen ubereinstimmen (Witkacy (1)/ (3)/ (2) Ingarden "Lautgebilde" ; "Bedeutungseinheiten"/ "schematisierten Ansichten"), wird die bei Ingarden werkkonstitutive Schicht der "dargestellten Gegenstăndlichen" von Witkacy als ein ontologisch notwendiger. aber ăsthetisch irrelevanter Bestandteil des sprachlichen Kunstwerkes betrachtet.

Witkiewicz, der nach eigenen Angaben "Das literarische Kunstwerk" nur fragmentarisch kannte, kritisierte an Ingardens Vierschichtenmodell, daB es auf alle Kunstwerke anwendbar ist und die besonderen asthetischen Qualitaten des sprachlichen Kunstwerks nicht expliziert. (Darauf weist Szymanska, 1971: 180, hin).

${ }^{16}$ Zur Reinen Form vgl. Kapitel 2.1.1. in dieser Arbeit.

${ }^{17}$ Vgl. dazu Hess, W.: Einleitung. In: Hess (Hrsg.), 1988: 7-13. 
man sich seit Beginn des 20. Jahrhunderts in der Literatur sowohl auf programmatisch-theoretischer als auch auf sprachexperimenteller Ebene, dem Wort ein ăsthetisches Eigengewicht, unabhăngig von referentieller Funktion und syntaktisch-semantischen Bindungen, zu verleihen. Als Beispiel wăre hier insbesondere die Literatur des Dadaismus, Futurismus und des russischen Kubofuturismus zu nennen. Bei den programmatischtheoretischen Außerungen denke man v.a. an die berühmten Manifeste von F.T. Marinetti, in denen er fur die künstlerische Sprache die Befreiung der Wörter, Zerstörung der Syntax, Abschaffung der Interpunktion, der Adjektive und der Flexionsendungen etc. verlangt ${ }^{18}$. Ferner denke man an die statischen und bruitistischen Gedichte der Dadaisten ${ }^{19}$ oder an die Konzeptionen des "samocennoe/samovitoe slovo" und der "zaum'-Sprache" der russischen Kubofuturisten ${ }^{20}$. Der Sprachauffassung der historischen Avantgarde entspricht auch die Struktur des avantgardistischen Werkes: es ist nicht als ein syntagmatisch geordnetes Sinngefuge sondern als ein paradigmatisches Montage-Gebilde konzipiert. P. Burger prăgt in diesem Zusammenhang das Begriffspaar: organisches (bzw. symbolisches) und nichtorganisches (bzw. allegorisches) Kunstwerk als Unterscheidungskriterium zwischen konventioneller und avantgardistischer Kunst ${ }^{21}$. Auch wenn Witkiewicz sich deutlich von der dadaistischen und futuristischen Bewegung distanzierte, so ist eine gewisse Ubereinstimmung in wesentlichen Positionen unverkennbar.

Das Streben nach Autonomie künstlerischer Mittel in der modernen Kunst und die damit einhergehenden Deformations- und Verfremdungsverfahren werden in der Forschung hăufig als Ausdruck von Weltentfremdung, Desorientierung aufgrund von Zusammenbruch der Werte etc. erklärt. Doch die Hăufigkeit. mit der diese Argumente immer wieder in der Literaturgeschichte als Erklärungsmodell herhalten muBten (etwa fur das Phănomen des Welt-

${ }^{18}$ Marinetti, F.T.: Zerstorrung der Syntax. Drahtlose Phantasie. Befreite Worte. Die futuristische Sensibilităt (1913). In: Apollonio (Hrsg.), 1972: $119-130$.

${ }^{19}$ Vgl. das Manifest von R. Huelsenbeck (1918). In: Pörtner (Hrsg.), 1960: 477-489.

${ }^{20} V_{g l}$. dazu 2.B. Krucenych, A., Chlebnikov, V.: Slovo kak takovoe. In: Markov (Hrsg.), 1967: 53-59.

${ }^{21}$ Burger, 1974: 76. 
schmerzes bzw. des Byronismus in der Spätromantik), stellt ihre Beweiskraft in Frage. So scheint es zutreffender, die formalistische Ästhetik des ersten Drittels des 20. Jahrhundert als Konsequenz einer neuen Auffassung der sprachlichen Erkenntnisfunktion zu erklären.

Die alteste und bis heute gebräuchliche Bedeutungstheorie der Sprache ist die Abbildungstheorie. Danach wird die Sprachfunktion in der Erzeugung und Vermittlung von isomorphen Modellen der außensprachlichen Objekte gesehen. In erkenntnistheorethischer Hinsicht wird die Sprache als eine Spiegelung bzw. Abbildung von kognitiv vermittelter Wirklichkeit betrachtet. Man geht dabei von einer "transzendentalhermeneutischen Funktion der Sprache" ${ }^{22}$ aus: es wird ein intersubjektiv identischer "Logos" der Menschen-Gemeinschaft angenommen, der eine "Sinn-Verstăndigung und Konsensbildung ${ }^{n^{23}}$ trotz Verschiedenheit der Laute und Zeichen ermöglicht. Obwohl die Auffassungen uber das Denken und die Wirklichkeit geschichtlich variierten, wurde die Sprache daher lange Zeit nicht als ein konstitutiver Faktor im ErkenntnisprozeB betrachtet, sondern nur als ein Hilfsmittel, vorgegebene Wirklichkeit und vorgegebenes Denken auszudrucken.

Mit W. von Humboldt beginnt die Abkehr von der Abbildungstheorie und die Hinwendung zur sprachlichen Relativitatstheorie. Als deren Hauptvertreter gelten E. Sapir und B.L. Whorf, die in den 30er Jahren des 20. Jahrhunderts das Relativitătsprinzip ${ }^{24}$ entworfen und popularisiert haben. Danach wird die Sprache nicht nur als ein Ausdrucksmittel von Gedanken betrachtet, sondern als ein wesentlicher konstitutiver Faktor der Erkenntnis. Die Sprache formt das Denken und die Weltanschauung des Individuums:

"It was found that the background linguistic system (in other words, the grammar) of each language is not merely a reproducing instrument for voicing ideas but rather is itself the shaper of ideas, the program and guide for the individual's mental activity, for his analysis of impressions, for his synthesis of his mental stock in trade. Formulation of ideas is not an independent process, strictly rational in the old sense, but is part of a particular grammar, and differs, from slightly to greatly, between different grammars. We

${ }^{22}$ Apel, K.-O.: Sprache. In: Handbuch philosophischer Grundbegriffe, 1974: 1388.

${ }^{23}$ Ebd.

${ }^{24}$ Vgl. dazu: Werlen, 1989. 
dissect nature along lines laid down by our native language. "25

Die Herausbildung der neuen relativistischen Auffassung der sprachlichen Erkenntnisfunktion, die neuerdings wieder in der Postmoderne-Debatte "entdeckt" wird" ${ }^{26}$ ging mit der Entwicklung der systematischen Linguistik (im Unterschied zu der früheren historisch orientierten Sprachwissenschaft) wie auch mit dem Entstehen von linguistischem Strukturalismus und der Semiotik einher. Das sprachliche Relativitătsprinzip kann wohl aber auch fur die Veränderungen in der Ästhetik verantwortlich gemacht werden.

Die Auffassung der Sprache als ein Zeichen-Bedeutung-System, dessen Beziehungen arbiträr oder gesellschaftlich-konventionell sind und das eine isomorphe Abbildung von autonomem Denken und vorgegebener Wirklichkeit nicht leisten kann, sondern im Gegenteil das Denken und die Wirklichkeitswahrnehmung beeinflußt, blieb auch fur die Ästhetik nicht ohne Folgen. Der traditionelle Anspruch der Kunst, metaphysische Wahrheiten oder Qualităten auszudrücken, der gerade um die Jahrhundertwende im Xsthetizismus und Symbolismus wiederauflebte, war mit einer relativistischen Sprachauffassung unvereinbar. Das fuhrte zu Versuchen, uber Sprachzertrummerung und -ăsthetisierung, den traditionell metaphysischen Anspru-

${ }^{25}$ Whorf, B.L., in: Carroll, 1956: $212 f$.

${ }^{26}$ Die These vom Relativitätsprinzip der Sprache liegt offensichtlich der bekannten Formel von dem "postmodernen Spiel der Signifikanten" zugrunde, wie sie z.B. von $P$. Büger beschrieben wird:

"Eine zentrale These postmodernen Denkens besagt, daß in unserer Gesellschaft die Zeichen nicht mehr auf ein Bezeichnetes verweisen, sondern immer nur auf andere Zeichen, daß wir mit unserer Rede so etwas wie Bedeutung gar nicht mehr treffen, sondern uns nur in einer endlosen Signiflkantenkette bewegen. Dieser These zufolge ware das Zeichen, das Saussure noch als Einheit aus Signifikant und Signifikat beschrieben hat, zerbrochen." (Birger, 1987).

P. Burger scheint ubrigens die Begriffe "Zeichen" und "Signifikant" in unzulăssiger Weise gleichzusetzen: bei Saussure sind Signifikant (lautliche Seite) und Signifikat (semantische Seite) untrennbare Teile, die zusammen das sprachliche Zeichen bilden. Erst das Zeichen (signe) als Einheit stellt den Weltbezug her, und zwar durch Verweis auf den Referenten (außersprachliches Objekt). Daher mußte man korrekterweise bei der postmodernen Sprachphilosophie von einer Abkehr von der Abbildungstheorie sprechen. 
chen an die Kunst zu genügen. Für eine solche Erklärung der avantgardistischen Ästhetik sprechen sowohl die Forderungen der oben erwăhnten dadaistischen und futuristischen Manifeste als auch die Kunstauffassung des russischen Formalismus. Im Mittelpunkt dieser im ProzeB der Theoretisierung der zeitgenठssischen avantgardistischen Kunstpraxis entstandenen Theorien steht der Begriff der Verfremdung ${ }^{27}$, der laut J. Striedter zwei Intentionen hat:

"Einmal dient die Verfremdung dazu, die durch sprachliche und gesellschaftliche Konventionen "automatisierte" Wahrnehmung zu erschweren, dadurch ein neues Sehen der Dinge zu erzwingen und so das eigene Verhăltnis zur Umwelt zu korrigieren. Zum anderen wird in einer Art gegenläufigen Bewegung die durch Verfremdung erschwerte Wahrnehmung auf die verfremdende und erschwerende Form selbst gelenkt. Diese Form und die für sie konstitutiven Verfahren werden zum eigentlichen Gegenstand der Kunst."

Die Ästhetisierung der formalen Elemente der Sprache und das Bestreben, mit einer künstlerischen Sprache uber die Grenzen eines konventionellen, erstarrten Zeichensystems hinauszugehen, um ein "Neues Sehen" (V. Sklovskij) der Dinge zu ermöglichen, ist vor dem Hintergrund der relativistischen Sprachauffassung gut nachvollziehbar.

Wichtiger als die Entautomatisierung der Wahrnehmung erweist sich fur Witkiewicz' formalistische Asthetik die zweite Funktion der Verfremdung, nämlich die Lenkung der Aufmerksamkeit des Rezipienten auf die Form des Kunstwerkes. Witkacys Begriff der Deformation kann zwar nicht vollig mit dem Begriff der Verfremdung bei den russischen Formalisten gleichgesetzt werden $^{29}$, einen wesentlichen gemeinsamen Bedeutungskern beider Begriffe scheint es dennoch zu geben. Sowohl die Deformation als auch die Verfremdung haben die Eigenschaft, innerhalb einer primär nichtkunstlerischen Sphăre (z.B. der Sprache) formal-ăsthetische Werte freizusetzen oder zu erzeugen.

\footnotetext{
${ }^{27}$ Russisch: "ostranenie", d.h. wörtlich "Verseltsamung" ${ }^{28}$ Striedter, 1981: 23.

${ }^{29} \mathrm{~V}_{\mathrm{gl}}$. Kapitel 2.1.4. in dieser Arbeit.
} 


\subsection{2. "REINE FORM" IM THEATER}

Witkiewicz' Kunst- und Theatertheorie entsprach weitgehend der zeitgenössischen antinaturalistischen Strömung und entstand zum großen Teil aus einem Impuls gegen den Determinismus und Materialismus der vorangegangenen Kunstrichtung und gegen den herrschenden Kanon einer naturalistischrealistischen Darstellungsästhetik. Dies wird besonders in seiner Theatertheorie deutlich, die zu großen Teilen aus witzig-giftigen Polemiken gegen das konventionelle Theater besteht.

Vor dem Hintergrund des formalistischen Kunstbegriffes und der metaphysischen Begrlundung der ästhetischen Erfahrung in Witkiewicz' Xsthetik ist es verständlich, daß seine Kritik sich insbesondere gegen die Dominanz des gegenständlichen Inhalts ${ }^{30}$ in der Kunst richtet. Massive Kritlk wird insbesondere an der Ideenbeladenheit und an den sozial-politischen Diskursen im Bereich der Thematik und Wirkungsintention des Dramas gellbt.

Das konventionelle Theater ist nach Witkiewicz

"<...> ein Platz fur das Äußern von 'Meinungen' des Autors Uber gefallene Fraven, Vierklassenwahlrecht, die Bedeutung des Syndikalismus oder ein anderes beliebiges Thema mit Hilfe schlecht arrangierter Situationen, die diese Meinungen illustrieren sollten. Ist es nicht besser ein Traktat, eine Broschure oder einen bescheidenen Aphorismus zu schreiben, anstatt einige Marionetten drei Stunden lang auf der Bühne rotieren zu lassen, damit der Zuschauer sich an die Stirn tippend beim Hinausgehen sagen kann: 'Die Sunde wird also tatsächlich bestraft, und die Tugend belohnt?'.'Es gibt also doch keine guten Schwiegermutter! Wie schade!' oder 'Verdammt! Syndikalismus ist also doch keine endgultige Losung fur den Klassenkampf'." ( $T: 289$ )

Ebenso hăufig und heftig ist die Kritik an elner realltätsbezogenen $R e-$

${ }^{30}$ Witkacy unterscheidet zwischen einem kinstlerischen Inhalt, der von rein formalen Elementen (Farben, Gestalten und in einer bestimmten Weise auch von Wortbedeutungen und Handlungen) gebildet wird und einem gegenständlichen Inhalt, der aus realitătsbezogenen Elementen besteht. Für eine ăsthetische Erfahrung ist nur der künstlerische Inhalt relevant, der gegenständliche Inhalt dagegen ist ein unvermeidbarer, produktionsăsthetisch bedingter Ballast, der nur gewisse kompositionelle Aufgaben (Richtungsspannungen) erfullt.

Vgl. dazu Kapitel 2.1.3. und 2.2.1. in dieser Arbeit. 
zeptionsweise der Werke. Witkacy wendet sich gegen ein Theater, das lebensnahe Inhalte und psychisch- geistige Gehalte vermitteln oder bestimmte Lebensgefuhle wie z.B. das Nationalgefuhl auslosen will. Er ironisiert das zeitgenóssische Publikum, das ins Theater geht:

"<...> um sich an dem Schmerz von Damen und Herren zu delektieren, die zwar imaginär sind, aber doch so realistisch wirken wie die eigene Geliebte oder Tante, der Schwager oder der Verlobte. Um in ihre Geheimnisse einzudringen, ihre intimen Gesprăche mit ungesunder Neugierde zu belauschen, mit ihrem Lebensungluck Mitleid zu empfinden, gedămpftes Nationalgefuhl zu wecken oder all das zu entladen, was nicht ausgelebt werden konnte, angefangen bei den schlimmsten Schweinereien bis hin zu den erhabensten Regungen der menschlichen Seele." (T: 287)

Die Ablehnung des Lebenslogischen und -wahrscheinlichen im Drama bezieht sich sowohl auf die Wirkungsintention und die Thematik als auch auf die Dramenstruktur, d.h. auf die Ordnungsprinzipien der Einzelelemente im Drama. Witkiewicz wendet sich gegen solche Strukturierungsmomente wie z.B. psychologische Motivierung der Figuren, raum-kausale Folgerichtigkeit der Ereignisse, und das konventionelle Aufbau- und Spannungsschema á la G. Freytag 31 :

"Zuerst wird einem die ganze Lage erklărt. Dann fangen die Verwicklungen an, es kommt zum Höhepunkt, dann - bumm!!, ein entsetzlicher Radau und alles ist aus." ( $\mathrm{Vgl}$. T: 248)

Witkiewicz' formalistisch und ästhetizistisch motivierte Polemik richtet sich aber nicht nur gegen den Naturalismus, sondern auch gegen andere Formen des zeitgenóssischen Theaters. So wird beispielsweise das impressionistische Stimmungsdrama, insbesondere das Schauerstuck in Maeterlinck-Manier, wegen seiner billigen Effekthascherei abgelehnt.

"<...> das Theater Maeterlincks, das nichts weiter als ein Apparat zum Erzeugen wilder Stimmungen ist. Der Mensch windet sich, sein Herz bleibt fast stehen, schwitzt, möchte heulen vor Angst und dann stellt er fest, daß alles nur eine Tăuschung war. Es ist erstaunlich, daß die Menschen nach so einer Vorstellung sich nicht derartig ărgern wie uber Personen, die einen mit Hilfe eines Lakens und eines

${ }^{31}$ Freytag, 1969. 
mit Phosphor beschmierten Gesichtes erschreckt haben. Normalerweise mubte das Theater nach einer solchen Vorstellung demoliert und die Schauspieler niedergemetzelt werden". ( $T$ : 288)

Sogar das symbolistische Drama, das in seiner Intention, transzendentale Wahrheiten zu vermitteln, gewisse Beruhrungspunkte mit der von Witkiewicz als metaphysisch postulierten ästhetischen Erfahrung hat, wird von ihm abgelehnt. Er ironisiert die gesellschaftliche Konventionalităt und Abgegriffenheit der Symbole, die nur auf Einzelerscheinungen in der Wirklichkeit verweisen können:

"Die dritte Art ist der Symbolismus: die ganze Zeit fliegt z.B. ein blauer Vogel auf der Bühne, und der Zuschauer muß ständig daran denken, daß dieser Vogel eben kein Vogel, sondern die ganz große Liebe ist. Schließlich krepiert der Vogel - das bedeutet, daß auch die Liebe in irgendeinem Herzen krepiert ist". ( $T$ : 248f).

Witkiewicz' Kritik an der Dominanz des gegenstăndlichen Inhalts im naturalistisch-realistischen Drama enthält zwar im Kern die wichtigsten Einwände, die im allgemeinen gegen eine Darstellungs- bzw. Ausdrucksăsthetik hervorgebracht werden, doch sie hat auch einen recht polemischen und unsachlichen Charakter. Wissenschaftliche Qualitat und philosophische Tiefe bekommt seine Argumentationsweise jedoch bei der Problematik des Wahrheitskriteriums in der Kunst.

Die Wahrheit einer Aussage bzw. einer Darstellung gehört in inhaltsorientierten Ästhetiken $z u$ den wesentlichen Wert- und Rangkriterien der Kunst. 32 Der Begriff "Wahrheit" bezieht sich dabei auf zwei Aspekte: Zum einen ist damit der reprăsentative Wert einer Darstellung, der Grad der Entsprechung des Dargestellten mit der Realität gemeint. Das Wahrheitskriterium wird in diesem Zusammenhang unter den Stichworten "Wahrheitsähnlichkeit", "Lebenswahrscheinlichkeit" oder "Mimesis" diskutiert. Zum anderen wird der Wahrheitsbegriff auf die Intention des Kunstlers und die "Aussage" des Werkes angewendet: die Bedeutung eines Kunstwerkes wird von der kognitiven Relevanz seines Inhalts abhängig gemacht. Eine Kunstwissenschaft, deren erkenntnisleitendes Interesse von einem inhaltsästhetischen Kunstbegriff bestimmt ist, sieht ihre Aufgabe darin, den kognitiven

${ }^{32}$ ggl. Kutschera, 1988: 221ff. 
Gehalt eines Kunstwerkes zu explizieren, und zwar entweder in Form einer subjektiv-kritischen Reflexion, oder in Form einer historisierenden, scheinbar unbeteiligten Darstellung der "Werkaussage" als geistige Zeiterscheinung. Der bekannteste und einflußreichste Vertreter einer solchen, teilweise noch heute gultigen Ästhetik, war G.F.W. Hegel:

"Das Kunstwerk muß uns die höheren Interessen des Geistes und Willens, das in sich selber Menschliche und Măchtige, die wahren Tiefen des Gemuls aufschließen; und daß dieser Gehalt durch alle Xußerlichkeiten der Erscheinungen durchblicke und mit seinem Grundton durch all das anderweitige Getreibe hindurchklinge, das ist die Hauptsache, um welche es sich wesentlich handelt."

Die Gultigkeit eines solchen Wahrheitsbegriffes wurde vielfach angezweifelt. Die radikalste Kritik formulierte bekanntlich Nietzsche in seinen Schriften "Uber Wahrheit und Lüge im außerliterarischen Sinn" und "Gotzen-Dămmerung" ${ }^{34}$. Neuerdings hat die Absage an den Wahrheitsbegriff durch J.F. Lyotards Kritik am Logozentrismus ${ }^{35}$ und J. Derridas Theorie der Dekonstruktion $^{36}$ wieder an Aktualităt gewonnen.

In diesem geistigen Umfeld - Nietzsches Einfluß auf Witkiewicz ist bekannt $^{37}$ - ist die Auseinandersetzung des polnischen Kunstlers mit dem Wahrheitsbegriff zu verstehen. Ähnlich wie Nietzsche erteilt auch Witkiewicz eine radikale Absage an den Wahrheitsanspruch einer Kunst, die sich am gegenständlichen Inhalt orientiert:

"Ein Theater, das sich als Wirklichkeitsdarstellung versteht oder als ein Mittel zum Hervorrufen eines bestimmten Gefuhlszustands, oder gar als ein Medium zur Erorterung von Problemen des Lebens, der Nation und der Gesellschaft, ein solches Theater enthalt implizit das Element der Luge." ( $T$ : 288)

Wăhrend jedoch Nietzsches Ablehnug des Wahrheitsanspruches der Kunst durch seinen erkenntnistheoretischen Nihilismus und durch seine Kritik am

\footnotetext{
${ }^{33}$ Hegel, VÄ, Werke, XIII: 360.

${ }^{34} \mathrm{Vgl}$. dazu: Werner, 1986.

${ }^{35} \mathrm{Vgl}$. Lyotard, 1986: 63-88.

${ }^{36}$ Vgl. Derrida, 1972 und Culler, 1988.

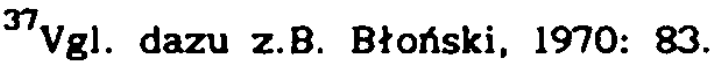


christlich-burgerlichen Kunstbegriff motiviert ist, argumentiert Witkiewicz mit formalistischen und kunstontologischen Kriterien. Demnach ist in der Heterogenităt der beiden Sphären: Kunst und Leben; Fiktion und Realităt; ästhetische und kognitive Erfahrung ein Wahrheitsanspruch des gegenstăndlichen Gehaltes von vornherein ausgeschlossen bzw. - bei unzulăssiger Vermischung dieser heterogenen Sphären - das Element der Lüge angelegt. Wenn in der imaginären Welt, die ein Theaterstuck aufbaut, Gegenstände der außerkünstlerischen Wirklichkeit "vorgefuhrt" und "nachgeahmt" werden, und die Erzeugung einer Illusion dieser außerkunstlerischen Wirklichkeit angestrebt wird, so ist ein solches Theaterstuck immer auch mit dem Makel der Unwahrhaftigkeit behaftet. ( $V g l$. $T: 326 f)$. Witkiewicz lehnt jeglichen kognitiven Charakter der Kunst ab und wendet sich dem asthetisch-formalistischen Wert zu. Das Wahrheitskriterium kann demnach in einem autonomen Kunstwerk verwirklicht werden, das ausschlieblich nach formalen Erfordernissen konstruiert wurde, und seinen Wert und Identităt nur aus der eigenen Struktur bezieht.

"Das Theaterstück in der Reinen Form ist etwas an sich, mit sich selbst Identisches und in diesem Sinne Absolutes, obwohl es fur seine Wertung kein objektives Kriterium gibt und geben kann. Die in einem solchen Stück, das von einem Schöpfer-Regisseur gleichermaßen wie vom Autor geschaffenen wurde, spielenden Kunstler imitieren nicht, mehr oder weniger gut, irgendwelche wahrscheinlichen Menschen, sondern kreieren ihre Rollen innerhalb der Einheit des szenischen Geschehens. Dieses besteht aus formal zusammengefugten Handlungen, Außerungen und Bildern, die, falls das die Erfordernisse der Komposition verlangen, vom Standpunkt des Lebens und des Sinns, auf allerphantastischste Weise verbunden werden können." <Hervh. im Original> ( $\mathrm{T}$ : 323 ).

Witklewicz bezleht seinen formalistischen Kunstbegriff nicht nur auf die Malerei und auf die Musik - dazu konnte er durch die beginnende ungegenstăndliche Malerei und die atonale Musik veranlaßt werden - sondern auch auf die sprachliche Kunst: auf die Dichtung und das Drama (den Roman schließt er wegen der Mittelbarkeit seiner Wirkungsweise aus). Seine literarische Xsthetik ist, wie noch zu zeigen sein wird, nicht unproblematisch, in einigen Punkten vielleicht sogar unzutreffend. Doch seine dramatische Praxis, die er als Experiment zur Verwirklichung seiner Theorie betrachtete, nimmt viele Phänomene der Gegenwartsliteratur vorweg. Im ubrigen entspricht der intermediale Denkansatz Witkiewicz' einigen 
zeitgenössischen Geistesströmungen. Als ein Erbe des Ästhetizismus war die Idee eines Eigenwertes des Ẍsthetischen weitverbreitet, der fur alle Kunstgattungen, trotz ihrer medienspezifisch unterschiedlichen Ausdrucksmittel, gleichermaßen verbindlich sein sollte. V. Kandinskij beispielsweise sprach von einer "Ubersetzbarkeit" der verschiedenen Kunste: der "innere Klang" eines Kunstwerkes wăre demnach auch mit den Mitteln einer anderen Kunstgattung wiederzugeben, Farbempfindungen etwa wăren in musikalische Klănge umsetzbar etc. ${ }^{38}$ Aus diesen synästhetischen Vorstellungen entstand auch der Gedanke eines interdisziplinăren Forschungsansatzes in den Kunstwissenschaften, wie ihn 0 .Walzel (1917) in seinem programmatischen Vortrag "Wechselseitige Erhellung der Künste" formulierte.

Witkiewicz Uberträgt seine Forderung nach der isthetisch-formalen Autonomie kunstlerischer Mittel gegenuber einem mimetischen Darstellungskanon von der bildenden auf sprachliche Kunst. Die metaphysisch begründete ăsthetische Erfahrung der Reinen Form soll im Theater, ahnlich wie in der abstrakten Malerei, durch eine subjektiv-ăsthetische Konstruktion rein-formaler Elemente vermittelt werden. Das Theaterstuck könnte infolge "rein formaler Ziele, d.h. um der Synthese aller Theaterfaktoren willen der Laute, des Buhnenbildes, der Bewegungen auf der Buhne, der gesprochenen Satze - zu einer unauflösbaren Einheit im allgemeinen Werden in der Zeit <...> werden." (T, 261). Demnach wirde das Buhnengeschehen durch die Beziehungen zwischen seinen Einzelelementen als eine abstrakte Zeitform ("Werden in der Zeit") wirken, ăhnlich wie die Musik oder deklamierte Dichtung 39 .

Der gegenständliche Inhalt (d.h. die realitătsbezogenen Elemente wie Psychologie der Figuren, zeitlich-kausale Folgerichtigkeit der Ereignisse) hat. laut Witkiewicz. eine untergeordnete Bedeutung. Fur die ăsthetische

${ }^{38}$ Kandinskij berichtete 1921 uber die zahlreichen empirischen Experimente, in denen er solche intermediale Transformationen untersuchte: "Ich selbst habe im Ausland zusammen mit einem jungen Musiker und einem Tanzkunstler experimentiert. Der Musiker suchte aus einer Reihe meiner Aquarelle dasjenige aus, das ihm in musikalischer Hinsicht am klarsten erschien. In Abwesenheit des Tänzers spielte er dieses Aquarell. Dann kam der Tanzer dazu, ihm wurde das Musikwerk vorgespielt, er setzte es in Tanz um und erriet danach das Aquarell, das er getanzt hatte." (Zitiert nach: Weiss, 1979: 191). 
Erfahrung ist er irrelevant, er erfullt lediglich kompositionelle und kreativ-psychologische Aufgaben als "ein notwendiger Vorwand für die Schöpfung der Form" und "ein 'Doping', um die ganze künstlerische Maschine in schöpferische Spannung zu versetzen". (T: 261).

Aufgrund kompositionell-formaler Erfordernisse kann der gegenstăndliche Inhalt auch deformiert werden ${ }^{40}$ : Die konsequente psychologische und temporal-kausale Motivierung der Handlung sowie logisch-kognitive "Aussagen" des Dramas sind, laut Witkiewicz, nebensăchlich und könnnen "um des Zieles willen, ein Ganzes zu schaffen, dessen Sinn einzig von der inneren, rein szenischen Konstruktion bestimmt wäre ${ }^{41}$, beliebig verăndert oder destruiert werden. Das Phänomen der Deformation in der modernen Kunst, das Witkiewicz mit Hilfe kompositionell-formaler oder geschichtsphilosophischer Argumente erklărt ${ }^{\mathbf{4 2}}$ und so seine werkkonstitutive Bedeutung herabsetzt, erweist sich aber bei der Dramenanalyse als eine ăsthetisch durchaus wirksame Kraft, die das vermeintlich unter formalen Kriterien konzipierte Werk als eine Groteske wirken läst.

Durch die Aufgabe des gegenständlichen Inhalts in einem literarischen Kunstwerk, d.h. durch die Gewichtsverlagerung von den signifikativen auf die evokativ-euphonischen Funktionen der Sprache und von den semiotischen auf die evokativ-optischen Funktionen der Handlungen im Drama will Witkiewicz das Theaterstulck in die Sphăre der Reinen Kunst, wie z.B. die Musik, heben.

"<...> in einer Welt, die uns lebenslogisch uberhaupt nicht Interes-
siert <...> könnten wir ein ahnliches metaphysisches Drama erleben,
wie es sich allein zwischen den Tönen einer Symphonie oder Sonate
vollzieht. Das SchluBergebnis bestehe dann nicht in einem Ereignis,
das für uns von lebenslogischen Interesse ist, sondern wir wilden es
vielmehr als den notwendlgen AbschluB von reln formalen, lautlichen,
dekorativen oder psychologischen Verflechtungen auffassen, die je-
doch frei wären von lebenslogischer Kausalität." (T: 265) <Hervh. im
Original>.

Das Zuruckgreifen auf die Musik als eines asthetischen Paradigmas fur das

\footnotetext{
${ }^{40} \mathrm{Zur}$ Bedeutung der Deformation in der Dramenstruktur und zu den einzelnen Deformationsverfahren vgl. Kapitel 2.2.3. in dieser Arbeit.

${ }^{41}<$ Hervh. im Original> $(T, 261)$

${ }^{42} \mathrm{Vgl}$. Kapitel 2.1.4. in dieser Arbeit.
} 
Theater erinnert stark an die Drameninnovationen und Theaterreformen der Jahrhundertwende ${ }^{43}$. In den vielfältigen und vielschichtigen künstlerischen Bewegungen dieser Zeit war die Ablehnug der rationalistischmaterialistischen X̂sthetik des Naturalismus und Nietzsches Formel von der Wiedergeburt des Theaters aus "dem Geiste der Musik" der gemeinsame Ausgangspunkt für zahlreiche theoretische Entwüfe, die eine Erneuerung des Kunstcharakters des Theaters (man denke an die bekannte Losung vom "thétre pur") zum Ziel hatten. Ähnlich wie bei Witkiewicz stand dabei die Forderung nach einer ästhetisch-formalen Werkstruktur und nach der Autonomie kunstlerischer Mittel im Vordergrund.

Als Beispiel wăre hier insbesondere A. Appia und seine 1899 veröffentlichte Arbeit Uber "Die Musik und die Inszenierung" zu nennen. In Zusammenarbeit mit E. J. Dalcroze, dem Begrulnder einer von den Ideen der Lebensreformbewegung getragenen Tanzgymnastik, experimentierte $A$. Appia zuerst in Genf und dann in Hellerau bei Dresden mit einem Theater, in welchem die formalen Elemente: Wort, Ton, Licht, Bewegung zu einer kunstlerischen Einheit, jenseits mimetischer Darstellung, vereinigt wurden. Die Inszenierungsideen von A. Appia und E.J. Dalcroze waren um 1913 in Europa weit verbreitet: es gab uber hundert Zweigstellen der Bildungsanstalt Hellerau (u.a. auch in Warschau und in Moskau). ${ }^{44}$

Von ahnlichen Momenten sind auch die Theaterreformen der Stilbuhne geprăgt. Deren wichtigsten Anhänger in Deutschland waren P. Behrens und die Darmstädter Künstlerkolonie sowie G. Fuchs und das Münchner Künstlertheater. Ein russischer Vertreter der Stilbuhne war W. Meyerhold (1906 Inszenierung von A. Bloks "Balagancik"). Obgleich in den Stilkunstbewegungen, im Unterschied zu der Inszenierungspraxis von A. Appia und E.J. Dalcroze, das Wort und der sprechende Schauspieler im Vordergrund stehen, wendet man sich gegen eine sprachliche Darstellungsästhetik: es geht um die Evokations- und Suggestionskraft von Worten und von symbolischen Buhnenrequisiten, die im Zusammenwirken mit Bewegungen, Mimik, Gestik, Ton- und

${ }^{43}$ Auf Witkiewicz' Verwurzelung im X̂sthetizismus der Jahrhundertwende (Junges Polen) und auf seine Rezeption von F. Nietzsche und St. Przybyszewski weist J. Btonski (1983: 10ff) hin.

${ }^{44}$ Vgl. dazu 2.B.: Giertz, 1975. 
Lichteffekten $^{45}$ eine åsthetische Buhnentotalităt erzeugen sollten.

Die innovativen Theatertheorien der Jahrhundertwende wurden von den Avantgardebewegungen der 20er Jahre fortgefuhrt und weiterentwickelt. Einen formalistischen Ansatz bei der Theatererneuerung, der stark an die Theorie der Reinen Form erinnert, verfolgten die Experimentiertheater von H. Walden ("Sturmbuhne" in Berlin, gegrundet 1917) und L. Schreyer ("Kampfbuhne" in Hamburg, gegrundet 1919) sowie O. Schlemmer am Bauhaus"6. Doch gerade in der Theaterarbeit von 0 . Schlemmer zeigt es sich, daß die konsequente Weiterfuhrung der formalistischen Ästhetik in Sprachkunstwerken wie dem Drama zur Entliterarisierung und damit zur Verănderung der Kunstgattung fuhrt: das Drama wird zu einem Tanz-Ton-Licht-Spektakel. Wie schon mehrmals erwähnt, hat sich Witkiewicz gegen einen solchen Schritt immer gewehrt und den werkkonstitutiven Wert der sprachlichen Bedeutung fur das Sprachkunstwerk Drama betont ${ }^{47}$. Theatergeschichtlich gesehen nimmt er dadurch eine nahezu konservative Haltung ein (die ihm auch von der zeitgenర̈ssischen Avantgarde vorgeworfen wurde ${ }^{48}$ ) - die Theaterentwirfe in den 20er Jahren bewegten sich auf das entliterarisierte, multimediale Gesamtkunstwerk und Massenspektakel hin. Die Konsequenz aus Witkiewicz' formalistischem Kunstbegriff und seinem gleichzeitigen Festhalten am sprachlichen Medium ist das Phănomen der Deformation von signifikativen Werten der Sprache und damit eher ein grotesker als ein formalistischer Charakter seiner Stucke.

Eine Analogie zwischen Witkiewicz' Theatertheorie und den Theaterreformen der Jahrhundertwende besteht in der Proklamation einer mythisch-sakralen

${ }^{45}$ Vgl. dazu: Brauneck, M.: "Theater der Zukunft". Stilbuhne und Theaterreformen um 1900. In: Brauneck (Hrsg.), 1986: 39-84.

${ }^{46}$ Zahlreiche Analogien zu Witkiewicz' Theorie der Reinen Form findet man vor allem in 0 . Schlemmers theoretischen Hauptwerk "Mensch und Kunstfigur", das 1925 als Bauhausbuch Nr. 4 erschienen ist. In: Schlemmer u.a., 1965.

${ }^{47}$ Vgl. z.B.: $T$ : 313 und Kapitel 2.2.4. in dieser Arbeit.

${ }^{48}$ Z.B. von Jalu Kurek: Przeciwko teorii teatru S. I. Witkiewicza. In: Marczak-Oborski (Hrsg.), 1973: 182-187.

Zu weiteren Einwănden der polnischen Theateravantgarde gegen Witkiewicz, die sich hauptsăchlich auf die Buhnenform und die Auffuhrungspraxis bezogen, vgl. Kapitel 2.2.4. in dieser Arbeit. 
Dimension des Theaters.

Die antinaturalistischen Theaterentwürfe der Jahrhundertwende waren von der Idee getragen, das Theater zu einem meditativ-ekstastischen Gemeinschaftserlebnis werden zu lassen. Das Gesamtkunstwerk sollte als ein "Fest des Lebens und der Kunst" (P. Behrens, 1900) die Qualităt einer festspielartigen Kulthandlung bekommen. Auf dieser Linie bewegt sich auch Witkiewicz, wenn er der formalistischen ăsthetischen Erfahrung eine metaphysische und dem Theater eine mythische Dimension verleiht.

Witkiewicz geht in seiner Theatertheorie davon aus, daß das Theater, wie auch die ganze Kunst, aus "religiösen Mysterien" entstanden ist.

"Die ganze Kunst hat ihre Quellen in metaphysischen Gefuhlen, ahnlich wie die Religion, die in fruheren Zeiten direkt mit ihr verbunden war." ( $T, 245 f)$

Dabei soll hier noch einmal Witkiewicz' Verstăndnis des Begriffes "metaphysisches Gefuhl" in Erinnerung gerufen werden ${ }^{49}$ : es ist eine existentielle Grunderfahrung, die im unbewußten Empfinden der Einheit, Identităt der eigenen Existenz besteht. Die ästhetische Erfahrung der Reinen Form betrachtet Witkiewicz als einen Ausloser von metaphysischen Gefuhlen: das unmittelbare Erleben der Struktur eines Kunstwerkes verweist den Rezipienten auf die Einheit, Identität der eigenen Existenzform. Er erlebt dadurch eine existentielle Grunderfahrung, die Witkacy als "metaphysisch" bezeichnet.

Es ist nachvollziehbar, daß ein solches Verstăndnis der asthetischen Erfahrung es leicht ermoglicht eine Brucke zwischen Kunst und Religion zu schlagen. Witkacy erörtert das Verhăltnis zwischen Kunst und Religion, rorm und Motaphyolk anhand oolnor Cooohiohtophllooophio ${ }^{50}$. Doi dom fort schreitenden Niedergang der metaphysischen Gefuhle wăhrend der sozialen Entwicklung loste sich die Kunst von ihrer religios-metaphysischen Intention und setzte sich lebenspraktisch-utilitaristische Aufgaben zum Ziel. Die Nachahmung der außeren Natur wurde fur sie strukturbildend und ein

${ }^{49}$ Vgl. Kapitel 2.1.2.

${ }^{50} V_{g l}$.: "Uber den Untergang der metaphysischen Gefuhle im Zusammenhang mit der sozialen Entwicklung". In: NFM: 100-149.

Zusammenfassung in Kapitel 1.2. in dieser Arbeit. 
Beurteilungskriterium. Mehr als auf die Musik oder die Malerei, die hauptsăchlich aus "reinen" Elementen bestehen, traf diese Entwicklung auf das Theater zu, dessen Elemente - die Menschen und ihre Handlungen realitătsnah, d.h. in ihrem formalen Gehalt komplex sind. Witkiewicz sieht in seiner Zeit eine Renaissance der Reinen Form in der Malerei, Dichtung und Musik, die aufgrund der "Formunersăttlichkeit" der Kunstler zu subversiven, antimimetischen Kompositionen neigt. Etwas Vergleichbares vermißt er im zeitgenössischen Theater, das, geprägt durch die naturalistischen Dramaturgiekonventionen und die Theatertheorie Stanislavskijs, mimetische Illusions- und Identifikationsbuhne ist. Witkiewicz polemisiert sehr scharf gegen dieses konventionelle Theater; lehnt "die heutige Vorstellung von Buhnengerechtheit, von Handlung und von der psychologischen Grundlage der Konstruktion eines Theaterstuckes" ab $(T, 248)$ und ein Theatererlebnis, das aus der Spannung der Handlung, aus hervorgerufenen Effekten oder intellektueller Entschlüsselung von Symbolen resultiert.

Als Gegenentwurf greift er auf das griechische Theater zuruck. Fur den antiken Rezipienten stand, laut Witkeiwicz, nicht die Handlung im Vordergrund (die ja nur eine Variation des bekannten Mythos war), sondern sein metaphysisches Erlebnis:

"Vor dem Hintergrund dieses bekannten Inhalts, der den metaphysischen Hintergrund des Geschehens auf der Buhne bildete, war alles, was geschah, der ganze Handlungsverlauf eine allein durch die Form wirkende Steigerung des metaphysischen Elements, dem die Menschen, abgesehen von außergewöhnlichen Momenten der Ekstase, im Leben immer weniger begegnen. Menschliche Gefuhle als solche waren nur Elemente des Geschehens, waren Vorwănde fur rein formale Verbindungen, die durch ihre Beziehungen, durch die Synthese der Bilder, Töne und Bedeutungen der ausgesprochenen Satze eine andere psychische Dimension zum Ausdruck brachten." ( $T, 248 f)$

Witkiewicz labt auBer acht, daß die religióse Rolle des Theaters in der Antike oder im Mittelalter auf einem allgemeinverstăndlichen und -gultigen Mythos (antiken oder christlichen) aufbaute, d.h. auf einem festen Gefuge von ins Ideelle verweisenden Symbolen sowie auf allgemeingultigen ethischen und sozialen Wertmaßstäben. Wahrscheinlich grülete die religibse Funktion solcher Kunstwerke eben in diesem Mythos und nicht in der ästhetischen Wirkung ihrer Struktur. 
Eine metaphysisch-religiöse Funktion will Witkiewicz auch im modernen

Theater verwirklicht wissen:

"Ist es möglich, daß - und sei es nur für eine kurze Zeit - eine Form des Theaters entsteht, in der der moderne Mensch unabhängig von erloschenen Mythen und Glaubensvorstellungen metaphysische Gefuhle so erleben könnte, wie sie der Mensch früher in Verbindung mit diesen Mythen und Glaubensvorstellungen erlebt hat?" ( $T$ : 247)

"Die Aufgabe des Theaters besteht unserer Meinung nach gerade darin, den Zuschauer in einen außergewöhnlichen Zustand zu versetzen, den man im Dahingleiten durch den Alltag in seiner reinen Form nicht so leicht erreichen kann, den Zustand in dem man das Geheimnis der Existenz gefuhlsmäsig erfaBt." ( $T$ : 249)

Die so beschriebene Wirkung des Theaters erinnert an Witkiewicz' Ausfuhrungen zur Kontemplation ${ }^{51}$, als einem Zustand, in dem das Erleben metaphysischer Gefuhle möglich ist. An einer anderen Stelle wird ein Vergleich zum Traum gezogen:

"Beim Verlassen des Theaters muß der Mensch den Eindruck haben, aus einem merkwurdigen Traum zu erwachen, in dem sogar die gewbhnlichsten Dinge einen merkwürdigen, unergruludlichen Zauber besaßen $\langle. .$.$\rangle ." (T: .2.264)$

Die von Witkiewicz geforderte "formistische" Erfahrung im Theater ist eine unmittelbare, irrationale Erfahrung, die in ihrer Qualităt durchaus mit einer religiösen Erfahrung vergleichbar ist.

Wie schon erwahnt, ist die Verbindung des Theaters mit rituellen Werten in der Ẍsthetik der Jahrhundertwende nicht unublich. Es gibt auch Parallelen zwischen der Theatertheorie Witkiewicz' und dem 'Theater der Grausamkeit" A. Artauds sowie der Peformancealsthetik im Theater der Erfahrung

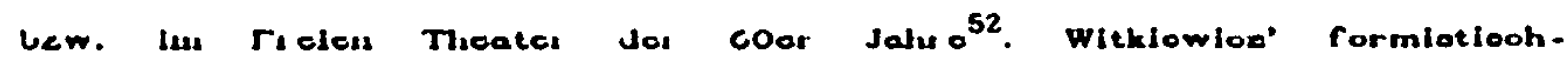
metaphysische Theaterăsthetik ist also weder in zeitgeschichtlicher noch in gattungsspezifischer Hinsicht etwas Ungewohnliches.

${ }^{51} V_{g l}$. dazu NFM: 8 und Kapitel 2.1.2. dieser Arbeit.

${ }^{52}$ Vgl. dazu: Falkiewicz, 1960.

$\mathrm{Zu}$ der sog. Performanceästhetik der Gegenwartskunst und des Theaters der 60er, 70er Jahre (Aktionismus, Konkretismus, Konzeptualismus) vgl. insbesondere Sauerbier, 1976. 
Will man eine theatergeschichtliche Elnordnung Witkiewicz' wagen, so muß man ihn wohl im Grenzbereich zwischen Symbolismus und der historischen Avantgarde ansiedeln. Mit den Theaterreformen der Jahrhundertwende verbindet ihn die metaphysisch-rituelle Wirkungsintention und das Ideal einer ästhetischen Autonomie künstlerischer Mittel. Seine Dramen haben aber nicht den lyrisch-pathetischen Charakter der Stilbuhne: Witkiewicz' Ẍsthetizismus bekommt in seiner literarischen Praxis durch die angewendeten Deformationsverfahren eine groteske Ausprägung, vergleichbar etwa mit "Ubu-Roi" von A. Jarry. Mit der historischen Avantgarde verbindet Witkiewicz' zum groben Teil seine Sprachauffassung: das Wort (und zwar sowohl in seiner Lautgestalt als auch in seiner Bedeutung) wird als ein eigenwertiges, kunstlerisches Element betrachtet, das aus den syntaktischen oder referentiellen Bezügen herausgelöst werden muß, damit es seine ästhetische Wirkung voll entfalten kann. Das trennende Moment zu der Xsthetik der Avantgarde bildet Witkiewicz' Asthetizismus. Von dieser Position aus kritisiert er den "programmatischen Unsinn", den die Avantgarde ohne ăsthetisch-kompositionelle Rucksichten durchfuhre; ferner die leere Provokationsăsthetik sowie die Inter- und Multimedialităt im Theater, die die Kunstgattungs- und Werkautonomie zerstort. 


\subsubsection{DEFORMATIONSVERFAHREN IM DRAMA}

Witkiewicz' intermedialer Denkansatz in der Ästhetik fuhrt unter anderem auch zur Ubertragung des Phänomens der Deformation von der bildenden auf die sprachliche Kunst der Dichtung und des Dramas.

"<...> der Deformation von Gegenständen der äußeren Welt in den Bildern entspricht in der Dichtung das Fehlen von Sinn in Begriffsverbindungen - im Ausdruck entweder bestimmter Gedanken oder Gefuhlszustände - und im Theater das Fehlen von Sinn in Xußerungen und Handlungen beliebiger Einzelexistenzen." ( $T$ : 265)

Wahrend sich die Deformation in der Malerei auf die sinnlich wahrnehmbare ăußere Gestalt der dargestellten Gegenstănde bezog, betrifft sie in Sprachkunstwerken das Sinnkriterium und damit eine kognitivintellektuelle Leistung. Auf den ersten Blick scheint es, als ob Witkiewicz zwei vollig unterschiedliche Erscheinungen zusammenbringen wollte. Beim genaueren Hinsehen wird jedoch eine Analogie deutlich - sie besteht in der Konventionalităt der beiden Phănomene. Die Deformation in der Malerei besteht in der Abweichung von einer imitativen "Naturtreue" bei der Darstellung von Gegenständen der ăußeren Welt. Wie R. Jakobsen richtig bemerkte, wird jedoch die Beurteilung einer Darstellung als wirklichkeitsnah oder wahrscheinlich durch "die Tradition der Darstellung und der Wahrnehmung bestimmt ${ }^{53}$. Daß im abendlăndischen Kulturkreis eine zentraiperspektivische Darstellung mit Fluchtpunkt und verkurzten Vertikalen als "răumlich" und bestimmte Farb- und Formgebung als "realistisch" empfunden wird, ist wohl eine Frage der Wahrnehmungs- und Darstellungskonventionen. Laut Witkiewicz besteht die Deformation in Sprachkunstwerken darin, daß ein Zustandekommen von ubergeordneten Sinneinheiten verhindert wird. Doch hat schon Witkiewicz' Ablehnung des Wahrheitsbegriffes in einer am gegenstăndlichen Inhalt orientierten Kunst gezeigt ${ }^{54}$, daß fur ihn der Sinnbegriff eine relative Größe ist. Das Sinnkriterium in der Kunst ist eine Frage von gesellschaftlich-kulturellen Konventionen und von literarischen Darstellungstraditionen. Im Naturalismus wurde beispielsweise eine be-

\footnotetext{
53 Jakobson, 1981: 377.

${ }^{54} \mathrm{~V}_{\mathrm{gl}}$. Kapitel 2.2.2. in dieser Arbeit.
} 
stimmte Darstellungstechnik als "wahr" und "sinnvoll" etabliert, deren Charakteristikum in der kausalen Motivierung der Ereignisse und in der psychologischen Motivierung der Figuren (wobei die historischen Anthropologie- und Psychologieerkenntnisse sowie eine zeitgenössische Weltanschauung eine große Rolle spielten) bestand. Ein solcher Darstellungskanon schränkte, laut Witkiewicz, die formal- kompositionellen Moglichkeiten des .Kunstlers ein, ohne ästhetisch wertvolle Schøpfungen hervorbringen zu können. Die naturalistische Darstellungsăsthetik bezeichnete der polnische Künstler als "das Einrennen einer undurchdringlichen Wand - der unerreichbaren Vollkommenheit der Natur" ( $T$ : 294).

Die Deformation ist fü Witkiewicz - und damit nimmt er einen klassischen Standpunkt der Moderne ein - ein notwendiges Ergebnis des innovativen Charakters der Kunst und eine historisch bedingte Station in der Formentwicklung.

\begin{abstract}
"In Analogie zu der 'Deformation' in der Bildhauerel und in der Malerei, zu der logischen und lebenspraktischen Sinnlosigkeit in der Dichtung (und vielleicht auch zu der Athematik und Arrhythmie in der Musik) erscheint im Theater das Lossagen von lebenslogischer Konsequenz in der Handlung <...und> die Phantastik der Psychologie irgendwelcher (phantastischen oder uns ähnlichen) Einzelexistenzen als ein weiteres notwendiges Entwicklungsmoment der Form." ( $T$ : 282)
\end{abstract}

Zur "Phantastik der Psychologie" bzw. Deformation der Figuren zăhlt Witkiewicz verschiedene Verfahren, die auf eine "unrealistisch" anmutende psychologische Unwahrscheinlichkelt bzw. Unmotiviertheit und bellebige Inkonsequenz der Figuren hinfuhren: so beispielsweise die "Veränderbarkeit der Psyche" und "lebenslogisch gesehen eine vollige Beliebigkeit in Reaktionen auf Vorgănge, die gleichfalls durch nichts gerechtfertigt

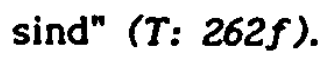

Die Deformation auf der Ebene der Handlungen besteht in der Zerstörung von kausaler Motivation und raum-zeitlicher Folgerichtigkeit.

"Wir wollen uns im Theater in einer ganz anderen Welt befinden, in der sich Vorgänge aus der phantastischen Psychologie von Personen ergeben, die aus lebenslogischer Sicht vollkommen inkonsequent sind, und zwar nicht nur in ihrem positiven Handeln, sondern auch in thren Irrtumern, Personen, die wirklichen Gestalten völlig unahnnlich sind. Diese Vorgănge sollen in der Wunderlichkeit ihrer Verknüpfung ein 
Werden in der Zeit als solches ermöglichen, das durch keinerlei Logik bedingt ist, außer der Logik der Form dieses Werdens." ( $T: 262)$

Die Handlungen im Theater sind zwar keine rein formalen kunstlerischen Elemente, sondern komplexe, mit gegenständlichern Inhalt verwobene Einheiten. Doch sie können, laut Witkiewicz, in ăhnlicher Weise wie die Wortbedeutungen $^{55} \mathrm{zu}$ artistischen Elementen werden. Durch die Deformation des gegenstăndlichen Inhalts werden ihre primär-ästhetischen Elemente freigesetzt: der evokative Gehalt der einzelnen, aus dem lebenslogischen Zusammenhang herausgelösten Handlung sowie die optischen und akustischen Effekte der Bewegungen auf der Buhne. Mit einer solchen Auffassung der dramatischen Handlung kann Witkiewicz das Theater als eine åsthetisch autonome, vierdimensionale Kunst bezeichnen. Sie besteht, ăhnlich wie die Dichtung, aus den Lauten, den evozierten Bildern und den Wortbedeutungen. Als viertes Element kommen die Handlungen hinzu: als "ein verånderliches konkretes Bild" vor dem Hintergrund der Dekorationen (vgl. T: 284). Wenn die Handlungen nicht unter lebenslogischen, sondern unter formalen Gesichtspunkten zu einer Einheit komponiert worden sind, so kann die vierschichtige Buhnenkonstruktion die ästhetische Erfahrung der Reinen Form und damit auch die "metaphysischen Gefuhle" im Sinn von Witkiewicz hervorrufen.

"Wie die neue, reine und abstrakte Form ohne eine unmittelbare religiöse Grundlage um den Preis entstanden ist, daß die Sicht der AuBenwelt deformiert wurde, genauso kann die Reine Form im Theater um den Preis der Deformation von Psychologie und Handlung entstehen." (T: 263)

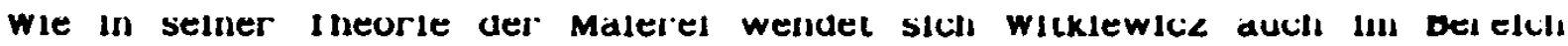
des Theaters gegen die programmatische Sinnlosigkeit der avantgardistischen Kunst. Er betont auch hier das UnbewuBte, Intuitive der schopferischen Tătigkeit. Das Theaterstück bußt seine formale Einheit ein, wenn eine programmatisch, kuhl kalkulierte Sinnlosigkeit auf der Buhne angestrebt wird. Das Ziel der Deformation ist es lediglich, die formalen Gestaltungsmøglichkeiten des Künstlers zu erweitern. Eine gewisse Wirklich-

${ }^{55} \mathrm{Vgl}$. dazu Kapitel 2.2.1. in dieser Arbeit. 
keitsnăhe der Gegenstăndlichkeiten sei sogar wünschenswert, und zwar wegen des Kompositionsmittels der Richtungsspannungen, die in der Theatertheorie "dynamische Spannungen" ( $T$ : 284) heißen: sie haben die Funktion, die Aufmerksamkeit des Zuschauers zu erregen und zu steuern.

Die Funktion der Deformation im Theater besteht, ăhnlich wie in der Malerei, in der "Erweiterung der kompositorischen Möglichkeiten durch die Loslösung von lebenslogischen Konsequenzen in der Kunst, nămlich die Phantastik der Psychologie und der Handlung", die "eine vollige Freiheit in der formalen Komposition erlaubt". ${ }^{56}$ Witkiewicz zahlt eine Reihe von neuen Kompositionsmbglichkeiten von deformierten und als artistisch konzipierten Handlungen und Dialogen auf:

1) Handlungen, die dem lebenslogischen Sinn der Außerungen entsprechen.

2) Handlungen, die dem lebenslogischen Sinn der Äußerungen nicht entsprechen.

3) Handlungen, die bis zu einem gewissen Grad von den sinnlosen Äußerungen abhăngen.

4) Völlige Divergenz von sinnlosen Handlungen und sinnlosen Xußerungen. ( $T$ : 285).

Es stellt sich nun die Frage, ob die Funktion der Deformation tatsăchlich nur - so wie Witkiewicz das darstellt - auf das Artefakt beschrănkt ist, oder ob die Deformation vielleicht doch als ein konstitutives Element der ästhetischen Erfahrung betrachtet werden kann.

In der Malerei kann der Komposition des Materials (Farben, Gestalten) in der Bildfläche tatsächlich ein autonomer Status zugesprochen werden: die asthetische Wirkung der Komposition kann von den dargestellten Gegenstăndlichkeiten der äußeren Welt weitgehend unabhängig sein.

In der Sprachkunst sieht es jedoch anders aus. Das sprachliche Material ist von Natur aus immer signifikativ: das Phonem hat nicht die Qualităt eines Musiktones, sondern ist ein bedeutungstragendes Zeichen. Nach F. Saussure besteht eine unauflosbare Einheit zwischen Signifikant (Lautform) und Signifikat (Bedeutung). Sprachliche "Bedeutung" ist aber daruber hinaus auch immer in sozial-kommunikative und referentielle Be-

\footnotetext{
${ }^{56}$ T: $268<$ Hervh. d. Verf.- A.S.>.
} 
ziehungen eingebunden.

Ahnlich verhălt es sich mit dem ästhetischen Material des Theaters, mit den Handlungen. Auch sie sind nicht einfach Bewegungen und Bilder im Buhnenraum, sondern haben ihre semiotische Dimension: sie sind innerhalb von Dramenkonventionen und Wirklichkeitsmodellen fest verankert und in raum-zeitliche und kausale Beziehungen eingebunden. Eine Abstraktion von diesem semiotischen Potential - und das ist es, was Witkiewicz mit seinem Begriff der Deformation eigentlich fordert - und eine Reduktion auf die primären "formalen" Gehalte fuhrt notwendigerweise zu neuen und für die asthetische Erfahrung konstitutiven Momenten. Zu denken wäre dabei an die ästhetische Kategorie des Grotesken, das ăhnlich wie das Tragische. Komische oder Pathetische eine bestimmte und häufig beschriebene Wirkung beim Rezipienten auslost. $\mathrm{Zu}$ den Stilmitteln und Kompositionsverfahren des Grotesken gehören unter anderem Verzerrung und unlogische Akzentverschiebung $^{57}$, ganz ăhnlich wie die Verfahren, die Witkiewicz unter seinem Deformationsbegriff beschreibt. Auf diese Problematik soll bei der Analyse von Witkiewicz' Dramen genauer eingegangen werden.

${ }^{57}$ gl. dazu: Foster, 1980b: 120. 


\subsubsection{AUFFUHRUNGSPRAXIS UND SCHAUSPIELKUNST}

Trotz seines formistischen Ansatzes in der Theatertheorie wendet sich Witkiewicz gegen die zeitgenössischen Versuche, durch Betonung der akustischen und optischen Elemente (Dekorationen, Tone, Bewegungen etc.) das Theater in Richtung Musik oder Malerei zu entfremden. Er betont den "inneren Charakter" eines Theaterstulckes, der durch seinen Autor bestimmt wurde, und der durch eine Inszenierung nicht verloren gehen darf: "Die Grenze der Identität des dramatischen Werkes mit sich selbst <Hervh. im Original> können wir nicht Uberschreiten." ( $T, 249)$. Zum Wesen des Theaters gehört auch der vom Autor konzipierte Text, denn "dort, wo im Theater das Wort fehlt, beginnt eine ganz andere Kunstart" ${ }^{{ }^{58}}$. Wie J. Degler festgestellt hat ${ }^{59}$, bedeutete die Theaterreform fur Witkiewicz in erster Linie eine Dramenreform. Witkiewicz Ubernahm weder die in seiner Zeit beginnende Tendenz zur Verdrängung des Literatur- durch das Regietheater $^{60}$, noch entwickelte oder ubernahm er neue Konzepte zur Buhnenarchitektur oder Auffuhrungspraxis. Seine innovative Leistung bezog sich elgentlich nur auf die Entwicklung neuer Verfahren im Drama und einer ăsthetisch-kulturgeschichtlichen Theorie des Theaters. Diese "Schwäche" in Witkiewicz' formalistischer Theatertheorie wurde fur die polnische Avantgarde ein Ansatzpunkt zur Kritik. Dabei ist der Inhalt der Vorwürfe ein weiterer Beweis für Witkiewicz Năhe zur Stilbuhne. J. Kurek beispielsweise hielt Witkacy folgendes vor: eine Uberbetonung des Wortes und damit ein fehlendes Bewußtsein für Buhnengerechtigkeit; eine Bevorzugung des sprechenden vor dem handelnden Schauspieler; mangelndes Ausfullen des Buhenraumes; Festhalten an der Buhnenrampe und damit an der Trennung zwischen Publikum und Buhne. ${ }^{61}$

Die einzigen theoretischen Äußerungen Witkiewicz' zur Auffuhrungspraxis

\footnotetext{
${ }^{58}$ Zitiert nach: Degler, 1986: 20.

${ }^{59}$ Ebd.

${ }^{60}$ Man denke z.B. an Tairovs Postulat der "Theatralisierung des Theaters" in seiner Schrift "Zapiski rezissera", die 1923 in Deutschland unter dem sprechenden Titel "Das entfesselte Theater" erschien.

${ }^{61}$ Kurek, J.: Przeciwko teorii teatru S. I. Witkiewicza. In: MarczakOborski (Hrsg.) 1973: 186.
} 
beziehen sich auf die Rolle des Schauspielers.

Erwartungsgemä $\beta$ wendet sich Witkiewicz gegen Stanislavskijs Theorie der Schauspielkunst ( $V g l$. $T$ : 290). Insbesondere die Kategorien des "pereživanie" (Nacherleben) und "voplošenie" (Verkörperung) lehnt er ab. Der Forderung des Ensemblespiels, dem Streben nach einer Einheit der Darstellung stimmt er dagegen zu.

Witkiewicz lehnt das Illusionstheater ab, folglich auch eine Schauspielkunst, die auf dem Nacherleben und Vermitteln von eventuell menschenähnlichen Gefuhlsregungen der Buhnenfigur beruhen. Er fordert vom Schauspieler die "Schöpfung der Rolle" entsprechend der "formalen Idee" (T: 292) des Werkes. Der Schauspieler soll, unterstutzt vom Regisseur, die formale Konzeption des Gesamtwerkes verstehen lernen, daraus und mit Hilfe seiner schöpferischen Intuition seine "Rolle" in der Konstruktion aus Einzelqualitäten (Dekoration, Laute, Bedeutungseinheiten) ableiten und diese Rolle auf der Buhne "ausfuhren" (poln.: wykonac). Es kommt nicht auf die Imitation der wirklichkeitsnahen Elemente der Figuren, etwa ihrer Erlebnisse oder Gefuhle, sondern auf die formalen Elemente an: auf den Klang und die Lautstärke der Stimme, auf das Spiel mit Wortbedeutungen und mit den sprachlich evozierten und realen Bildern auf der Buhne.

"Sein Schaffen wird nur dann wirklich kunstlerisches Schaffen sein, wenn er sich selber als ein Element der gegebenen Einheit begreift. Im Augenblick, in dem er die Buhne betritt, bleibt ihm nur die Ausfuhrung, die wahrend der Proben und Vorstellungen sich immer weiter vervollkommnen kann, die aber trotzdem nur eine Ausfuhrung bleibt, ahnlich wie z.B. die Ausfuhrung eines komponierten Bildes, das Schreiben von Symphonien und ihre Ausfuhrung durch das Orchester." (T: 292)

Coino Auffaooung dor Cohauppiolkunot hringt witkiowirs ahanfalle in dis Nahe des Symbolismus und der Stilbuhne. In diesen Reformbewegungen gehorte die Ablehnung des Identifikationsprinzips in der Schauspielkunst zu den wesentlichsten Forderungen (etwa in G. Fuchs' "Die Schaubuhne der Zukunft" oder in W. Meyerholds "Biomechanik"). Am signifikantesten spiegelt sich diese Haltung in dem von E. Craig 1907 geprăgten Begriff der "Uber-Marionette" als eines Ideals, nach dem sich der Schauspieler bilden soll. Anders als "ein Mensch aus Fleisch und Blut", der zufälligen Stimmungen und Schwankungen unterworfen ist, sei die Uber-Marionette fur den Regisseur ein berechenbares und planbares Material, das eine perfekte 
Ausf thrung seiner asthetischen Konzeptionen vollbringt. ${ }^{62}$

Xhnlich wie Craig sieht auch Witkiewicz als Ziel einer Inszenierung die Ausfuhrung der im Drama angelegten formalen Konzeption an. Die ăsthetische Dimension des Buhnenwerkes darf dabei nicht von lebenslogischen Elementen gestört werden. Sich der Schwierigkeit dieser Aufgabe bewuBt, gibt Witkiewicz dem Regisseur folgenden Ratschlag:

"<...> dás Leben völlig vergessen und keine lebenslogischen Konsequenzen davon beachten, was auf der Buhne in diesem Augenblick geschieht, im Verhältnis dazu, was im folgenden Augenblick geschehen wird <Hervh. im Original>. Selbstverständlich im năchsten Augenblick auf der Buhne. Wir sprechen hier naturlich nicht von den lebenslogischen Konsequenzen hinter der Büne, etwa solchen wie: eine leere Kasse, das Verprugeln des Regisseurs, der Schauspieler, und des Autors durch die Massen und ähnliche Vorfalle, denen die Leitung eines Experimentiertheaters, unserer Ansicht nach, vorerst auch keine Beachtung schenken sollte." ( $T$ : 293)

${ }^{62}$ Wie bei Witkiewicz ist auch Craigs Beschreibung des neuen SchauspielerIdeals sehr vage und seine Schauspieltheorie besteht zum groBen Teil aus der Kritik am traditionellen "Nachahmungsschauspieler":

"Er versucht, natur zu reproduzieren, und denkt selten daran, mit hilfe der natur etwas zu erfínden; niemals trăumt er davon, etwas eigenes zu schaffen. das beste, wie gesagt, was er zu tun weik, wenn er die poesie eines kusses, die hitze eines gefechts oder die stille des todes erfassen und ausdrucken will, ist, fotografisch, sklavisch genau die natur zu kopieren, d.h. er kusst, kämpft, legt sich hin und mimt den tod - und wenn sie sich das alles vorstellen, kommt es ihnen nicht schrecklich stumpfsinnig vor? Ist es nicht eine armselige kunst und eine bescheidene begabung, die dem publikum nicht den geist und das wesentliche einer idee offenbaren kann, sondern nur eine unkunstlerische kopie, eine faksimlle-anslcht der wirklichen dinge zu zeigen vermag? Das heisst nachahmer, nicht küstler zu sein." <Hervh. und Kleinschreibung im Original>.

Craig, E.G.: Der Schauspieler und die Uber-Marionette. In: Craig, 1969: 55. 


\section{DRAMENANALYSE}

Nach R. Ingarden ist das literarische Kunstwerk ein mehrschichtiges, sprachliches Gebilde, das aus folgenden vier Hauptschichten besteht:

"a) die Schicht der Wortlaute und der sprachlautlichen Gebilde und Charaktere höherer Ordnung, b) die Schicht der Bedeutungseinheiten: der Satzsinne und der Sinne ganzer Satzzusammenhănge, c) die Schicht der schematisierten Ansichten, in welcher die im Werk dargestellten Gegenstănde verschiedener Art zur Erscheinung gelangen und d) die Schicht der dargestellten Gegenständlichkeiten, welche in den durch die Sătze entworfenen intentionalen Sachverhalten dargestellt werden. ${ }^{\text {I }}$

Jede dieser Schichten bildet einerseits die Grundlage fur die nachfolgende werkkonstituierende Schicht und besitzt andererseits aber ihre eigenen, materialspezifischen, ästhetischen Wertqualităten. Die ăsthetischen Werte der einzelnen Schichten bilden zusammen die individuelle ăsthetische Polyphonie des literarischen Werkes. R. Ingarden spricht in diesem Zusammenhang von "zwei Dimensionen" des literarischen Werkes: "die eine, in welcher sich der Gesamtbestand der Schichten erstreckt, und die zweite, in welcher die Teile aufeinanderfolgen. "2

R. Ingardens Arbeit wird noch immer als eine der besten Darstellungen des Phänomens des literarischen Werkes betrachtet ${ }^{3}$, und sein Vierschichtenmodell liegt auch dieser Untersuchung zugrunde. Dabei werden die Schichten der Laut- und Bedeutungseinheiten nicht getrennt, sondern innerhalb eines Kapitels untersucht. Der ästhetische Eigenwert der Lautschicht in Witkiewicz' Dramen ist nămlich relativ gering: reine Lauteffekte, die

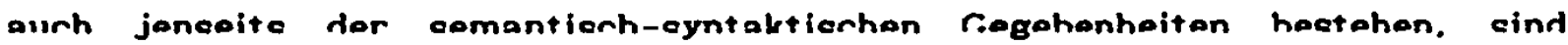
selten. Die Lautschicht hat in den Dramen vorwiegend die Funktion, Grundlage für die nachfolgende Schicht im Aufbau des Dramas zu bilden - die

Ingarden, 1968: 12. Ausfuhrlich dazu: Ingarden, 1972.

2 Ingarden, 1968: 11.

3 So z.B. Strelka, 1978: 6

Strelka wendet Ingardens Kategorien praktisch an in einer "Einfuhrung in die literarische Textanalyse" (Strelka, 1989). 
Bedeutungsschicht ${ }^{4}$.

Eine untergeordnete Rolle bei der nachfolgenden Untersuchung wird auch die Schicht der schematisierten Ansichten spielen.

Die schematisierten Ansichten ${ }^{5}$ haben, laut Ingarden, die "Funktion des Zurerscheinungbringens ${ }^{\prime 6}$. Sie bereichen das literarische Kunstwerk um das Kriterium der Anschaulichkeit, indem sie die dargestellten Gegenstănde in der Vorstellung des Rezipienten zur Erscheinung bringen. Wurden die Ansichten im Werk fehlen, so "müßten die dargestellten Gegenstände während der Lektüre nur leer vermeint, auf völlig unanschauliche Weise gedacht werden <...>. Die dargestellten Gegenstăndlichkeiten wăren dann leere, rein "begriffliche" Schemata, und nie hatte man den Eindruck, daß man es in ihnen mit einer eigenen, lebendigen Quasirealitat zu tun hat $\langle. . .\rangle^{n^{7}}$ Dem, laut Ingarden, grundsătzlich schematischen und intentionalen Charakter des Kunstwerkes ${ }^{8}$ gemäß liegen die Ansichten im literarischen Werk nur "schematisiert" vor, sie werden "paratgehalten" 9 und erst vom Rezipienten im ProzeB der Konkretisation aktualisiert.

Wie P. V. Zima richtig bemerkte, sind Ingardens Ansichten als "Erzählperspektiven zu umschreiben, in denen Protagonisten, Situationen oder Handlungen auf eine bestimmte Art und mit bestimmten Mitteln dargestellt werden. ${ }^{10}$ Ferner gehören dazu solche literarische Phănomene wie Metaphorik und Mehrdeutigkeit". Zweifellos spielen die "schematisierten Ansichten" daher eine wichtige und eigenstăndige Rolle in der Polyphonie der

Vgl. dazu Kapitel 3.1. in dieser Arbeit.

5 Ingarden verwendet das Wort "Ansicht" nicht im Sinn von "Meinung", sondern von "Anblick" bzw. "Blickwinkel". Seine Ausfuhrungen gehen von der phănomenologischen Theorie der sinnlichen Wahrnehmung aus. Den Begriff "Ansicht" fuhrt Ingarden auf E. Husserl zuruck. Vgl.: Ingarden, 1972: 272 (Anm. 3).

6 Ebd.: 296.

7 Ebd.: 295.

8 Die Ontologie des Kunstwerkes und insbesondere die Theorie der Unbestimmtheitsstellen und der Konkretisationen von $R$. Ingarden wurde zur Grundlage einiger rezeptionsasthetischen Literaturtheorien, 2.B. von F. Vodicka.

9 Ebd.

${ }^{10}$ Zima, 1991: 242.

"Vgl. Ingarden, 1972: 296. 
ästhetischen Werte eines literarischen Kunstwerkes. Bestimmte Ansichtentypen (Ingarden fuhrt als Beispiel innere, äußere, visuelle, akustische Ansichten $a^{12}$ ) können ein Werk, aber auch ganze literarische Richtungen und Schulen prägen.

Obwohl der eigenständige, ästhetische Wert der schematisierten Ansichten evident ist, bleibt unklar welche Position diese Schicht im vertikalen Querschnitt durch Ingardens Vier-Schichten-Modell einnimmt. Besonders problematisch ist das Verhältnis der Ansichten zu den dargestellten Gegenständlichkeiten. ${ }^{13}$ Da die einzelnen Schichten hierarchisch aufeinanderbauen, stellt sich die Frage, ob die Ansichten die Grundlage fur die Gegenstăndlichkeiten bilden, oder ob es gerade umgekehrt ist. Ingarden scheint von einer Parallelităt bzw. einer gegenseitigen Durchdringung dieser beiden Schichten auszugehen. ${ }^{14}$

Gerade bei einer konkreten Textanalyse ist es besonders schwierig, bei den Ansichten von den dazugehörigen Gegenständlichkeiten zu abstrahieren. Bei der nachfolgenden Analyse der Dramen von Witkiewicz sollen deshalb die Schicht der schematisierten Ansichten und die Schicht der dargestellten Gegenstăndlichkeiten zusammen in einem Kapitel betrachtet werden. Die speziellen ăsthetischen Qualităten der beiden Schichten werden in relevanten Fällen gesondert erörtert.

Die ästhetischen Arbeiten von $R$. Ingarden sind jedoch nicht nur in bezug auf sein Vierschichten-Modell des literarischen Kunstwerkes interessant. Von weit größerer Bedeutung fur die vorliegende Arbeit sind seine Erörterungen zum Form- und Inhaltproblem. In seinen, in polnischer Sprache geschriebenen Arbeiten: "Ze studiów nad zagadnieniami formy i tresci dzieła sztuki" (dt.: Aus den Studien zu Fragen der Form und des Inhalts in einem Kunstwerk) und "O formie $i$ tresci dzieła sztuki literackiej" (dt.: Uber

${ }^{12}$ Ebd. $297 \mathrm{f}$.

${ }^{13}$ Dieser Aspekt war auch einer der wichtigsten Ansatzpunkte fur die Kritik an Ingarden. Im allgemeinen wurde in der Forschung die Eigenstăndigkeit der Schicht der schematisierten Ansichten mit dem Argument abgelehnt, daß die Gegenstănde außerhalb ihrer Ansichten nicht existieren können. Vgl.: Makota, 1964: 210-216. Szczepanska, 1989: 100-106.

14Ingarden, 1972: $296 \mathrm{f}$. 
Form und Inhalt eines literarischen Kunstwerkes) ${ }^{15}$ setzt sich Ingarden zuerst ausfuhrlich mit den zahlreich vorhandenen Definitionen auseinander und entwickelt anschließend einen eigenen Form- und Inhaltbegriff des literarischen Kunstwerkes, der auf seinem Vier-Schichten-Modell aufbaut.

Witkiewicz behandelte das Form- und Inhaltproblem eigentlich nur im Bereich der allgemeinen Ǎsthetik und der Malerei erschöpfend, wăhrend seine Erörterungen im Bereich der Sprachkunst eher postulativ denn argumentativ blieben. Bei der nachfolgenden Analyse seiner Dramen werden also die fundierten Untersuchungen zum Phănomen des literarischen Kunstwerkes von $\mathbf{R}$. Ingarden aufgegriffen. Dabei soll dieser Dramenanalyse nicht nur Ingardens Vier-Schichten-Modell zugrundegelegt werden, sondern auch sein Formund Inhaltbegriff, der auf dieses Modell zuruckgreift. Von dieser theoretischen Position aus kann dann letztendlich die Frage nach der Verwirklichung der Theorie der Reinen Form im sprachlichen Kunstwerk bzw. nach dem Verhaltnis von Theorie und Praxis in Witkiewicz' Werk beantwortet werden.

R. Ingarden weist darauf hin $^{16}$, daß die Begriffe der Form und des Inhalts "korrelativ" sind: sie bestimmen sich bei ihrer Definition gegenseitig. In seinem Hauptwerk zur Ontologie "Der Streit um die Existenz der Welt" differenziert er zwischen neun essentialen Form- und Inhaltsbegriffen. Durch die Anwendung dieser essentialen Begriffe auf die literarische X̀sthetik kommt er zu funf Hauptbegriffen der Form und des Inhalts. Dabei sind das nicht seine eigenen Begriffe, vielmehr faßt er in diesen Hauptgruppen die găngigen Definitionen zusammen und kommentiert sie von seiner eigenen literaturtheoretischen Position aus ${ }^{17}$ :

I. Inhalt als Ereignisse und Prozesse, die in einem Werk dargestellt sind. Form ist in diesem Fall: (A) die zeitliche und räumliche Ordnung dieser Ereignisse und Prozesse; (B) die Art der Darstellung (z.B. Darstellungsperspektiven); (C) die "Sprache" des Werkes, d.h. die typischen Laut- und Bedeutungsphănomene eines Werkes, deren Verănderung - etwa bei

${ }^{15}$ Erschienen in: Ingarden, R.: Studia $z$ estetyki. Bd. 2. Warszawa 1958. S. 319-475.

${ }^{16}$ Fü das Folgende vgl. Ingarden, 1958, II: 319ff.

${ }^{17}$ Ebd.: $359 f$. 
einer Ubersetzung - auch eine Veränderung des Inhalts nach sich zieht.

Bei einem solchen Inhalt- und dementsprechenden Formbegriff wird der Schwerpunkt auf die Schicht der dargestellten Gegenstăndlichkeiten gelegt: die Auffassung steht der gegenstandsorientierten Ästhetik des 19. Jahrhunderts und somit der Position von Witkiewicz' Kritikern nahe.

I1. Inhalt als das Sinnganze bzw. die "vollstăndige Bedeutungsschicht ${ }^{\text {18 }}$ eines literarischen Werkes. Form als seine charakteristische Lautgestalt bzw. seine "vollstăndige Lautschicht"19. Diese Einteilung Uberschneidet sich teilweise mit dem oben beschriebenen Formbegriff (C) Nach Ingardens elgener Aussage liegt ihr jedoch ein anderer essentiale Formbegriff zugrunde. Form wird hier als das sinnlich Wahrnehmbare und Inhalt als das Gedachte, Gemeinte verstanden. Daruber hinaus wird im (C) Laut und Bedeutung eines Wortes oder Satzes als eine Einheit betrachtet, wăhrend in Il zwischen den beiden Elementen des Zeichens eine abstrakte Trennung vollzogen wird.

Ingarden betont den Unterschied zwischen dem "Gegenstand" und der "Bedeutung" einer sprachlichen Handlung: die Bedeutung "ist nicht der Gegenstand <...> sondern das Darstellungsmittel des Gegenstandes." 20 Der arbiträre Charakter des sprachlichen Zeichens begründet den ästhetischen Eigenwert der sprachlichen Bedeutungen unabhăngig von den dargestellten Gegenstănden. Gleichzeitig ist die Bedeutungsschicht eines literarischen Werkes sein medienspezifisches Unterscheidungskriterium zu anderen Kunsten.

III. Inhalt als die "Idee" des Werkes. Form als das ganze Werk, das in der Gesamtheit seiner kognitiven und ästhetischen Qualităten diese "Idee" ausdrúckt.

Einer idealistischen essentialen Form- und Inhaltsauffassung entspricht die Bestimmung des Inhalts im literarischen Werk als einer "Idee" im Sinne eines Kerngedankens, eines Sinnzentrums. R. Ingarden prăzisiert den Begriff der "Idee", der in der Literaturkritik sehr kontrovers definiert wird, als einen ubergeordneten, jedoch im Werk selber nicht expressis verbis, sondern nur potentiell vorhandenen Sinn des Ganzen, der in der

\footnotetext{
${ }^{18}$ Ebd.: 417 .

19 Ebd.: 418.

${ }^{20}$ Ebd.: 416.
} 
Konkretisation zur Anschauung gelangt. ${ }^{21}$

IV. Inhalt ist das Material (ein Grundschema /der Stoff/ oder eine bestimmte Nationalsprache); Form wird dann bestimmt als die Bearbeitung des Materials bzw. alle diejenigen Eigenschaften, die das fertige Werk vom Material unterscheiden.

V. Ein strukturalistischer, essentialer Form- und Inhaltbegriff impliziert schlieblich eine Definition, die auch Witkiewicz' Formverstăndnis am nächsten kommt:

"Man kann schlieblich als den Inhalt eines <literarischen> Werkes die Gesamtheit seiner Elemente (Teile) betrachten. 〈...> Als Elemente können dann seine vier Schichten oder einzelne Telle dieser Schichten gelten (z.B. Worte, Sătze, dargestellte Gegenstăndlichkeiten, einzelne Ansichten usw.). (Inhalt V). Die Form des Werkes wăre dann die strukturale Einhelt, die durch die Ordnung aller dieser Faktoren (der Schichten und ihrer Elemente) sowie durch alfe anderen, zwischen ihnen bestehenden Beziehungen hervorgerufen wird.

Dabei distanziert sich Ingarden ausdrucklich von linguistischformalistischen Positionen, die das literarische Werk auf seine Laut- und Bedeutungsschicht reduzieren wollen und betont die werkkonstitutive Leistung auch der beiden anderen Schichten: der intentional entworfenen "dargestellten Gegenstăndlichkeiten" und "schematisierten Ansichten". 23

In seiner eigenen Definition des Form- und Inhaltsbegriffes lehnt Ingarden zunăchst einmal jegliche Anwendung dieser Begriffe auf die gegenstăndliche Schicht, auf die "Idee", auf das "Thema", oder auf die "Sprache" des literarischen Kunstwerkes ab. ${ }^{24} \mathrm{Er}$ wendet das Begriffspaar "Form und Inhalt" auf drei Bereiche an und unterscheidet dabei zwischen folgenden Begriffen:

1. "Kategoriale Form und Materie" des literarischen Kunstwerkes im Sinne formaler Ontologie. Ingarden bezeichnet die kategoriale Form auch als "zweidimensionale Struktur", die sich einerseits als eine mehrschich-

${ }^{21}$ Ebd.: 430.

22Ebd.: $363 f$.

${ }^{23}$ Ebd.: 436.

${ }^{24}$ Ebd.: 439. 
tige Einheit und anderseits als ein spezieller zeitlicher Prozeß konstituiert. $^{25}$

2. "Struktur" des Werkes als die Gesamtheit aller Beziehungen, die zwischen seinen Einzelelementen bestehen und "Gehalt" (poln.: zawartosc) als die Gesamtheit dieser Elemente. Diese Unterscheidung entspricht dem essentialen Formbegriff $\mathrm{Nr}$. $\mathrm{V}$.

3. "Inhalt" (poln.: tresc) als die gesamte Bedeutungsschicht des Werkes (entspricht dem Punkt II). Demgegenuber steht die "aubere Form" als die gesamte Lautschicht sowie die "innere Form" als die Gesamtheit der Darstellungsarten.

Die Form- und Inhaltsbegriffe von R. Ingarden erscheinen fur diese Arbeit aus drei Grunden interessant. Als sehr wichtig erweist sich zunacht einmal die Feststellung der Korrelativität des Begriffspaars: Form und Inhalt bestimmen sich gegenseitig. Ebenso relevant ist es, daß Ingardens kategorialer Formbegriff, d.h. der Formbegriff, der sich auf das Wesen des literarischen Werkes im allgemeinen bezieht, strukturalistischer $\mathrm{Na}-$ tur ist: das Werk ist eine Einheit, die sich aufgrund von besonderen Beziehungen zwischen seinen vielen Schichten und Phasen einstellt. Dabei billigt Ingarden jeder Schicht und auch jedem Einzelelement des literarischen Kunstwerkes eigene formale und inhaltliche Momente zu. So spricht er beispielsweise von der "Struktur der dargestellten Welt" ${ }^{26}$ oder vom Gehalt (poln.: zawartosc) und von der Struktur der Fabel ${ }^{27}$ etc.

Der dritte, fur die vorliegende Arbeit wichtige Aspekt des Form- und Inhaltsbegriffes von Ingarden, besteht darin, daß Ingarden eine Anwendung des Inhaltsbegriffes auf die gegenstăndliche Schicht des Werkes ablehnt. ${ }^{28}$ Die dargestellte Welt in einem literariscnen werk hal eluen veshumuleu Gehalt an Einzelelementen und eine bestimmte Struktur. Dabei ist ihre Xhnlichkeit mit der außerkünstlerischen Welt, die sog. "gegenstăndliche

${ }^{25}$ Ebd.: 438.

${ }^{26}$ Ebd.: 439.

27Ebd.: 443ff. Als Struktur der Fabel betrachtet Ingarden die raumzeitliche Ordnung der Situationen.

28

Ebd.: 441. 
Konsequenz" ${ }^{29}$, nichts weiter als eines der möglichen Strukturelemente. Ähnlich wie Witkiewicz wendet sich auch Ingarden gegen einen naturalistischen Form- und Inhaltsbegriff (essentialer Begriff $\mathrm{Nr}$. I), der den Inhalt des Kunstwerkes mit den mimetisch dargestellten Gegenständen und die Form mit der Darstellungsart gleichsetzt.

In seiner Theorie der Reinen Form formulierte witkiewcz zwei wichtige Postulate fur die "Reine Kunst": die Deformation des gegenstăndlichen Inhalts und die subjektiv-ästhetische Konstruktion der kinstlerischen Einzelelemente.

Für die Analyse der Dramen von Witkiewicz sind nun folgende Fragen relevant: Was sind die gegenstăndlichen bzw. - um witkacys Terminus zu verwenden - die "lebenslogischen" Elemente und was die rein formalen bzw. ästhetischen Elemente im Drama?; Welche Arten von Beziehungen treten zwischen diesen Elementen auf?; Durch welche Verfahren wird die Deformation des gegenstăndlichen Gehaltes erreicht?; Worin besteht die rein werkimmanente Struktur des Dramas, d.h. eine Struktur, die auf den Beziehungen der rein formalen Elemente untereinander und nicht auf einer mimetischen Abbildung der außerkünstlerischen Welt beruht?

Diese Fragen sollen bei der nachfolgenden Dramenanalyse erkenntnisleitend wirken. Bei ihrer Beantwortung sollen die Untersuchungsergebnisse von ahnlichen Problemstellungen zur Hilfe herangezogen werden: in erster Linie die phănomenologischen Arbeiten $R$. Ingardens, weiterhin einige Erkenntnisse der formalistischen und strukturalistischen Forschung.

${ }^{29}$ Ebd. 444. 


\subsection{DIE SCHICHT DER LAUT- UND BEDEUTUNGSEINHEITEN}

Gegenstand dieses Kapitels ist die Laut- und Bedeutungsschicht in den Dramen von Witkiewicz. Die entsprechenden wirkungsästhetischen Qualităten werden zunăchst auf der Ebene des Wortes und Satzes nachgewiesen. Als Untersuchungsbereich sind dazu besonders die Titel und die Figurennamen geeignet, die beim Drama im Vergleich mit anderen Gattungen eine relativ eigenständige und signifikante Rolle spielen: da sie noch vor Beginn des Spiels dem Programm entnommen werden können, erfullen sie die Funktion der Vorinformation bzw. einer Vor-Exposition und bestimmen den Erwartungshorizont des Zuschauers. ${ }^{30}$ Auf der Ebene der Satzzusammenhănge und der textkonstitutiven, satzubergreifenden Bedeutungseinheiten sollen die semantischen und syntaktischen Eigenheiten der Sprache Witkiewicz' an der Art der Dialogfuhrung in seinen Dramen untersucht werden.

In seiner Theorie der Reinen Form ${ }^{31}$ fordert Witkiewicz - und befindet sich damit weitgehend im Einklang mit den zeitgenठssischen avantgardistischen Kunstauffassungen - die Autonomie der kunstlerischen Mittel, ihre Unabhăngigkeit von Zwăngen einer mimetischen Darstellung. Fur die Malerei bedeutet das ein Anordnen von Farben und Formen auf der Bildflache aus einem subjektiven Formempfinden des Kunstlers heraus und ohne RUcksicht auf die Erzeugung einer Illusion von Wirklichkeitstreue der dargestellten Gegenstănde. Die Ubertragung dieser Malerei-Theorie auf die Sprachkunst fuhrte bei Witkiewicz zur Konzeption einer Wort- und Satzbedeutung, die. herausgelost aus syntaktischen und referentiellen Bezügen, ein kunstlerisches Eigengewicht besitzt. Der Signifikant lost beim Rezipienten Vor-

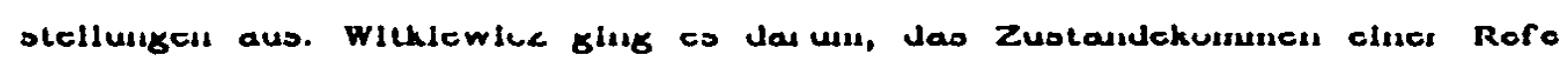
renz, eines Weltbezugs im Sinne von "Wledererkennen" zu verhindern und dafur eine Reihe von fluchtigen, rasch wechselnden Assoziationen zu erzeugen, die einerseits nach formalen Gesichtspunkten (etwa in Form eines bestimmten Tempos oder Rhythmus durch die Geschwindigkeit des Wechsels und Wiederkehrens der gleichen Bilder) geordnet sind, und anderseits durch die Erwartung einer "sinnvollen" (d.h. eine dem Erwartungshorizont

\footnotetext{
${ }^{30} \mathrm{Vgl}$. dazu 2.B. Pfister, 1988: 68ff

${ }^{31} \mathrm{~V}$ l. Kapitel 2 in dieser Arbeit.
} 
des Rezipienten entsprechenden) Lösung Spannung erzeugen. Nach Witkiewicz' theoretischen Ausfuhrungen ist also im Hinblick auf die Deformation in der Bedeutungsschicht seiner Dramen eine bewußte Zerstörung der Sinnkontinuitát des Textes und der referentiellen Sprachfunktion zu erwarten.

Der Lautschicht widmet Witkiewicz in seinen theoretischen Schriften wenig Aufmerksamkeit. Laute gehören fur inn - ăhnlich wie die Tone in der Musik - zu den rein-formellen Elementen in der Kunst. Bei der Komposition eines Reine-Form-Werkes gilt es nun, Lauteffekte wie Assonanzen, Alliterationen, Reime etc. zu erzeugen, ohne Rücksicht auf grammatikalischsyntaktische Syntagmen bzw. auf die Bildung von nachvollziehbaren Bedeutungsisotopien zu nehmen.

Fragt man nach den Deformationsmöglichkeiten der Lautschicht, so kann man naturlich nicht, wie im Falle der Bedeutungsschicht, daran die Frage nach der Lebenslogik, Wirklichkeitsnahe der sprachlichen Laute anknüfen. Man muß eher davon ausgehen, daß die Deformation in der Lautschicht an dem phonetischen Erwartungshorizont in einer natürlichen Sprache ansetzen wird. Man könnte dabei an die Deformation der gesamten phonologischen Struktur denken, wie z.B. in den dadaistischen Lautgedichten, oder an ungewbhnliche Rekurrenzen einzelner Phoneme wie 2.B. in Alliterationen, Assonanzen etc. Eine solche Problemstellung spielte eine große Rolle bei den Untersuchungen der russischen Formalisten der 20er Jahre und den nachfolgenden struktural-semiotischen Schulen zur "kunstlerischen Sprache" als einem nach dem Prinzip der Verfremdung bzw. Abweichung von der "praktischen Sprache" entstandenen sekundăren Sprachsystems. ${ }^{32}$

Witkiewicz geht in seinen theoretischen Schriften auf diese Problematik nicht ein. In seinen Stucken dagegen findet man zwar interessante Lauteffekte, sie sind aber relativ selten und greifen niemals so radikal die phonologische Struktur der Sprache an wie die Experimente der Dadaisten oder der Futuristen.

Aus diesem Grund wird auch bei der nachfolgenden Dramenanalyse die Lautschicht nicht gesondert, sondern zusammen mit der Bedeutungsschicht untersucht. Auf eventuelle Lauteffekte, die einen asthetischen Eigenwert auch außerhalb der semantischen Bezlge haben, wird im Laufe der Untersuchung hingewiesen.

${ }^{32}$ ggl. z.B.: Hansen-Love, 1978; Link, 1985: 98-194. 


\subsubsection{TITEL}

Der Titel hat die Funktion, durch gezielte Vorinformationen den Erwartungshorizont des Zuschauers oder des Lesers zu bestimmen. ${ }^{33}$ Der Haupttitel erteilt dabei im allgemeinen die thematische Vorinformation in bezug auf die zu erwartenden Konflikte und Handlungstrăger. Der Untertitel dagegen leistet die gattungsspezifische Information, die vom Zuschauer in Abhăngigkeit von seiner Vertrautheit mit literarischen Konventionen aufgenommen wird und seine Erwartung hinsichtlich der Komposition (2.B. Akteinteilung, Handlungsverlauf) und des asthetischen Grundtons (z.B. komisch, tragisch, tragikomisch) bestimmt. GemáB der rhetorischen Tradition, daß ein Titel auf das thematische Zentrum des Textes verweist, sind beim Drama hăfig titelgebend: Handlungsschemata, Teilereignisse, Personennamen, soziale Rollenbezeichnungen, Ortsangaben, Sentenzen etc. ${ }^{34}$ Der Erwartungshorizont wird dabei geprägt durch eine symbolische Bezugnahme auf Vorgănge und Gegebenheiten der empirischen Wirklichkeit, z.B. soziale Rollen (Schiller: "Die Răuber"; Molière: "Der Bürger als Edelmann"; Shakespeare: "Der Widerspenstigen Zăhmung"); auf historische Gestalten und Ereignisse (z.B. Buchner: "Dantons Tod"; WeiB: "Trotzki im Exil"); oder auf bekannte Mythen und literarische Stoffe: (z.B.: Goethe: "Iphigenie auf Tauris"; Aischylos: "రdipus").

Die Deformation beim Dramentitel kann folglich an zwei Punkten ansetzen: erstens an der durch die literarische und rhetorische Tradition gebildeten Erwartungshaltung hinsichtlich der Beschaffenheit des Artefaktes und des ăsthetischen Objektes und zweitens an der Sinnbildung durch Verweise auf Historisches, auf bekannte Mythen oder empirische Fakten. Eine gezlelte renunformation des litels kann durch die uiskiepalle ewisclien uem tatsăchlich Dargestellten und dem durch den Titel hervorgerufenen Kontext Ironie erzeugen. Dementsprechende Verfahren werden hăufig im Theater des Absurden angewandt, z.B. indem mit der Gattungserwartung der Kombdie gespielt wird oder die titelgebende Person im Stuck gar nicht auftritt (z.B. Ionesco: "Die kahle Sängerin"). Die andere Moglichkeit der Deforma-

${ }^{33}$ Zur Funktion des Titels im Drama vgl.: Pfister, 1988: 68ff und Danek, 1972.

${ }^{34}$ Vgl. Asmuth, 1984: 20. 
tion besteht darin, den Informationswert des Titels uberhaupt zu zerst8ren, indem schon auf der Ebene der Bedeutungseinheiten die Entstehung einer zusammenhăngenden Außerung verhindert wird. Letzteres Verfahren trifft besonders auf Witkiewicz' Stücke zu. 


\subsubsection{HAUPTTITEL}

Entgegen der traditionell stark informativen Funktion des Titels ist die Bedeutung der Dramentitel bei Witkiewicz auffallend unbestimmt und sogar rătselhaft. Um diese Wirkung hervorzurufen, wird hăufig eine semantische Binäropposition innerhalb eines Wortes oder einer Wortgruppe gebildet. Ein gutes Beispiel fur dieses Verfahren ist der Titel "Maciej Korbowa i Bellatrix". In jedem Namen der Titelhelden sind die zwei oppositionellen semantischen Merkmale 'männlich' und 'weiblich' vereinigt, wodurch eine starke Verfremdung des Signifikats erreicht wird. So ist das Wort "Maciej" ein männlicher Vorname, wăhrend der Nachname "Korbowa" durch die Endung " $\mathrm{a}$ " weibliches Geschlecht signalisiert. Ähnliches findet auch in dem Vornamen Bellatrix statt. Das semantische Merkmal 'weiblich' wird durch das Morphem 'bella' und die Klangăhnlichkeit mit dem bekannten Vornamen "Beatrix" konnotiert, dem Merkmal 'männlich' dagegen entspricht der konsonantischer Auslaut. Diese semantische Opposition kehrt auch in der gegenstăndlichen Schicht wieder: Bellatrix ist ein hermaphroditisches Wesen, das im Verlaufe des Dramas ständig sein Geschlecht wechselt.

Auch der Titel "Metafizyka dwugłowego cielęcia" (dt.: Die Metaphysik des zweiköpigen Kalbes) wird von einer Binăropposition getragen: das Wort "Metaphysik" evoziert die Vorstellung von 'geistig', 'beseelt'; demgegenuber steht das semantische Merkmal 'tierisch', 'unbeseelt', das von dem Wort "Kalb" hervorgerufen wird.

Die semantische Binäropposition hat eine große sprachästhetische Kraft, die in der traditionellen Rhetorik bekannt war und hăufig eingesetzt wurde: das Oxymoron, dem sie zugrunde liegt, gehört zu den beliebtesten rhetorischen piguren. Inre wirkung veruht woll aur der spanumg, welclie die beiden gegensätzlichen semantischen Merkmale auslösen, und die die Rezipientenaktivităt anregt. Doch im Hinblick auf den Informationswert, der von einem Dramentitel traditionsgemă $\beta$ erwartet wird, stellt sich der Effekt der Verfremdung ein: die Aussage bleibt unbestimmt und besteht höchstens in dem indirekten Verweis auf einen "unrealistischen" Inhalt des Stuckes.

Die Wirkung der Unbestimmtheit und Rătselhaftigkeit im Titel erzeugt auch die Verwendung von Pronomina (z.B. "Oni", dt.: Die da) bzw. Abstrakta 
2.B. in "Niepodległosć trójkątów" (dt.: Die Unabhăngigkeit der Dreiecke) oder "Metafizyka' dwugłowego cielecia" (dt.: Die Metaphysik des zweiköpfigen Kalbes).

Ẍhnlich wie die Binäroppositionen sind Abstrakta und Pronomina sprachliche Erscheinungen, deren formal-ästhetische Wirkung Witkiewicz in seiner Sprachtheorie analysiert. ${ }^{35}$ Danach beruht der künstlerische Wert dieser Begriffe auf ihrem relativ hohen Grad an "innerer Spannung" (BW, 91), die von dem Umfang der assoziierten Vorstellungen herruhrt und im Moment der Sinnzuweisung, d.h. der Herstellung des Weltbezugs, sich auflost. Diese bewuBte Anwendung theoretischer Erkenntnisse in der dramatischen Praxis soll hier als Gegenargument für die weit verbreitete Meinung angefuhrt werden, "Witkacys Dramen seien aus Lust und Schabernack entstanden und aus der Laune des Augenblicks hingeschrieben". ${ }^{36}$

Als eine deutliche ironische Anspielung auf die informative Funktion des Dramentitels wăren "Bezimienne dzieło" (dt.: Das namenlose Werk) und "Dramat nie rozpoznany" (dt.: Das nicht erkannte Drama) ${ }^{37}$ zu bezeichnen.

Einen direkten Hinweis auf den "unrealistischen" Inhalt des Dramas scheinen Titel zu geben, die aus wirklichkeltsfernen Namen der Hauptfiguren bestehen. Die Figurennamen sind bei Witkiewicz im allgemeinen phantasievolle Neologismen, die keinen Weltbezug erlauben: dem Rezipienten werden weder Hinweise auf Stănde- oder Milieuzugehörigkeit noch auf individuelle, menschliche Charaktere gegeben. ${ }^{38}$ Als Beispiel wäre hier insbesondere der Titel "Tumor Mózgowicz" (dt.: etwa: Tumor Hirnmann) zu nennen. Der Neologismus entspricht der Wortbildungskonvention bei Personennamen: der konsonantische Auslaut des Vornamens und die Endung "-owicz" suggerieren einen mannlichen Personennamen. Ein witziger, doch an Jeglicher Lebenslogik vorbeigehender Effekt entsteht durch die Rekurrenz des semantischen Merkmals 'Hirn' (poln.: mózg) in dem Nachnamen "Mozgowicz" und in dem

${ }^{35}$ Sie entsprechen wahrscheinlich den "widersprulchlichen", "unbestimmten" und "abstrakten" Begriffen in Witkiewicz" "Theorie der Begriffe". Vgl. dazu $B W, 92 f$ und Kapitel 2.2.1. in dieser Arbeit.

${ }^{36}$ Kosny, 1989: 1. Dieses Vorurteil wird auch von W. Kosny in seiner Untersuchung zum Nebentext in Witkiewicz' Dramen widerlegt.

${ }^{37}$ Nur in Fragmenten erhalten.

${ }^{36} \mathrm{Zu}$ Figurennamen vgl. Kapitel 3.1.2. in dieser Arbeit. 
Vornamen "Tumor" (Gehirnkrankheit).

Eine interessante, doch nicht übersetzbare Wirkung hat auch der Name der Hauptheldin "Kurka Wodna" im gleichnamigen Drama, der wortlich als "Das Wasserhuhn" Ubersetzt wird ${ }^{39}$. Im Polnischen ist dieser Ausdruck aber auch - aufgrund der phonetischen Ähnlichkeit - ein Ersatzausdruck fü das Wort "Kurwa" (dt. wörtlich: Hure), das hăufig die Funktion eines Fluches erfullt.

SchlieBlich seien hier noch Titel erwăhnt, die sich auf andere literarische Werke beziehen und ihre Wirkung den vielfăltigen Möglichkeiten der Intertextualităt (Parodie, Anspielung etc.) verdanken. So könnte beispielsweise "W małym dworku" (dt.: Im kleinen Landhaus) eine Anspielung auf T. Tittners Stuck "W matym domku" sein; "Nowe Wyzwolenie" (dt.: Neue Befreiung) auf St. Wyspianskis "Wyzwolenie". "Janulka, corka Fizdejki" (dt.: Janulka, Tochter des Fizdejko) nimmt sowohl im Titel als auch im Handlungsort Bezug auf den in Polen im 19. und beginnenden 20. Jahrhundert sehr popularen Roman von Feliks Bernatowicz "Pojata, córka Lezdejki, albo Litwini w XIV wieku" ${ }^{40}$.

Ein auffallend großer Teil von Witkiewicz' Dramen hat ausladende Doppeltitel, die an barocke Tradition erinnern (z.B. Gryphius: "Cardenio und Celinde oder Unglucklich Verliebte"; "Catharina von Georgien oder Bewehrete Bestăndigkeit"). Der barocke Doppeltitel bestand im allgemeinen aus dem Namen der Hauptfigur und der gedanklichen Quintessenz des Dramas - es wurden darin also die beiden von Harsdörffer formulierten Forderungen verbunden, die dem Rezipienten eine rasche Orientierung ermöglichen: "Den Namen deß Trauersplels sol man nernemen von der Haublyetsull, viler aull von der Lehre auf welche alles gerichtet seyn sol." ${ }^{41}$

Witkiewicz greift parodierend diese Tradition auf: seine Doppeltitel entsprechen der barocken Tradition in ihrer außeren Form, jedoch nicht, wie

${ }^{39}$ Z.B. von Kunstmann. Frankfurt a.M. 1965.

${ }^{40}$ Dt.: Pojata, Tochter des Lezdejko, oder die Litauer im 14. Jahrhundert. Der 1826 erschienene historische Abenteuerroman a la W. Scott erfuhr bis 1898 acht Auflagen.

${ }^{41}$ Harsdbrffer, G.Ph.: Poetischer Trichter, 1648-53, Nachdruck 1969, Teil 2. S. 80. Zitiert nach Asmuth, 1984: 22. 
die nachfolgenden Beispiele zeigen werden, in der informativen, sinnstiftenden Funktion. Der Sinn dieser Kleintexte wird durch semantische Binäroppositionen oder durch bewußt herbeigefuhrte Sinndiskontinuität zerstort.

Eines der ersten Dramen Witkiewicz' mit einem Doppeltitel ist das Stuck "Mister Price, czyli Bzik tropikalny" (dt.: Mister Price oder Der Tropenkoller). Der sprechender Name "Mister Price" evoziert die semantischen Merkmale 'Geld' resp. 'Handel' und 'englisch'. Durch das kontextuelle Merkmal 'tropisch' wird die Bedeutung 'englische Kolonialherrschaft' resp. '-handel' hervorgerufen, die tatsăchlich mit Ort und Handlung des Drama ubereinstimmt. Doch die vor dem Hintergrund von historischen Wissen konnotierte Sinneinheit (etwa die Erwartung von Konflikten um Geld und Kolonialherrschaft) wird durch den zweiten Teil des Titels "Der Tropenkoller" erschuttert - in bezug auf die traditionsgemäß erwartete Lehre oder das Thema des Drama bleibt die Aussage des Titels unzusammenhăngend. Der Absicht, das Wort "Koller" im Sinne einer selbstironischen Gattungsbezeichnung auf das Drama selber zu beziehen, beugt der Autor im Vorwort vor. Darin erklärt er in grotesk-ernsthafter Weise, daß der Tropenkoller eine bekannte Krankheit ist, die man entweder fur eine Luge hălt ("erfunden von sadistischen Kolonial-Europăern, um ihre Verbrechen an farbigen Menschen zu entschuldigen" oder als eine Art Paranoia betrachtet, die "unter dem Einfluß wahnsinniger Temperatur, 〈...> scharfer Speisen, des Alkohols und des stăndigen Anblicks nackter, schwarzer Körper" (Werke, IV: 277 ) entsteht. Letzterer Meinung schließst sich auch der Autor an. Durch das Vorwort wird der Rezipient motiviert, den "Tropenkoller" auf die Schicht der Gegenstandlichkeiten zu beziehen: der Titel dehnt den Assoziationsraum aus, seine Aussage bleibt unzusammenhängend.

Eine ăhnliche Funktion hat auch der zweite Teil des Doppeltitels "Gyubal Wahazar, czyli Na przełęczach bezsensu" (dt.: Gyubal Wahazar oder Auf den Paßhöhen des Unsinns). Der Name "Gyubal Wahazar" ist ein Neologismus, der jedoch unschwer auf dem Hintergrund der Titelgebungstradition als Personenname und aufgrund der konsonantischen Endungen als mănnlicher Personenname erkannt wird. Gyubal Wahazar ist der Hauptheld des Dramas und ein Ubermăchtiger Tyrann, worauf auch - nach einer Interpretation von D.C. Gerould - sein Name hindeutet: der Nachname "Wahazar" erinnert an "We- 
sir". der Vorname "Gyubal" an den biblischen "Jubal" (im Buch Genesis der Erfinder von Musikinstrumenten) oder an den ungarischen Vornamen "Gyula" (Julius). All diese semantischen Merkmale assoziieren einen exotischठstlichen Ubermăchtigen Alleinherrscher ${ }^{42}$, und diesbezÜliche Erwartungen werden im Drama auch bestätigt. Doch ahnlich wie in "Mister Price oder der Tropenkoller" erweitert der zweite Teil des Titels "Auf den PaBhbhen des Unsinns" den Assoziationsspielraum des Rezipienten und legt statt der Erwartung traditioneller Konflikte zwischen Macht und Moral ein groteskes pathologisches Thema nahe. Dieser Eindruck wird noch verstärkt durch das vorangestellte Motto, das Nietzsche-Zitat: "Es ist doch teuer zu Macht zu kommen - Die Macht verdummt. <Deutsch im Original>".

Ein Zusammenhang deutet sich ironischerweise auf der funktionalen Ebene an: Im Titel kommt die Deformation der Bedeutungseinheiten dadurch zustande, daß dem Rezipienten der Bezug auf literarische Tradition oder auf sein Weltwissen bei Bildung von Sinneinheiten verbaut wird. Dieses Deformationsprinzip bleibt auch fur die anderen Schichten des Werkes strukturbildend und stimmt somit indirekt mit der "Aussage" des Dramas uberein.

Ein von vornherein sehr rătselhaft anmutender Titel ist: "Mątwa, czyli Hyrkaniczny swiatopoglą" (dt.: Der Tintenfisch oder die Hyrkanische Weltanschauung). Das Adjektiv "Hyrkanisch" assoziiert das Lexem "Hyrkanien" - nach "Meyers Lexikon" eine historische Landschaft am südöstlichen Ufer des Kaspischen Meeres - oder "Hyrkanos", den Namen judischer Hohenpriester. Werkimmanent bezieht sich das Adjektiv auf eine der Dramenfiguren: Hyrkan IV - König von Hyrkanien (poln.: król Hyrkanii). In schon bekannter Weise wird dem aussagekräftigen Ausdruck: "Hyrkanische Weltanschauung" der Sinn entzogen, nämlich durch die vorangehende Gleichsetzung mit dem Lexem "lintentisch", der aut den ersten blick keine gemeinsiumeı semantischen Merkmale mit dem Ausdruck "hyrkanische Weltanschauung" hat. Eine verborgene Bedeutung kann in diesen Titel hineingelegt werden durch Konstruktion eines geeigneten Referenzrahmens aus den Kontexten, in denen das Wort "mątwa" von Witkiewicz verwendet wird. Wie D.C. Gerould hinweist, betont Witkiewicz folgende Bedeutungseinheiten des Wortes "Tintenfisch": hartnăckig, Lebenssäfte aussaugend, festklebend, weich, zerstz-

\footnotetext{
${ }^{42}$ gl. Gerould, 1981b: 210.
} 
rerisch. Das Wort kommt in Vergleichen mit Kapital, Liebe, dămonischen Frauen vor. ${ }^{43}$ Vor diesem Hintergrund wirkt der Titel aussagekräftig, indem er Informationen uber die Weltanschaung des Haupthelden gibt. Doch in Anbetracht der literarischen Theorie und Praxis Witkiewicz' erscheint das Vorgehen, die vermeintliche "versteckte" Bedeutung aus der hermetischen "Privatsprache" des Autors erschließen zu wollen, als fragwlirdig.

Der erste Teil des Titels "Nadobnisie i koczkodany, czyli zielona pigułka" wirkt ungewohnlich, aber semantisch nachvollziehbar. Der Neologismus "nadobnisie" wird von dem Adjektiv "nadobny" (schön, anmutig) durch die Femininum- Plural-Endung "-isie" gebildet und kann soviel wie "die Schönen" oder "die Anmutigen" bedeuten. Fur das Lexem "koczkodan" (dt.: "Meerkatze") ist im Polnischen die ubertragene Bedeutung "Vogelscheuche", "häbliche Frau" fest verankert. Wahrend also der erste Teil des Titels durch die Opposition "die Schönen" und "die HåBlichen" oder treffender ubersetzt: "Die Grazien und die Vogelscheuchen"44 Ruckschlusse auf die möglichen Dramenkonflikte und die Handlungstrăger evoziert und damit die traditionelle Funktion des Titels auszufuhren scheint, wird durch den zweiten Teil des Titels: "Die grüne Pille", der keine gemeinsamen semantischen Merkmale mit dem ersten Teil aufweist, der Zusammenhang der Gesamtaussage wieder aufgehoben.

In dem Titel: "Wariat i zakonnica, czyli nie ma złego, co by na jeszcze gorsze nie wyszto" ("Narr und Nonne oder es gibt nichts Schlimmes, was sich nicht zum Schlimmeren wenden willden) sind traditionsgemä $B$ die Hauptfiguren titelgebend. Eine Opposition auf der semantischen Ebene fallt auf, wenn man die Etymologie der beiden Worte berucksichtigt. Die polnische Vokabel "Wariat" (dt.: Verrulckter) wird von der lateinischen Wurzel "varia-" mit der Bedeutung "verschieden", "abweichend" (2.B. in "variantia", "varietas") gebildet. Das Wort "zakonnica" (dt.: "Nonne") kommt von "zakon" - im heutigen Polnisch in der Bedeutung "der Orden", im Altkirchenslavischen, Altpolnischen und im heutigen Russischen in der Bedeutung "Gesetz", "Regel". Daher liefert der Titel nicht nur Informationen uber die Hauptfiguren, sondern assoziiert auch durch die fur einen Slaven

43Ebd.: 258.

${ }^{44}$ L. Niesielska ubersetzt: "Nixen und Hexen oder die Grune Pille". (Wien 1974). 
leicht spürbare semantische Opposition zwischen "Gesetz" und "Anarchie" den dramatischen Konflikt - eine thematische Erwartung, die in Witkacys Stil im Stück freilich nicht erfullt wird. Der zweite Teil des Titels ist eine deutliche Parodie auf die Tradition literarischer Titel: die Sentenz "Es gibt nichts Schlimmes, was sich nicht zum Schlimmeren wenden würde" ist eine ironische Verkehrung des bekannten polnischen Sprichwortes: "Es gibt nichts Schlimmes, was sich nicht zum Guten wenden wüde". Will man, der literarischen Konvention entsprechend, die Titelsentenz als Interpretationshilfe nehmen und das Schicksal des Helden als eine Wendung zum Schlimmeren verstehen, ${ }^{45}$ so entsteht vielschichtige Ironie: der Lebensweg des Kunstlers Walpurg fuhrt vom Aufenthalt im Irrenhaus Uber Selbstmord und anschlieBende Auferstehung in die Aufnahme in die bügerliche Gesellschaft und darnit konsequenterweise in gesellschaftliche Abhăngigkeiten und Selbstvermarktung. Eine Wendung, die je nach Standort des Rezipienten als eine Wendung zum Guten - im Sinne der ursprunglichen Form des Sprichwortes, oder eben - und das durfte der Autorintention eher entsprechen als eine Wendung zum Schlimmeren verstanden werden könnte.

Auch das letzte Drama der Schaffensphase in den 20er Jahren trăgt einen Doppeltitel: "Sonata Belzebuba, czyli Prawdziwe zdarzenie w Mordowarze" (Die Belzebubsonate oder Ein wahrer Vorfall in Mordowar"). Auffallend ist hier die Binăropposition zwischen den semantischen Merkmalen 'realistisch' ("ein wahrer Vorfall") und 'unrealistisch' ("Belzebub"). Ähnliches ist auch in Ortsangabe "w Mordowarze" zu bemerken. Der "unrealistische" Ortsname "Mordowar" ist ein Neologismus und setzt sich zusammen aus dem Wort "mordo" und "war" (poln.: Sud, kochendes Wasser, "wrzec" - kochen, brodeln). Die urslavische Wurzel "wir" tritt bei der Wortbildung in den melocen slavisulics 3pialics in Ja Dodoutung ron koohon, brodoln auf. In der Bedeutung "Quelle" (var) ist sie im Tschechischen auch ortsnamenbildend, 2.B. Karlovy Vary (Karlsbad) ${ }^{46}$ - eine Analogie, die die groteske Wirkung des Neologismus Mordowar (etwa Mordosud, Mordobad) ahnen laßst.

Zusammenfassend kann man feststellen, daß die Doppeltitel bei Witkiewicz auf zweifache Weise ihre deformative Funktion ausuben. Zum einen parodie-

\footnotetext{
${ }^{45} \mathrm{~V}_{\mathrm{gl}}$. die Interpretation von Kosny, 1989: 10.

${ }^{46}$ Vgl.: Bruckner, 1974: 633.
} 
ren sie die Titelgebung des Barocks - in diesem Fall kann man also von einer bewußten Deformation der literarischen Konventionen sprechen. Gleichzeitig aber bieten sie durch ihre zweiteilige form ein geeignetes Mittel zur Deformation von Sinneinheiten im Sinne der Theorie der Reinen Form. Dabei wird insbesondere durch Bildung von semantischen Binäroppositionen und durch Verbindung von Ausdrücken, die keine gemeinsamen semantischen Merkmale besitzen, eine zusammenhängende Bedeutungsstruktur des Textes zerstört und dafur ironische, groteske oder komische Effekte hervorgerufen. Durch die Deformation der referentiellen Funktion des Titels wird der am naturalistischen oder symbolistischen Drama gebildete Erwartungshorizont des zeitgenössischen Rezipienten enttăuscht und der Effekt der Verfremdung hervorgerufen. Der Titel verliert jedoch nicht volllig seine medienspezifische Funktion der Vorinformation. Allerdings kommt sie nicht durch die sprachliche Sinnaussage zustande, sondern durch eine atmosphărische Einstimmung auf die Struktur des Ganzen mittels ästhetischer Effekte: die referentielle Sprachfunktion tritt hier zugunsten der phatischen und appellativen zurulck. 


\subsubsection{UNTERTITEL}

Die Deformation im Untertitel bezieht sich hauptsächlich auf den durch Vertrautheit mit literarischen Konventionen gebildeten Erwartungshorizont des Rezipienten hinsichtlich der Akteinteilung und des Spannungsverlaufs des Dramas. Einige von Witkiewicz' Stucken folgen der literarischen Tradition und geben im Untertitel sachliche Gattungsinformationen an, 2.B. : "Drama in drei Akten" (P); "Stuck in drei Akten" (WMD); "Tragödie in funf Akten mit Prolog" (MKiB). Doch vor allem in den späteren StUcken werden durch zusătzliche Attribute zur Genrebezeichnung Hinweise auf den Ton und Stil des Stuckes gegeben, wodurch recht ungewöhnliche, groteske Benennungen entstehen: "Cztery akty dost przykrego koszmaru" (dt.: Vier Akte eines ziemlich peinlichen Alptraums) (BD): "Nieeuklidesowy dramat $w$ czterech aktach" (dt.: Nichteuklidisches Drama in vier Akten) GW); "Tragedia sferyczna w trzech aktach" (dt.: Sphärische Tragödie in drei Akten) (KW); "Niesmaczna sztuka w dwóch aktach z epilogiem" (dt.: Geschmackloses Stück in zwei Akten mit Epilog) (Matka): "Sztuka bez tezy w dwóch aktach $z$ epilogiem" (dt.: Stuck ohne These mit einem Epilog) (SL); "Naukowa sztuka ze 'spiewkami' w trzech aktach" (dt.: Wissenschaftliches Stuck mit 'Liedchen' in drei Akten) (Sz).

Hăufig wird mit der Gattungsbezeichnung ein ironisches Splel mit den durch die literarische Tradition gebildeten Erwartungen des Rezipienten getrieben: so z.B. in "Dramat $w$ dwóch $i$ pół aktach" (dt.: Drama in zweieinhalb Akten) (Oni) - wobei der "halbe Akt" an Anfang des Stuckes steht und uber ein Drittel seines Inhalts ausmacht. Xhnliches geschieht auch, wenn Witkiewicz von einer "Komödie mit" (NiK) und einem "Drama ohne Lei(liell" spillitl (JMKW), wet It sellotis utsochat Arsopiolung an ooino "Thoorie der Reinen Form" das Stuck "Panna Tutli-Putli" 47 als ein "Libretto do operetki w trzech aktach w czystawej formie" (dt.: Operettenlibretto in drei Akten in relnlicher Form) bezeichnet.

Die Deformation in den Untertiteln spielt sich also auf der intertextuellen Ebene der Parodie und anderer Mittel der literarischen Verfremdung ab. Der Verfremdungseffekt erscheint primär als Folge von Enttăuschung

\footnotetext{
${ }^{47}$ Nur in Fragmenten erhalten.
} 
einer literarisch-kulturell gebildeten Normerwartung. Anders als beim Haupttitel spielt die Destruktion referentieller Leistungen der Sprache beim Untertitel eine sekundäre Rolle. 


\subsubsection{MOTTO UND WIDMUNG}

In einem großen Teil seiner Dramen verwendet Witkiewicz Motti und Widmungen. $^{48}$ Dieser Nebentext gehört zwar nicht direkt zum Titel, ist aber. schon rein optisch auf dem Titelblatt, eng mit ihm verbunden. Die thematischen und stllistischen Analogien zwischen Titel, Motto und Widmung in Witkiewicz' Dramen sprechen eigentlich dafur, die ganze Titelseite als einen zusammenhängenden Text zu betrachten ${ }^{49}$.

Der Bezug der Motti zum Stuck und zum Titel ist hăufig thematischer Art: das Motto spielt auf Elemente der Fabel oder auf die Figuren an (SL, BD). Beispielsweise basiert die Fabel des Dramas "Verruckte Lokomotive" (SL) auf einer ublichen "Dreiecksgeschichte": der Lokomotivfuhrer begehrt die Verlobte des Heizers. Die beiden Männer beschließen, eine Art "Gottesgericht" auszufuhren: sie wollen die Lokomotive zur Hochstgeschwindigkeit anheizen und bis zum Zusammenstoß mit einem entgegenkommenden Zug rasen. Die beiden Motti spielen auf ironische Weise auf Handlungsort und Konflikt des Dramas an:

"No more run'. Billy Buns in 'Treasure Island' RLS" und

"Aus den Geboten für Lokomotivfuhrer: '6. Frauen sollten sich von Maschinen fernhalten; auf keinen Fall sollten sie mit auf die Lokomotive genommen werden.' (Aus: 'Handbuch für rasende Lokomotivführer')". (Werke, V: 279)

Neben solchen inhaltlichen Anspielungen erfullt das Motto die traditionelle Funktion einer Interpretationshilfe in Hinblick auf die "Lehre" des Etllokoo odor dio moraliooho Dowortung for Figuren (7P in CW. $M$. $S B$ ). Auch in diesem Fall werden durch den hyperbolischen und verzerrten Charakter dieser BezUge groteske Effekte erzeugt. In dem Stulck "Gyubal Wahazar" z.B. spielt das Motto, ein vermeintliches Nietzsche-Zitat, auf den Titelhelden, einen pathologischen Tyrannen an: "Es ist doch teuer zu Macht zu kommen - Die Macht verdummmt." (Werke, IV: 587)

\footnotetext{
${ }^{48} \mathrm{Vgl}$. Kosny, 1989: $11 \mathrm{f}$ und die tabellarische Aufstellung S. 17. ${ }^{49}$ Darauf weist auch Kosny (1989: 11) hin.
} 
Die Widmung eines Werkes liegt konventionell schon außerhalb der literarischen Fiktion und ist daher im allgemeinen nur unter biographischem Aspekt interessant. Die meisten Dramen widmet Witkiewicz seinen Freunden und Bekannten, 2.B. B. Malinowski, L. Chwistek, u.a. In einigen Fallen durchbricht er auch diese Konvention, indem er eine Beziehung zwischen dem Titel, der Fabel des Dramas und der Widmung herstellt. "Narr und Nonne" z.B. wird gewidmet: "allen Verruckten der Welt (y compris anderen Planeten unseres Systems und ebenso Planeten anderer Sonnen der Milchstraße) und Jan Mieczysławski". Das Drama "W małym dworku", dessen Hauptfigur das Gespenst einer zu Lebzeiten leicht nymphomanischen Mutter ist, wird ironischerweise "der Mutter" gewidmet. Ähnlich wie beim Verhaltnis zwischen Titel und Motto fallt auch hier der groteske und ironischer Stll dieser Beziehungen auf. 


\subsubsection{FIGURENNAMEN}

Die Möglichkeiten der Figurendarstellung im Drama sind aus medienspezifischen Gründen reduziert: die Abwesenheit eines Erzăhlers ${ }^{1}$ fuhrt dazu, daß die Charakter- und Bewußtseinsqualităten der Figuren hauptsăchlich uber deren perspektivisch und situativ gebundenen Xußerungen vermittelt werden. Die psychologische und emotionelle Disposition der Figuren, der "Innenraum" ihres Bewußtsein und ihres Verstandes können nicht beliebig breit entfaltet werden. M. Pfister spricht in diesem Zusammenhang von dem "stărkeren Fragmentcharakter einer dramatischen Figur gegenuber einer Figur in einem Roman"2. Man könnte in Anlehnung an R. Ingarden ergänzend einwenden, daß die Figuren in einem epischen Werk nur in Form von sprachlich "entworfenen bloB intentionalen Sachverhalte<n> und <den> schematisierten paratgehaltenen Ansichten ${ }^{m^{3}}$ existieren, wăhrend die Figuren in einem aufgefuhrten Drama in concreto bestimmt werden, nachdem die Konkretisation durch die vorhergehende Regiearbeit erfolgt ist und durch die darstellerische Leistung der Schauspieler aktualisiert wird. Das Fragmentarische der dramatischen Figur besteht eigentlich nur für den lesenden Rezipienten und ergibt sich aus der gattungsspezifischen Ausrichtung auf die Auffuhrung und aus der. Mitautorschaft der Schauspieler und des Regisseurs. Doch gerade das gelesene Drama ist ja vorwiegend Gegenstand literaturwissenschaftlicher Arbeiten.

Die Begrenztheit der Informationen zur Figurencharakterisierung im Haupttext ${ }^{4}$ begr undet den relativ hohen informativen Wert der Bedeutungseinheiten im Nebentext und insbesondere im Personenverzeichnis, das ăhnlich wie der Titel die Funktion einer Vorexposition leistet. Der Nebentext nimmt, zumindest beim gelesenen Drama, die Funktion des auktorialen Erzăhlers

1 Um einer gattungstypischen Betrachtung willen soll an dieser Stelle von den neueren Experimenten mit epischen und lyrischen Formen im modernen Drama abgesehen werden.

2 Pfister, 1988: 222.

3 Ingarden, 1972: 341.

4 Die Begriffe Hauptext (fur Figurendialog) und Nebentext (fur Regieanweisungen), die $R$. Ingarden geprägt hatte (1972: 220), haben sich inzwischen in dramentheoretischen Arbeiten allgemein durchgesetzt, obwohl gegen die ihnen beiwohnende Wertung hăufig Vorbehalte erhoben werden. (Vgl. Hubler, 1973: 43f; Pfister, 1988: 35.) 
ein 5 . In Witkiewicz' Dramen geht $e^{6}$ ubrigens in seinem Umfang, Inhalt und Stil haufig uber die Funktion reiner Spiel- und Regieanweisungen hinaus. 7 Im folgenden sollen die Deformationsmöglichkeiten und -verfahren im Nebrentext, und zwar bei den Figurennamen in Personenverzeichnissen von Witkiewicz' Stlicken untersucht werden.

M. Pfister versteht unter "Figurenkonzeption das anthropologische Modell, das der dramatischen Figur zugrunde liegt, und die Konventionen seiner Fiktionalisierung und unter Figurencharakterisierung die formalen Techniken der Informationsvergabe, mit denen die dramatische Figur präsentiert wird. ${ }^{8}$ Dem "anthropologischen Modell", das wohl gleichbedeutend mit den "lebenslogischen Elementen" in Witkacys Terminologie ist, liegt ein bestimmtes Wissen um soziale und menschlich-organische Normen zugrunde, das dazu ruhrt, daß der Rezipient bei der Konkretisation der sprachlichen Bedeutung und beim Entwerfen fiktiver Figuren auf empirische Personen zurUckgreift. Das "anthropologische Modell" und die Konventionen seiner Fiktionalisierung und Ästhetisierung bilden also den Erwartungshorizont des Rezipienten in bezug auf die Konzeption der dramatischen Figuren. An diesen beiden Punkten wird wohl auch die von Witkiewicz theoretisch formulierte Deformation der Lebenslogik ansetzen.

Bei der auktorialen Figurencharakterisierung durch Namen unterscheidet $M$. Pfister zwischen expliziten - sog. "sprechende Namen" - und impliziten Verfahren - sog. "charakterisierende Namen", d.h. Namen, die den realen Konventionen der Namensgebung entsprechen und gleichzeitig indirekt die Figur charakterisieren, (2.B. der intrigante Sekretăr Wurm aus Schillers "Kabale und Liebe")".

Die "sprechenden Namen", deren Tradition bis in die antiken Komødien

5 Vgl. dazu: Pfister, 1988: 262ff.

6 Vgl. dazu: Kosny, 1988 und 1989.

7 Die Verstărkung der epischen Momente durch Ausdehnung des außerdialogischen Textes - der Name Nebentext scheint hier nicht mehr gerechtfertigt - ist eine typische Eigenschaft des modernen Dramas, angefangen bei den ausfuhrlichen Orts- und Personenbeschreibungen im naturalistischen Drama bis hin zu den Stucken von S. Beckett und P. Handke, in denen der "Haupttext", der Figurendialog, völlig entfallt.

8

Pfister, 1988: 240.

9 Vgl. Pfister, 1988: 263. 
reicht, haben nach $M$. Pfister die Funktion, "ein auktoriales Bewertungssignal <zu setzen: Namen wie z.B.> Witwouds ('Hătte-gern-Witz') und Petulants ('Mutwillig- Launenhaft') ${ }^{10}$ legen noch vor dem ersten Auftritt die Bewertungsperspektive der Rezipienten fest.

Eine weitere Funktion der "sprechenden Namen" besteht in der Auskunft uber typische Charakter- und Standesmerkmale. H. Kunstmann ${ }^{11}$ weist in diesem Zusammenhang darauf hin, daß die avantgardistische Namensgebung sich als Gegenbewegung zum Naturalismus entwickelte: wăhrend der Realismus und der Naturalismus das Auffällige und Typische vermieden und zum individuellen Wesen der Figur passende Namen gebraucht hătten, greife die Avantgarde - naturlich in abgewandelter Form - die antike Tradition der "sprechenden Namen" wieder auf.

Als eine dritte Funktion wäre noch der Hinweis auf die Figurenkonstellation zu nennen. Durch phonologische oder semantische Entsprechungen innerhalb der Figurennamen werden dem Rezipienten schon bei der Lekture des Personenverzeichnisses die Zusammensetzung der Konfliktgruppen suggeriert.

Zusammenfassend kann man feststellen, daß der Erwartungshorizont des Rezipienten, und damit auch der Gegenstand der Deformation, in bezug auf Figurennamen vom "anthropologischen Modell", d.h. von einem bestimmten Weltwissen um soziale und menschliche Normen und von literarischen Konventionen ihrer Fiktionalisierung und Ästhetisierung gebildet wird. Letzteres bedeutet fur den Rezipienten, und insbesondere fur den am klassischen bzw. naturalistischen Drama geschulten Zeitgenossen Witkiewicz', daß in bezug auf die "sprechenden Namen" Informationen uber auktoriale Wertungen, typische Charakter- und BewuBtseinseigenschaften sowie Konstellationen von Figuren erwartet werden.

Die originellen "sprechenden Namen" in Witkiewicz' Dramen haben immer wieder das Interesse der Forschung auf sich gelenkt. Die Namengebung wurde dabei hauptsăchlich unter etymologischen und lexikalischen Gesichts-

\footnotetext{
${ }^{10}$ Pfister, 1988: 94.

"Kunstmann, 1965: 383f.
} 
punkten untersucht. So weist $M$. Nowotna-Szybistowa ${ }^{12}$ nach, daß Witkacy sprachliches Material aus einer Vielzahl von Sprachen (Polnisch, Russisch, Englisch, Deutsch, Französisch, Italienisch, Spanisch, Ungarisch, Altgriechisch, Latein u.a.) spielerisch zu Phantasienamen zusammenfugte. Dieses Zusammenfugen blieb aber stets im Rahmen der morphologischen Normen des Polnischen, und der semantische Wert der Neologismen ist meistens transparent. H. Kunstmann differenziert Witkiewicz' Gestaltungsweisen der Figurennamen in: makkaronische, z.B. Halucyna Bleichertowa (Oni); etymologische, z.B. Chraposkrzecki (KW) - von chrapac (dt.: schnarchen) und skrzeczec (dt.: kreischen); Effekte, die auf dem "Unterschied' zwischen Schrift und Sprache, zwischen Optik und Akustik aufbauen", z.B. Sajetan Tempe (Sz) - von tepy, (dt. stumpf); und exotisch klingende, doch nicht authentisch exotische Namen: z.B. Radza Patakulo, Ksiąze (dt.: Fürst) Tengah (TM), Yabawa $(N T)^{13}$.

Im folgenden sollen die "sprechenden Namen" in Witklewicz' Dramen weniger unter lexikalischen und morphologischen Aspekten ${ }^{14}$ als im Hinblick auf ihre Wirkung und Funktion im Werkganzen untersucht werden.

In Witkacys Personenverzeichnissen werden die epischen Momente und der ästhetische Elgenwert dieses Nebentextes besonders deutlich. Die Figurenbeschreibungen muten wie Parodien auf die genauen Personenangaben im naturalistischen Drama an. Sie sind auf eine ironische Weise ausfuhrlich und genau: es werden pedantisch präzise Details angegeben uber Farbengebung, Kleidung, KörpergroBe, Haar- und Augenfarbe, Alter, Mimik, Gestik, Gesichtsausdruck, bei weiblichen Figuren meistens auch deren Wirkungsweise auf das andere Geschlecht ("attraktiv", "dămonisch" etc.). Doch die Ubergezauen Angaben gehen an der Funktion der Inszenierungsanweisung hăufig vorbei und viele der mitgeteilten Details sind fur die Kommunikationsstruktur unbedeutend, wie das folgende Beispiel aus dem Stuck "Tumor Mózgonicz" zeigt:

"Lord Arthur Persville - vierter Sohn des Fursten Osmond (der zukinftige Duke of Osmond, Marquis of Broken Hill, Viscount of Duris-

${ }^{12}$ Nowotny-Szybistowa, 1973.

${ }^{13}$ Kunstnann, 1965: $388 \mathrm{ff}$.

${ }^{14} \mathrm{Zu}$ deser Problemstellung sei v.a. auf die Arbeit von M. NowotnySzybistowa, 1973 verwiesen. 
deer, Master of Takoomba-Falls), der gröBte Dämon des Central and General Mathematical Office und der großte der nichtstrafbaren Verbrecher: der sogenannte 'King of Hells', König der Holle und der Spielhölle - (Amphibolie des Plurals von Hell). 33 Jahre alt. Der măchtigste Geometriker auf der Erdkugel. Ein Schuler Hilberts. König der Mode. In einer Cutaway-Kombination mit Zylinder, ein Spazierstock in der Hand. Das Gesicht eines Jünglings von ungewöhnlicher Schönheit. Rasiert, schwarze Augen. Ein stark brünetter Typ, etwa zwischen einem echten Lord und einem Strafkolonie-Individuum. Distinguierte Bewegungen. Die Augen lachen nie, wăhrend die wunderschön geformten, vollen Lippen, eingesetzt in einem zarten, doch ungeheuer starken Kiefer, das Lächeln eines dreijăhrigen Mădchens haben. AuBerdem ist das ein Mensch (falls man ihn Uberhaupt als Menschen bezeichnen kann), der die höllischste Eifersucht und den hollischsten Neid auf dem ganzen Globus auslost." (Werke, Iv: 232).

Wie das Beispiel zeigt, gehen die Personenverzeichnisse in den Dramen von Witkiewicz uber die Funktion reiner Inszenierungsanweisungen hinaus und bilden selbstăndige Prosastücke, die einen eigenen ăsthetischen Wert besitzen. Ihre Funktion in bezug auf das Drama ist einstimmender, appellativer Art: die von den Wortbedeutungen ausgelosten Assoziationen entwerfen noch vor Beginn des Stückes oder im gelesenen Drama ein Pandămonium grotesk-absurder Gestailen und setzen damit einen bestimmten Erwartungshorizont beim Rezipienten fest.

Auch die originellen, phantasievollen Figurennamen haben einen ausgesprochenen Lesecharakter. Wie schon erwähnt, ergibt sich ihre groteske Wirkung hăufig erst aus dem Unterschied zwischen Schrift und Aussprache. So erscheint der Name "Baron Vessanyi" (MKiB) in der Schrift als fremdsprachig. während er in der Aussprache an das polnische Wort "wieszany"16 erinnert. Der umgekehrte Fall tritt bei dem Namen des - laut Personenbe-

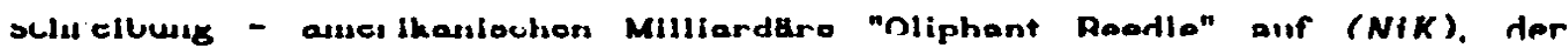
in der Schrift das polnische Wort "bydle" (dt.: Vieh) assoziiert - eine Wirkung, die bei einer amerikanischen Aussprache des Namens nicht zustandekommen würde. Ein weiterer Grund fü den Lesecharakter des Personenverzeichnisses ist die Uberlänge der Namen, die damit "gegen den Grundsatz der dialogischen Anwendbarkeit" verstoßen ${ }^{16}$. Der volle Name erscheint daher nur im Personnenverzeichnis, im restlichen Nebentext und im Dialog

${ }^{15} \mathrm{Dt}$. : auf gehăngter, gehenkter.

${ }^{16}$ Kunstmann, 1965: 386. 
wird dann eine Abkurzung verwendet, z.B. Kontradmirał Maksym Grygoriewicz kniaz Bublikow-Tmutarakanskij (NT) wird im Stuck selber als "admirat" bzw. "Eks-admirat" bezeichnet und von den Figuren mit der polnischen Anredeform "pan" oder mit der russischen "Maksym Grygoriewicz" angesprochen.

Der episch-auktoriale und hochinformative Charakter der Personennamen rechtfertigt die eingehende Untersuchung von deren Bedeutungselementen. Als theoretische Grundlage sollen im weiteren die von R. Ingarden unterschiedenen Elemente der Wortbedeutung herangezogen werden:

"1. der intentionale Richtungsfaktor,

2. der materiale Inhalt,

3. der formale Inhalt,

4. das Moment der existentialen Charakterisierung und manchmal auch

5. das Moment der existentialen Position." ${ }^{17}$

Besonders wichtig für diese Untersuchung ist Ingardens Differenzierung zwischen formalem und materialem Inhalt der Bedeutung ${ }^{18}$. Der materiale Inhalt bestimmt "die qualtatlve Beschaffenheit des Gegenstandes <...>, er "'weist' 〈...> dem intentionalen Gegenstande bestimmte materiale Merkmale 'zu' und 'schafft' inn dadurch im Verein mit dem formalen Inhalt der nominalen Bedeutung. ${ }^{19}$ Der formale Inhalt ubt dem Gegenstand gegenuber eine "formende Funktion" aus, indem er "das durch den materiellen Inhalt Bestimmte als eine formal bestimmte strukturierte Einheit, z.B. als ein 'Ding', eine 'Beschaffenheit von Etwas', ein 'ProzeB', ein 'Zustand' u. dgl. mehr behandelt". 20

Im folgenden soll der Beweis orbracht werden, daß in Witklewtcz' Figurennamen bel elner starken Verfremdung des materiellen Inhalts der formale Inhalt die notwendigen kommunikativen Funktionen lbernimmt.

In den traditionellen "sprechenden Namen" werden mit Hilfe von deren ma-

\footnotetext{
${ }^{17}$ Ingarden, 1972: 62f.

${ }^{18}$ Ingardens Beobachtung entspricht Ubrigens der von L. Hjelmslev 30 Jahre spăter formulierten Unterscheidung zwischen Form und Substanz jewells auf der Inhalts- und Ausdrucksebene der Sprache.

${ }^{19}$ Ebd.: 65 <Hervh. im Original>.

${ }^{20}$ Ebd.: $69 f$. <Hervh. im Original>.
} 
terialem Inhalt Informationen Uber typische Charakter- oder Standesmerkmale der Figuren erteilt. Vor dem Hintergrund des "anthropologischen Modells", d.h. durch Weltbezug, entwirft der Rezipient fiktive Figuren, die naturlich den empirischen Menschen ähneln. Bei Witkiewicz wird der materiale Inhalt stark verfremdet, so daß der Entwurf "lebenslogischer" Figuren unmoglich gemacht wird. Der formale Inhalt der Wortbedeutung kann aber vor dem Hintergrund literarisch-theatralischer Konventionen auf die Stellung der Figur in der Personenkonstellation und hăufig auch auf die Struktur des dramatischen Konfliktes verweisen.

Diese Aussage soll an der Figurenkonstellation in dem Drama "Gyubal Wahazar, oder Auf den Paßhbhen des Unsinns" verdeutlicht werden. Die Fabel sofern sie aus dem absurden Geschehen uberhaupt zu abstrahieren ist kann folgendermaßen wiedergegeben werden: der Ubermăchtige Diktator Gyubal Wahazar will sein Volk auf dem Weg gewaltsamer Entindividualisierung und Automatisierung zur vermeintlichen Gluckseligkeit in einer nivellierten Massengesellschaft fuhren. Er scheitert am Widerstand von mönchartigen Gruppen, die am Ende die Staatsgewalt Ubernehmen. Seine persönliche Stărke und Entschlossenheit werden aber auch durch seine văterlichen und sexuellen Gefuhle zu einer zehnjärigen Kindfrau ausgehöhlt.

Die angedeuteten Konflikte und die Personenkonstellation spiegeln sich in dem formalen Inhalt der Figurennamen wieder. Gyubal Wahazar ist ein reiner Phantasiename, der an seiner Form (konsonantische Endungen) als mănnlicher Name erkennbar ist und durch Assoziationen mit "Wesir" und dem ungarischen Vornamen "Gyula" (Julius) die vage Vorstellung eines "exotischen, großen Herrschers" hervorruft. Die Opposition "der Herrscher und die Beherrschten" wird durch die Opposition "fremdsprachige und polnische Namen" in der Namenform wiedergegeben. So tragen die Helfer Gyubal Wahazars fremdsprachig klingende Namen: die beiden Matressen Donna Scabrosa Macabrescu und Donna Lubrica Terramon, der Kommandeur der Leibgarde Baron Oskar von den Binden Gnumben, der Oberhenker Morbidetto und der Mediziner Józef Rypmann. Die beiden letzteren sind "sprechende Namen", doch ihre Aussage bezieht sich nur auf die Rolle im Stück, keinesfalls auf individuelle Charaktereigenschaften der Figuren. Die anderen Namen enthalten zwar semantische Merkmale ('macabre', 'terra'), doch sie ergeben keinen Sinn. Die Beherrschten, das Volk, tragen polnisch bzw. slawisch klingende Namen: der Muller Mikołaj Kwibuzda oder die Naherin Lidia Bochnarzewska. 
Eine mittlere Stellung nimmt dabei der Literat Fletrycy Dymont ein. Sein Name klingt zwar französisch, aber der Vorname hat eine polnische Endung und der Nachname enthält das polnische Wort "dym" (dt.: Rauch). Daruber hinaus erinnert er stark an den Namen des polnischen Schriftstellers W.S. Reymont.

Zu den Widersachern Wahazars gehören die Mönche: Unguenty, Pungenty, czterech Perpendikularistów, dwóch Pneumatików Bosych ${ }^{21}$. Auch in diesen Namen sind Seme enthaiten ('unguento'- Salbe, 'perpendicolare' - senkrecht), doch charakterisierend ist eigentlich die Namenform: die lateinischen Elemente rufen erstens das Bild von klosterlich-mittelalterlichen Ideologietrăgern hervor, welches die Rolle im dramatischen Konflikt festlegt, und deuten zweitens auf die Zusammengehörigkeit dieser Handlungstrăger innerhalb der Konfliktparteien hin.

Der Gruppe der bewußten, ideologisch bestimmten Feinde Wahazars steht die Gruppe entgegen, die das unbewußte, triebhafte Prinzip verkorpert. Dazu gehort v.a. die zehnjăhrige Kindfrau Swintusia Macabrescu, die Tochter von Donna Scabrosa Macabrescu und, wie zum Schluß angedeutet wird, von Gyubal Wahazar. Sie ubt eine geheimnisvolle Macht uber den Tyrannen aus: er wird durch die von inr erweckten văterlichen und sexuellen Gefuhle, seiner titanenhaften, brutalen Kraft beraubt. Der Name Swintusia ist das Feminimum des Wortes "swintuch" (dt.: Schweinehund, Schweinigel), enthălt also das Konnotat: 'sexuell' als 'unanstăndig'. Die diminutive Form weist auf die Kindlichkeit der Figur und schafft gleichzeitig eine Verbindung zu den anderen Diminutivnamen des Dramas: "Przyjemniaczek" (von "przyjem$n y^{\prime \prime}=$ nett, angenehm + die Diminutivendung -czek), "Jabuchna Musiołek" (Diminutivendung: -chna im Vornamen, der Nachname besteht aus "musiec" mussen und "aniołek" - Engelchen). Sie alle stehen im Drama in einer rătselhaften Opposition zu Wahazar und naturlich auch zu der Gruppe der Mornche.

Diese Beispiele sollten zeigen, daß Witkiewicz' "sprechende Namen" eigentlich gar nicht so viel sagen. Sie erfullen ihre Informationsfunktion nicht so sehr uber ihren materialen, d.h. die Beschaffenheit der Figuren bezeichnenden, Inhalt: die Bedeutung der Namen ist gering, allenfalls einstimmend-assoziativ (z.B. Swintusia) oder sie bezieht sich nur auf die

${ }^{21}$ Dt.: vier Perpendikularisten und zwei barfussige Pneumatiker. 
"Rolle" im Stuck. Letzteres ist zwar in seiner Wirkung komisch, aber in seinem Informationswert tautologisch und daher nichtig. beispielsweise wenn bei den Namen Rypmann und Morbidetto gleich deren Berufe angegeben werden als Mediziner und Henker.

Die eigentliche informative Funktion ubt der formale Inhalt der Namenbedeutung aus: durch ihn werden Personenkonstellationen und mogliche Konflikte angedeutet. Dadurch wird, durchaus im Sinne der Theorie der Reinen Form, der Abstraktionsgehalt dieser Stücke erhbht. Der Hinweis auf die Konstruktion, auf das Gemacht-Sein des Werkes liegt hier im Vordergrund und nicht die weltbezogene Aussage.

Die Bewußtmachung der Konstruktion wird noch deutlicher, wenn man das Personenverzeichnis des Stückes "Die Unabhängigkeit der Dreiecke" (NT) betrachtet. Eine Gruppe von Regierungsvertretern wird auf der formalen Ebene durch Elemente des Altgriechischen signalisiert, die auf witzige Weise mit polnischem Sprachmaterial vermengt sind. Es handelt sich um die zwei Anarchonten 22 (Anarchie + Archont): Krakaton (poln.: krakac - krăchzen) und Monoflakon (von Flakon oder flak - Darm); sechs Erarchen ${ }^{23}$ (vielleicht von gr. Ẍrar - Staatsschatz; auf jeden Fall die leicht erkennbare griechische Endung -arch). Die Zahl sechs kehrt in der Anzahl der exotischen Geliebten des Haupthelden wieder. Deren Namen ergeben sich aus den sechs Kombinationsmöglichkeiten der drei Silben: ya-, ba-, wa-: Yabawa, Wabaya, Bayawa, Wayaba, Yawaba, Bawaya.

Der Name des Haupthelden Viriel Pembrok ist eine phonetische Aufzeichnung in polnischer Schrift des englischen Ausdrucks "virile pen broke", der nach der Interpretation von D.C. Gerould ${ }^{24}$ auf die sexuelle und kunstlerische Impotenz des Helden hinweisen soll.

Eine stark verfremdende Wirkung hat auch die Verwendung von extrem vielen Sprachen bei der Namengebung innerhalb eines Stückes. In der "Unabhăngigkeit der Dreiecke" (NT) sind es neben Altgriechisch und Englisch: Italienisch (Semptembriusz Viviani), Russisch: Maksym Grygoriewicz kniaz Bublikow-Tmutarakanskij (von bublik - Kringel und dem im "Igorlied" erwăhnten Gebiet T'mutorokan') und eben die schon erwahnten exotisch klingenden

\footnotetext{
22 Poln.: dwóch Anarchontów.

${ }^{23}$ Poln.: Szesciu Erarchów.

${ }^{24}$ Gerould 1981b: 180.
} 
Phantasienamen. Die Vielzahl der verwendeten Sprachen hat eine desorientierende und antilllusionistische Wirkung: es wird verhindert, daß der Rezipient sich in Orts- und Zeithinsicht orientieren und in irgendeiner Weise in das Geschehen einfuthlen kann.

Nach R. Ingarden gehören zu den Elementen der Wortbedeutung auch die existentiale Position des Gegenstandes (im literarischen Werk ist sie immer fiktiv) und die existentialen Charakterisierungsmomente, die den Seinsmodus der Gegenstände (real, ideal, fiktiv) in "funktionaler oder expliziter Weise vermeinen." 25

In Witkiewicz' Personenverzeichnissen beobachtet man eine Vermischung der existentialen Charakterisierungsmomente, und zwar entweder innerhalb eines Namens oder innerhalb der Figurenkonstellation.

So treten z.B. in dem Drama "Janulka, die Tochter von Fizdejko" (JCF) Personennamen auf, die als in der Wirklichkeit moglich erscheinen und daher reale Charakterisierungsmomente enthalten, z.B. Alfred ksiąze (dt.: Fürst) de La Tréfouille, seine Frau Amalia de La Tréfouille, Joel Kranz und die zwölf litauischen Bojaren. Eine Vermischung der Seinsmodi wird erreicht in Namen, die zwar formal reale Charakterisierungsmomente haben, gleichzeitig aber Anspielungen auf bekannte literarische bzw. historische Personen beinhalten. Dazu gehören 2.B. die Namen der Hauptfiguren: Eugeniusz (Gienek) Pafnucy Fizdejko - laut Personenbeschreibung "kniaż Litwy i Białorusi" ${ }^{26}$, seiner deutschstămmigen Frau Elza Fizdejkowa und Tochter Janulka Fizdejkówna. Der Nachname der Füstenfamilie Fizdejko ist eine Anspielung auf den im zeitgenठssischen Polen sehr populären Roman von F. Bernatowicz: "Pojata, córka Lezdejki, albo Litwini w XIV wieku"27. Dieser 1826 entstandene Abenteverroman in Walter-Scott-Manier erschien 1898 in achter Auflage und wurde wahrscheinlich von Witkiewicz in seiner Kindheit gelesen. ${ }^{28}$ Die Angabe vertraulicher Verkleinerungsformen von Vornamen der Furstenfamilie (Gienek von Eugeniusz, Elza von Elisabeth, Janulka von Janina) ist ein zusătzlicher witziger Verfremdungseffekt. Reale Charakte-

\footnotetext{
${ }^{25}$ Vgl. Ingarden, 1972: 70.

${ }^{26}$ Dt.: Furst von Litauen und WeiBrussland.

${ }^{27}$ Dt.: Pojata, Tochter des Lezdejko, oder die Litauer im 14. Jahrhundert.

${ }^{28} \mathrm{Vgl}$. Gerould 1981b: 315.
} 
risierungsmomente und gleichzeitig Anspielungen auf fiktionale oder historische Personen enthalten auch Namen wie Bernard Baron v. Plasewitz (Clausewitz?) und Gottfried Reichsgraf von und zu Berchtoldingen (Götz von Berlichingen?) - laut Personenbeschreibung "Wielki Mistrz Neo-Krzyzaków ${ }^{29}$.

Neben diesen Namen, die gewisse reale Charakterisierungsmomente enthalten, findet man im Personenverzeichnis des Stuckes "Janulka, die Tochter von Fizdejko" reine Phantasienamen, in denen nur die poetische Funktion der Sprache ${ }^{30}$ dominiert: Haberboaz und Rederhagaz. Ihre Wirkung beruht auf der phonetischen Form (Kombination weniger, sich wiederholender Laute zu zwei Namen). Im Vordergrund steht also das formale Element, und das Bewußtmachen der Konstruktion hat eine ahnliche antiillusionistische Wirkung wie die oben erwăhnten Verfahren. Den realen Bezug stellt dann die Personenbeschreibung her: Haberboaz und Rederhagaz werden als Anhänger des Chassidismus und Helfer Joel Kranz' bezeichnet und bekommen durch diese Attribute einen realen Habitus.

Anders sieht es bei drei anderen Figuren aus: bei den zwei vogelartigen "postacie bez nog" und "naczelnik seansów" ${ }^{32}$ - laut Figurenbeschreibung: "czarownik z bajki. Nazywa się Der Zipfel" ${ }^{33}$. Im Unterschied zu den oben erwăhnten Namen, die noch reale Charakterisierungsmomente beinhalteten, muBte man das existentiale Charakterisierungsmoment dieser Bedeutungen als "phantastisch" ${ }^{34}$ bezeichnen. Der starke Verfremdungseffekt ergibt sich dabei aus dem Nebeneinander von "realen" (sogar quasi "historischen") und "phantastischen" Charakterisierungselementen innerhalb der Personenkonstellation eines Stuckes.

${ }^{29}$ Dt.: Großer Meister des Neo-Kreuzritterordens.

${ }^{30} \mathrm{Vgl}$. Jakobson, 1971.

${ }^{31}$ Dt.: zwei beinlose Gestalten.

${ }^{32}$ Dt.: Seance-Leiter.

${ }^{33}$ Dt.: ein Mărchenzauberer. Man nennt ihn Der Zipfel.

${ }^{34} \mathrm{R}$. Ingarden nennt nur reale, ideale und fiktive Momente der existentialen Charakterisierung. (Ingarden, 1972: 70). Die Begriffe "phantastische" und "intertextuelle" (s. weiter unten) Charakterisierungsmomente werden hier von mir eingefuhrt, um eine evidente Differenzierung innerhalb der "fiktiven" Charakterisierungsmomente Ingardens bezeichnen zu können. Die existentiale Position des von ihnen entworfenen Gegenstandes ist natürlich fiktiv. 
Ein anderer Kunstgriff Witkiewicz' bei der Deformation der Figurennamen ist die Verwendung von existentialen Charakterisierungsmomenten, die ich als "intertextuell" bezeichnen möchte ${ }^{35}$. Er besteht entweder im direkten Einsetzen von bekannten literarischen Figuren, z.B. Wyspianskis Chochoł (Sz), Lessings Minna von Barnhelm ${ }^{36}$ (SL) oder in einer Anspielung, z.B. Pandeusz Klawistynski ( $N(K)$ - der Vorname bezieht sich auf das polnische Nationalepos von A. Mickiewicz "Pan Tadeusz".

Die Vermischung der existentialen Charakterisierungsmomente (real, historisch, phantastisch, intertextuell) bei Figurennamen ist ein Kunstgriff, der in allen Dramen Witkiewicz' angewendet wird. Xhnlich wie das Konglomerat von Fremdsprachen innerhalb eines Namens oder der Personenkonstellation eines Stückes erzeugt es eine starke desorlentierende und antiillusionistische Wirkung. Die fiktive existentiale Position dieser Figuren wird dem Rezipienten explizit vorgefuhrt, sie wird nicht, wie im naturalistischen Drama, hinter dem illusionistischen Mantel einer scheinbaren Wirklichkeitsnăhe versteckt.

Bei der Reihe der Beispiele wird hier keine pedantische Vollstăndigkeit angestrebt, aber einige Kuriosităten aus dem Panoptikum der Figuren in den Dramen von Witkiewicz sollen noch genannt werden: Józef Maszejko (Anspielung auf den polnischen Maler Jan Matejko?) (WmD); Ludwig ksiąze (dt.: Fürst) von und zu Thurm und Parvis; Jack Rivers (MDC); Kapitan Fitz-Gerald ( $T M$ ); Juliusz II - mit der Regieanweisung: "papiez z XV wieku. Ubrany tak jak na portrecie Tycjana" ${ }^{37}(M)$; Mieczysław Walpurg (WIZ); Król Ryszard III ${ }^{38}$ (NW); Posąg (dt.: Statue) Alice d'Or; eine "geschlechtslose" Person namens Kobieton ${ }^{39}(P)$; Mumia Chinska (P); u.s.w.

${ }^{35}$ Vgl. o.a. Anm.

${ }^{36}$ Bei Witkiewicz: "Minna, hrabianka de Barnhelm".

${ }^{37}$ Dt.: Der Papst aus dem XV Jh. Angezogen wie auf einem Tizian-Portrait.

${ }^{38}$ Dt.: König Richard III.

${ }^{39} \mathrm{Dt}$. etwa: Frauon. 


\subsubsection{DIALOGFUHRUNG}

Nachdem in den vorangehenden Kapiteln die Deformationsverfahren in der Schicht der Bedeutungseinheiten auf der Ebene des Wortes (Personennamen) und der Wortverbindung (Titel) analysiert worden sind, soll im folgenden die Ebene der Satzzusammenhänge, d.h. die Technik der Dialogfuhrung und das Konstituieren des Textes untersucht werden.

Als exemplarischer Untersuchungsgegenstand wird dabei eine kurze Szene mit dem Titel "Negatyw szkicu" ("Negativ einer Skizze") herangezogen, die Witkiewicz bewuBt als ein reprăsentatives Beispiel fur sein formistisches Theater konzipiert und 1921 zusammen mit einem programmatischen Feuilleton in der "Gazeta Zakopanska" ("Zakopaner Zeitung") veröffentlicht hat. Dieses vom Autor als "Sketch" bezeichnete Stuck hat - seinem Titel entsprechend - einen ausgesprochen autoparodistischen Charakter und enthalt in komprimierter Form die wichtigsten Techniken der Dialogfuhrung, die Witkacy in seinen Dramen anwendet. Es eignet sich daher besonders gut fur eine exemplarische Analyse. Die Abgeschlossenheit des Werkes bietet zudem die Morglichkeit, die von Witkiewicz angewendeten Deformationsverfahren nicht nur paradigmatisch darzustellen, sondern auch in Beziehung zu der Struktur des Ganzen zu setzen.

Um das Zergliedern der nachfolgenden Ausfuhrungen durch längere Zitatabschnitte $z u$ vermeiden, soll das Stuck vorab mit einer Ubersetzung abgedruckt werden; im weiteren Text wird die Nurnmer der zitierten Replik angegeben.

1 Der polnische Text aus: Werke, II: 661-665. Die Ubersetzung stammt von der Verfasserin A.S. 
RUFIA DE PLOUGAVEC - lat 38. Ruda - RUFIA DE BESOUDEL - 38 Jahre alt. wsciekle ponętna.

Rothaarig - ungeheuer attraktiv.

TEMPORELLO i ROSPORESCU - pOde jrza-TEMPORELLO und ROSPORESCU - zwieni młodziency.

lichtige Junglinge.

EFEMER TYPOWICZ - starzec w czarnym EFEMER TYPOWITSCH - ein Greis im anglezie.

schwarzen, englischen Anzug.

FLETRYCY - poeta, ogolony zupełnie. FLETRIZIUS - ein Dichter, grundlich

Lat 30.

rasiert. 30 Jahre alt.

ROMUALD DE POKORYA-PĘCHERZEWICZ ROMUALD DE DEMUYT-BLASEWITSCH - ein

szlachcic lat 40 .

ARABELLA I BEZDENIA - młode, egzo-

tyczne księzniczki.

JABUCHNA MUSIOKEK - słuząca
Adliger von 40 Jahren.

ARABELLA I BODEENLOSA - junge, eXOtische Prinzessinen.

APFELCHEN MUBTCHEN - Dienerin.

Rufla sledzl w salonie. Rozmawia $z$ Rufla sitzt im Salon. Efemer Typo nia Efemer Typowicz. Jabuchna stol.wicz unterhält sich mit thr. Apfel-

1) RUFIA

Jabuchno, daj nam kawy.

2) JABUCHNA

Dobrze, prosze wielmoznej pani.

Wychodzl.

3) RUFIA

Teraz powiem ci otwarcie. Zginęlismy. Oni zaraz tu będą.

4) EFEMER TYPOWICZ

Schowaj wszystko! Wiesz, ze on ma twoje listy.

5)RUFIA

Te akcje sprzedałam. Cargo i embargo konto i dyskonto, para i kontrapara. We łbie mi się kręci.

6) EFEMER TYPOWICZ

wstając

Daj klucz!

7) RUFIA zrywajac sie

Nie dam! Ja jestem bądz co bądz kobieta!

8) EFEMER TYPOWICZ

Musisz!

Dusi ja za gardło. Wchodzi Fletrycy.

9) FLETRYCY

Dzien dobry!

Efemer dusi daleJ Rufie

10) EFEMER TYPOWICZ duszac

Dzien dobry. Nalej pan sobie kawy.

11) FLETRYCY nalewajac soble kawe Zbyt wiele akcji $w$ sztuce jest dowodem płytkosci autora. Kto jest tu autorem? chen steht.

1) RUFIA

Apfelchen, bring uns Kaffee.

2) APFELCHEN

Jawohl, Gnadige Frau. Sle geht ab.

3) RUFIA

Jetzt sage ich dir ganz offen. Wir sind verloren. Sie werden gleich hier sein.

4) EFEMER TYPOWITSCH

Verstecke alles! Du weiB, daß er deine Briefe hat.

5) RUFIA

Diese Aktien habe ich verkauft. Kargo und Embargo, Konto und Discounto, Paar und Kontrapaar. In meinem Kopf dreht es sich.

6) EFEMER TYPOWITSCH steht auf Gib mir den Schlussel!

7) RUFIA springt auf

Nein! Ich bin doch immerhin eine

Frau!

8) EFEMER TYPOWITSCH

Du muBt!

Er wirgt sie am Hals. Fletrizius kommt herein.

9) FLETRIZIUS

Guten Tag!

Efemer wirgt Rufla weiterhin.

10) EFEMER TYPOWITSCH wirgend

Guten Tag! Nehmen Sie doch Kaffee.

11) FLETRIZIUS schenkt Kaffee ein

$\mathrm{Zu}$ viel Handlung im Stlick beweist

die Oberflächlichkeit des Autors.

Wer ist hier der Autor? 
12) RUFIA wyrywając sie Efemerowi $\mathrm{Ja!} \mathrm{Ja}$ ! On tu nie jest winien!

13) FLETRYCY gładząc ja po głowie Uspokój się, moje dziecko. Ludzkosć jest tylko miazga, dostarczająca słów dla poetów.

Wchodza Temporello i Rosporescu 14) TEMPORELLO

Paradne sa te kobiety, stworzone przez księge Monelli Schwoba. Nigdy nie były ladacznicami, a jednak dzwigaja na sobie skutki tego okropnego fachu.

15) ROSPORESCU

Tak. skutki nigdy niebywałych wypadkow.

Siadaja

16) RUFIA

obłędnie

Maurycy Galaktos oniemiał ujrzawszy

w rękach nieznanego hermafrodyty

kule koloru swego spalonego ciała. (Wchodzl Jabuchna z nowa porcja kawy.) Moze panowie pozwola troche apo-transforminy?

Wstaje. Wchodzl Pęcherzewicz.

17) PECCHERZEWICZ

Nie znosze tych tragobykow i komediowotow. Sa to tylko nedzne mariowodaze piernatów kokosowych złudzen.

Rzuca się na Rufię $l$ zaczyna ją dusic.

18) EFEMER TYPOWICZ

Cha! cha! Teraz na pana kolej, panie Romualdzie!

Wychodzt, trzaskajac drzwlami. Wchodza ksteintczkl.

19) BEZDENIA

Jakiez to cudowne! Alez on ja zadusi! Ludzie są jak kwiaty.

20) ARABELLA

Niech dusi. Tak rozkosznie się czuję! Czyz nie widzisz, ze to sie tylko tak wydaje?

21) FLETRYCY

Tak. Siedemnascie psychicznostek katzenjammeru na minutę. Jest to tylko zazębianie się incydentów odwrotowych o pepowine rodzącego sie tytanka arystokratycznych ganglionów - w stosunku do komórki tkanki tacznej oczywiście.

22) RUFIA
12) RUFIA, entwindet sich Efemer

Ich! Ich! Er ist nicht schuldig!

13) FLETRIZIUS strelchelt thren Kopf Beruhige dich mein Kind. Die Menschheit ist nur ein Brei, der dem Dichter Worte liefert.

Temporello und Rosporescu treten ein 14) TEMPORELLO

Ulkig sind die Frauen, diese Schöpfungen des Buches von Monella Schwoba. Sie waren zwar niemals Dirnen, tragen aber die Konsequenzen dieses schrecklichen Faches.

15) ROSPORESCU

Ja, die Konsequenzen von niemals stattgefundenen Vorfallen.

Sie setzen sich

16) RUFIA im Wahn

Maurycy Galaktos verstummte, als er in den Hănden elnes unbekannten Hermaphroditen eine Kugel in der Farbe seines verbrannten Leibes sah. (Apfelchen tritt mit elner neuen Portion Kaffee eln) Darf ich ihnen etwas Apo-Transforminum anbieten?

Sle steht auf. Blasewitsch kommt hereln.

17) BLASEWITSCH

Ich hasse diese Tragostiere und Komodioochsen. Sie sind einfach nur elende Mariowăsser von Kokostrăumeunterbetten.

Er stüzt stch auf Rufla und beginnt sie zu wirgen.

18) EFEMER TYPOWITSCH

Ha! ha! Jetzt sind Sie dran, Romuald!

Geht hinaus und knallt die Tur zu. nie Prinzessinen kommen herein.

19) BODEENLOSA

Wie wunderbar! Er erwürgt sie ja! Die Menschen sind wie Blumen.

20) ARABELLA

Soll er doch wirgen. Ich fuhle mich so herrlich! Siehst du nicht, daß uns das alles nur so vorkommt?

21) FLETRIZIUS

Ja. Siebzehn Psychonheiten des Katzen jammers pro Minute. Es handelt sich nur um ein Verzahnen von umgekehrten Zwischenfallen mit der $\mathrm{Na}-$ belschnur eines Titanchens aristokratischer Ganglionen - natürlich im Verhältnis zur Bindegewebszelle 22) RUFIA 
Pusc mnie! Nie wiedziałam, ze Fletrycy jest tak uczonym. Masz klucz. W szafce na lewo...

Umiera

23) PĘCHERZEWICZ dysząc cięzko

$Z$ szybkoscia cyklonu przecina moje obszary nieznany hetyta. Zdobyłem nonsens zasadniczy.

24) ARABELLA

Zadusił ja. Jakiez to piekne!

25) BEZDENIA

Biedna pani de Plougavec!

26) TEMPORELLO

Lepiej chodzmy na spacer.

27) ROSPORESCU

Tak! Błękitne muszki obetrą skrzydełkami nasze spocone czoła.

\section{8) FLETRYCY}

Co? Wy chcecie isc? Teraz gdy ja zaczynam grac $w$ ciu-ciu-duszke?? Gdy perwersyjny rozczyn codziennosci, avec des points saillants nigdy nie dających się zasosowac objawien. zaczyna...

Pęcherzewicz przeblja go sztyletem. Fletrycy pada.

29) PĘCHERZEWICZ do kięzniczek $i$ pode jrzanych młodzienców.

Wynoscie sie. psiakrew! Testament jest mój. (Podnosi klucz z ziemi.) Tamcl wychodzą. Pęcherzewtcz rzuca sle do trupa Ruf(l.) Ja jeden cie kochałem! Ja jeden byłem $w$ stanie dac ci szczęscie. O! co za okropnosc!

Całuje ją. Rufia budzi się z omdlenia.

30) RUFIA

Ja tylko udawałam, zebys przestał mnie dusic. Kocham cie. (do Jabuchny Musiołek) Jabuchna! wynies trupka pana Fletrycego do lodowni.

Jabuchna spetnia rozkaz.

\section{EFEMER TYPOWICZ wchodząc}

Spózniliscie sie. Wyjałtem wszystkie papiery $z$ szafki $\mathrm{nr} 17$. $\mathrm{Na}$ kolana (Rufla $l$ Pęcherzewicz padaja na kolana) No - teraz ja wam pokazę!
Laß mich los! Ich wußte nicht, daß Fletrizius so gebildet ist. Hier ist der Schlussel. Links im Schrank...

Sie stirbt.

23) BLASEWITSCH schwer atmend

Mit Zyklongeschwindigkeit uberquert ein unbekannter Hethiter meine Răume. Ich habe den Urnonsens erobert.

24) ARABELLA

Er hat sie erwurgt. Ist das schön!

25) BODEENLOSA

Die arme Frau de Besoudel!

26) TEMPORELLO

LaB uns doch lieber spazierengehen.

27) ROSPORESCU

Ja! Die himmelblauen Fliegen werden mit ihren Flügeln unsere schweißnassen Stirnen trocknen.

28) FLETRIZIUS

Was? Ihr wollt gehen? Jetzt, wo ich beginne Tschut-Tschut-Seelchen zu spielen. Wo die perverse Alltăglichkeitslosung, avec des points saillants von niemals anwendbaren offenbarungen beginnt...

Blasewitsch durchbohrt thn mit dem Dolch. Fletrizius fält hin.

29) BLASEWITSCH zu den Prinzessinen und zwielichtigen Junglingen.

Hinaus mit euch, verdammt! Das Testament gehört mir. (hebt den Schlussel auf. Die anderen gehen hinaus. Blasewitsch stiurzt zu Rufias Leiche.) Ich war der einzige, der dich liebte! Ich war der einzige, der dir Gluck zu geben vermochte. O! wie schrecklich!

Er kubt sle. Rufla erwacht aus inrer Ohnmacht.

30) RUFIA

Ich hab nur so getan, damit du aufhorst mich zu wilirgen. Ich liebe dich. (zu Apfelchen MuBtchen) Apfelchen! bringe die Leiche von Herrn Fletrizius in den Kuhlraum.

Apfelchen fuhrt den Befehl aus.

31) EFEMER TYPOWITSCH elntretend

Ihr habt euch verspătet. Ich habe alle Papiere aus dem Schrank $\mathrm{nr}$. 17 herausgenommen. Auf die Knie (Rufla und Blasewitsch fallen auf die Knie) $\mathrm{Na}$ - jetzt werde ich es euch zeigen! 
Die stilistische und semantische Diskontinuităt fallt in dem angefuhrten Beispiel auf den ersten Blick auf.

Doch es wird trotzdem eine gewisse Bedeutungsstruktur wahrgenommen, die vor dem Hintergrund der dramenstrukturellen Konventionen als ein rudimentärer dramatischer Konflikt konkretisiert wird. Will man semiotische Begriffe zu Hilfe nehmen, so kann eine vage ausgeprăgte narrative Struktur diagnostiziert werden. Entsprechend dem Aktantenmodell von A.J. Greimas bzw. V. Propp werden die Positionen des Helden (Efemer Typowicz) und des Gegners (Pęcherzewicz) besetzt. Das Wunschobjekt bildet offensichtlich der geheimnisvolle Inhalt des Schrankes $\mathrm{Nr}$. 17, der einmal als "wichtige Briefe" (4), dann als "Wertpapiere" (5) und zum Schluß als "Testament" (29) bezeichnet wird. Die Position der etwas widerwilligen Helferin Ubernimmmt Rufia, die den Schlussel zu dem besagten Schrank besitzt und deshalb vom Helden und vom Gegner abwechselnd gewurgt wird.

Diese rudimentär vorhandene narrative Struktur bildet das "Ruckgrat" des Textes und verhindert, daß das Ganze in ein Aggregat von diskreten Zeichen zerfallt. Die uber den ganzen Text verstreuten Hinweise auf den dramatischen Konflikt garantieren einen Zusammenhang, der auf einer spannungsvollen Erwartung seiner Auflosung beruht.'

Entsprechende Bruchstucke von narrativen Strukturen sind eigentlich in jedem Drama Witkiewicz' vorhanden, so daß man immer eine Fabel und sogar ein Thema vage rekonstruieren kann. Daß diese Dramatik trotzdem weit von jeglicher konventionellen, mimetischen Kunst entfernt ist, liegt an ihrem Verzicht auf "lebenslogische" Motivierung der Ereignisse und Handlungen.

1 Dabei läBt sich eine interessante Parallele zur Theorie der Reinen Form feststellen. Wie im vorangehenden Kapitel ausgefuhrt, spielte das Phänomen "Spannung" in Witkacys kusttheoretischen Uberlegungen eine wichtige Rolle. In der Malerei war die "Richtungsspannung" ein wichtiges kompositorisches und rezeptionslenkendes Mittel und der einzige Grund, der lebenslogische Elemente in der Kunst rechtfertigte: durch die Wirklichkeitsăhnlichkeit einiger Formen sollte im Bild eine Blickrichtung (z.B. oben und unten) bestimmt und damit die Rezeptionstătigkeit gelenkt werden. In der Theorie der Begriffe wurde der Begriff der Spannung von Witkiewicz leider unzureichend erläutert. nahm aber einen hohen Stellenwert ein: die erzeugte Spannung war ein Maßstab fur den künstlerischen Wert eines Begriffes. Sie stellte sich beim Zusammenfugen widersprüchlicher oder unsinniger Bedeutungen, d.h. bei der MiBachtung lexikalischer Solidarităten ein. ( $\mathrm{Vgl}$. dazu Kapitel 2.2.1. in dieser Arbeit). 
In seinem 1921 erschienenen und dem zeitgenossischen, avantgardistischen Denken nahestehendem Aufsatz "Uber den Realismus in der Kunst" bezeichnete R. Jakobson "die konsequente Motivierung, die Rechtfertigung von poetischen Konstruktionen" als ein Merkmal des Realismus". Die konsequente Ablehnung dieser Darstellungstechnik ist bei der formalistischen Haltung Witkiewicz' durchaus verstăndlich. Sie wird in seinen theoretischen Schriften häufig thematisiert, hauptsăchlich in den kategorischen Absagen an die "lebenslogischen" Elemente in der Kunst und gehört zu den wichtigsten darstellerischen Merkmalen seiner Dramen und Romane. Der Verzicht auf Motivierung soll noch im Kapitel uber die Schicht der Gegenständlichkeiten năher erlăutert werden. ${ }^{3}$

Für die Satzzusammenhänge, die an dieser Stelle untersucht werden, hat der programmatische Verzicht auf realistische Motivierung eine wichtige Folge: er fuhrt zur Verletzung der Präsuppositionen. Dieses Phănomen liegt den meisten grotesken Effekten in den Mikrostrukturen von Witkiewicz' Dramen zugrunde. Die Prăsuppositionen sind Voraussetzungen, die einer Aussage zugrundeliegen und vom Sprecher mitbehauptet werden. Man unterscheidet zwischen semantischen (die vermeinten, doch unausgesprochenen Bedeutungen in einer Außerung) und pragmatischen Präsuppositionen (durch den situativen Kontext mitvermeinten Bedeutungen). In den 70er Jahren, im Zusammenhang mit der Entwicklung der generativen Transformationsgrammatik, war die Prăsuppositionsproblematik Gegenstand heftiger Diskussionen und intensiver Forschung in der Linguistik. Ein fur die vorliegende Arbeit wichtiges Ergebnis der linguistischen Prăsuppositionsuntersuchungen ist der Beweis, daß ein gewisses gemeinsames Weltverständnis und Hintergrundwissen der Kommunikationspartner die notwendige Grundlage jeder sprachlichen Kommunikation ist." In sprachlichen Kunstwerken dagegen können die Präsuppositionen zu ästhetischen Zwecken eingesetzt werden. So werden beispielsweise im Theater des Absurden ${ }^{5}$ an Dialogen,

2 Jakobson, 1981: 390.

3 Vgl. Kapitel 4 in dieser Arbelt.

4 Vgl. dazu Petofi/Franck (Hrsg.), 1973.

5 Besonders eindrucksvolle Beispiele fur Dialoge, die auf dem Prinzip der Prasuppositionsverletzungen aufgebaut sind, findet man in $E$. lonescos "Die kahle Săngerin", etwa in der 4. Szene, als zwei Ehepartner in einem längeren Dialog staunend herausfinden, daß sie seit Jahren ver- 
die nach dem Prinzip der Verletzung von Prăsuppositionen aufgebaut sind, die Kommunikationsunfahigkeit der Dialogpartner oder das Unvermb̈gen der Sprache, wahre Kommunikation entstehen zu lassen, anschaulich vorgefuhrt. Ferner können Prăsuppositionsverletzungen zu komischen oder grotesken Effekten fuhren. Beim letzteren Verfahren erweist sich Witkiewicz als wahrer Meister.

In der angefuhrten Beispielszene gehort zu den Prăsuppositionsverletzungen die makabre Behandlung der Mord- und Gewalttaten. Wenn man davon ausgeht, daß in unserem Wirklichkeitsmodell Gewalt und Mord tabuisiert sind und die Bedeutungen "ungewöhlich", "furchterregend", "kriminell" implizieren, so wirken einige Äußerungen sehr befremdlich, beispielsweise die Repliken 8, 9 und 10 und der dazugehorige Nebentext. Die dreifache Wiederholung des Ausdrucks "er wirgt sie" steht in einem grotesken Kontrast zu der folgenden Replik "Guten Tag. Nehmen Sie doch Kaffee" und zum Nebentext "Fletrizius schenkt sich Kaffee ein", die einen situativen Kontext von "gewöhnlich", "friedlich", "geborgen" implizieren. Xhnliches ist auch in den Repliken der beiden Prinzessinnen (19, 20, 24) oder der "zwielichtigen Junglinge": Temporello und Rosporescu (26, 27) feststellbar. Besonders makaber wirkt die einer Liebeserklärung folgende Äußerung von Rufia: "Apfelchen, bringe die Leiche" von Herrn Fletrizius in den Kuhlraum" und weiter unten im Nebentext: "Apfelchen fuhrt den Befehl aus" (30).

Als eine Verletzung der Präsuppositionen wären auch die Repliken 6 und 7 zu betrachten. In Rufias Absage wird als Begrundung "ich bin doch schließlich eine Frau" eine semantische Voraussetzung dieser Aussage suggeriert, die weder durch lexikalische noch durch außersprachliche Bezüge nachvollziehbar ist.

Die Verletzungen der Prăsupposition gehören zu den Hauptmerkmalen der Dialogfuhrung in Witkacys Dramen. Neben den grotesken oder komischen Wirkungen, die dadurch ausgelöst werden, wirkt es sich auf die Satzzusammenhănge und auf die Struktur des Werkes aus: der Text bekommt dadurch elnen

heiratet sind, zusammenleben und eine gemeinsame Tochter haben. ( $\mathrm{ggl}$. Hempfer, 1976).

- Im Polnischen besteht ein zusätzlicher, schwer ubertragbarer sprachlicher Effekt: das Wort "Leiche" (trup) steht im Deminutiv (trupek), dt.: etwa "Leichlein". 
inkohärenten, polysemischen Charakter.

Ein weiterer Komplex im Problemkreis der Deformationen auf der Ebene der Satzzusammenhănge sind die Sprachfunktionen und dabei insbesondere die metasprachliche Funktion ${ }^{7}$. Sie spielt eine dominierende Rolle und zwar sowohl in der angefuhrten Beispielszene als auch in den Ubrigen Dramen. Dabei wird die Sprache entweder explizit thematisiert oder implizit anhand von zahlreichen Wortspielen, Neologismen, Normverletzungen in ihrer Funktionalităt und Struktur "vorgefuhrt". Als Beispiele wăren hier die Repliken 5 und 16 zu nennen. Der "Text" hat hier eine zyklischgeschlossene Struktur, er wird durch ein Spiel selbstbezuglicher Zeichen untereinander ohne referentielle Funktion konstituiert. Diese Verfahren erinnern Ubrigens stark an postmoderne Ästhetik ${ }^{8}$ und können als einer der Grüde für die Zuordnung Witkiewicz' zur Postmoderne gelten.

Neben ihrer sinndestruktiven Wirkung haben solche Autothematismen die fur das moderne Drama typische antlillusionistische Funktion. Die Ablehnung der Guckkastenbuhne und des Illusionsprinzips in postnaturalistischen Theatertheorien fuhrte zur verstärkten Anwendung von Effekten, die auf eine Vermittlung zwischen den beiden Kommunikationssystemen im Drama hinzielen. Ein beruhmtes Beispiel dafur ist L. Pirandellos Stuck "Sechs Personen suchen einen Autor" (1921), in dem die neue theatertheoretische Haltung auf der gegenstăndlichen Ebene thematisiert wird. In der germanistischen Forschung haben sich für diese Verfahren die Begriffe "epische Elemente" oder "Vefremdungseffekte" eingeburgert, die von B. Brecht in seinen sehr einfluBreichen Theaterkonzepten geprägt worden sind'.

M. Pfister stellt in diesem Zusammenhang folgendes fest:

"Im außeren Kommunikationssystem ist die metasprachliche Funktion nicht auf den primären Sprachcode bezogen, sondern auf die Konventionen dramatischer Texte als eines Systems sekundärer Codes. Nicht

7 Entsprechend der Differenzierung von Jakobson, 1971.

8 Vgl. z.B. die Interpretation von P. Burger: Das Verschwinden der Bedeutung. Versuch einer postmodernen Lektüre von Michel Tournier, Botho StrauB und Peter Handke. In: Kemper (Hrsg.), 1988: 294-312.

9 Die neuere Brecht-Forschung berucksichtigt allerdings in komparatistischer Weise die Tradition und die Inhalte der Begriffe des Epischen im Drama und der Verfremdung. Vgl. Knopf, 1988: 378-388. 
die Thematisierung der Sprache, sondern die Thematisierung von Drama und Theater läBt also hier die metasprachliche Funktion dominant werden."

In der angefuhrten Beispielszene ist der ganze mittlere Teil, und insbesondere die Repliken 11 und 13 von der Dominanz einer so verstandenen metasprachlichen Funktion geprägt.

Witkiewicz wendet in seinen Dramen fast das ganze Instrumentarium der aus dem epischen Theater Brecht'scher Prägung bekannten Kunstgriffe an. An erster Stelle wăre hier die Thematisierung des Stückes 2.B. in der Art des von V. Sklovskij formulierten Prinzips des "obnaženie priema" ("Bloßlegung des Verfahrens") zu nennen. Ein schönes Beispiel dafur findet man am Anfang des Dramas "Im kleinen Landhaus". In den ersten Repliken wird ein bekanntes Motivierungsverfahren der Exposition bzw. des analytischen Dramas "bloßgelegt": ein Neuankömmling fragt nach den Neuigkeiten, die Antwort beinhaltet dann die expositionellen Informationen fü das Publikum.

\begin{abstract}
ANETA:
Na, Onkel. Erzăhl mal, wie hat sich das eigentlich zugetragen. NIBEK helter:

Also, dann machen wir einfach eine ganz normale Exposition. Betrachten wir das alles als ein Drama, als den Anfang eines Dramas. (zieht an der Pfelfe) Ausgezeichneter Tabak. Also, die Geschichte ist ganz einfach: meine Frau, deine Tante Anastasja, ist gestorben (springt auf und klopft die Pfelfe am Stiefel aus) und das ist alles! Verstehst du! Und daß du nie wieder danach fragst! <...>" (Werke, IV: 421)
\end{abstract}

7." weiteren antilllusionistischen Verfremdungseffekten gehoren Anspielungen auf die Auffuhrungssituation beispieisweise mittels Anrede bzw. Beschimpfung des Publikums. So sagt z.B. Sajetan (Sz) inmitten einer längeren Replik von vortraghaftem Charakter: "<...> Doch zuruck zum letzten Punkt, selbst wenn unser heutiges vollig schwachsinniges Publikum bei jedem lăngeren, doch dafur gescheiten Gespräch das große Kotzen kriegt." (Werke, V: 519)

Ganz besonders zahlreich sind in Witkiewicz' Stucken Selbstthematisierun-

${ }^{10}$ Pfister, 1988: 165. 
gen des Autors in Form autoparodistischer, selbstironischer Anspielungen auf die eigenen philosophischen Werke und die Theorie der Reinen Form". Das reicht von der namentlichen Erwăhnung Witkacys uber bruchstuckhafte Zitate und Begriffe seiner Philosophie und Ästhetik bis hin zu langen Disputen der Figuren Uber die Theorie der Reinen Form (Sz). In dem Drama "Oni" wird die Kunsttheorie schließlich sogar zum Element der Thematik und des Sujets. Neben Witkiewicz' Werken werden aber auch andere zeitgenössische Autoren genannt und zitiert, interessanterweise sind das hăufig - aber nicht ausschlieBlich - Autoren, die auch in Witkiewicz theoretischen Arbeiten eine Rolle spielen (Carnap, Husserl, Wittgenstein, Micinski).

Die Funktion dieser Kunstgriffe geht uber die Wirkung Ublicher antiillusionistischer Verfremdungseffekte hinaus. Eine Parallele dazu findet man auf der Ebene der Wortbedeutung: wie oben am Beispiel der Personennamen ausgefuhrt, gehört die Vermischung der Seinsmodi (fiktiv, realistisch) innerhalb eines Wortes oder einer Wortkonstellation (Personenverzeichnis) zu den wichtigsten Deformationsverfahren in der Schicht der Bedeutungseinheiten. Doch diese intertextuellen Bezlige haben keinen diskursiven Charakter. Sie erscheinen vielmehr als ein spielerisches Ineinandergleiten und Schweben zwischen den beiden Bereichen: Fiktionalität und Realität. Das erinnert eher an die avantgardistische Zielsetzung, Kunst in Leben zu uberfuhren, die in extremster Form in der Aktionskunst verwirklicht wurde ${ }^{12}$.

Als letzter Punkt bei der Untersuchung der Satzzusammenhänge in Witkiewicz' Dramen sollen hier noch die Fragen der Textkohärenz und Bedeutungskonstltution erobrtert werden.

Nach găngigen textlinguistischen Erkenntnissen entsteht der Sinn bzw. die referentielle Leistung eines Textes durch Monosemierung der einzelnen

\footnotetext{
${ }^{11} R$. Fieguth leitet daraus eine neue interessante These fur die alte Debatte um das Verhältnis zwischen Witkiewicz' Dramentheorie und -praxis ab. Danach handelt es sich nicht um ein Verhaltnis von Theorie und Anwendung, sondern um intensive intertextuelle Bezllge zwischen den beiden Textsorten. In den Dramen wird die Theorie der Reinen Form weiterdiskutiert und ironisch gewertet. (Vgl. Fieguth, 1987b: 157-172).

${ }^{12}$ Vgl. dazu: Burger, 1974.
} 
Bedeutungen im Kontext und durch die Einbindung der Einzelbedeutungen in einen aufgrund kognitiver Schemata und eines außersprachlichen Weltwissens gebildeten Referenzrahmen ${ }^{13}$. Als ein geeignetes Instrument zur Analyse von Textkohărenz fuhrte A.J. Greimas ${ }^{14}$ den Begriff der Isotopie ein. Nach Greimas wird der textkonstitutive Bedeutungszusammenhang durch die Rekurrenz von identischen oder ăhnlichen Bedeutungseinheiten (sog. Klasseme) auf der syntagmatischen Achse erzeugt. Ein kohărenter Text entsteht durch die Entfaltung von Isotopien, d.h. von hierarchischen Klassemfügungen. Greimas' Isotopiebegriff ist zwar in seiner textkonstitutiven Bedeutung nicht unumstritten, doch durch sein textanalytisches Potential entwickelte er sich rasch zur Grundlage von struktural-semiotischen Textanalysen $^{15}$.

Er soll auch dieser Untersuchung zugrundegelegt werden. Dabei liegt es nahe, daß bei der Analyse von Satzzusammenhăngen in Witkiewicz' Dramen nicht die Isotopiekonstitution und -entfaltung, sondern die Isotopieverfremdung im Vordergrund stehen wird.

Eine der Moglichkeiten von Isotopieverfremdung ist die Isotopievarlation, die von Greimas am Beispiel seines vielzitierten Toilettenwitzes $^{16}$ beschrieben wird. Sie besteht in einem "Kurzschluß" von zwei Isotopien, der aufgrund von phonetischer oder semantischer Ähnlichkeit eines ihrer Glieder (meistens eines Wortes) ausgelost wird. Die schlagartig einsetzende Erkenntnis der unerwarteten zweiten Bedeutungsstruktur hat eine entlarvende, hăufig auch komische oder befremdende Wirkung, die das Phănomen der Isotopievariation zur Grundlage der sog. "Freud'schen Versprecher" und zahlreicher witze macht.

Witkiewicz verwendet die Isotopievariation in seinen Texten hăufig zur Erzeugung von komischen oder grotesken Effekten und zur Entlarvung des Unterbewußtseins der Figuren. Nicht selten dient die Isotopievariation der Verhinderung der Textkohärenz und hat durch den direkten Verweis auf das Artefakt, auf die bewuBte Konstruktion des dargestellten Geschehens

${ }^{13}$ Vgl. 2.B.: Bellert, 1970.

${ }^{14}$ Greimas, $1966 / 1971$.

${ }^{15}$ Vgl. dazu: Keller/Haffner, 1990; Schulte-Sasse/Werner, 1977.

${ }^{16}$ Greimas, A.J.: Die Isotopie der Rede. In: Kallmeyer u.a. (Hrsg.), 1974: 128. 
eine antiillusionistische Wirkung. In der angefuhrten Beispielszene liegt eine Isotopievariation in den Repliken 11 und 12 vor. Es werden hier uber das Wort "schuldig" ("winien") die Klasseme "Autor" und "Ubeltäter" und damit auch auf ironische Weise die Bedeutungsstrukturen "Wirklichkeit" und "Fiktionalităt" zusammengeschlossen.

Eine andere Form der Isotopieverfremdung bilden Texte mit schwach gefigter Isotopie. Sie konstituieren keinen ubergreifenden Sinn, haben aber eine in gewisser Weise wirklichkeitsnahe, assoziative Struktur: sie erinnern an die Rede eines psychisch Kranken oder an Träume. Ein solcher Fall liegt in der Replik 5 vor.

Die extremste Form von Isotopieverfremdung stelllen schließlich völlig isotopielose Texte dar, die aus diskreten Semen ohne jeglichen Zusammenhang bestehen. Diese Form von Isotopiedeformation wird zusätzlich verstärkt durch den Einschub von völlig sinnlosen Neologismen, die an die dadaistische Manier erinnern, sowie von ungeworhnlichen bzw. widersprüchlichen Wortzusammenstellungen. In seiner Sprachtheorie ${ }^{17}$ maß Witkiewicz gerade solchen Wortgebilden einen hohen künstlerischen Wert zu: da es dem Rezipienten nicht gelingt, die vom Signifikanten hervorgerufene Vorstellung durch den Bezug auf die außersprachliche Wirklichkeit aufzuheben, werden eine länger andauernde geistige Dynamik und Spannung hervorgerufen. Witkiewicz betrachtet daher eine Konstruktion von Signifikanten bei gleichzeitiger Deformation semantischer Zusammenhănge zwischen den dazugehörigen Signifikaten als ein geeignetes Mittel, um Spannungen, die von einzelnen Worten oder von Wortgruppen ausgehen, auszulosen und aufrechtzuerhalten. Eine solche Dynamik innerhalb von Wortgruppen mubte dem Text einen formalen Zusammenhang auch auBerhalb der referentiellen Bezuge verleiten. Die relevanten Beispiele in der angefuhrten Beispielszene (die Repliken 16, 17, 21) geben einen Einblick in die praktische Ausfuhrung von Witkiewicz' ästhetischen Vorstellungen.

Bei der Beobachtung der Wirkungsweise solcher deformierenden Kompositionsverfahren wird allerdings neben der dynamischen, spannungserzeugenden Wirkung noch ein zusätzlicher, medienspezifisch bedingter, Effekt deutlich. Durch die Dualităt der Kommunikationssysteme bei dramatischen Texten kann beim Rezipienten der Eindruck hervorgerufen werden, daß die

${ }^{17} \mathrm{Vgl}$. dazu Kapitel 2.2.1. in dieser Arbeit. 
Figuren auf der Bühne sich in einem ihm unzugănglichen Idiolekt verstăndigen. Das Schauspiel bekommt dadurch den Charakter eines mystischen, esoterischen Zeremoniells.

Die dramenspezifischen Gegebenheiten spielen fur die Analyse von Satzzusammenhängen auch in einem anderen Zusammenhang eine große Rolle. Grundsătzlich kann das übergangslose Zusammenfüen von verschiedenen Isotopien als literarische Montage ${ }^{18}$ bezeichnet werden. Dieses Verfahren gehört zu den konstitutiven Darstellungsmitteln in der Gegenstandsschicht und dabei insbesondere in den Raum-Zeit-Strukturen und im antikausalen Fabelverlauf ${ }^{19}$. Das Montageprinzip bestimmt auch die Dialogfuhrung. Doch die isotopieverfremdende Wirkung entfaltet sich vollständig eigentlich nur innerhalb einer Replik. Im Dialogganzen tritt diese Wirkung abgeschwächt hervor, denn semantische Richtungswechsel und das Aufeinanderprallen der Kontexte bis hin zur Stichomythie werden im allgemeinen als dialogspezifisch betrachtet ${ }^{20}$. Auf diese Weise bekommen die im äußeren Kommunikationssystem inkohärent wirkenden Repliken durch die Perspektivenvielfalt und die situativen Kontexte eine quasi-mimetische Begründung. Darüber hinaus wird der Zusammenhang der Rede durch zahlreiche phatische, expressive und appellative Äußerungen hergestellt. Alle diese pragmatischen bzw. dramenspezifischen Aspekte begrunden zwar keine semantischen, aber doch gewisse formale Satzzusammenhänge ${ }^{21}$. Doch seine referentielle Funktion fur das äußere Kommunikationssystem erfullt der Text nicht, er bleibt im Ganzen inkohärent, polysemisch. Seine eigentliche Bedeutung besteht in der ästhetischen Funktion, die durch unterschiedliche Kategorien und Effekte zustande kommt. Dazu gehören 2.B. die antilllusionistischen Momente, die durch Hinweise auf die fiktionale Seinsweise der entworfenen Gegenstände und durch Bewußtmachung der Konstruktion entstehen. Ferner das Groteske, das durch die Deformation von "lebenslogischen" und literaturkonventionellen Elementen ausgelöst wird. Und schließlich bil-

${ }^{18}$ In diesem Sinne wird Montage von Link (1985: 138) definiert.

${ }^{19} \mathrm{Vgl}$. dazu Kapitel 3.2.2. in dieser Arbeit.

${ }^{20}$ Auf dieses strukturell-pragmatische Kriterium des Dialogs hat zuerst J. Mukaxovsky (1967: 116f) hingewiesen.

${ }^{21}$ Die Möglichkeit von Zusammenhängen aufgrund der Satzform wird auch von R. Ingarden (1972: 161) in Betracht gezogen. 
det die Spannung (ausgelöst entweder durch die narrativen Strukturen oder durch besondere Wortzusammenstellungen) ein entscheidendes strukturelles Element in Witkiewicz' Dramen ${ }^{22}$.

${ }^{22} V_{g l}$. dazu Kapitel 4 in dieser Arbeit. 


\subsection{DIE SCHICHT DER DARGESTELLTEN GEGENSTXNDLICHKEITEN}

\subsubsection{FIGUREN}

Wie bei der Darstellung der Theorie der Reinen Form hăufig hervorgehoben, sieht Witkiewicz den ästhetischen Wert eines Dramenelementes nicht in seinem gegenstăndlichen Inhalt', d.h. in seinem semantisch-semiotischen Weltbezug, sondern in seiner Făhigkeit, im Zusammenspiel mit anderen Elementen des Kunstwerkes, formal-konstruktive Einheiten zu bilden.

Was bedeutet eine solche Auffassung für das grundlegende Element des Dramas - fur die dramatische Figur?

Der gegenstăndliche Inhalt einer Figur besteht wohl - im Sinne Witkacys in denjenigen Konzeptionselementen, die einem mimetischen Prinzip entspringen: d.h. in der "Lebenslogik" der Handlungsmotivierung und in der "Wirklichkeitsnăhe" der Psychologie. Anders ausgedruckt: zum gegenständlichen Inhalt einer dramatischen Figur gehören die Elemente, die M. Pfister als das der Figurenkonzeption zugrundeliegende "anthropologische Modell $^{\prime 2}$ bezeichnet. Der gegenstăndliche Inhalt, den Witkiewicz in seinen theoretischen Erwagungen als asthetisch irrelevant betrachtet, wird in seinen Dramen verschiedenen Deformationsverfahren ausgesetzt ${ }^{3}$.

Doch welche Elemente bilden den formalen bzw. künstlerischen Inhalt und was macht die kunstlerische Form einer dramatischen Figur aus?

In der Malerei sind es die Farben, in der Musik die Töne, die Witkiewicz als rein formale Elemente bezeichnet: es sind also die primären werkkonstitutiven Elemente, losgelost aus ihren semiotischen Funktionen und Bezu-

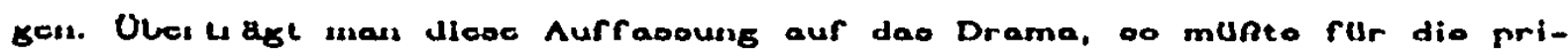

1 Witkiewicz unterscheidet in der Theorie der Reinen Form zwischen einem gegenstandlichen und einem formalen bzw. kunstlerischen Inhalt. Der gegenstăndliche Inhalt setze sich aus den "lebenslogischen", sich auf die außerkUnstlerische Wirklichkeit beziehenden Elementen zusammen und sei fur die ästhetische Erfahrung irrelevant. Der kunstlerische Inhalt dagegen bestehe aus den rein formalen Elementen wie Farben und Formen und die Komposition dieser Elemente vermittele die metaphysische Erfahrung der Reinen Form.

Vgl. dazu Kapitel 2.1.3. und 2.1.4. in dieser Arbeit.

2 Pfister, 1988: 240.

3 Vgl. dazu weiter unten. 
mären, künstlerischen Elemente das Kriterium der Werkkonstitutivităt und Funktionalităt ausschlaggebend sein. Wie schon bei der Darstellung der Theorie der Reinen Form erwahnt, betrachtet Witkiewicz das Drama als eine Zeitform: das reine Geschehen als ein abstraktes "Werden in der Zeit" soll dem Rezipienten die ăsthetische Erfahrung der Reinen Form vermitteln. Der künstlerische Inhalt einer Figur wurde demnach in der Handlungsträgerfunktion bestehen: in der Făhigkeit der Figur, konfigurationskonstitutiv und situationsmodifizierend $\mathrm{zu}$ wirken und somit die Grundlagen für die năchsten Schichten des Werkes - Fabel und Geschichte, Raumund Zeitstrukturen - zu schaffen.

Ruft man sich Witkiewicz' strukturalistischen Formbegriff in Erinnerung Form wird von ihm als etwas aufgefaßt, das Beziehungen zwischen einzelnen Elementen und Erscheinungen schafft, ihnen eine Einheit verleiht ${ }^{4}$ - so kann die Form auf der Ebene der dramatischen Figuren als eine potentielle Interaktionsstruktur des Personals aufgefaßt werden.

Die vorangehenden Uberlegungen sollen die Grundlage fur die nachfolgende Untersuchung der Figurenkonzeptionen und -konstellationen in Witkiewicz' Dramen werden. Von großem Interesse sind dabei insbesondere Fragen nach den Deformationsverfahren beim gegenständlichen Inhalt sowie nach den strukturalen Eigenheiten der Gesamtkomposition.

Vgl. dazu Kapitel 2.2.3. in dieser Arbeit. 


\subsubsection{FIGURENKONZEPTION}

M. Pfister versteht unter "Figurenkonzeption das anthropologische Modell, das der dramatischen Figur zugrunde liegt, und die Konventionen seiner Fiktionalisierung und unter Figurencharakterisierung die formalen Techniken der Informationsvergabe, mit denen die dramatische figur prăsentiert wird." 5

Bei der Analyse der Figurennamen ${ }^{6}$ ist schon auf die verschiedenen Verfahren in der Schicht der Laut- und Bedeutungseinheiten hingewiesen worden, die Witkiewicz bei der auktorialen Charakterisierung seiner dramatischen Figuren (Personenbeschreibung im Nebentext und sprechende Namen) anwendet, und die alle eine verfremdende, antiillusionistische Wirkung erzeugen. Im Lichte der auktorialen Charakterisierung erscheinen die Figuren als ein Pandamonium grotesk-absurder Gestalten, die außerhalb jeglicher biologisch-psychologischer Wahrscheinlichkeiten existieren. Im folgenden soll die Untersuchung der Figurenkonzeption mit der Analyse der figuralen Charakterisierung $^{7}$ in der Schicht der dargestellten Gegenständlichkeiten ergănzt und vertieft werden.

Wohl das auffallendste Deformationsverfahren auf der Ebene der Personenkonzeption in Witkiewicz' Dramen ist die Inkonstanz psychlscher und physischer Eigenschaften. Dieses Verfahren, das in der Theorie der Reinen Form mehrmals gefordert und erörtert wurde, hat nichts mit dem im konventionellen Drama hăufig auftretenden Phănomen der moralischen Entwicklung und Bildung der Charaktere gemeinsam. In dieser Hinsicht haben die Figuren in Witkiewicz' Dramen einen ausgesprochen statischen Charakter. Sie sind - wie L. Sokół zutreffend bemerkt - "'fertig', im Laufe des Stuckes entwickeln sie sich nicht psychisch, sondern probieren verschiedene Reaktionsmbglichkeiten auf bestimmte Reize oder Situationen aus und răso-

5 Pfister, 1988: 240.

6 Vgl. dazu Kapitel 3.1.2. in dieser Arbeit.

7 Die Begriffe "figurale" und "auktoriale Charakterisierung" stutzen sich auf die differenzierte Darstellung der verschiedenen Techniken der Figurencharakterisierung von M. Pfister (1988: 253ff). 
nieren uber ihre Erlebnisse, Uber ihr psychisches Inneres" ${ }^{8}$. Die Theorie der Reinen Form macht deutlich, daß Witkiewicz eine rationalistische Bildungs- und Aufklärungsintention wie die des konventionellen Dramas völlig fern lag. Die Veränderung der psychischen und physischen Eigenschaften der Figuren zielt vielmehr auf die Zerstörung der Theaterillusion und Hervorrufung grotesk-absurder Effekte, die den Rezipienten auf der Ebene des UnterwuBtseins ansprechen wollen. Das Verfahren, das dabei in erster Linie angewendet wird, ist die Verfremdung des anthropologischen Modells und der literarischen Konventionen, die den Erwartungshorizont des Reziplenten hinsichtlich dramatischer Figuren weitgehend bestimmen.

Die extremste und augenscheinlichste Form nimmt die Figurendeformation dann an, wenn sie sich auf die physischen Eigenschaften der Figur bezieht. So kann z.B. eine Figur im Laufe des Stuckes thr Geschlecht wechseln. In dem Stuck "Maciej Korbowa i Bellatrix" beispielsweise ist das Geschlecht der Titelhelden schon vom Namen her unbestimmt ${ }^{9}$; wăhrend der Handlung wird - laut der eindeutigen Regieanweisungen - Bellatrix gelegentlich zum Mann, und Maciej Korbowa zur Frau. In dem Stuck "Pragmatyści" wird die Verănderlichkeit des Figurengeschlechts explizit im Personenverzeichnis angekundigt, und zwar erstens durch den sprechenden Namen "Kobieton" (dt. etwa: Frauon) und zweitens durch folgende Personenbeschreibung: "Frauon - eine geschlechtslose Person, doch die Betonung liegt eher auf der Weiblichkeit" (Werke, IV: 198).

Ein weiteres wirkungsvolles Deformationsverfahren ist die Reverstbiltikt des Todes. Der Tod ist in Witkiewicz' Stucken keinesfalls ein endgultiges Ereignis: die Figuren werden wieder lebendig und nehmen mit absurd wirkender Selbstverstăndlichkeit aktiv am Buhengeschehen teil. Daruber hinaus wird das Todesmotiv in einer Art und Weise behandelt, die von dem konventionellen tragisch-ernsthaften Darstellungsmodus und dem "Weltbild" des Rezipienten völlig abweicht. Auch dieses Verfremdungsverfahren trägt daher zu dem grotesken Charakter der Stucke Witkiewicz' im hohen MaBe bei. Der unkonventionelle, verfremdende Einsatz des Todesmotivs und seine asthetischen Effekte werden von Witkiewicz in seinen theoretischen Schriften breit erörtert und in seinen Stucken hăufig praktiziert.

8

Sokót, 1973: 128.

${ }^{9} \mathrm{~V}$ gl. Kapitel 3.1.1.1. in dieser Arbeit. 
Als Beispiel wăre hier insbesondere die Titelheldin des Dramas "Wasserhuhn" (KW) zu nennen. Das Drama beginnt mit einer grotesken Hinrichtungsszene: die Titelheldin steht unter einem Laternenmast und verlangt sehr energisch von ihrem, verständlicherweise verunsicherten, Verlobten Edgar, erschossen $z \mathrm{u}$ werden ${ }^{10}$ :

"Nun mach doch ein Experiment.

<...> Der Tod bedeutet mir nichts - das ist richtig, aber ich will ja gar nicht sterben. Doch das Leben bedeutet mir genausowenig wie der Tod. Am meisten quălt mich das Stehen unter diesem Pfahl hier." (Werke, $V:$ il).

Nach einer existentialphilosophisch angehauchten Diskussion Uber den Lebens- und Todessinn schießt Edgar zweimal und die Titelheldin kommentiert mit "unveränderter Stimme": "Der erste Schuß daneben, der zweite mitten ins Herz" (Werke, V: 13). Es folgt noch ein kurzes Gespräch mit dem plotzlich erscheinenden Kind Tadzio und nach der ruhigen Ankündigung: "ich sterbe jetzt" gibt die Heldin ihren Geist auf. Im zweiten Akt erscheint sie wieder lebendig auf der Buhne und nimmt fortan an der weiteren Handlung teil. Dabei wird ihre "Auferstehung" weder realistisch motiviert (etwa durch das Motiv des "unerwarteten Uberleben des Helden", wie man es aus wiederaufgelegten Fernsehserien kennt), noch ruft sie bei den ubrigen Figuren größeres Erstaunen hervor. Die Titelheldin nimmt ganz selbstverständlich am weiteren Geschehen teil.

Witkiewicz' Behandlung der Motive des Todes und der Auferstehung steht außerhalb eines mimetischen Darstellungskanons. Sie kann aber auch nicht auf die "primitive" Lust auf Schabernack zurUckgefuhrt werden, die dem Avantgardekünstler von seinen Zeitgenossen hăufig unterstellt wurde. Gerade in dem Stuck "Das Wasserhuhn" wird deutlich, daß die Motive der Hinrichtung und der Auferstehung in Ubergeordnete Strukturen eingebunden sind. Dazu gehort zum einen die Thematik des Dramas: Edgars innerer Kampf zwischen dem Wunsch nach titanenhaftem, skrupellosen Ubermensch-Dasein

${ }^{10}$ Dabei ergibt das semantische Merkmal "Laternenmast" im Zusammenhang mit dem Namen der Heldin einen ironischen Nebeneffekt - in der polnischen Sprache wird dem Lexem "Kurka Wodna" (dt.: Wasserhuhn) aufgrund der phonetischen Ahnlichkeit das Konnotat "kurwa" (dt.: Hure) beigelegt.

Vgl. dazu auch die genauere Analyse der Figurennamen in Kapitel 3.1.2. in dieser Arbeit. 
und -Handeln und seinen menschlich-moralischen Schranken, die das Töten verwerfen, wird an seinen Zweifeln, Selbstvorwürfen im Zusammenhang mit dem Mord an der Verlobten demonstriert. " Zum anderen ist es die zirkelartige Handlungsstruktur des Dramas, in die das unkonventionell behandelte Todesmotiv eingebunden ist: in der Schlußszene findet, ăhnlich wie in der Anfangsszene, erneut eine Hinrichtung statt; die Heldin wird wieder doch diesmal gegen ihren Willen - von Edgar erschossen.

Noch wesentlich wirkungsvoller als im "Wasserhuhn" ist das Verfahren der Todesreversibilităt in dem Drama "Narr und Nonne" (WIZ) durchgefuhrt. Die Hauptfigur, der Dichter Mieczysław Walpurg, Insasse einer Irrenanstalt, begeht in der vorletzten Szene Selbstmord, indem er sich an den Gittern seiner Zelle erhängt. In der nachfolgenden Szene kommt er, gepflegt und in eleganter Kleidung, zur Tur seiner Zelle herein und verblufft die um seine Leiche versammelte Trauergemeinde. Der Absurditătseffekt könnte kaum frappierender sein: laut einer ausdrulcklichen Regieanweisung des Autors sind nun sowohl Walpurg als auch seine Leiche gleichzeitig auf der Buhne. An der nachfolgenden Schlägerei zwischen den Anwesenden ist auch Walpurgs Leiche beteiligt: "Alle vier wälzen sich auf dem Boden und dreschen nach Kräften aufeinander ein. In diesen raufenden Haufen ist auch Walpurgs Leiche einbezogen, die sich schlaff zwischen ihnen bewegt." (Werke, V: 276).

Auch in diesem Fall könnte man Bezulge auf die Thematik des Stuckes sehen: Walpurg als Insasse einer Irrenanstalt verkörpert die einzig mögliche Existenzform eines wahren, absoluten Kunstlers, nămlich die jenseits der bürgerlich-gesellschaftlichen Normalităt. Ein gesellschaftlich anerkannter Walpurg - worauf sein elegantes Außeres in der letzten Szene hinweist - hat mit dem wahren Kunstler Walpurg, nichts gemeinsam: seine erste Existenzform ist fur inn "gestorben". Diese thematische Korrespondenzen zeigen, daB - ăhnlich wie im Fall des "Wasserhuhns" - die enorme groteske Wirkung des unkonventionell behandelten Todesmotivs nicht nur um des Einzeleffektes wegen inszeniert wird, sondern in einer ubergeordneten Dramenstruktur eingebunden ist. Eine solche organische Einheit des Werkes hat freilich wenig mit dem konventionellen, auf einem mimetischen Dar-

\footnotetext{
"Eine genauere Analyse der Fabel und des Sujets von "Wasserhuhn" erfolgt im Kapitel 3.2.2. in dieser Arbeit.
} 
stellungsmodus aufbauenden Drama gemeinsam. Statt die Erkenntnis des Rezipienten uber Einfühlung in eine realitătsnahe Buhnenillusion herbeizufuhren, wird ihm mittels Allegorie der Sinngehalt anschaulich-konkret vorgefuhrt. Anders aber als in konventioneller, etwa barocker Literatur, wird dieser allegorische Sinngehalt gleichzeitig durch die ihn begleitenden Absurditătseffekte in Frage gestellt bzw. quasi "entideologisiert".

Neben solchen augenscheinlichen Beispielen für die Inkonstanz der physischen Eigenschaften wie die Veränderlichkeit des Geschlechts und Reversibilităt des Todes gibt es eine Reihe von Merkmalen fur die mangelnde psychische Identität der Dramenfiguren. Ein wichtiges Charakteristikum der Witkiewicz'schen Figuren ist die innere Widerspruchlichkelt ihrer psychischen Eigenschaften. Wenn man der Beurteilung ihres Verhaltens und ihrer Charakterzüge das anthropologische "lebenslogische" Modell zugrunde legt, so erscheint die Paradoxie als das tragende Element ihres Wesens. ${ }^{12}$ Besonders deutlich wird das an den titanenhaften männlichen Figuren (z.B. Tumor Mózgowicz oder Gyubal Wahazar), die einem stăndigen Wechsel zwischen extremer Macht und Ohnmacht, Energie und Passivităt, Kraft und Schwäche unterworfen sind. Der Ubermăchtige Diktator Gyubal Wahazar beispielsweise, der eine gewaltsame Willkürherrschaft uber sein Volk ausubt, und der von sich behauptet: "Ich bin wie Gott. Ich allein herrsche uber alles und ich bin fur alles verantwortlich, und das nur vor mir selber." (Werke, IV: 598), gerät zeitweise völlig unter den Einfluß des zehnjăhrigen Mädchens Swintusia. Eine wellenartige Bewegung stellt auch der Wechsel zwischen Wahazars ubermenschlichen Energieausbruchen und den Zuständen absoluter Passivitát, sogar Apathie dar. Wahazar, von dem sein Arzt Rypmann sagt: "Der Mensch hat ubermenschliche Krafte. 〈...> er scnlast eine Stunde, manchmal eineinhalb Stunden pro Tag. Und arbeitet wie sechzig Dampfnilpferde." (Werke, IV: 596), erlebt auch Phasen volliger Ohnmacht und Schwäche. Diese Apathie fuhrt schlieBlich zu seiner Entmachtung und Ermordung, die von ihm selbst herbeigefuhrt und inszeniert werden. Die wellenartige Bewegung zwischen Wahazars Energieausbruchen und seiner

${ }^{12}$ Auf die innere Widersprüchlichkeit der Figuren in den Dramen von Witkiewicz ist in der Forschung schon mehrmals hingewiesen worden (z.B. Błonski, 1973a: 15ff: Sokót, 1973: 135ff). 
Apathie, sowie zwischen Phasen gewaltsamer Machtaustbung und volliger Unterordnung unter Swintusia bestimmen, nach einer Interpretation von $D$. C. Gerould ${ }^{13}$, die rhythmische Struktur des Stulckes. Durch die pulsierende Verlagerung der Handlungsdynamik zwischen dem Diktator und dem Volk entsteht eine wellenartige Struktur der dramatischen Aktion und Spannung, die zusătzlich noch durch die abwechselnd zentrifugale (zu Wahazar hin) und zentripentale Bewegung der Volksmassen auf der Buhne unterstrichen wird.

Ein solches Wechselspiel zwischen extremer Dynamik und Apathie ist fur eine Reihe von Witkiewicz' Figuren charakteristisch: neben dem schon erwăhnten Titan-Typus wie Gyubal Wahazar und Tumor Mózgowicz gehören dazu obwohl bei ihnen der Kontrast nicht so evident ist - auch der Typus des Künstlers und der dămonischen Frau.

Die Widerspruchlichkeit in der Psyche der Figuren außert sich aber auch in deren Handlungen und Zielen. In Witkiewicz' Dramen verachten die Machthaber die Macht (z.B. Gyubal Wahazar, Maciej Korbowa); die intellektuellen Genies den Verstand (z.B. Tumor Mózgowicz); die Verliebten wenden sich nicht dem Objekt ihrer Zuneigung zu, sondern betrügen es - obwohl sie dabei leiden - mit einem Dritten (2.B. Janulka und Mistrz) etc.

Trotz der grotesken Effekte solcher Deformationsverfahren vernimmt man in Witkiewicz' Figurenkonzeptionen archetypische Inhalte und zeitgenठssische Erkenntnisse in der Tiefenpsychologie, etwa S. Freuds Thesen Uber Verdrăngungs- und Sublimierungsmechanismen oder A. Adlers Theorie des Minderwertigkeitskomplexes ${ }^{14}$. Der psychoanalytische Hintergrund ist sowohl in der schon erwăhnten Zerrissenheit und Widerspruchlichkeit der Figuren spurbar, als auch in der sehr stark ausgeprăgten erotischen Thematik. Das verleiht den Dramen eine tiefere thematische Dimension, die zwar immer wieder angedeutet, gleichzeitig aber mit Hilfe grotesker oder ironischer Kunstgriffe destruiert wird. Ein einheitlicher psychologischtheoretischer Hintersinn bei den Figuren in den Dramen Witkiewicz' kann

${ }^{13}$ Gerould, 1981b: $216 \mathrm{ff}$.

${ }^{14}$ Die Psychoanalyse und insbesondere die Theorien von S. Freud waren Witkiewicz bekannt. Er begegnete ihnen zum ersten Mal 1913, als er eine schwere psychische Krise durchmachte und von dem Freudianer Dr. K. Beaurain in Zakopane behandelt wurde. Wie seine Korrespondenz beweist, beschäftigte er sich seit dieser Zeit viel mit S. Freud. 
nicht dingfest gemacht werden. Die Figurenkonzeption erinnert eher an die postmoderne Negation der Individualităt und Subjektivităt des Ichs. Witkiewicz' Figuren sind weder individuelle Charaktere, denen ein biologisches oder gar traditionell-humanistisches Modell zugrunde lăge, noch Repräsentanten sozial-politischer Positionen. Sie erscheinen vielmehr und entsprechen somit den dramentheoretischen Äußerungen Witkiewicz' als willkürliche Konstrukte aus isolierten psychisch-physischen Einzeleigenschaften und als marionettenhaften Träger von szenisch-konstruktiven Funktionen. Der fiktive Seinsmodus der Figuren wird jederzeit deutlich signalisiert.

An die postmoderne Dekonstruktion des Helden erinnert auch ein weiteres Verfremdungsverfahren in Witkiewicz' Stucken, namlich der Identitätswechsel der Figuren. Die Motive der Verkleidung, Verwechslung, des Inkognito erscheinen in fast allen Dramen: uberraschend und weder realistisch noch thematisch motiviert, ăndern die Figuren mitten im Stulck ihre Indentităt. In der "VerUlckten Lokomotive" (SL) beispielsweise entpuppt sich am Ende des ersten Aktes der Heizer Mikołaj Wojtaszek als Travaillac und der Lokomotivfuhrer Zygfryd Tengier als Karol Tréfaldi - beide sind weltweit gesuchte Schwerverbrecher. Die Entlarvung wird von den Hauptfiguren ironisch-antiillusionistisch kommentiert:

"TRAVAILLAC:

Sicher, wir alle müssen uns stăndig verăndern. Doch stellen Sie sich das mal vor: wir unterhalten uns hier daruber, und dort, in irgendeinem der Waggons unseres Zuges ist jemand, der eine ahnliche Gesahirhte alls der Reisekriminalbibliothek liest. Komisch!

TREFALDI:

Möglich, aber so ein Zufall verringert weder die Große unserer Gedanken noch die Merkwurdigkeit unserer Begegnung." (Werke, V: 292)

Die Inkonstanz psychischer und physischer Eigenschaften in ihren verschiedenen, oben beschriebenen Variationen: Reversibilitat des Todes, Inkonstanz des Geschlechts bei einer Figur, innere Widersprüchlichkeit der psychischen Eigenschaften, Identitătsdestruktion und -wechsel zeigen ganz deutlich, daß die Figuren in den Dramen Witkiewicz' nicht als menschliche Individuen konzipiert worden sind. Ganz im Gegenteil: die im naturalistischen Drama dominante individualistische Form der Figurenkon- 
zeption, die uber eine Fulle von charakterisierenden Details im Bereich der Sprache, Aussehen, Verhalten. Biographie etc. eine Spezifizierung der Figur uber ihre soziale oder psychologische Typik hinaus erreichen wolIte, wird von Witkiewicz durch Ubersteigerung des Individuellen ins $\mathbf{A b}$ surde parodiert und ironisiert. Seine "Individuen" haben nicht nur die soziale und ideologische Typik, sondern auch die anthropologischen und biologischen Normen verlassen.

Genausowenig kann man bei den Figuren Witkiewicz' von sozialen Typen sprechen. Zwar treten in seinen Dramen Vertreter bestimmter sozialer Klassen auf: das Volk und die Herrschenden (GW), die Arbeiter, das Burgertum und der Adel ( $S z$ ). Doch auch in diesem Fall wird durch die Deformation eine Bezugnahme auf die empirische Wirklichkeit verhindert. Das wirkungsvollste Verfahren, das Witkacy zu diesem Zweck anwendet, ist das Vertauschen der Soziolekte zwischen den verschiedenen sozialen Stănden und Gruppen. So fuhren Vertreter der Unterschicht betont niveauvolle Gesprăche uber philosophische und wissenschaftliche Themen (etwa die Schuster in Sz oder der Heizer und Lokomotivfuhrer in SL), wahrend die Vertreter der Intellektuellen oder des Adels sich eines primitiv-ordinären Jargons bedienen (z.B. die Fürstin Irina Wsiewołodowna Zbereznicka-Podberezka in Sz). Als Beispiel sollen hier einige Repliken der Repräsentanten des Volkes in der ersten Szene von "Gyubal Wahazar" angefuhrt werden:

"1. WEIB graues Kopftuch, in Lumpen:

Es geht hier um die vollige Entwertung jeglicher Bewertung von Fakten. <...>

2. WEIB rotes Kopftuch, in Lumpen:

Jawohl. In einem Staat des sechsdimensionalen Kontinuums sind Kriterien eine wahrlich allzu banale Sache. (...>

2. WEIB:

Eine Verrückte! Sie glaubt, daß keine von uns die Theorie von Einstein kennt. Heute lernt man doch die absolute Differentialrechnung schon in der Mittelschule."

(GW in Werke, IV: 592)

Fur die Figurenkonzeption in den Dramen Witkiewicz' spielen also weder das individualistische noch das sozial-typologische Prinzip eine wesentliche Rolle. Die reduzierte Psychologie und das Stereotype der Figuren, die in der Forschung mehrmals bemerkt und untersucht worden sind, sind 
wohl eher als ein parodistisch-ironisches Zuruckgreifen Witkiewicz' auf die durch innerliterarische Tradition vorgeprägten dramatischen Typen zu erklăren.

Auf das Stereotype der Witkiewicz'schen Figuren wiesen als erste schon seine Zeitgenossen $\mathrm{T}$. Boy-Zelenski ${ }^{15}$ und $\mathrm{K}$. Irzykowski ${ }^{16}$ hin. Irzykowski kritisiert an den Dramenfiguren Witkiewicz' die Reduktion der Psychologie auf einige wenige Eigenschaften und die hyperbolische Verzerrung dieser Eigenschaften als einen Ruckgriff auf Uberholtes. Einem in der naturalistischen Ästhetik verwurzelten Kritiker erscheint die Entdeckung der als längst Uberwunden geglaubten Merkmale der antiken Typenkomödie, der Commedia dell'arte, oder der Charakterkomödie à la Molière als ein Rückschritt. Doch gerade diese Merkmale der Figurenkonzeption weisen der weiteren Entwicklung des modernen grotesken Dramas bis hin zum Theater des Absurden die Richtung. Irzykowski schlägt auch als erster eine Typologie der Witkiewicz'schen Helden vor. Er unterscheidet dabei die zwei wichtigsten Typen: "ein kolossales, kluges und brutales Vieh" und "einen eleganten Dekadenz-Vertreter" ${ }^{17}$

In der folgenden Witkiewicz-Forschung wurde die Erstellung und Beschreibung einer Figuren-Typologie zum bevorzugten Untersuchungsgegenstand.

J. Kłossowicz erweiterte die Typologie Irzykowskis um eine Reihe weiterer Gestalten. Auch er betrachtet die Gestalt des Titanen als die zentrale Figur in Witkacys Buhnenwelt. Der Titan, sei es in Gestalt eines genialen Mathematikers (Tumor Mózgowicz) oder eines Diktators (Gyubal Wahazar) ist "von dămonischer Kraft, voll Lebensenergie, ein ungewöhnliches Exemplar jeglicher geistigen und physischen Energie; Nietzsches Ubermensch, der in cluct Epucho vorfangon iot, dio ooinor Natur nirht antanrirht "18 Neben dem Titan tritt hăufig der Typus des "jungen Schnosel" (poln.: "bubek") auf: eine unklare Gestalt, ein cleverer Hochstapler und Pragmatiker. Der dritte månnliche Typus in Witkiewicz' Dramen ist nach Kłossowicz der Dichter - "hamletisierend" und hăufig mit autobiographischen Zugen ausgestattet. Auch die weiblichen Figuren werden in entsprechender Weise sys-

\footnotetext{
${ }^{15}$ Boy-Zeleriski, 1957, VI: 70-85.

${ }^{16}$ Irzykowski, 1929/1976.

${ }^{17}$ Ebd.: 270.

${ }^{18}$ Kłossowicz, 1959: 88.
} 
tematisiert. Das weibliche Pendant zum Titan ist die Hetăre - von dămonischer Attraktivităt und verheerender Wirkung auf ihre (insbesondere mănnliche) Umgebung. Daneben tritt noch die Gestalt der Matrone und die des anmutig-naiven Mădchens auf. Und schließlich nennt Kłossowicz noch als das letzte Charakteristikum in Witkiewicz' Buhnenwelt die Volksmenge (poln.: "ttum"), die in fast allen Stucken auftritt. Die Volksmenge ist weder ein selbstăndiger Handlungsträger, noch hat sie symbolische Bedeutung. Es handelt sich um eine Gruppe von Komparsen, die das Buhnengeschehen optisch und akustisch untermalt und manchmal auch in der Rolle eines deus ex machina auftritt: "Arbeiter oder Soldaten treten auf die Buhne und töten die Helden des Dramas oder fuhren sie hinaus". ${ }^{19}$

Konstanty Puzyna, der Witkiewicz' in den Jahren nach 1956 "entdeckte" und 1962 den ersten Sammelband seiner Dramen herausgab, schlug in der Einleitung zu dieser Dramenausgabe folgende, weitgehend an Kłossowicz anknupfende Klassifikation vor: "<...> in den Stucken von Witkacy kehren einige konstante Typen immer wieder - der titanische Fuhrer, der Tyrann, der Kunstler oder Gelehrte, die perverse Hetäre aus der Oberschicht, ein sußes Mădchen mit einem zweideutig naiven Gesichtsausdruck. "20

Eine sehr umfangreiche und genaue Klassifikation der Witkiewicz'schen Figuren liefert M. Masłowski ${ }^{21}$. Er zăhlt in allen Dramen Witkiewicz' etwa zweihundertachtzig Individuell- und einige Kollektivfiguren ("Menschenmengen". "Wachen" etc.). Masłowski's Typologie umfaßt etwa siebzehn wichtigere Stereotypen:

1. "der Titan" - das letzte große Individuum in einer zunehmend nivellierten Massengesellschaft (Gyubal Wahazar, Maciej Korbowa, Hyrkan, Tumor Mózgowicz u.a.);

2. "die Hetăre" - das weibliche Pendant zum Titan: eine dămonische, unersăttliche Frau, hăufig eine Aristokratin (Fürstin Irina Wsiewołodowna Zbereznicka-Podberezka in Sz, Hilda Fajtcacy in SB);

3. "der Kunstler" - meistens ein Dichter, manchmal auch Maler oder Musiker; introvertiert und philosophierend (Pembroke in NT, Istvan in SB, Walpurg in $W i Z$, Bezdeka in $M$ );

\footnotetext{
${ }^{19}$ Ebd.: 89.

${ }^{20}$ Puzyna, K.: Wstęp. In: Werke, IV: 32.

${ }^{21}$ Masłowski, 1967.
} 
4. die "Tintenfisch-Frau" (poln.: mątwa): eine Frau, die den Mann insbesondere den Kunstler - mit teils mütterlichen, teils sexuellen Tricks umgarnt und unterwirft (Ella in $M$, Wanda in $J M K W$, das Wasserhuhn etc.);

5. "der Schurke" - zynisch, kalt, brutal, egoistisch; hăufig ein Partner des Titans oder das zweite Ich des Kunstlers (Telek in $P$, Golders in $M P$, Morbidetto in $G W$ );

6. "der einfache Dămon" - als die Hetăre zweiter Klassse. Zu diesem Figuren-Typus gehorren alle weiblichen Figuren, die den ubrigen Stereotypen nicht entsprechen. Masłowski fuhrt dafur leider keine Beispiele an;

7. "der junge Schnösel" (poln.: "bubek") - ein Dandy, hăufig adliger Herkunft, dekadent, ohne individuelle Charakterzüge und ohne "metaphysische Bestrebungen" (Florestan in NW).

8. "die Kindfrau" - (poln.: "dziewczą tko") ein sehr junges Mădchen von naiv-erotischer Ausstrahlung (Swintusia in GW, Izia in $T M$, Zosia i Anetka in $M D$, Nina in $N(K)$;

9. "der Ephebe" - ein außerordentlich intelligenter und sensibler Jungling im Alter zwischen siebzehn und achtzehn Jahren (Tadzio in $K W$, Przy jernniaczek in $G W$ );

10. "der Gelehrte" - ein ehrgeiziger und skrupelloser Wissenschaftler, der die Wissenschaft als Quelle der persönlichen Macht und der eigenen materiellen Vorteile miBbraucht (Rypmann in GW. Sir Grant in $N i K$, Grun in $W(Z)$. Nicht selten fällt der Typus des Gelehrten mit dem Titan zusammen (z.B. Tumor Mózgowicz);

11. "die Herren in mittlerem Alter" - "treten bei Witkiewicz meistens in erotischen Konfllkten aur, und swas als dio Dots ugonon und Vorlassenen, die bereit sind, für die - nunmehs letzte - Liebe alles herzugeben. ${ }^{22}$ (Bublikow in NT, Melchior Abłoputo in Oni etc.);

12. "der Alte" - ein alter Mann als eine bedrohlich-dămonische und brutale Gestalt (Unguenty in $C W$. Wojciech Brzechajło in MP, Wojciech Wałpor in $K \boldsymbol{W}$ );

13. "die Matrone" - eine zweideutige Heldin von mutterlich-naiven und dămonischen Zügen. Hăufig drogen- oder alkoholsüchtig (Janina Wegrzewska in Matka, Großmutter Julia in SB. Elza Fizdejkowa in JCF);

22Ebd.: 93. 
14. "der Diener" oder "die Dienerin" - im allgemeinen von untergeordneter Bedeutung im Stück.

15. "der Titan der Vergangenheit" - der wahre Individualist aus den fruheren, unwiederbringlich verlorenen Zeiten. Er verkörpert all diejenigen Charaktereigenschaften, die in der gegenwärtigen Kultur nicht mehr anzutreffen sind (Ryszard III in NW, Papst Juliusz in $M$ );

16. "das Ungeheuer" - Phantasiegestalten als Personifikationen und Mystifikationen des "Geheimnisses der Existenz" (Chinesische Mumie in P);

17. "die Wilden" - als ein positiver Gegenpol zu der degenerierten europäischen Kultur (in TM oder NT). ${ }^{23}$

Die angefuhrte Typologie läßt auf den ersten Blick erkennen, daß sich das Personal in den Dramen von Witkiewicz nicht nur auf einige wenige, stăndig wiederkehrende Typen reduzieren läßt, sondern daß auch all diese Stereotypen ihre Entsprechung in der dramatischen Tradition haben. Wie bei vielen anderen Autoren des 20. Jahrhunderts, spielt auch fur Witkiewicz das Phănomen der Intertextualtaat ${ }^{24}$ eine große Rolle. M. Masłowski bezeichnet seine Methode der Figurenkonzeption als ein splelerisches Zusammenfugen von Elementen, die durch bisherige kulturelle Entwicklung bereitgestellt worden sind. ${ }^{25}$

So ist, laut Masłowski, Witkiewicz" "Hetăre" eine ironische Abwandlung der eleganten und koketten "Salondame" aus den französischen Salonstucken des 19. Jahrhunderts. Ergănzend muß in diesem Zusammenhang aber auch auf einen anderen Prototyp verwiesen werden, der sowohl der "Hetăre" als auch den anderen dămonischen weiblichen Gestalten Witkiewicz' zugrunde zu liegen scheint, nämlich der Typus der "femme fatale". Der dramatische Prototyp der "femme fatale" oder des "Vamps" geht auf das Rollenfach der Kokette im klassischen französischen Theater (2.B. die Célimène aus Molières "Le Misanthrope") zurück und wurde im 19. Jahrhundert in abgewandelter Form als "Salondame" wiederbelebt. Im Drama der Jahrhundertwende erlebt die "femme fatale" bekanntlich Hochkonjunktur (z.B. Wedekins Lulu

${ }^{23}$ Ebd.

${ }^{24}$ Der Begriff "Intertextualităt" taucht in der hier zitierten WitkiewiczForschung der 60er und 70er Jahre (Błonski 1967a, Masłowski, 1967, Ziomek 1972 - vgl. auch weiter unten) freilich noch nicht auf.

${ }^{25}$ Masłowski, 1967: 91. 
oder Salome) - die Grunde dafür dürften in dem symbolischen, auf archetypische Vorstellungun und Ängste zurückgehenden Gehalt des WeiblichDămonischen zu finden sein.

Witkiewicz greift bei der Konzeption einiger seiner Figuren (insbesondere der des Typus: "Hetăre", "gewöhnlicher Dämon", "Matrone") auf die "femme fatale" der vergangenen literarischen Epoche zuruck: freilich geschieht dieser Ruckgriff nicht im Sinne eines Fortfuhrens und Weiterentwickelns von bestehenden Traditionen, sondern hat wegen seiner verzerrthyperbolischen Art den Charakter einer Parodie.

In ahnlicher Weise wird von Witkiewicz ein anderes traditionelles Rollenfach "deformiert": das der sog. Naiven. Die Tradition dieses Figurentypus geht bis ins 18. Jahrhundert zuruck (z.B. Kathchen in $H$. v. Kleists "Kăthchen von Heilbronn") und bezeichnet ein unschuldiges, argloses Mădchen mit natürlichen, ungekünstelten Gedanken, die frei und ohne Rucksicht auf Konventionen geăußert werden. Im 18. Jahrhundert stellte man der "Naiven" gerne die "Soubrette" gegenuber. Deren Gewitztheit und Koketterie unterstrich die rührende Wirkung der treuherzigen "Naiven". In seinem Typus der "Kindfrau" (poln.: "dziewczątko") vereinigt Witkiewicz quasi die beiden weiblichen Rollenfächer: das der "Naiven" und der "Soubrette" in einer Person und mit dem ihm eigenen Sarkasmus verbindet er die Unschuld mit Verderbtheit und Perversion. Im Ubrigen hat Witkiewicz' Behandlung dieses traditionellen Rollenfaches zukunftsweisende Tendenzen: da die klassische "Naive" der modernen Geisteshaltung kaum mehr entspricht, tritt an ihre Stelle in der modernen Literatur nicht selten der Typus der "Lolita", der durchaus Gemeinsamkeiten mit Witkiewicz' "dziewcza tko" aufweist.

M. Masłowski weist auf weitere literarische Prototypen der Figuren hin. Demnach sei der "Kunstler" eine grimmige Umgestaltung des romantischen Genie-Küstlers und der "Wissenschaftler" eine Abwandlung des "bösen Zauberers". Die "Tintenfisch-Frau" nehme deutlich Bezug auf den modernistischen Typus der "kleinburgerlichen Geliebten $\langle\ldots\rangle$, die das tragische Schicksal des Kunstlers in einer konventionalisierten Welt verdeutlichen sollte ${ }^{m^{26}}$. Die "Matrone" verkörpere die "bis ins Absurde gesteigerten

${ }^{26}$ Ebd.: 90. 
Eigenschaften der positivistischen guten Mutter" ${ }^{1}$ und die "Herren im mittleren Alter" entsprecher. dem Typus des "gehörnten Ehegatten".

Die literarische Provenienz der Witkiewicz'schen Figuren sowie die zahlreichen intra- und intertextuellen Bezüge in seinen Dramen veranlaßten J. Btonski zu der bildhaften Feststellung: "<...> die Dramen von Witkiewicz haben $\langle. . .>$ gewissermaßen einen parasitären Charakter. Wie die Mistel von den Saften der Eiche, năhren sie sich von der vorangegangenen Kunst. ${ }^{2}$ In der Witkiewicz-Forschung fehlt es auch nicht an genetischen Untersuchungen zu diesem Phănomen. Zu den am hăufigsten angefuhrten intertextuellen Bezügen gehören: die Parallelen zwischen der "Neuen Befreiung" (NW) und Shakespeares "Richard III" oder Wyspianskis "Hochzeit"; die wörtlichen und indirekten Anspielungen auf Ibsens "Gespenster" in der "Mutter" (Mat$k a) ;$ die Analogien zwischen "Im kleinen Landhaus" (W matym dworku) und Rittners "Im kleinen Haus" ( $W$ małym domku); der spürbare Einfluß J. Conrads in "Tumor Hirnmann (TM) oder in der "Unabhängigkeit der Dreiecke" (NT) sowie die Parallelen zwischen "Janulka, die Tochter des Fizdejko" und dem Roman von F. Bernatowicz "Pojata, die Tochter des Lezdejko" ${ }^{3}$. Die Gefahr der Einseitigkeit und des Positivismus, die derartigen Forschungen zur EinfluB- und Stoffgeschichte immer anhaftet, wird ungangen, wenn der Untersuchungsschwerpunkt mehr auf den Charakter und die Funktion dieser Intertextualităt und weniger auf die Objekte der Analogien gelegt wird.

So interpretiert Błonski die Struktur und Thematik der Dramen von Witkiewicz schon 1967 im Sinne des heute vieldiskutierten poststrukturalistischen Intertextualitătsbegriffes ${ }^{4}$. Błonski versteht die Stücke als ein "Spiel im Spiel", das nicht auf die außerkunstlerische Wirklichkeit, sondern auf die vorhandenen Kunstwerke bezug nimmt. Das Drama als ein Gefuge aus literarischen Versatzstucken soll - der Philosophie Witkiewicz' entsprechend - dem Rezipienten "die Einheit in der Vielfalt" bzw. das "Ge-

${ }^{1}$ Ebd.

2Błonski, 1967a: 73.

${ }^{3}$ Vgl. dazu insbesondere: Puzyna, 1972/1985: 9ff; Błonski, 1967a: $73 f$ und Sokót. 1969.

4Vgl. dazu 2.B.: M. Pfister: Konzepte der Intertextualităt. In: Broich Pfister (Hrsgg.), 1985. S. 1-30. 
heimnis der Existenz" suggerieren. "Die Kunst als Ganzes kann sich auf das schon Geschriebene stüzen ${ }^{\text {31 }}$.

J. Ziomek ${ }^{32}$ dagegen untersucht den 'Parasitismus Witkiewicz' auf dem Baum der Literatur ${ }^{33}$ mit den historischen Begriffen der Einzeltextreferenz: Parodie, Travestie, Pastiche, Quasi-Zitat ${ }^{34}$, Cento. Zunăchst einmal lehnt er die in der Forschung vielfach in Anspruch genommene Anwendung des Begriffes "Parodie" auf Witkiewicz' intertextuelle Vorgehensweise ab. Ziomek sieht bei Witkacy ein wesentliches Kriterium der Parodie nicht erfullt, nămlich, "die Uberzeugung von der Superiorităt der Vorlage (der parodierten Konvention), oder eine polemischen Einstellung gegenuber dem Theman $^{35}$. Witkiewicz dagegen beziehe sich, insbesondere bei seiner Figurenkonzeption, auf die niederen Literatur- und Kunstgattungen: auf die Trivialliteratur, das Kabarett, Boulevardstuck und Melodrama. Die Prototypen seiner Figuren - dazu zählt Ziomek auch die "femme fatale", die noch bei Wedekind und Micinski zur hohen Literatur gehorte - seien durch ihre hohe Popularităt abgenutzt und wirken lăcherlich. Trotz der interessanten weiterfuhrenden Ausfürungen Ziomeks Uber "die Funktion der Konventionen aus den niederen Kunstgattungen in der innovativen Literatur", etwa bei Gombrowicz ${ }^{36}$, scheint hier der Einwand angebracht zu sein, daß der Autor die Historizităt der Rezeptionshaltung zu wenig berucksichtigt: was fur den heutigen Rezipienten den Status der Abgegriffenheit und Trivialităt besitzt, konnte dem Zeitgenossen Witkiewicz' durchaus noch als originell und hochwertig erscheinen. Das durfte vor allem die Elemente des Naturalismus und des Ästhetizismus und Witkiewicz' Anspielungen auf

${ }^{31}$ Błonski: 1967a: 73.

Năhere Erlăuterungen zu der Interpretation von J. Błonski und zur Intertextualitat bei Witkiewicz in den Kapiteln Uber Figurenkonstellation (3.2.1.2.) und Uber Geschichte und Fabel (3.2.2) in dieser Arbeit.

32 Ziomek, 1972: 86ff.

${ }^{33}$ Ebd.: 87.

${ }^{34}$ Unter Quasi-Zitat bzw. Struktur-Zitat versteht J. Ziomek eine Art Pastiche, die in das zitierende Werk miteinbezogen ist. Der polemische Charakter des Quasi-Zitates verlangt es, daß seine Anwesenhelt im Werk deutlich signalisiert werden muß. Der Autor bezieht sich auf die Definition von D. Danek, 1968.

${ }^{35}$ Ziomek, 1972: 89.

${ }^{36}$ Ebd.: 91. 
H. Ibsen, J. Conrad, St. Wyspianski oder F. Wedekind betreffen.

Doch Ziomeks Ablehnung des Parodiebegriffes fur Witkiewicz' Kunst und insbesondere fur seine Figurenkonzeption erscheint auch aus der Sicht der Theorie der Reinen Form vollig gerechtfertigt: Witkiewicz wollte konventionalisierte Formen nicht imitieren - nicht einmal im spbttischen Ton wie bei der Parodie - sondern sie grundlegend zerstören. Mit Recht schlägt Ziomek zur Beschreibung der intertextuellen Vorgehensweise Witkiewicz' andere Begriffe der Textreferenz vor: Quasi-Zitat, Cento und Kontrafaktur:

"Die Figurenstereotypen $\langle. . .>$ sind Quasi-Zitate, die in der Art eines Cento zusammengefügt worden sind, und hăufig die Funktion eines kontrafakturăhnlichen Stilwechsels erfullen. Den Terminus "Kontrafaktur" benutzen wir hier mit folgender Einschrănkung: Witkacy transkribiert nicht vom niedrigen in den hohen Stil, sondern zerstört die ganze Skala der Stile, indem er stăndig die Grenzen zwischen dem Hohen und dem Tiefen, zwischen Ernst und Hohn und zwischen Kitsch und Meisterwerk Uberschreitet.

Zusammenfassend kann man nun die Figurenkonzeption in Witkiewicz' Dramen folgendermaßen umreißen: Die ablehnende Haltung Witkiewicz' gegenuber gegenständlichen und kognitiven Inhalten in der Kunst hat in der Figurenkonzeption die Deformation des anthropologischen Modells und der sozialtypischen Eigenschaften der Figuren zur Folge. Die gebräuchlichsten Kunstgriffe, die Witkiewicz' zu diesem Zweck anwendet, sind: die Inkonstanz der psychischen und physischen Eigenschaften der Figuren wie z.B. die Reversibilităt des Todes und des Geschlechts bei einer Figur; innere Widerspr Uchlichkeit der Charaktereigenschaften; Identitatsdestruktion und -wechsel; Reduktion der Psychologie auf einige wenige, zudem hyperbolisch-verzerrte Eigenschaften; auffallender Widerspruch zwischen dem gesellschaftlichen Stand und dem Soziolekt der Figur u.a.

Das gesamte Personal in den Dramen Witkiewicz' laBt sich auf einige wenige Stereotypen reduzieren: der Titan, die dämonische Frau, die Kindfrau u.a. Die literarische bzw. theatralische Provenienz dieser Typologie ist unverkennbar. Doch auch in diesem Fall tritt Witkiewicz' Prinzip der Deformation auf: Der RÜckgriff auf die historisch vorgeprägten dramatischen

${ }^{37}$ Ebd.: 92. 
Typen entspricht nicht etwa einer Fortfuhrung und Weiterentwicklung von Traditionen, sondern hat den Charakter eines polemischen Struktur-Zitats und eines kontrafakturăhnlichen Stil- und Traditionsbruchs. 


\subsubsection{FIGURENKONSTELLATION}

Nachdem im vorangehenden Abschnitt die Konzeption der Einzelfigur in den Dramen Witkiewicz dargestellt worden ist, sollen nun im folgenden die strukturellen Relationen innerhalb des Personals: Figurenkonstellationen und Konfigurationen erörtert werden. Diese Vorgehensweise entspricht der Fragestellung, die von Witkiewicz' Theorie der Reinen Form aufgeworfen worden ist: inwieweit sind kunstlerische Einzelelemente - in diesem Fall dramatische Figuren - in der Lage, rein formal-ästhetische Einheiten zu bilden, die sich jenseits eines mimetischen Darstellungsmodus und jenseits kognitiv-aufklärerischer Wirkungsintentionen befinden, und deren sinn- und einheitsstiftende Momente sich nur aus den innerstrukturellen Gegebenheiten des Werkes ergeben. Bei der Untersuchung dieser Fragestellung verlagert sich der Untersuchungsschwerpunkt von der Beschaffenheit der Einzelfigur oder des Typus auf die dynamische Interaktionsstruktur des Ensembles.

Die erste Interpretation der Witkiewicz'schen Figuren unter dem Aspekt ihrer Funktionen im Werkganzen lieferte J. Błonski ${ }^{38}$.

Bei seiner Drameninterpretation greift er auf die Philosophie von Witkiewicz zuruck und postuliert das Streben nach den in der Theorie der Reinen Form haufig thematisierten "metaphysischen Gefuhlen" als das Handlungsziel der Dramenfiguren. Das metaphysische Gefuhl ist ja in Witkiewicz' Philosophie ein Maßstab fur das Individuum oder fur das Menschsein schlechthin im Unterschied zu dem vom Gattungserhaltungstrieb bestimmten Massenmenschen. Błonski Uberträgt den ontologisch-anthropologischen Aspekt von der Philosophie Witkacys auf seine Dramen :

"Die Helden von Witkacy sind einfach damit beschäftigt, wonach auch er strebte: sie jagen nach den berlichtigten 'metaphysischen Gefuhlen', nach dem 'Geheimnis der Existenz', nach der 'Einheit in der Vielfalt' $<. . .>.^{39}$

Diese Interpretation wird mit Zitaten aus JCF und $M$ belegt.

Ein solches Handlungsziel schließe logischerweise eine mimetische, le-

${ }^{38}$ Błonski: $1967 b$.

${ }^{39}$ Ebd.: 27. 
benslogische Motivation der Handlungen aus. An ihre Stelle tritt die Deformation, die Błonski als die Umkehrung und Negation des Lebensnotwendigen und -wahrscheinlichen in der Kunst definiert. Die Deformation habe ein doppeltes Ziel: erstens soll sie die sichtbare, logisch und vertraut erscheinende Welt so erschuttern, daß dadurch ein Verlangen nach dem Geheimnis der Existenz und nach dem metaphysischen Gefuhl aufkommt; zweitens soll sie sogar das metaphysische Gefuhl selbst auslösen, und zwar durch das Erleben der Reinen Form des Werkes. ${ }^{40}$

Das Streben der Helden nach metaphysischen Gefuhlen könne nicht im Rahmen des sog. "normalen Lebens" verwirklicht werden. Die Helden auf der Buhne veranstalteten daher ein künstliches, deformiertes Leben, um zu dem wahren Leben vorzudringen. Diese Tatsache liege der Fabel in den meisten Dramen Witkiewicz' zugrunde.

Von dieser Annahme ausgehend stellt Błonski eine Typologie der Witkiewicz'schen Figuren auf, die die Funktionen der Figuren im ganzen Stllck berUcksichtigt:

1. der "Răsoneur", der dem Zuschauer das Stück erlăutert;

2. der "Regisseur" der Ereignisse, der das kunstliche Leben organisiert, in welchem das Geheimnis des Seins sich offenbaren soll;

3. die "Schauspieler", die an der metaphysischen Komödie teilnehmen und darunter insbesondere der Adept, der erst in das Spiel eingeweiht wird;

4. die "Menschen von Außen", die das Spiel beenden.

Seine Interpretation der Dramen als eines Spiels im Spiel fuhrt Błonski in seinem Aufsatz "Teatr Witkiewicza: forma formy" (1967) und in anderen Publikationen aus. Man kann gegen Błonskis methodische Vorgehensweise den Einwand erheben, $d a \beta$ er in unzulässiger Weise den theoretischphilosophischen Ansatz Witkiewicz' auf die dramatische Praxis Uberträgt und zu wenig die zeitgenössischen literarischen Strömungen beachtet, beispielsweise den Pirandellismus, der das "Spiel im Spiel" in den 20er Jahren des 20. Jahrhunderts popularisiert hat. Außerdem erscheint es ungewőhnlich, daß Błonski die von der Deformation hervorgerufene Verfremdung als einen Auslöser des metaphysischen Gefuhls betrachtet, obwohl Witkiewicz eigentlich nur das Formerlebnis für die ăsthetische Erfahrung

${ }^{40}$ Ebd.: 31. 
verantwortlich machte und die Deformation eher fur ein untergeordnetes Phånomen hielt. Doch die interessante Interpretation der Witkiewicz'schen Figuren nach ihren Handlungsfunktionen ist zweifellos für viele der Dramen zutreffend und beeinflußte stark die Witkiewicz-Forschung der 70er Jahre.

J. Ziomek ${ }^{41}$ geht wie Błonski davon aus, daß das Handlungsziel der Figuren in dem Streben nach metaphysischen Gefuhlen besteht. Die Kategorie des "Spiels im Spiel" ist jedoch für inn unbedeutend: seiner Typologie liegt der Grad des Verlangen nach den metaphysischen Gefuhlen zugrunde: "Die Figuren in den Dramen Witkiewicz' werden am Schnittpunkt zweier Kristallisationsachsen gebildet" ${ }^{42}$ : die eine ist der Grad der Unersăttlichkeit oder des Gesăttigt-Seins an metaphysischen Gefuhlen des Helden; die andere bezeichnet die Lebensbereiche, in denen die Figuren die metaphysischen Gefuhle erreichen wollen: Kunst, Erotik, Herrschaft, Philosophie, Wissenschaft und das sog. Lebensschaffen. In den beiden zuletzt genannten Bereichen gibt es keine unersättlichen Individuen mehr, sondern nur mechanisierte, lebenspraktisch orientierte Vertreter der menschlichen Gattung.

Ein wichtiges Verfahren, das die vielzitierte "Einheit in der Vielfalt" im Bereich des Personals eines Dramas herstellt, ist die Strukturierung durch semantische Korrespondenzen und Kontrastbezige. Da die Figuren nicht nur Handlungstrăger, sondern auch Reprăsentanten und Konkretisierungen von semantischen Merkmalen eines Textes sind, wird die Einheit innerhalb des Personals durch die ubergreifende Bedeutungsstruktur eines Stückes gewăhrleistet. Die bisher behandelten Charakteristika der Dramen von Witkiewicz - Inkohärenz der Textzusammenhănge, Vermeidung der Monosemierung, absurd-wirklichkeitsferne Figurenkonzeption - läßt freilich von vornherein annehmen, daß die Bedeutungsstruktur einen nur rudimentären Charakter hat. Tatsächlich ist sie motivisch und thematisch nicht so stark entwickelt wie im konventionellen Drama, und es wäre sicherlich verkehrt, von Witkiewicz' Stücken eine eindeutige "Aussage" oder "Lehre" zu erwarten. Wie es die Theorie der Reinen Form hinlänglich beweist, lehnte Witkacy jegliche aufklärerisch-rationalistische Intentionen der

\footnotetext{
${ }^{41}$ Ziomek, 1973: 99rf.

"22Ebd.: 100.
} 
Kunst ab. Doch anders als bei den zeitgenössischen dadaistischen und futuristischen Theaterexperimenten liegt seinen Stücken immer ein semantisches Gerüst zugrunde, das die Einheit und innere Spannung des Werkes garantiert.

Eine solche ubergreifende Bedeutungsstruktur wird in dem Drama "Das Wasserhuhn" ( $K W)$ paradigmatisch aus der semantischen Opposition "Freiheit" vs. "Gebundenheit" entwickelt bzw., konkret auf die Figuren bezogen, aus der Gegenuberstellung "der Mensch als ein freies, absolut autonomes Individuum" vs. "als ein soziales Wesen". Der Rezipient wird gleich in der ersten Szene in diese Bedeutungsstruktur eingefuhrt. Die Titelheldin verlangt von ihrem Freund Edgar, erschossen zu werden. Edgar zögert, und in dem nachfolgenden, durch eine befremdende Lăssigkeit gekennzeichneten Dialog argumentiert die Heldin immer wieder mit der Idee der großen Tat und des großen, autonomen Individuums, sowie mit dem Ideal einer Handlungsweise, die von jeglichen ethischen Bindungen und Konventionen befreit ist:

"Ein jedes existierende Wesen ist einzigartig, also groß. Du bist groß, Edgar, und ich auch. Wenn du mich nicht augenblicklich erschießt, werde ich dich verachten wie den letzten Hund. " (Werke, V: 12)

Der groteske Charakter dieser Xußerungen laßt zwar keinen in sich geschlossenen und logischen Diskurs aufkommen, setzt aber gewisse semantische Signale für den Rezipienten und erzeugt dadurch Spannung auf die Weiterentwicklung des Geschehens.

Dic somantiooho Oppoaition. "Fraihait" ve "Infraiheit" wird im I.aufe des Stuckes nicht nur sprachlich immer wieder aktiviert, sondern sie spiegelt sich auch im Buhnenbild wider. In der ersten Szene stellt das Buhnenbild ein weites, freies Feld und ein Meer am Horizont dar. Wahrend des Sterbens der Titelheldin wird das Buhnenbild auf offener Buhne verăndert: das weite Feld wird mit zwei Wănden und einer Hausfront in den abgeschlossenen Hof einer Kaserne verwandelt. Damit wird das nachfolgende Leben von Edgar und Tadzio angedeutet - es wird sich nun innerhalb von anerkannten

"Im Original: "pogardzac jak ostatnim flakiem" (Werke, V: 12) - dt.: wörtlich: wie das letzte Gedărm verachten. 
und konventionalisierten sozialen Lebensweisen abspielen: im Kreise der Familie und innerhalb einer bestimmten sozialen Schicht. Die Wirkung des Eingeschlossen-Abgegrenzt-Seins wird im zweiten Akt noch verstärkt: die Handlung findet in einem Salon statt, in dem es, laut einer ausdrúcklichen Regieanweisung, keine Fenster gibt (Werke, V: 28). Die letzte Szene, in der es zu einer erneuten Erschießung der Titelheldin und zu Edgars Selbstmord kommt, findet wieder im Buhnenbild der ersten Szene statt.

Auch die Kostüme spiegeln symbolisch die Grundthematik des Werkes wider. In den beiden Hinrichtungsszenen trägt Edgar ein Kostum aus dem 18. Jahrhundert, das - laut Regieanweisung - an die Figuren in einer bestimmten "illustrierten 'Robinson'-Ausgabe erinnert". (Werke, V: 9). Diese ironische intertextuelle Bezugnahme auf Robinson - das Symbol eines freien, autonomen Individuums - wird noch sprachlich vertieft, indem Edgar ausdrucklich das Ethik-Thema anspricht:

"Die Ethik ist nur das Ergebnis der Vielfalt der Individuen einer Gattung. Der Mensch auf einer unbewohnten Insel würde diesen Begriff Uberhaupt nicht kennen." (Werke, V: 44)

Die semantische Opposition "Freiheit" vs. "Gebundenheit" bzw. auf die Figuren bezogen "der Mensch als ein freies, absolut autonomes Individuum" vs. "als ein soziales Wesen" ist schlieBlich auch fur die Struktur des Personals auschlaggebend. Wie schon angedeutet, hat das Stuck "Wasserhuhn" hinsichtlich des Handlungsortes und -verlaufs eine tektonische Kreisstruktur. Als tektonisch kann gleichermaßen die Figurenkonstellation bezeichnet werden. Außer einigen Kollektivfiguren mit relativ unbedeutenden Statistenrollen treten in dem Stuck nur sechs Personen auf, die aufgrund ihrer semantischen Merkmale in annähernd symmetrische Gruppen geordnet werden können. Als Ordungskriterium fungieren einerseits die semantische Opposition: "männlich" vs. "weiblich" und anderseits die schon erwăhnte Opposition: "autonomes Individuum" vs. "soziales Wesen". So gibt es auf der einen Seite die Gruppe der gesellschaftlich anerkannten und in soziale Strukturen eingebundenen Figuren: die Lady und die "Familie" ("Vater - Wojciech Wałpor; Er - Edgar Wałpor und der kleine Sohn - Tadzio" $\left.{ }^{44}\right)$. Auf der anderen Seite stehen die gesellschaftlichen Außenseiter:

"Im Personenverzeichnis werden eben diese Verwandschaftsbeziehungen ex- 
der Schurke (poln.: "dran"), Ryszard de Korbowa-Korbowski recte Maciej Wiktos $^{45}$ und das "Wasserhuhn" (poln.: "Kurka Wodna"), Elzbieta FlakePrawacka. Darüber hinaus wird das Personal durch die Opposition "mănnlich" vs. "weiblich" strukturiert. Den beiden jungen Mănnern: Edgar und Korbowa stehen zwei etwa gleichaltrige Frauen: die Lady und das "Wasserhuhn" gegenuber. Die Opposition "gesellschaftlich anerkannt" vs. "Außenseiter" ruft hier noch einen zusätzlichen Dualismus hervor: so wird im Personenverzeichnis der Lady, Furstin Alice of Nevermore, das "Wasserhuhn" - laut Personenbeschreibung - "eine Person unbekannter Herkunft" (Werke, V: 6) gegenubergestellt. Ziel dieser semantischen Oppositionen ist nicht nur das Strukturieren von Dramenpersonal, sondern auch das Anlegen von latenten Konflikt- und Handlungsmöglichkeiten, die im Verlaufe des Stückes zum Tragen kommen. Dabei spielt die Thematik der sozialen Bindungen und Strukturen eine handlungskonstitutive Rolle. Das Kind Tadzio, das aufgrund seiner nahezu permanenten Präsenz auf der Buhne als die Hauptfigur des Stückes bezeichnet werden kann, ist stăndig auf der Suche nach einer Auskunft Uber seine Herkunft und nach seiner Familie:

"Ich will meinen Anfang kennen: woher ich gekommen bin und wohin das alles geht. Das geht von alleine, doch es schaut so aus, als ob es ein Ziel hătte. Was ist das, wohin das alles so eilt?" (Werke, V: 28)

Daruber hinaus wird das Thema: Familie und soziale Strukturen leitmotivisch immer wieder aufgenommen und dabei die Willkurlichkeit und Zufalligkeit der familiăren und sonstigen sozialen Bindungen diskutiert. So > R knmmantiert Fdgar. nachdem er vollig unvermittelt und innerhalb weniger Minuten Tadzio adoptiert und sich mit der Lady, der Witwe seines Freundes, verlobt hat: "Die Frau des Freundes - der Sohn der Geliebten. Endlich habe ich mir eine Familie geschaffen." (Werke, V: 27).

Die Opposition "Freiheit" vs. "Gebundenheit" bestimmt auch das Geschehen in dem Raum des off stage: wie man aus Berichten der Buhnenfiguren erfahrt, sind "draußen" soziale Unruhen im Gange, die schließlich in eine

plizit genannt, obwohl das Verhältnis Tadzios zu Edgar im Laufe des Stückes unklar bleibt. (Werke, V: 26).

${ }^{45}$ Der Name spielt auf Maciej Korbowa an, die Titelfigur eines anderen Stulckes von Witkiewicz. 
Revolution münden. In der Schlußszene des Stuckes spielen die Vertreter der sozialen Ordnung und des Establishments Karten, wăhrend der Lärm von Geschossen und Detonationen sowie der Feuerschein von außen auf die Buhne drăngt. "Die Welt bricht auseinander" - lauten die letzten Worte.

Die semantische Opposition "Freiheit" vs. "Gebundenheit" und die von ihr abgeleiteten Oppositionen: "Anarchie" vs. "sozial-politische Strukturen"; "autonomes Individuum" vs. "soziales Wesen" etc. stellen also das semantische Gerust dar, das sowohl das Thema als auch die Figurenkonstellation des Dramas "Wasserhuhn" bestimmt.

Wenn man die Ergebnisse der strukturalistischen Narrativik-Forschung der $60 \mathrm{er}$ und $70 \mathrm{er}^{46}$ Jahre auf dieses Phänomen anwendet, so kann man im weiteren folgern, daß die semantischen Korrespondenzen und Kontrastbezuge den Text nicht nur - wie weiter oben beschrieben - auf dem Tiefenniveau organisieren, sondern daß sie auch die narrative Oberflăchenstruktur bestimmen.

Somit stellt sich die Einhaltung der narrativen Struktur als ein weiteres Verfahren dar, das die Einheit der Einzelelemente des Dramas: Figuren, Situationen, Handlungen gewăhrleistet. Die narrative Struktur wird in der Forschung infolge der struktural-syntaktischen Untersuchungen von $L$. Tesnière $^{47}$ und den morphologischen Untersuchungen von V. Propp ${ }^{48}$ als eine allgemeingultige Sprachfunktion betrachtet. Sie bestimmt weitgehend den Erwartungshorizont des Rezipienten hinsichtlich der Handlungsstruktur. Deren Einhaltung oder Durchbrechung in einen literarischen Werk bietet daher die Möglichkeit, unterschiedliche ästhetische Erfahrungen auszulösen. So bildet die Einhaltung der narrativen Struktur fur den Rezipienten eine Orientierungshilfe und erzeugt Spannung auf die Weiterentwicklung des Geschehens. Eine Durchbrechung lost den Verfremdungseffekt aus und ist für den grotesken Charakter des Werkes verantwortlich.

Wendet man das Aktantenmodell von A.J. Greimas und $\mathrm{Cl}$. Lévi-Strauss, in dem die Ansătze von V. Propp und L. Tesnière weiterentwickelt wurden, auf die Dramen von Witkiewicz an, so stellt man fest, daß die einzelnen Figu-

\footnotetext{
${ }^{46}$ Vgl. dazu 2.B.: Barthes, 1970; Greimas, 1966/1971 und 1976; LeviStrauss, 1978/1980; Todorov, 1969 und 1972 u.a.

${ }^{47}$ Tesnière, 1953/1969.

${ }^{48}$ Propp, 1975.
} 
ren aufgrund ihrer Handlungsfunktionen in eine einheitliche Interaktionsstruktur eingebunden sind.

Witkacy ruft zwar hăufig einzeine groteske Effekte hervor, indem er den narrativen Erwartungshorizont des Rezipienten durch widerspruchliche und unerwartete Ereignisentwicklungen, Uberraschende Lösungen und Wendungen oder durch das unvermittelte Wechseln der Aktantenpositionen innerhalb einer Figur erschüttert. Die grundsätzliche Ubereinstimmung der Figurenkonstellation in seinen Dramen mit dem Aktantenmodell - das ja die allgemeingultige narrative Sprachfunktion widerspiegelt - garantiert die Einheit und die innere Spannung seiner Werke.

So lassen sich in dem Stück "Das Wasserhuhn" unschwer die aktantiellen Positionen bestimmen. Als "das Wunschobjekt" kann der ideelle Wert "absolute Autonomie des Individuums" bestimmt werden. Das Streben nach diesem Wert bestimmt die Handlungsweise Edgars und ăußert sich insbesondere in den beiden Hinrichtungsszenen, die eine Art "Prufung" für Edgars Unabhängigkeit von moralischen Bindungen darstellen. Edgars Schicksal spiegelt sich in dem Lebensweg des Kindes Tadzio wider, der, nachdem er die Zufalligkeit und Willkürlichkeit der sozialen Bindungen erfahren hat, am Ende des Stückes beschließt, ein asozialer Schurke zu werden. Die Position des "Helfers" und zugleich des "Auftraggebers" ("destinateur") nimmt die rătselhafte Titelheldin ein. Dagegen hat die Lady, die Edgar und Tadzio gleichzeitig in ein bequemes Establishment und in den Opportunismus verstricken will, die Position des "Gegners", während der Vater die Position des "Gegenauftraggebers" ("destinataire") einnimmt.

Ein weiters gutes Beispiel für die innere Einheit der Figurenkonstellation ist "Die Beelzebubsonate" (SB). Dieses Drama entstand als das letzte in Witkiewicz' intensiver Schaffensphase in den $20 \mathrm{er}$ Jahren - danach vęrabschiedete sich der Autor spektakulär von der Reinen Kunst durch die Grundung seiner Portrătfirma. In der "Beelzebubsonate" zieht Witkiewicz alle Register seiner dramaturgischen Kunstgriffe: verküzte Fabel und reduzierte Psychologie, Mehrperspektivik und Simultaneităt, überraschende Wendungen, Auferstehungen etc. Wie D.C. Gerould richtig feststellt, kann dieses Werk als ein "Lehrbuch der Witkacy-Dramaturgie" 49 betrachtet

${ }^{49}$ Gerould, 1981b: 345 . 
werden.

Die semantische Ausgangsposition, die das narrative Programm auslöst, wird konstituiert durch die Opposition: "absolute" vs. "kommerzielle" Kunst. Im Spannungsfeld dieser Opposition steht der junge Komponist Istvan, der mittelmaßige Unterhaltungsmusik produziert und von der reinen und wahren Kunst trăumt:

"Ach - wenn ich das in Töne einschließen könnte. Doch ich setze Noten auf die funf Linien wie der Buchhalter Zahlen in seine Bucher, und meine Arbeit ist leblos fur mich, obwohl meine Musik anderen gefallt. Das ist eben gut gemachte Musik und keine Kunst." (Werke, V: 442).

Seine unbewuBte Sehnsucht nach der reinen Kunst bekommt konkretere Gestalt und gewinnt an Stärke, als die GroBmutter Julia ihm eine alte Legende ihres Wohnortes Mordowar erzählt, uber einen Musiker, der mit dem Teufel einen Pakt schloB und daraufhin die sog. "Beelzebubsonate" komponierte. Das "Wunschobjekt" in diesem Drama ist also die "Beelzebubsonate", die symbolisch für die absolute Kunst steht. Interessant ist die Behandlung der Position des "Helfers". Witkiewicz greift hierbei auf die Faust-Sage $^{50}$ und die Teufelspakt-Geschichten zurück, doch seine Adaptation hat einen verfremdenden, kontrafakturartigen Charakter. Um sein Ziel zu erreichen, schließt Istvan zwar den Pakt mit dem Teufel, der damit die aktantielle Position des "Helfers" einnimmt. Doch die Teufelsgestalt in Witkiewicz' Werk - ein Plantagenbesitzer mit dem Namen Joachim Baltazar de Campos de Baleastadar - entpuppt sich als ein leidenschaftlicher Pianist, der eben Istvans Komposition für die eigene Karriere benbtigt. Zeitweise erscheint der Teufel als der eigentliche Held und Istvan als der Helfer. Nachdem Istvan - der Legende aus der Anfangsszene entsprechend - die "Beelzebubsonate" komponiert und anschließend Selbstmord verlubt hat - bricht der Pianist Baleastadar zu einer Tournee mit der neuen Komposition auf: "Her mit dem Koffer. Wir erreichen noch den Express nach Budapest, der in Uj-Mordowar um $6.15 \mathrm{Uhr}$ halt. Wir fahren zur letzten

${ }^{50}$ Auf die Elemente der Faust-Sage in Witkiewicz' "Beelzebubsonate" macht Błonski (1968/69) aufmerksam.

D.C. Gerould zieht einen Vergleich zwischen Witkiewicz' Istvan und Adrian Leverkuhn von Th. Mann und weist auf das gemeinsame reale Vorbild fur die beiden Gestalten hin: A. Schönberg. 〈Gerould, 1981b〉. 
Weltalltournee, und danach ist Schluß mit dem Beelzebub." (Werke, V: 482f).

Die aktantiellen Positionen des "Helden" und des "Helfers" werden also in der narrativen Struktur dieses Dramas an manchen Stellen vertauscht. Dieser Kunstgriff sprengt zwar nicht den Rahmen des Aktantenmodells - es ist auch aus anderen Texten bekannt, daß gewisse Figuren, die vom ganzen Text aus gesehen eine bestimmte Aktantenposition einnehmen, diese Position in einzelnen Textteilen wechseln können. ${ }^{51}$ Er bestimmt aber durch seine befremdende und desorientierende Wirkung ebenso den grotesken Charakter des Stuckes wie die ungewöhnliche Adaptation der Faust-Sage: dieser traditionelle Tragödienstoff, der schon seit dem 16. Jahrhundert mit einer aufklärerisch-erbaulichen Intention bearbeitet wurde, gestaltet Witkiewicz zu einer Farce. Besonders anschaulich wird das bei der Darstellung der Holle, in der der zweite Akt stattfindet: es handelt sich um ein kabarettăhnliches Etablissement, das der Teufel Baleastadar mit einem epischen Kommentar folgendermaßen bezeichnet: "Das ist hier alles so hoffnungslos in der Art eines Kabaretts und Dancings. Aber ohne Hintergrund können wir ja nichts schaffen."

Doch trotz solcher Verfremdungseffekte bleibt die narrative Struktur rudimentăr erhalten. Ebenso wie die Instanzen des "Helden" und des "Helfers" findet man auch die übrigen Elemente des Aktantenmodells. Die Instanz des "Gegenspielers" wird u.a. durch Istvans bürgerliche Verlobte Krystyna besetzt, die den Teufelspakt und Istvans Abkehr von der bürgerlich-kommerziellen Kunst verhindern will. Die Funktion des "Auftraggebers" erfullt die der Handlung vorgeschaltete Legende des Ortes, die Oma Julia erzăhlt: Istvans Streben und sein Schicksal erscheinen als vun einer höheren Macht vorbestimmt.

Zusammenfassend kann man nun folgendes feststellen: Die Figurenkonzeption in Witkiewicz' Dramen ist durch das Deformationsprinzip bestimmt: mit viel Einfallsreichtum zerstört der Autor die biologische, psychologische und soziale "Lebenswahrscheinlichkeit" der Figuren und polemisiert mit

${ }^{51}$ Dieses Phănomen wird unter dem Begriff der "Hierarchisierung" von Keller/Hafner (1990: 98) beschrieben. 
den historisch vorgeprägten dramatischen Typen ${ }^{52}$. Damit dieses alleine auf der Destruktion und Umkehrung des Bestehenden und Gewohnten beruhende Verfahren nicht in eine völlige Beliebigkeit und Willkürlichkeit fuhrt, wirkt auf der Ebene der Figurenkonstellation ein einheitsstiftendes, auf der Funktion der Einzelfigur im Werkganzen beruhendes Prinzip. Die Figuren sind in eine semantische und aktionale Einheit eingebunden. Witkiewicz' Deformation greift nicht die narrative Struktur des Werkes an: in seine Dramen kann man sowohl in der Tiefen- als auch in der Oberflächenebene eine einheitliche Struktur feststellen. Sie wird in der Tiefenebene durch semantische Korrespondenzen und Kontrastbezlge und in der Oberflächenebene durch eine dynamische Interaktionsstruktur gemăß dem Aktantenmodell hergestellt.

${ }^{52} \mathrm{Vgl}$. dazu Kapitel 3.2.1.1. in dieser Arbeit. 


\subsubsection{FABEL UND GESCHICHTE}

In Anbetracht der Problematik und der kontroversen Definitionen der $\mathrm{Be}-$ griffe "Fabel" und "Geschichte" in der literaturwissenschaftlichen Forschung soll zuerst die Begriffsverwendung knapp erörtert werden. In der vorliegenden Arbeit werden die Begriffe im Sinne der von M. Pfister geleisteten Definition verwendet. Pfister definiert die Geschichte als "eine Kategorie auf der Ebene des Dargestellten", die "das rein chronologisch geordnete Nacheinander der Ereignisse und Vorgänge" ${ }^{n^{1}}$ beinhaltet. Die Fabel dagegen sei eine Kategorie auf der Ebene der Darstellung und berge "bereits wesentliche Aufbaumomente in sich - kausale und andere sinnstiftende Relationierung. Phasenbildung, zeitliche und räumliche Umgruppierung usw." ${ }^{2}$ Mit dieser Definition entspricht Pfister weitgehend der in der angelsächsischen Literatur- und insbesondere Romantheorie ublichen Unterscheidung zwischen "story" und "plot".

Eine entsprechende Differenzierung wurde schon in den 20er Jahren von den russischen Formalisten in die Literaturtheorie eingefuhrt und unter dem Begriffspaar "fabel" und "sjužet" diskutiert. Trotz der weitgehend ubereinstimmenden Sichtweise des Phănomens bei den russischen Formalisten und bei dem späteren angelsächsichen New Criticism besteht heute eine etwas verwirrende terminologische Divergenz. Der "Geschichte" bzw. der "story" in der angelsächsischen Forschung entspricht bei den russischen Formalisten die "fabel"; und die angelsăchsische "Fabel" korrespondiert mit dem russischen "sjužet" ${ }^{3}$. Die terminologische Verwirrung wird noch zusătzlich durch die Begriffsverwendung der französischen Poststrukturalisten verstărkt. Sie benutzen im entsprechenden Konnex das Begriffspaar "histoire"

1 Pfister, 1988: 266.

2 Ebd.

3 B. Tomasevskij bezeichnet als Fabel "die Gesamtheit der Motive in ihrer logischen, kausal-temporalen Verknupfung" und das Sujet (sjužet) als "die Gesamtheit derselben Motive in derjenigen Reihenfolge und Verknupfung, in der sie im Werk vorliegen".

Tomasevskij war die Begriffsproblematik offensichtlich bewußt. In der Fußnote zu dieser Definition merkt er an, daß die Begriffe "Fabel" und "Sujet" "in der Praxis in den unterschiedlichsten Bedeutungen gebraucht werden, mitunter genau entgegengesetzt zu der hier gewăhlten Verwendung." (Vgl. Tomasevskij, 1985: 218). 
und "discours", wobei sie jedoch von einer unterschiedlichen, eher rezeptionsåsthetischen als strukturalistischen Betrachtungsweise der Narratologie ausgehen.

Ebenso wichtig erscheinen in diesem Zusammenhang die Begriffe der "Handlung" und des "Geschehens".

Der Begriff der "Handlung" bürgerte sich in der Dramentheorie als eine seit dem 18. Jahrhundert gebräuchliche Ubersetzungsvokabel fur den aristotelischen "Mythos" ein und hat eine gleichermaßen lange wie auch widerspruchliche Verwendungstradition vorzuweisen. Elne verwirrende Doppeldeutigkeit ist in diesem Begriff semantisch angelegt, indem er sowohl die einzelne Handlung einer Figur als auch den ubergreifenden Handlungszusammenhang des ganzen Dramas bezeichnen kann. Um diese Doppeldeutigkeit zu vermeiden, soll in der vorliegenden Arbeit - entsprechend der Terminologie von M. Pfister ${ }^{4}$ - der Begriff der "Handlung" nur in der erstgenannten Bedeutung (als Einzelhandlung einer Figur) verwendet werden. Eine Aneinanderreihung von Handlungen wird dagegen mit dem Begriff "Handlungssequenz" bezeichnet. Unter Handlung wird dabei die bewrubte, intentionale Situationsverănderung durch eine Figur verstanden. Dieses Kriterium der Intentionalităt bildet - laut $M$. Pfister - das Unterscheidungskriterium zwischen Handlung und Geschichte. "Geschichte" ist der umfangreichere Begriff: "jede Handlung und jede Handlungssequenz <ist> eine Geschichte oder Teil einer Geschichte $\langle. .$.$\rangle , aber nicht \langle. .$.$\rangle jede Geschichte be-$ steht nur oder auch nur zum Teil aus Handlungen oder Handlungssequen$z^{\prime \prime} .^{5}$ Ein anderes Bestandteil der Geschichte außer der Handlung kann das sog. "Geschehen" sein.

Die Differenz zwischen den Begriffen "Handlung" und "Geschehen" beschreibt M. Pfister ${ }^{6}$ mit Hilfe der Kriterien der Selbst- bzw. Fremdbestimmung des Menschen: Handlung sei die bewubte, intentionale Tat einer Figur, die eine Situationsverănderung zur Folge hat. Die Handlung setze daher ein autonom uber sich verfügendes Individuum voraus. Das Geschehen dagegen, das zu den wesentlichen strukturellen Eigenheiten des modernen

\footnotetext{
4 Pfister, 1988: $269 f \mathrm{f}$.
}

${ }^{5}$ Ebd.: 270.

6 M. Pfister folgt bei seiner Begriffsbestimmung A. Hubler, 1973. 
Dramas gehore, gehe von der Figurenkonzeption eines genetisch und sozial determinierten Menschen aus, der zu einer freien Handlung nicht făhig sei. Das Geschehen vollziehe sich "am und mit dem Menschen"

Es erhebt sich nun die Frage nach den Aufbauelementen der Fabel bzw. der Geschichte und nach den Verknüpfungsmöglichkeiten dieser Elemente. Als das grundlegende Elementarteil des Dramas wird in der Dramentheorie traditionell die "Situation", d.h. die augenblickliche Lage bzw. Konstellation der Figuren, betrachtet. Auch bei diesem Begriff, der ăhnlich wie der Begriff der "Handlung", im Laufe der langen ăsthetischen Diskussion einen erheblichen Umfang an Mehrdeutigkeit erworben hat, soll auf die Definition von M. Pfister ${ }^{8}$ zurückgegriffen werden. Pfister lehnt eine Situationsdefinition ab, die sich nur auf die Ebene der Darstellung bzw. auf die Oberflăchensegmentierung des Textverlaufs (etwa im Sinne einer Szene bzw. eines Konfigurationswechsels) bezieht und siedelt den Situationsbegriff auf der Ebene des Dargestellten, d.h. in der Geschichte an. Daruber hinaus bestimmt M. Pfister - aus der Erfahrung des modernen. konfliktarmen Dramas heraus - die Kategorie des Konfliktes, die in einigen Situationsdefinitionen als konstitutiv galt, lediglich als ein fakultatives Kriterium:

"Die konflikthaft strukturierte, gespannte Situation eröffnet die Möglichkeit eines situationsverändernden Handelns, durch das die Figuren in ein neues Beziehungssystem gebracht werden. In einer konfliktfreien, statischen Situation dagegen ist nur Geschehen möglich, es sei denn, sie wird durch eine Intervention von außen (Hinzutreten neuer Figuren, Naturereignis, deus ex machina usw.) verăndert."

Zusammenfassend kann man die Begriffsbestimmung, die der nachfolgenden Dramenanalyse zugrundeliegt, folgendermaßen umreißen: Das grundlegende Element des Dramas ist die Situation, d.h. eine semantische Einheit in

7 Pfister, 1988: 270 .

${ }^{8}$ Pfister, 1988: 271f.

M. Pfister bezieht sich bei seiner Begriffsbestimmung auf E. Souriau, 1950.

9

Ebd.: 272. 
der Tiefenstruktur der Geschichte ${ }^{10}$ mit fakultativ konflikthaftem Charakter. In den Situationsmodifikationen, die entweder aufgrund von intentionalen Handlungen der Figuren oder in Form von Geschehen erfolgen können, entfaltet sich die Fabel des Dramas. Hinter der Fabel steht das kausaltemporale Gerust der Geschichte, die vom Rezipienten aufgrund seines Weltwissens und sicherlich auch aufgrund seiner Vertrautheit mit literarischen Stoffen und Konventionen konstruiert wird.

Wenn man die obengenannten Definitionen auf die Theorie der Reinen Form anwendet, so kann man wohl annehmen, daß die "Geschichte" als eine temporal-kausale Ordnung von Situationen, Handlungen und Geschehnissen in Witkiewicz' Terminologie zu den "lebenslogischen" Elementen eines Dramas gehøren wurde. Zu den Elementen also, die kein asthetisches Eigengewicht haben und nur die Funktion ausuben, "Richtungsspannungen" zu erzeugen, d.h. das Interesse des Rezipienten zu erzeugen und zu lenken. Die kausaltemporale Ordnung der Geschichte kann in einem Kunstwerk - laut Witkiewicz - zerstort werden, falls die subjektive Einheit der künstlerischen Komposition das erfordert. Nicht zufallig haben die Geschichten, die den Dramen Witkiewicz' zugrunde liegen, so wenig mit der außerkunstlerischen Wirklichkeit gemeinsam und sind in erster Linie von der verfremdenden Wirkung der Deformation von Lebenslogik geprägt. Die Fabel dagegen, d.h. der künstlerische Aufbau und die Darstellung der Situationen und anderer dramatischen Einzelelemente mußte dann, entsprechend den Grundannahmen der Witkiewicz'schen Ästhetik, zu den formalen bzw. ästhetischen Elementen des Dramas gehören. In diesem Sinne ăußerte sich beilăufig V. Sklovskij: "Măchen, Novelle, Roman sind jeweils eine Kombination stilistischer Motive; deshalb sind Sujet und Sujethaftigkelt eine ebensolche Form wie der Reim. "1l Wenn man die weiter oben behandelten terminologischen Divergenzen berucksichtigt - das "Sujet" der russischen Formalisten

${ }^{10}$ Es ergibt sich hier eine weitere Analogie zu der Literaturtheorie von B. Tomasevskij. Auch er betrachtet als die Grundelemente der Fabel die "kleinsten Bruchstuluke thematischen Materials", die er mit den nicht unproblematischen Begriffen "Motive" oder manchmal auch "Ereignisse" benennt. (Tomasevskij, 1985: 217f).

"<Hervh. d. Verf. A.S.> Sklovskij, 1925: 25. Zitiert nach Lotman, 1989: 331. 
entspricht der "Fabel" in der westlichen Forschung - so kann man annehmen, daß die Art der Fabelbildung (oder - laut Sklovskij - der "Sujetfugung") auf der Ebene der dargestellten Gegenständlichkeiten in einem Sprachkunstwerk ebenso ein formales Kriterium ist wie etwa der Reim auf der Ebene der Wortlaute oder der Rhythmus in der Musik.

In der nachfolgenden Analyse der Witkiewicz'schen Dramen sollen nun die wesentlichen Verfahren der Deformation der "Lebenslogik" und der Einheit der künstlerischen Komposition im Bereich der Geschichte und der Fabel untersucht werden.

Was der Rezipient gleich auf der Oberflăche der Dramentexte Witkiewicz' wahrnimmt, sind die verschiedenen Deformationsverfahren, die die kausale Struktur der Geschichte zerstören.

Es ist natülich nicht unproblematisch, den Begriff der Kausalităt auf die Situationen und Handlungen in einem fiktionalen Werk anzuwenden. Sie sind ja - wie R. Ingarden bewiesen hatte - intentionale Schopfungen des Autor-Subjektes und spielen sich in einer Seinssphäre ab, die außerhalb der temporal-kausalen Gegebenheiten der Realităt liegt. ${ }^{12}$ Vom Standpunkt der Lebenslogik und -kausalităt aus ist es ja gleichgultig, ob beispielsweise ein Schauspieler auf der Buhne einen lebenden Menschen spielt oder eine lebende Leiche. Ebenso irrelevant sind das Phantastische der Ereignisse oder ein nichtlinearer Verlauf der dargestellten Zeit. Richtiger ist es also, im Bereich der Fabel oder der Geschichte vom Kriterium der Wahrscheinlichkeit zu sprechen, das sich aufgrund der referentiellen Funktion der Sprachkunst konstituiert und sowohl fur die Situationen selost als auch rur de cusanuneiliange cwloulicil limen gulelg soln kans. Das konventionelle Drama des Realismus und Naturalismus ist in diesem Punkt weitgehend der Asthetik von Aristoteles verpflichtet, der in seiner "Poetik" als Gegenstand der Dichtung "das nach den Regeln der Wahrscheinlichkeit oder Notwendigkeit Moglichen bestimmte ${ }^{13}$. Die Einzelaspekte der Wahrscheinlichkeit einer kunstlerischen Darstellung wurden jedoch von Aristoteles nicht nărer bestimmt und so konnte dieser Begriff in einer

${ }^{12} \mathrm{Zu}$ Ingardens Thesen uber den Status der sog. "gegenstăndlichen Konsequenz" im literarischen Kunstwerk vgl. Ingarden, 1958, II: 444f.

${ }^{13}$ Aristoteles: Poetik, Kapitel 9; S. 29. 
jahrhundertelangen poetologischen und ăsthetischen Diskussion eine reiche Aura an Implikationen und Assoziationen bilden. Die Mehrdeutigkeit des Begriffes ist dabei im Phänomen selbst angelegt: künstlerische Wahrscheinlichkeit wird durch die Tradition der Darstellung und der Wahrnehmung bestimmt und eine Darstellung hat immer einen semiotischen und daher auch gesellschaftlich-konventionellen Charakter.

Eine eingehende Untersuchung der Wahrscheinlichkeits- und Realismus-Frage in einem Kunstwerk lieferte $R$. Jakobson in einer seiner fruhen Schriften ${ }^{14}$. Die realitătsbezogene Wahrscheinlichkeit einer Darstellung betrachtet Jakobson als Bedingung fur den Realismus in der Kunst, und er erstellt ein Paradigma an Aspekten der kunstlerischen Wahrscheinlichkeit sowohl auf der Produktions- als auch auf der Rezeptions-Ebene. Als das Kriterium einer "realistischen" Darstellung bestimmt Jakobson neben den historisch variablen Konventionen der Darstellung und der Wahrnehmung die "konsequente Motivierung, die Rechtfertigung von poetischen Konstruktionen ${ }^{15}$. Die Situationen und Handlungen in einem literarischen Werk werden in einer Weise eingefuhrt, die dem historisch gegebenen Weltmodell des Rezipienten entspricht und bei ihm die Illusion der Realitătsnăhe auslöst. ${ }^{16}$

In den Dramen von St. I. Witkiewicz gehört nun die Demotivierung von Handlungen zu den wesentlichen Deformationsverfahren auf der Ebene der Fabel. Wie schon weiter oben ausgefuhrt, lehnt Witkiewicz in seinen theoretischen Schriften die verschiedenen Motivierungsverfahren des Realismus und Naturalismus $a b$ und setzt sich in seinen Stucken in provokativuberzogener Weise uber diese Tradition hinweg. Wegen ihrer schockierenden Wirkung sind bei inm insbesondere alle die Situationen beliebt, die aus den gesellschaftlich tabuisierten Bereichen kommen wie z.B. Gewalt, Mord

14 Jakobson, 1981: 374-391.

${ }^{15}$ Ebd.: 389.

${ }^{16}$ Der Begriff der "Motivierung" gehörte zu den zentralen Forschungsgegenstănden im frühen russischen Formalismus (etwa bei V. Sklovskij, B. Ejchenbaum). Trotz einer gewissen terminologischen Inkonsequenz in der Begriffsverwendung unterschied man zwischen einer außerküstlerischen Kausalităt ("motivacija") und einer werkimmanenten, autonomen Gesetzlichkeit ("motivirovka") in den Beziehungen zwischen den Einzelelementen eines Werkes.

Vgl. dazu: Hansen-Löve, 1978: $197 \mathrm{ff}$. 
und Sexualităt. Das Todesereignis beispielsweise, das im konventionellen Drama im allgemeinen der Höhepunkt einer sorgfăltig arrangierten kausaltemporalen Kette von Situationen und Handlungen bildet, wird von Witkiewicz völlig unvermittelt eingeführt und als eine reversible Nebensächlichkeit behandelt. Der Tod in Witkiewicz' Dramen hat im allgemeinen nicht nur keine Ursachen, sondern auch keine der gewohnten Wirkungen, wie z.B. Trauer oder Betroffenheit. Ein schönes Beispiel fur diesen Kunstgriff ist eine Szene in dem Stück "Pragmatiker": Franz von Telek reagiert auf eine aufdringliche Liebeserklärung von Kobieton völlig unvermittelt mit einem schaurigen Mord, und die Umstehenden nehmen das vollig gleichgultig hin:

"Mit einer plötzlichen Bewegung zieht Franz v. Telek einen großen Polstererhammer aus der seitlichen Tasche seines Jacketts und zerschlägt damit den Kopf des knieenden Frauon. Der nămliche sinkt klagelos auf den Teppich. Franz atmet schwer. Plasfodor klappt ruhig das Album zu und trinkt noch einen Schluck Schokolade. Mamalla fuhrt weiter ihren freudigen Tanz auf." <Hervh. im Original> (Werke, IV: 218)

Bei einer gewissen Vertrautheit mit Witkiewicz' Dramen, ist es nicht weiter verwunderlich, daß in der năchsten Szene Frauons Leiche wieder am Geschehen teilnimmt: "<...> die Leiche von Frauon sitzt mit einem dick umwickelten Kopf auf dem Sofa" heißt es in der Regieanweisung am Anfang der nachfolgenden Szene. (Werke, IV: 219). Auf Befehl der Chinesischen Mumie fuhrt die Leiche später verschiedene Bewegungen wie Aufstehen, Kriechen etc. aus.

Fin ancrhallirhos Reispiel flir Witkiewicz' Technik der unmotivierten Handlung bzw. der bewußten Destruktion eines traditionell geltenden Motivierungsverfahrens ist auch eine makabre Szene in "Janulka, die Tochter des Fizdejko" (JCF). Fürst Fizdejko ordnet völlig unvermittelt ein Massaker unter seinen Bojaren an:

"FIZDEJKO:

Also laß uns spielen. Ich verurtelle alle Bojaren, meine Vasallen und Rivalen mit diesem müdlichen Urteil zum Tode. Unterschreiben werde ich nicht mehr, denn das realistische Regieren hat mich mude gemacht. Stellt Euch der Körpergröße nach auf.

Die Bojaren stellen sich in einer Reihe vor dem Thron auf. $\langle$...>

Und jetzt soll jeder denjenigen, der vor ihm steht, mit dem Beil 
erschlagen." (Werke, V: 346f)

Wie so oft in Witkiewicz' Stucken wird die Wirkung des innovativen formalistischen Kunstgriffes von der Wirkung des semantischen Gehaltes ubertroffen. Die realitătsnahe Problematik, die in dieser Szene berührt wird (Totalitarismus, MachtmiBbrauch, Menschenverachtung), løst - insbesondere bei dem heutigen Rezipienten, der die geschichtlichen Erfahrungen des Nationalsozialismus oder des Stalinismus vor Augen hat - Beklemmung und Grauen hervor. Die beabsichtigte Wirkung der Form tritt also vor der Wirkung des Inhalts zurllck.

Das Verfahren der Demotivierung bzw. der Destruktion von konventioneller Motivierung bezieht sich auf der Ebene der dramatischen Handlungen hauptsăchlich auf die Figurenpsychologie: Witkiewicz destruiert hier das naturalistische Verfahren der psychologischen Motivierung von Handlungen.

Auf der Ebene der dramatischen Situationen erscheint das Verfahren der Demotivierung als Abruptheit und Inkausalltät beim Zusammenfügen von Situationen. Auch in diesem Fall kann man von einer bewuBten Destruktion des in Witkiewicz' Zeit herrschenden Regelkanon des realistischen und naturalistischen Dramas. Die Tradition dieser mimetischen Stilrichtungen wurde zum großen Teil durch die aristotelische Poetik geprägt. Aristoteles beschreibt die "Beschaffenheit <der> Zusammenfügung der Geschehnisse" in einer Tragödie folgendermaßen:

"Ein Ganzes ist, was Anfang, Mitte und Ende hat. Ein Anfang ist, was selbst nicht mit Notwendigkeit auf etwas anderes folgt, nach dem jedoch natUrlicherweise etwas anderes eintritt oder entsteht. Ein Ende ist umgekehrt, was selbst natürlicherweise auf etwas anderes folgt, und zwar notwendigerweise oder in der Regel, wăhrend nach ihm nichts anderes mehr eintritt. Eine Mitte ist, was sowohl selbst auf etwas anderes folgt als auch etwas anderes nach sich zieht. Demzufolge dürfen Handlungen, wenn sie gut zusammengefügt sein sollen, nicht an beliebiger Stelle einsetzen noch an beliebiger Stelle enden, sondern sie müssen sich an die genannten Grundsătze halten. "'

Das aristotelische Kriterium fur die Zusammenfugung von Situationen bzw. Geschehnissen in einem Drama ist demnach das Kriterium der Folgerichtig-

${ }^{17}$ Aristoteles: Poetik. Kapitel 7. S. 25. 
keit, die auf Natürlichkeit, Notwendigkeit und Regelhaftigkeit beruht. Von großer Bedeutung ist in diesem Zusammenhang auch das Kriterium der Ganzheit und Geschlossenheit der "Handlung"18. Obwohl diese Begriffe, athnlich wie der Begriff der "Wahrscheinlichkeit", schon in ihrem Bedeutungsgehalt unpräzise und mehrdeutig sind und darubber hinaus auch in der jahrhundertelangen poetologischen Debatte einen weiten Raum an Konnotationen gebildet haben, kann aus ihnen ein grundlegender Bedeutungskern abstrahiert werden: In einem aristotelischen Drama werden Situationen und Handlungen derartig zusammengefugt, daß sie eine Xihnlichkeit mit den temporal-kausalen Gegebenheiten der außerkunstlerischen Welt evozieren.

In Witkiewicz' Dramen wird eine solche lllusionsbildung bewußt zerstort. Die Stucke sind voll von völlig Uberraschenden Wendungen, unvermittelt eintreffenden Ereignissen etc. Dabei gehen diese Uberraschungs-Effekte weit uber das bekannte Motiv des Zufalls hinaus, das ja eine lebenslogische Motivierung des Uberraschenden in literarischen Werken darstellt. Die Deformation von Lebenslogik bei der Zusammenfügung von Situationen in Witkiewicz' Dramen zerstört jegliche referentielle Dimension des Stuckes und entzieht dem Rezipienten jegliche vom Weltwissen geprăgte Verstăndnis- und Orientierungshilfen.

Trotzdem versteht es Witkiewicz zu vermeiden, daß die einzelnen Situationen und Handlungen in seinen Stucken völlig isoliert nebeneinander stehen und das Ganze ein Aggregat aus beziehungslos zueinander stehenden Einzelelementen wird. Fur die kompositorische Einheit des Stllckes sorgt allein die Verknupfung durch Uberschneidung der Figurenkonstellationen und durch gelegentliche situative und thematische Äquivalenzen, die den Text mit einem Netz von Assoziationen und semrekkurenzen uvet clelien mul dadurch das StUck "zusammenhalten".

Ein eindrucksvolles Beispiel fur diese Dramentechnik liefert Witkiewicz selber in einer seiner theoretischen Schriften:

"<...> Drei rotgekleidete Personen treten auf und verneigen sich, man weik nicht vor wem. Eine von ihnen deklamiert irgendein Gedicht

${ }^{18}$ Vgl. ebd.

Der Begriff der "Handlung" als einer seit dem 18.Jh. gebräuchlichen Ubersetzungsvokabel fur den aristotelischen "Mythos" entspricht in der Terminologie von M. Pfister, die in der vorliegenden Arbeit ubernommen wurde, in etwa dem Begriff der "Fabel". 
(es muß den Eindruck erwecken, gerade in diesem Augenblick notwendig zu sein). Ein sanfter alter Mann, der eine Katze an der Leine fuhrt, tritt auf. Bis hieiher vollzog sich alles vor einem schwarzen Vorhang. Der Vorhang geht auf, und eine italienische Landschaft ist zu sehen. Orgelmusik ist zu hören. Der Alte redet etwas mit den Personen, etwas, das eine zu allem Vorhergehenden passende Stimmung erzeugen muß. Von einem kleinen Tisch fallt ein Glas herab. Alle werfen sich auf die Knie und weinen. Der Alte verwandelt sich aus einem sanften Menschen in einen rasenden "Bewahrer" und ermordet ein kleines Mädchen, das kurz zuvor von der linken Seite herangekrochen ist. Darauf eilt ein schöner Jüngling hinzu und dankt dem Alten fur diese Mordtat, wăhrend die rotgekleideten Personen singen und tanzen. Anschließend weint der Jüngling uber der Leiche des Mädchens und sagt dabei sehr lustige Dinge, worauf der Alte sich wieder in einen sanften und gutigen Menschen verwandelt und in einer Ecke lachend erhabene und klare Ansichten außert." ( $T: 264$ ).

An diesem Beispiel kann man ablesen, worauf es Witkiewicz bei seinen Stücken ankommt. Die referentiellen Elemente werden deformiert und dadurch auch die am Weltwissen gebildete Erwartungshaltung des Rezipienten enttăuscht. Die natürliche oder regelhafte Folgerichtigkeit, die Aristoteles zum Prinzip der Handlungsstruktur erhob, wird von Witkiewicz parodistisch ins Negativum verkehrt. Die Handlungen und Situationen sind ohne jegliche gewohnte, lebenslogische Regeln aneinandergereiht; die Geschichte hat keinen "Sinn". Ästhetisch interessant wirkt die angefuhrte Beispielsszene jedoch durch folgende Aspekte: die rein formalen, z.B. optischen (Buhnenbild) und akustischen (Musik) Elemente; die angedeuteten Konflikte und die sehr "dramatischen" (im Sinne von "spannungsgeladenen") Einzelhandlungen (z.B. die Mordtat); rasch wechselnde, auffallig starke Gefuhle und Stimmungen (Freude und Trauer; Sanftmut und Tobsucht etc.). Die Dramen selber verlangen freilich, bedingt durch ihren Umfang, ein stärker ausgebildetes Gefuge an evozierten Assoziationen und Sinneinheiten, als das in der angefuhrten Beispielsszene der Fall ist. Wie schon erwăhnt, sind die Situationen und Handlungen in eine ubergreifende Struktur aus semantischen Äquivalenzen eingebunden. Doch im wesentlichen entspricht das Prinzip der Zusammenfugung von Situationen in den großen Dramen dem Strukturierungsprinzip in der angefuhrten Szene: das Drama ist voll von Uberraschenden Wendungen und Ereignissen.

Als Beispiel soll hier das Stück "Narr und Nonne" (WiZ) angefuhrt werden. Die wichtigsten Situationen und Handlungen auf der Fabel-Ebene können folgendermaßen wiedergegeben werden: Der Klosterschwester Anna wird ein 
never Patient in der Irrenanstalt anvertraut - der Dichter Walpurg. Walpurg verfuhrt seine Betreuerin. In der năchsten Szene zeigt er sich gegenuber seinen Arzten so "vernüftig", daß Dr. Grün, "ein Psychoanalytiker aus der Freud-Schule" (Werke, V: 251), glaubt, an ihm Behandlungserfolge zu bemerken und inn von der Zwangsjacke befreit. Es entwickelt sich ein Streitgesprăch mit Dr. Burdygiel - einem Psychiater der traditionellen Schule. Daraufhin ermordert Walpurg Dr. Burdygiel und verkündet: "jetzt bin ich vollkommen gesund" (Werke, V: 266), was Dr. Grun mit Begeisterung kommentiert: "Unglaublich. Er hat seinen Komplex selber ge16st." (Werke, V: 267). Walpurg wehrt sich nicht, als man ihm die Zwangsjacke wieder anlegt. In der Nacht befreit inn Schwester Anna von seiner Jacke. Die Liebenden werden von der Anstaltsleitung entdeckt. Walpurg begeht plötzlich Selbstmord. In der năchsten Szene treten Walpurg und Burdygiel - beide nicht nur wieder lebendig, sondern auch auffallend gepflegt und elegant angezogen - in das Zimmer, in dem sich Schwester Anna, die Anstaltsleitung und Walpurgs Leiche befinden, ein. Das Stück endet mit einer Schlägerei unter allen Anwesenden, laut Regieanweisung: "obszczaja rukopasznaja schwatka ${ }^{19}$ a la maniere russe". (Werke V: 276).

Die Fabel des Stuckes "Narr und Nonne" zeigt eine für Witkiewicz' Dramatik typische Verbindung von Tradition und Deformation. So sind die konventionell-literarischen Elemente beispielsweise in den Motiven der Verfuhrung und Verstellung sowie in der gelegentlichen Kritik an der Psychoanalyse, an der Borniertheit der Wissenschaft und an der burgerlichen Moral spurbar. Die deformativen Elemente dagegen werden insbesondere in den letzten Szenen des Stulckes deutlich. Diese Verbindung von Tradition und Deformation macht eigentlich den Reiz der Witkiewicz'schen Stucke aus: Das Beibehalten einiger literarisch-konventioneller Elemente und eine ubergreifende semantisch-narrative Struktur in jedem Drama verhindern den Eindruck von Beliebigkeit und Zwecklosigkeit, der von der deformativen, ungegenstăndlichen Kunst hăufig erweckt wird. Doch die traditionellen Elemente haben eigentlich immer nur einen funktionellen Charakter: sie erzeugen dramatische Spannung und lenken das Interesse des Rezipienten ganz im Sinne der theoretischen Äußerungen Witkiewicz' zu den soge-

${ }^{19}$ Polnische Transkription des russischen Ausdrucks: "obšcaja rukopašnaja schvatka" (dt.: ein allgemeines Handgemenge). 
nannten "Richtungsspannungen" in der ungegenstăndlichen Kunst ${ }^{20}$.

Ein weiteres Deformationsverfahren auf der Ebene der Fabel in Witkiewicz' Dramen besteht in der Uberlagerung von verschiedenen Fiktionsebenen. Diese Technik ist zwar keinesfalls eine Witkiewicz'sche Erfindung, doch sie wird von ihm auffallend hăufig und auf originelle Art benutzt.

Eine zutreffende Beschreibung der allgemein-dramaturgischen Praxis der Uberlagerung von Fiktionsebenen liefert M. Pfister:

"Dabei wird in eine primäre Spielebene, deren ontologischer Status durch die Fiktionalităt dramatischer Präsentation gekennzeichnet ist, eine zweite Spielebene eingelagert, die ein zusätzliches Fiktionsmoment mit sich bringt. Die zwei wichtigsten Formen, in denen sich eine solche Uberlagerung von Spielebenen realisiert, sind die Traumeinlage, in der das zusätzliche Fiktionsmoment in der Irrealităt des Traumes und in dessen konkreter Vergegenwărtigung auf der Buhne liegt, und das Spiel im Spiel, in dem die Fiktionalitat dramatischer Präsentation durch die Einfuhrung der zweiten Fiktionsebene einer Theaterauffuhrung im Rahmen der primären Spielebene potenziert wird." 21

Die Technik der Uberlagerung von Fiktionsebenen spielt in Witkiewicz' Dramen eine große Rolle. Sie ist schon im Zusammenhang mit Figurennamen und Figurenkonzeption in der vorliegenden Arbeit erörtert worden. ${ }^{22} \mathrm{~J}$. Błonski machte die auffallende Hăfigkeit dieser Technik zum Ausgangspunkt seiner bekannten intertextuellen Interpretation der Dramen von Wit$k^{k}{ }^{23}{ }^{23}$. Błonski versteht die Stücke als ein "Spiel im Spiel": die Helden veranstalten auf der Buhne ein kunstliches, deformiertes Leben, um zu dem wahren, jenseits der Bußeren Wirklichkeit stehenden Leben, vorzudringen und dadurch "metaphysische Gefuhle" zu erleben. Als Vorlage fur dieses "Spiel im Spiel" diene dabei nicht nur die außere Wirklichkeit, die deformiert wird, sondern auch die durch schon vorhandene literarische Werke entworfene fiktionale Welt. Witkiewicz' Dramen seien ein Gefuge aus literarischen Versatzstucken.

\footnotetext{
${ }^{20} \mathrm{~V}_{\mathrm{gl}}$. dazu Kapitel 2.1.4. in dieser Arbeit.

${ }^{21}$ Prister. 1988: $294 f$.

${ }^{22}$ gl. dazu Kapitel 3.1.2. und 3.2.1.1. in dieser Arbeit.

${ }^{23} \mathrm{Vgl}$. dazu auch Kapitel 3.2.1.2. in dieser Arbeit.
} 
Die Traumerzăhlung und die Traumeinlage, d.h. die im konventionellen Drama am hăufigsten vertretenen Formen der Uberlagerung von Fiktionsebenen, werden von Witkiewicz kaum benutzt. Die Gründe dafur düften gerade in der Popularităt dieser Kunstgriffe bei Witkiewicz' Zeitgenossen zu finden sein. Im Drama des ausgehenden Naturalismus (z..B. Strindbergs "Ein Traumspiel") oder des Impressionismus (hier wäre als Beispiel insbesondere der von Witkiewicz hăufig erwăhnte Maeterlinck zu nennen) war die Traumeinlage ein beliebtes Verfahren zur Darstellung des Innenlebens der Helden. In dieser Zeit ist auch ein weiter Umfang an Bühnenzeichen vom ikonischen Charakter entstanden, die dem Rezipienten die Grenzen zwischen den zwei Ebenen Fiktionalităt und Imaginiertheit verdeutlichten und damit auch die konventionelle, nichtepische Dramenform noch weitgehend beibehielten.

Die von Witkiewicz am hăfigsten benutzte form der Uberlagerung von Fiktionsebenen ist die des "Spiels im Spiel". Dabei wird die primăre Fiktionalităt des Bühnengeschehens mit der sekundăren oder gar tertiăren Fiktionalităt anderer Spielebenen verwoben.

Das "Spiel im Spiel" hat eine lange Theatertradition" ${ }^{24}$. Es ging meistens aus einer Gegenbewegung zur Illusions- und Identifikationsăsthetik hervor: so z.B. in der romantischen Komödie (etwa in L. Tiecks "Die verkehrte Welt" oder "Der gestiefelte Kater") oder in den epischen Tendenzen im Drama des frühen 20. Jahrhunderts (z.B. in L. Pirandellos "Sechs Personen suchen einen Autor" oder im Epischen Theater B. Brechts und E. Piscators).

In Witkiewicz' Dramen erfullt das "Spiel im Spiel" zumeist die Funktion des "obnaženie priema" (dt.: Bloßlegung des Verfahrens) im Sinne von V. Sklovskij. Fiktionalităt ist die Existenzform der im Dramentext entworfenen Gegenstăndlichkeiten: sie konstituiert damit also auch die form des Dramas selbst. Mit der impliziten Thematisierung der Fiktionalităt wird diese dramatische Form sichtbar gemacht und dem Rezipienten eine automatisierte Konkretisierung der dargestellten Gegenstăndlichkeiten vor dem Hintergrund bekannter Vorgänge der außerkünstlerischen Wirklichkeit erschwert. Das "Spiel im Spiel" in den Dramen von Witkiewicz entspricht also der Wirkung der Verfremdung, wie sie von Sklovskij beschrieben wur-

${ }^{24}$ gl. dazu: Schmeling, 1977; Voigt, 1954. 
$\mathrm{de}^{25}$. Wenn man an Witkiewicz' Ásthetik der Reinen Form denkt, so ist es auch verständlich, was ihn an der Uberlagerung von Fiktionsebenen reizte. Es war einerseits der formalistische Aspekt, nămlich die Moglichkeit, Form spübar zu machen, und anderseits der antimimetische Aspekt, der in den antiillusionistischen Momenten des "Spiels im Spiel" bestand.

In seinen Dramen benutzt Witkiewicz eine Reihe von verschiedenen Techniken, die eine Uberlagerung von Fiktionsebenen auslosen sollen.

Als erstes ist hier die Verbindung des äuBeren und des Inneren Kommunikationssystems im Drama zu nennen. Witkiewicz wendet hier all die Verfahren an, die man aus dem sog. Epischen Theater kennt: Publikumsansprache, Beiseitesprechen, Autothematisierung etc. Sehr hăufig findet man Thematisierungen des Stuckes und der Auffuhrungssituation, die von vielschichtiger Ironie getragen sind, wie beispielsweise in den "Schustern":

"1. GESELLE in höchstem Maße erstaunt:

Hier geht's ja genau so $z u$, wie es die unaufgeklärten Literatniks, diese Durcheinanderwlihler von Begriffssystemen, diese unreinen Monisten, in ihrer heiligen Zote beschreiben: 'das Leben ist Kunst, und Kunst ist Leben'! Dabei haben wir's hier, sehen Sie, auf unserer kleinen Schusterbühne, all das, was sich diese Wirrköpfe aus dem Finger saugen." (Werke, V: 500).

Ebenso hăufig sind die Verweise auf den Autor des Stuckes:

\footnotetext{
"SAJETAN:

Brauchst dich nicht zu schămen, Jędrek. Es stimmt nicht: Der biologische Materialismus, wie ihn der Autor dieses Stückes vertritt, meint etwas ganz anderes: das Ganze sel eine Synthese aus dem verbesserten Psychologismus Cornelius' und aus der verbesserten Monadologie Leibniz'. 〈...> " (Werke, V: 499).
}

Sajetans Replik ist ein nahezu wortliches Zitat aus Witkiewicz' philosophischem Hauptwerk "Der Daseinsbegriff und die von ihm implizierten Begriffe und Behauptungen". In der Zusammenfassung seines Werkes bezeichnet Witkacy sein System als eine 'Kombination von einem 'verbesserten' Psychologismus im Sinne von Hans Cornelius und einer gleichfalls 'verbesser-

${ }^{25}$ Sklovskij. 1981. 
ten' Leibnizschen Monadologie. Diese Kombination durfte wohl als eine Art des 'biologischen Materialismus' (im Gegensatz zum physikalischen) angesehen werden". 26

Ein sehr innovativer Kunstgriff Witkiewicz' besteht darin, daß die Schauspieler in einigen seiner Stucke ihr Rollenspiel für den Rezipienten deutlich machen: sie kommentieren gegenseitig ihre Rollen und ihre Sprechweise, machen Fehler, versprechen sich etc. ${ }^{27}$ Witkiewicz praktizierte also in den 20er Jahren eine ähnlich distanzierte Schauspielkunst, wie sie B. Brecht in seiner "Neuen Technik der Schauspielkunst" zwischen 1935 und 1941 theoretisch beschrieb.

In dem nachfolgendem Beispiel wurden die Äußerungen, die sich auf die Auffuhrungssituation beziehen, kursiv hervorgehoben.

\section{"FIZDEJKO:}

Also, dann laB uns, zum Teufel mit dieser teuflischen Komödie anfangen. Ich rede - darauf möchte ich euch hinweisen - mehr als Căsar Augustus. Er gestand alles erst am Ende und ich - gleich am Anfang. Und im ubrigen sind das andere Dimensionen und Koeffizienten: er begann, Rom zu ruinieren - und wir sitzen hier, wie alte Pilze, im tiefsten Innern der bolschewisierten Wälder - das helBt, was habe ich gesagt? Menschllchkeit? Weg damlt! Wir sitzen im Innern des Urwalds.

\section{MEISTER}

0 - jetzt ist es gut. Was wird dein erster Schritt als Herrscher sein? <...>" (Werke, V: 342f)

Dabei muß hervorgehoben werden, daß hier nicht etwa Wirklichkeit und Fiktionalităt vermengt werden, sondern eine primăre und eine sekundäre Stufe der Fiktionalităt: ähnlich wie in L. Pirandellos "Sechs Personen suchen einen Autor", spielen die "wirklichen" Schauspieler auf der Buhne Schauspieler, die wiederum ihre Rollen: Fizdejko bzw. Meister spielen. Es ist nicht so, daß durch die potenzierte Fiktionalităt die Kunst der Wirklichkeit năhergerUckt wird, wie das z.B. die Performance-X̌sthetik der 50er und 60er Jahre wollte, sondern es wird lediglich die Form der Kunst spürbar gemacht.

${ }^{26}<$ Deutsch im Original> Schriften, III: 543.

${ }^{27}$ Den ersten Hinweis auf diese Technik lieferte wahrscheinlich B. Błonski (1967a). 
Die oben beschriebene Verbindung der beiden Kommunikationsebenen in Witkiewicz' Dramen spielt sich eigentlich auf der Schicht der Bedeutungseinheiten ab.

Das Verfahren der Uberlagerung von Fiktionsebenen ist aber auch fur die Schicht der dargestellten Gegenstăndlichkeiten von großer Bedeutung: als "Spiel im Spiel" ist es konstitutiv fur große Teile der Fabel. Sehr bekannt in der Witkiewicz-Forschung wurde in diesem Zusammenhang die schon mehrmals erwahnte These von J. Błonski. Als grundlegende Konzeption des gesamten dramatischen Werkes Witkiewicz' betrachtet Błonski die Kategorie des selbstzweckhaften Spiels ohne jegliche referentielle Funktion:

"Die Einheit der Witkiewicz'schen Welt besteht in der Einheit des Spiels - des Figurenspiels - und in der Einheit des einmaligen Kunstwerkes - des Schriftstellerwerkes. Sie besteht aber nicht in der vereinbarten Einheit der konventionellen Form, die der Schriftsteller wăhlt, um eine bessere oder verstăndlichere Darstellung zu erreichen - eine Darstellung von Erscheinungen ${ }_{28}$ die typisch oder zumindest kennzeichnend fur die ăußere Welt sind. ${ }^{26}$

Błonskis Hauptinteresse gilt dem Handlungsziel der Figuren. Er greift bei seiner Dramenanalyse - methodisch nicht ganz unbedenklich - auf die geschichtsphilosophischen Schriften Witkiewicz' zuruck und bestimmt als das Handlungsziel der Figuren ihr Streben nach metaphysischen Gefuhlen bzw. nach dem Erleben des Geheimnisses der Existenz. Dieses Ziel wollten die Figuren durch ein künstliches, die äußere Wirklichkeit deformierendes Leben erreichen. Es wird hier ein alter Gedanke des Idealismus aufgenommen: das Spiel soll den Menschen von den Zwăngen und Grenzen der Scheinwirklichkeit befreien und inn fur das Wahre, fur die Idee empfanglich machen.

Błonski berucksichtigt jedoch kaum die rezeptionsästhetische Seite des "Spiels im Spiels", die ja im Hinblick auf Witkiewicz' ästhetische Theorie doch wesentlich interessanter erscheint. Die Thematisierung der Fiktionalităt lenkt die Aufmerksamkeit des Rezipienten auf das Werk als solches, auf sein Gemacht-Sein, auf seine Konstruktion. Diese Tatsache entspricht durchaus den von Witkiewicz formulierten ästhetischen Intentionen, und ihre Wirkung wird noch zusatzlich durch die verschiedenen Defor-

${ }^{28}$ Ebd.: 76. 
mationsverfahren im Drama unterstutzt. Da die Fabel sich auf keine temporal-kausale Ordnung einer herkömmlichen Geschichte stutzt, sondern durch Kontraste, Ubertriebene Beladenheit mit Ereignissen und Affekten, abrupte Situationsmodifikationen usw. geprăgt ist, wird dem Rezipienten ein automatisierter Weltbezug - etwa in Gestalt einer abstrahierten "Aussage" des Textes - verbaut und verweist inn auf die "reine" Form des Kunstwerkes.

Einen weiteren Aspekt der Uberlagerung von äuBerem und innerem Kommunikationssystem findet man innerhalb der Zeltstruktur.

Das außere Kommunikationssystem besteht auf der Ebene der Raum- und Zeitstruktur als der reale Buhnen- und Theaterraum sowie die reale Zeit der Schauspieler und der Zuschauer. Das innere Kommunikatiossystem dagegen entspricht dem fiktiven Raum und der fiktiven Zeit der dargestellten Geschichte. Eine strikte Trennung der beiden Kommunikationssysteme gehort zu den wichtigsten Merkmalen der Guckkastenbühne und der Illusionsăsthetik. In der Dramatik von Witkiewicz wird diese Trennung hăufig Uberwunden. Das geschieht jedoch nicht nur mit Hilfe von expliziten Thematisierungen der Spannung zwischen den beiden Kommunikationssystemen im Sinne der Brecht'schen V-Effekte. Witkiewicz versucht auch - und entspricht damit der Performance-Xsthetik der 60er und 70er Jahre - die fiktive und reale Dimension des Dramas zusammenzuschließen und das Publikum in das aufgefuhrte Stück miteinzubeziehen. Das "Spiel im Spiel" ist in den Dramen von Witkiewicz nicht nur fur die Fabel konstitutiv, sondern bezieht sich auch auf das Verhăltnis Bühne - Auditorium. Das Publikum wird in das Buhnengeschehen miteinbezogen und damit die fiktive Zeit und der fiktive Raum zerstort. Dieses Einbeziehen erfolgt mit Hilfe entsprechender Xußerungen der Flguren, wie beispielsweise in dem Drama "Die Mutter" (Matka):

\section{"LEON zum Publikum:}

Ich bitte Sie, die jetzige Situation als realistisch zu betrachten. Es ist etwas Unmittelbares, wie zum Beispiel die rote Farbe oder der Laut $A$, naturlich trotz der ganzen Komplikationen. Einige von Ihnen werden das fur eine Luge, fur einen Traum, fur ein Symbol oder weiB der Teufel was halten. Ich lasse ihnen vollige Interpretationsfreiheit, denn selbst wenn ich ihnen die Freiheit nicht găbe, willden sie alle sowieso das Gleiche tun." (Werke V: $414 f$ ).

Eine besondere Bedeutung bekommt in diesem Fall die historische Norm der Einheit von Zeit, Ort und Handlung. Für Witkiewicz' Dramen gilt in diesem 
Zusammenhang die Beobachtung, die M. Pfister für das moderne Drama im allgemeinen machte:

"Dieser Verzicht auf eine fiktive, von der Realităt abweichende raumzeitliche Deixis wird im folgenden dann als Erfullung der Norm der Einheit von Zeit, Ort und Handlung ausgegeben, wobei in pointierter Neudefinition der klassizistischen Konzeption - Einheit als luckenlose Kontinuität $\langle. .$.$\rangle - hier Einheit als die deiktische Einheit von$ Buhne und Auditorium gefaßt wird." ${ }^{29}$

Ein großer Teil der Dramen von Witkiewicz entspricht in der Raum- und Zeitstruktur der historischen Norm der Einheit von Raum und Zeit ${ }^{30}$, die als Bestandteil der Theorie von den drei Einheiten in der dramentheoretischen Diskussion seit der Renaissance eine große Rolle spielt. Diese Norm besteht bekanntlich in der Forderung nach einer einzigen linear und kontinuierlich durchgefuhrten Fabel und nach einer raum-zeitlichen Kontinuităt des Dramas oder - negativ ausgedrúckt - im Verbot von Schauplatzwechseln und zeitlichen Aussparungen. In der Renaissance- und Klassizismuspoetik wurde diese Einheitsforderung zum dramaturgischen Kanon erhoben. Man berief sich dabei theoretisch auf Aristoteles, der jedoch in seiner "Poetik" ausdrucklich nur die Einheit der Fabel forderte, wăhrend er die Einheit des Raumes Uberhaupt nicht behandelte und die Einheit der Zeit nur kurz als eine Eigenschaft der Tragödie erwăhnte, innerhalb eines "Sonnenumlaufs" abgewickelt zu werden. ${ }^{31}$ Praktisch aber bedeutete die neuzeitliche Theorie der drei Einheiten eine Unterstutzung des besonderen Charakters der Guckkastenbuhne: sie verfestigte die Trennung zwischen dem ăußeren und dem inneren Kommunikationssystem und forderte damit die IIlusions- und Identiflkationswirkung. Der Zuschauer sollte die Buhne nicht als einen Ort des Spiels, sondern als einen Ausschnitt aus der außerkünstlerischen Realităt erleben. Vor diesem Hintergrund ist es auf den ersten Blick uberraschend, diese traditionelle und schon im ausgehenden 18. Jahrhundert hăufig abgelehnte Norm der drei Elnheiten bei einem Avantgarde-KUnstler des 20. Jahrhunderts wiederzufinden. Doch der Uberwiegende Teil der Dramen von Witkiewicz folgt den unterschiedlichen, mehr

${ }^{29}$ Pfister, 1988: 329.

${ }^{30} V_{g l}$. dazu z.B.: Klotz, 1960; Putz, 1970.

${ }^{31}$ Vgl. dazu: Aristoteles: Poetik. Kapitel 7-8. S.25ff. 
oder weniger engen Auslegungen der Einheitennorm in den Poetiken der $\mathbf{R e -}$ naissance. So entspricht die Raum- und Zeitstruktur in den Dramen "Neue Befreiung" (NW), "Der Tintenfisch" (M), "Verrückte Lokomotive" (SL) der rigorosen Interpretation der Einheit des Ortes als eines unveränderten Schauplatzes und der Einheit der Zeit als einer Deckung von realer Spieldauer und fiktiver, gespielter Zeit: die genannten Dramen spielen sich an einem Ort und innerhalb weniger Stunden ab. Einige Dramen Witkiewicz' folgen der etwas weiteren Auslegung der Einheitenregel: die dargestellte Zeit entspricht der aristotelischen Forderung: "innerhalb eines Sonnenumlaufs", und der dargestellte Raum beschränkt sich auf die verschiedenen Răume eines Hauses oder einer Stadt - so beispielsweise in "Gyubal Wahazar", "Jan Maciej Karol Wuterich" (JMKW), "Narr und Nonne" (WIZ), "Pragmatiker", "Die da" (Ont) "Im kleinen Landhaus" (WMD), "Beelzebubsonate" (SB) , "Das namenlose Werk" (BD) . "Grazien und Vogelscheuchen" (NiK) .

Bei einer genaueren Betrachtung, stellt sich freilich heraus, daß von einer Fortfuhrung der klassizistischen Traditionen bei Witkiewicz nicht die Rede sein kann. Der Kunstler ubernimmt zwar die außere Form dieser Tradition (Zeit- und Raumkontinuităt), zerstört aber gleichzeitig die beabsichtigte Wirkung (Illusion und Identifikation) durch eine glaubwirdige Abbildung der außerkünstlerischen Wirklichkeit auf der Guckkastenbuhne. Man kann also in diesem Fall berechtigterweise von Parodie sprechen. Die Destruktion erfolgt mit Hilfe der schon beschriebenen Deformationsverfahren. Sie bewirken, daß trotz der außerlichen Raum- und Zeitkontinuităt weder der dargestellte Raum noch die dargestellte Zeit als ein Abbild der außerküstlerischen Wirklichkeit akzeptiert werden können. Als Beispiel fur solche parodistischen Verfahren eignet sich besonders gut die "Verruckte Lokomotive". Das Drama hat eine klassizistische, streng "geschlossene Form" ${ }^{32}$ : linearer Fabelverlauf; ein einziger Schauplatz; ein kontinuierlicher Zeitverlauf von wenigen Stunden. Doch der dargestellte Raum und die dargestellte Zeit können weder geographisch noch historisch bestimmt werden: Die Figuren haben Phantasienamen aus unterschiedlichem Sprachmaterial (polnisch, lateinisch, deutsch, französisch) oder sie sind Anspielungen auf andere Dramen ("Minna, Grăfin de

${ }^{32} V_{g 1}$. Klotz, 1960. 
Barnhelm"). Der Zugfuhrer trägt eine österreichische Uniform, doch der Zielort des Zuges hat einen englischen Namen ("Dumbell-Junction") und im Abfahrtsort sind Wolkenkratzer $2 u$ sehen $^{33}$ etc.

Die historische Unbestimmtheit der dargestellten Zeit sowie die allgemeine Relativität des Zeitbegriffes wird in dem Drama "Janulka, die Tochter des Fizdejko" (JCF) auf sehr eindrucksvolle Weise von den Figuren selber reflektiert:

\footnotetext{
"FIZDEJKO:

Papa, hör' doch auf, von 'unserer Epoche' zu sprechen. Das ist keine Epoche, sondern irgendeine Stauung von Anachronismen. Ich weiB selber nicht, in welchem Jahrhundert ich lebe: im vierzehnten oder im dreiundzwanzigsten.
}

\section{v. PLASEWITZ:}

Unsere Epoche ist eben eine Epoche von Menschen jenseits der Zeit. Die Zeit ist relativ geworden, sogar in der Geschichte. Fruher gingen die Verănderungen langsam vor sich. Bei unserer Beschleunigung mulssen wir auch in der Geschichte die Formeln von Einstein akzeptieren. Unsere epochale Bedeutung beruht auf dem Entgleiten aus den zyklischen Gesetzen der Geschichte. Wir fliegen auf der Tangente.

$\langle\ldots\rangle$

FIZDEJKO:

<...> jetzt verstehe ich: - In unserer Epoche müssen wir entsprechend der Geschwindigkeit der Ereignisse eine immer längere Zeit annehmen. Das fuhrt dazu, daß je weiter wir in die Geschichte hineingeraten, desto länger wird uns die Zeit aufgrund der Langeweile." (Werke, V: 317)

Mit Hilfe derartiger Deformationsverfahren wird die referentielle Dimension der Raum- und Zeitstruktur in den Dramen von Witkiewicz zerstört und die klassizistische Norm der drei Elnheiten um ihre beabsichtigte Wirkung gebracht: die Entstehung einer Illusion und einer Identifikation beim Rezipienten wird unmbglich gemacht. Trotz des peinlich genauen Einhaltens der ăuBeren Form der Einheitenregel gelingt es Witkiewicz, den ursprünglichen Gehalt dieser Regel auszuhöhlen.

Neben einer solchen parodistischen Behandlung der klassizistischen Norm der drei Einheiten spielt die Einheit von Raum und Zeit auch noch - wie weiter oben beschrieben - innerhalb des Phänomens der Uberlagerung des ăußeren und inneren Kommunikationssystems eine große Rolle. Die Regel der

${ }^{33}$ Vgl. Werke, V: $280 f f$ 
drei Einheiten hilft die fiktive raum-zeitliche Dimension des inneren Kommunikationssystem zu durchbrechen und eine Einheit zwischen Bünne und Auditorium herzustellen.

Als Beispiel für die Funktion des Spiel-im-Spiel-Phănomens in der Fabel eines Dramas von Witkiewicz soll hier "Neue Befreiung" ( $N W$ ) angefuhrt werden. Wie immer bei Witkacys Stucken ist es auch bei der "Neuen Befreiung" eigentlich unmoglich, eine Geschichte, d.h. eine temporal-kausale, am Weltwissen des Rezipienten orientierte Ordnung, aus dem Geschehen zu abstrahieren. Doch man kann eine ubergreifende semantische Struktur erkennen, die dem Drama zugrunde zu liegen scheint. Es handelt sich um die aus dem Symbolismus und der Décadence-Epoche bekannten semantischen Oppositionen: "Endlichkeit vs. Unendlichkeit" "Lebensuberdruß vs. Lebensbejahung" etc., die sich sowohl in Witkiewicz geschichtsphilosophischen Schriften (etwa in dem Schlagwort "Unersättlichkeit") als auch in vielen seiner Dramen widerspiegein. In dem Drama "Neue Befreiung" spielt z.B. bei der Figurenkonstellation die Opposition "großes Individuum" (König, Tatjana) vs. "angepaßter Philister" (Florestan) oder "die Masse" (Mörder, Schurken, Jemand) eine große Rolle. Die Dialoge entwickeln sich als Diskussion uber "Metaphysik" vs. "Physik"; "Unersättlichkeit" vs. "Genügsamkeit"; "Freiheit und Größe" vs. "philisterhafte Selbstbeschränkung" etc.

Der Einakter hat - ăhnlich wie "Die Pragmatiker" - den Charakter eines knappen Experimentalstuckes: $\mathrm{Er}_{r}$ ist einerseits relativ unaufwendig was die Personal- und Bühnenausstattung anbetrifft, anderseits aber treten in ihm fast alle für Witkiewicz typischen dramaturgischen Mittel in verdichteter Form auf.

Von besonderem Interesse ist hier die Slmultantechnik: das Stuck ist durchwoben von verschiedenen Fiktionsebenen und Zeitdimensionen. Die unterschiedlichen Zeitdimensionen werden dem Zuschauer gleich am Anfang des Stückes durch das Buhnenbild und die Kostüme suggeriert. Darin kommen einerseits mittelalterliche Attribute vor: "gotische Pfeiler"; "riesiger Saal": König Richard III trägt "eine Teil-Rüstung" und "ein großes, mit zwei Hănden zu fuhrendes Schwert" (Werke, IV: 339). Anderseits aber steht als Kontrast daneben das vertraute Ambiente eines bürgerliches Wohnzimmers: "dunkelolivgrunes Sof a" "kleiner, gelber Tisch" etc. Simultan nebeneinander verlaufen auch die zwei Handlungssequenzen am Anfang des Stückes: während König Richard III von zwei Mördern bedroht und zum 
Stehen am Pfeiler genötigt wird, findet daneben eine Szene aus dem bürgerlichen Familienleben statt - mit einer Mutter, die Handarbeiten macht und ihre frisch aus der Klosterschule entlassene Tochter in ihr bevorstehendes burgerliches Eheleben einweiht. Tatjana erweist sich als die Spielleiterin des Geschehens, die sowohl dem Mådchen "Zabawnisia" (dt.: etwa Spielinchen) die Regeln des bürgerlichen Lebens und potentielle Heiratskandidaten vorfuhrt ("Ich zeige dir heute einen neuen Menschen. Sein Name ist Florestan" (Werke, IV: 343), als auch die Folter des Konigs organisiert:

\section{"TATJANA:}

Das ist Richard III. Er bekam unbefristeten Urlaub und fuhrt seine Buße aus. Es ist elne von mir arranglerte Komödie. <Hervh. d. Verf. - A.S.> (Werke, V: 346)

Beide Handlungssequenzen erheben für sich den Anspruch auf Wirklichkeit und weisen sich gegenseitig den fiktionalen Status zu. So sagt der König:

"Jeden Tag muß ich eure scheußlichen Dramen mitansehen, eure herausgerissenen psychischen Gedärme samt Inhalt, eure metaphysischen Nabel, die auf Stöckchen gespießt und wie kandierte Fruchte verkauft werden". (Werke, IV: 345).

Und kurz darauf macht Zabawnisia folgende Bemerkung uber den König:

"Herr Florestan, es mußte doch schon genug sein, sich mit diesem Strohmann zu beschăfigen. Das ist kein wirklicher Mensch." (Werke, IV: 346$)$.

Die beiden Handlungssequenzen uberschneiden sich und verlaufen zeitweise zusammen: zu einer bestimmten Tagesstunde schlafen die Folterknechte des Königs ein und er selber nimmt wie ein Familienvater am Tisch Platz.

In den letzten Szenen kommt es dann zur Entlarvung der Figuren und zur Zerstörung des "bügerlichen Spiels": Florestan wird als ein Hochstapler, Tatjana als seine Geliebte und Florestans Mutter als die Geliebte des Königs entlarvt. Das "bürgerliche Spiel" Tatjanas bricht wie ein Kartenhaus zusammen. Es treten neue, namenlose Gestalten auf ("Jemand", "Schurken"), die nun die Spielleiterfunktion von Tatjana ubernehmen und ein neues Spiel beginnen: der König wird respektvoll vertrieben und an seiner 
Stelle Florestan gefoltert. Die Haushalterin kommentiert die neue Situation folgendermaßen: "Na, jetzt geht das Spiel erst richtig los" (Werke, IV: 359).

In dem Drama "Neue Befreiung" wird also schon mit Hilfe der verschiedenen Zeitdimensionen und Handlungssequenzen eine fur den Zuschauer verwirrende Potentialisierung der Fiktionalităt erreicht. Der Effekt wird noch durch die zahlreichen intertextuellen Bezulge des Stúckes verstărkt. König Richard III ist fü den Rezipienten leicht als eine Figur aus dem Shakespeare-Drama erkennbar. Daruber hinaus gibt es deutliche Anspielungen auf einige andere Werke: S. Wyspianskis "Befreiung"; L. v. Beethovens "Fidelio" (Witkacy Ubernimmt den Namen Florestan für eine seiner Hauptfiguren) und J. Conrads "Almayers Wahn" (den beiden Werken gemeinsam sind die drei Gongschläge, die jeden neuen Besuch ankundigen).

Das Phănomen der Intertextualităt in Witkiewicz" "Neue Befreiung" ist in der Forschung seit langem bekannt. Eine ausfuhrliche Untersuchung der intertextuellen BezUge sowohl unter dem biographisch-genetischen Aspekt als auch im Hinblick auf seine Funktion fur die Struktur des Dramas lieferte L. Sokof ${ }^{34}$. Seine Analyse soll hier nicht in allen Einzelheiten wiedergegeben werden, doch das Schlußergebnis ist für die vorliegende Arbeit interessant:

"<Witkiewicz> geht wie ein Weber vor, der vielfarbige Fäden hernimmt und sie zu einem eigenen, hochst originellen, in seiner Art einzigartigen Muster zusammensetzt. Die Beziehungen zu Wyspianski und Shakespeare beweisen auf paradoxe Weise die Originalitat seines Dramas: sie sind der Stoff, dessen Elemente, nachdem sie in eine ganz andore Finhoit angofligt worden aind. airh ihren Regeln interwerfen und ihr ursprüngliches Wesen vollig verändern. Im Falle der "Neuen Befreiung" ist es schwierig, abgesehen vielleicht von einigen Einzelheiten, bei Witkiewicz eine parodistische Intention im Hinblick auf seine Vorlagen zu sehen. Er benutzt vielmehr, bzw. er ubernimmt - wie wir gesehen haben - bestimmte Konzeptionen, Motive, Bilder. Das Wichtigste: künstlerische Vision und Problematik gehören ihm ganz alleine und in den wesentlichen Angelegenheiten braucht er weder Wyspianski noch Shakespeare. Der Parodie-Anschein entsteht wahrscheinlich deshalb, weil Witkiewicz ein sehr deformiertes Weltbild prassentiert. Jede Parodie ist ja auch eine Deformation."

\footnotetext{
${ }^{34}$ Sokót, 1973: 88-99.

${ }^{35}$ Ebd.: $98 f$.
} 
Sokót argumentiert mit Recht gegen die Parodie-These, die in der Witkiewicz-Forschung lange Zeit zur Bezeichnung der intertextuellen Bezüge herhalten mußte. Die Begriffe der Parodie, Travestie oder der Literatursatire können auf Witkiewicz' intertextuelle Verfahren nicht angewendet werden, weil sie ein bestimmtes, im allgemeinen auch ein bekanntes und geschätztes Objekt voraussetzen, das in dem parodierenden Werk durchgehend und systematisch angegriffen wird. In den Dramen von Witkiewicz dagegen treten die intertextuellen Reminiszenzen zerstreut auf und beziehen sich auf verschiedene Werke. Für eine zutreffende Bezeichnug des Intertextualităts-Phănomens bei Witkiewicz scheint der Begriff der Montage geeignet zu sein.

In Anbetracht der leicht inflatorischen Verwendung dieses Begriffes in der Umgangs- und auch in der Wissenschaftssprache soll hier den weiteren Darlegungen die Definition von V. Żmegac zugrundegelegt werden. Zmegac definiert Montage als ein Verfahren (und auch ein Ergebnis), "fremde Textsegmente in einen eigenen Text aufzunehmen, sie mit eigenen zu verbinden bzw. zu konfrontieren." Collage wäre dann ein Unterbegriff von Montage, "ein Extremfall $\langle\ldots$.$\rangle , als der Text \langle\ldots\rangle$ ausschlieblich entlehnte, aus verschiedenen Quellen stammende Elemente enthielte." 36

Witkiewicz' Technik in der Verwendung von Versatzstücken aus der Literatur und aus anderen Bereichen kommt dem Montage-Verfahren sehr nahe. Er ubernimmt in seinen Text Motive, Figuren und andere Versatzstucke aus bekannten literarischen Werken in Form von Zitaten, Allusionen, Paraphrasen etc. Daruber hinaus setzt er konventionelle Sprachstile (pathetisch, melodramatisch, vulgär, etc.), Dialekte und Idiolekte (z.B. Fachsprache) In ahnlicher Welse eln: Dadurch, daß die Redeweise der Figuren ihrem sozialen Stand, ihrer Bildung oder auch der konkreten Situation nicht entspricht, wird die Rede zur einen fremden Rede, zu einem Zitat verfremdet. Eine solche Wirkung stellt sich ein, wenn z.B. ein Heizer und ein Lokomotivfuhrer sich uber Einsteins Relativitătstheorie unterhalten (SL) oder einige Schuster in ihrem Tatra-Dialekt Uber Kretschmers "Korperbau und Charakter" philosophieren (Sz). Xhnliche Effekte erzielt Witkiewicz auch durch die nahezu beliebige Mischung von konventionellen literarischen Stilarten wie Telegrammstil, Melodrama-Stil und die "romantische oder

${ }^{36}$ Borchmeyer/Zmegac (Hrsg.), 1987: 259. 
modernistische Phraseologie der Seelenzustände und innerer Qualen ${ }^{\text {"37 }}$ in seinen Dramen. Derartig verfremdete Redeweisen werden montageartig, hăufig ohne eine logische semantische Verbindung, zu einem Dialog zusammengefügt. Die Montage-Technik Witkiewicz' hat einen demonstrativen Charak$\operatorname{ter}^{38}$. Es geht nicht darum - wie im konventionellen Werk - fremdes Textmaterial aus Grüden der höheren Authentizităt und besseren Wirklichkeitsnachahmung in das eigene organisch-illusionistisch abgeschlossene Werk aufzunehmen. Witkiewicz' Montage-Technik weist vielmehr - ahnlich wie dadaistische Werke - auf die Konstruktion, auf das Gemacht-Sein der Kunst hin. Die in der vorliegeden Arbeit schon hăufig festgestellten kunstlerischen Intentionen Witkiewicz': Vermeidung einer referentiellen Funktion durch die Deformation und Hinfuhrung des Rezipienten auf die Form des Kunstwerkes, entsprechen weitgehend den Funktionen der Montage, wie sie von V. Zmegac herausgearbeitet wurden:

\begin{abstract}
"Das eine Moment des Verfahrens ist ein metapoetlsches: Die M.<Montage> legt die Machart des Textes frei und lenkt damit den Blick des Lesers/Beobachters auf die Technik der Literatur/Kunst. Die eigentliche Problematik ist in diesem Fall kunstphilosophisch, denn die M. signalisiert, wohl mehr als analoge Stilmittel, einen Bruch mit der organologischen Ästhetik. Das andere Moment zielt auf einen Erkenntnisschock ab und ist darin der Verfremdung verwandt. Die aus diesem Grunde provozierend genannte $M$. arbeitet zumeist mit scharfen Kontrasten, d.h. mit der Gegenuberstellung von Erfahrungsbereichen, die ublicherweise nicht miteinander in Verbindung gebracht werden. <...> Das Disparate wird durch die $M$. als etwas nur vermeintlich vollig Unverbundenes gezeigt, so daß die Erkenntnisarbeit des Rezipienten hier ihren entscheidenden Ansatz findet: in der Kritik herkömmlicher Rubrizierung."
\end{abstract}

Die Erkenntnisfunktion, die Żmegac im Gefolge der philosophischen Tradition von E. Bloch und Th.W. Adorno der Montage zuschreibt, wird von Witkiewicz freilich weder in seinen theoretischen Schriften gefordert, noch ist sie in seinen grotesk-absurden Dramen faßbar. Wie schon mehrmals erwahnt, will Witkiewicz Uber das Formerlebnis in der Kunst dem Rezipienten eine existentielle Grunderfahrung und damit ein "metaphysisches Gefuhl"

\footnotetext{
37 Błonski, 1967a: 74.

${ }^{38} \mathrm{Vgl}$. Borchmeyer/Zmegac (Hrsg.), 1987: 260.

${ }^{39}$ Borchmeyer/Zmegac (Hrsg.), 1987: 261.
} 
vermitteln $^{40}$

Es stellt sich nun die Frage nach der "Einheit in der Vielfalt" der disparaten dramaturgischen Einzelelemente, die von Witkiewicz scheinbar wahllos zusammengefugt werden. Gibt es ein Moment, der eine Elnheit der Fabel, trotz der Deformation der referentiellen Dimension des Stuckes garantiert? Welche Verfahren und Phănomene fugen die dramatischen Situationen und Handlungen zusammen, wenn das am Weltwissen orientierte kausal-temporale Gerist der Geschichte fehlt?

Dieser Frage soll im folgenden an der exemplarischen Analyse des Dramas "Pragmatiker" nachgegangen werden. Dieses Drama nimmt eine besondere Stellung im Schaffen Witkiewicz' ein: es ist eines der wenigen Werke, die noch zu seinen Lebzeiten bekannt geworden und breit diskutiert worden sind. Es wurde relativ fruh (1920) publiziert und 1921 in dem Warschauer Avantgardetheater "Elsynor" uraufgefuhrt. Witkiewicz hielt am Tag der Premiere einen Vortrag ("O Czystej Formie") Uber seine ăsthetische und dramaturgische Konzeptionen und loste eine breite publizistische Diskussion Uber seine Theorie und sein Stuck aus ${ }^{41}$.

Der experimentelle und demonstrative Charakter der "Pragmatiker" spiegelt sich im Aufbau wider: sein relativ geringer Umfang und die geringe Anzahl der Figuren machen das Stück ideal geeignet fü die kleine Buhne und das kleine Ensemble eines elitären Experimentiertheaters. Wegen seines kompakten und innovativen Charakters wurde das Drama "Pragmatiker" auch hier fur eine exemplarische Analyse ausgewăhlt.

Die Geschichte, die der gegenständlichen Schicht dieses StUlckes zugrundeliegt, kann etwa folgendermaßen wiedergegeben werden: Plasfodor Mimęcki, ein verhinderter Kunstler, schăndet seine achtjăhrige Schwester Mamalia und mikhandelt einige Jahre spater in Saigon die chinesische Prinzessin Tsui: er verfuhrt sie in einer kleinen Bambushutte und saugt "den letzten Schluck ihres Blutes mit Hilfe eines Strohhalms aus dem getrockneten Gras Wu aus". (Werke, IV, 206). Mamalia, die dieser schrecklichen Tat beiwohnt, verliert daraufhin ihre Sprache. Diese Situationen werden nicht direkt auf der Buhne dargestellt, sondern es wird am Ende des ersten Ak-

\footnotetext{
${ }^{40} \mathrm{~V}_{\mathrm{gl}}$. Kapitel 2.1.2. in dieser Arbeit.

${ }^{41}$ ggl. dazu: Degler, 1973: 35-51.
} 
tes episch uber sie berichtet. Das Drama selbst beginnt funf Jahre nach diesen chronologisch geschilderten Vorgängen. Mamalia und Plasfodor fuhren zusammen ein exzessives und gleichzeitig qualvolles, unbefriedigtes Leben, das Plasfodor mit folgenden Worten ironisch kommentiert:

"Diese schreckliche Banalităt der Existenz. Es ist vier Uhr nachmittags. Danach gibt es das Abendessen, dann eine Orgie, dann eine Séance, dann năchtliche Alptrăume, dann die gewöhnliche Portion von Aufputschmitteln. Oh! Es ist nicht auszuhalten." (Werke, IV:. 204).

Die unzusammenhängenden, befremdenden Dialoge der Hauptfiguren kreisen um die semantischen Oppositionen "Leben" vs. "Tod". "Endlichkeit" vs. "Unendlichkeit". Dabei werden dem Zuschauer keine bewußt handelnden und rational diskutierenden menschenahnlichen Figuren vorgefuhrt, sondern eher, wie D.C. Gerould zutreffend bemerkte, die Psyche und das Gehirn von potentiellen Selbstmördern veranschaulicht ${ }^{42}$.

Den Gegenpol zu den beiden gespenstischen Gestalten Plasfodors und Mamalias bildet der Graf Franz von Telek - ein bodenstăndiger Vertreter der Wirtschaft, der seine bürgerliche Vitalităt und Unempfindlichkeit immer wieder mit den Worten zum Ausdruck bringt: "ich bin gesund wie ein Stier". Wie schon für andere Dramen Witkiewicz' nachgewiesen, ist auch in dem StUck "Pragmatiker" an der Figurenkonstellation sofort auch das semantische GerUst des Dramas ablesbar, nämlich die Opposition zwischen einem diesseitsorientierten, philisterhaften Leben und dem Streben nach Unendlichkeit und nach metaphysischen Erlebnissen.

Ein weiterer thematischer Strang - Thematik des Geschlechterkampfes wird ironisch in der Gestalt der Dienerin symbolısiert - eines anarogynen Wesens namens "Kobieton" (dt. etwa Frauon).

Am Ende des ersten Aktes erscheint die vermeintlich tote Prinzessin Tsui als Chinesische Mumie auf der Buhne. Sie erzăhlt nun die ganze Vorgeschichte und entfuhrt zum Schluß Mamalia, Kobieton und Plasfodor in ein jenseitiges Reich, das durch den "dunklen Schlund der offenen Tur" (Werke, IV: 221) symbolisiert wird. Es findet die von Witkiewicz in seinen Schlußszenen hăufig verwendete Technik der Segregation statt: wăhrend die Gruppe der lebensuberdrussigen und metaphysisch empfindenden Figuren die

${ }^{42}$ Gerould, 1981b: 106. 
Bühne verläßt, bleibt zurück der philisterhafte, "wie ein Stier gesunde" Franz von Telek.

Die hier dargestellte Geschichte liegt als Fabel im Drama fast unverändert vor. Der einzige Unterschied besteht im temporalen Ablauf: das Drama beginnt funf Jahre nach den schrecklichen Ereignissen in Saigon, die Vorgeschichte erfahrt der Rezipient erst am Ende des ersten Aktes aus der Erzăhlung der Mumie.

Es ist offensichtlich, daß das Stuck "Pragmatiker", trotz der vielen deformativen und innovativen Elemente, letztendlich auf einem traditionellen dramatischen Konflikt und auf einer traditionellen Losung basiert. Die Geschichte ist eingespannt zwischen den semantischen Merkmalen: "begangene Schuld" und "nachfolgende Suhne". Witkiewicz greift nicht nur mit der Figur der Chinesischen Mumie auf den schon aus dem antiken Drama bekannten Typus der "Rachefigur aus der Vergangenheit" zurllck, sondern auch auf ein traditionelles Konfliktmuster. Dabei bleibt er - und das gilt für alle seine Dramen - in der Technik der Konfliktbildung und -lossung im Rahmen der bekannten Kriterien der narrativen Struktur. Die Darstellung der Geschichte in dem Stück "Pragmatiker", die zwischen den beiden Polen "Schuld" und "Suhne" eingespannt ist, folgt im wesentlichen dem in der strukturalistischen Forschung erarbeiteten narrativen Modell fur das erzahlte Geschehen: Ausgangsposition - Mangelposition - Mediation bzw. Neutralisation - Ausgangsposition ${ }^{43}$. Oder wie das T. Todorov mit den Begriffen der "Intrige" und des "Gleichgewichtes" beschrieben hat:

"Man kann die minimale vollstăndige Intrige als den Weg von einem Gleichgewicht zu einem anderen darstellen. Dieser Begriff 'Gleichgewicht', den ich der genetischen Psychologie entnehme, druckt das Vorhandensein einer dauerhaften, aber dynamischen Beziehung zwischen den Gliedern einer Gesellschaft aus; es ist ein soziales Gesetz, eine Spielregel, ein bestimmtes System des Austausches. Die zwei ahnlichen und verschiedenen Momente des Gleichgewichtes sind durch eine Periode der Gleichgewichtsstörung getrennt, die durch einen Proze $B$ der Degradation und der Verbesserung bestimmt ist".

Eine "soziale Spielregel" im Sinne Todorovs durfte fur das Drama "Pragmatiker" der Satz: "Ein Verbrechen erfordert die gerechte Strafe" bilden.

\footnotetext{
${ }^{43}$ Vgl. dazu z.B.: Keller/Hafner: 1990: $57 \mathrm{ff}$.

${ }^{44}$ Todorov, 1972: 273.
} 
Unabhängig davon, ob man diese Aussage als einen Ausdruck des menschlichen Rachegefuhls oder als eine ethische Norm begreift, ist es verstăndlich, daß eine solche Regel beim Rezipienten bestimmte Erwartungen an das Geschehen und damit auch die Spannung auf seine Fortsetzung hervorruft. Das Verbrechen, das Plasfodor an Mamalia und an der Prinzessin Tsui einst begangen hatte, erfordert im Erwartungshorizont des Rezipienten eine gerechte Strafe. Die Erwartung dieser Strafe konstituiert gleichzeitig die dramatische Spannung.

Ein weiteres Moment der dramatischen Spannung kommt aus dem semantischen Gerust des Textes. Die semantischen Einheiten im Drama "Pragmatiker" haben einen existenzialphilosophischen und archetypischen Charakter "Kampf der Geschlechter" sowie die Oppositionen: "Endlichkeit" vs. "Unendlichkeit"; "Leben" vs. "Tod"; "Existenz" vs. "Nichts"; "gesellschaftliche Moral" vs. "individualistische Willkür". Diese semantischen Einheiten werden jedoch nicht auf der diskursiven Ebene ausfuhrlich entwickelt, sondern nur in der Tiefenebene des Textes diskret angedeutet. Ihre Wirkung beruht also nicht auf einer Monosemierung des Textes, sondern auf der Erweiterung des Assoziationsraumes und auf der Aktivierung der Rezipiententătigkeit. Die Konfliktstruktur und das semantische Gerust in den Dramen von Witkiewicz verleihen dem Werk eine innere dynamische Einheit, indem sie beim Rezipienten die Spannung auf Fortsetzung und Losung wecken.

Die Bedeutungseinheiten, die den Geschichten in Witkiewicz' Dramen zugrundeliegen, lassen sich einerseits auf die geschichtsphilosophischen Theorien des Autors und andererseits auf das allgemeine Gedankengut im ersten Viertel des 20. Jahrhunderts zurulckfuhren. So wird beispielsweise die semantische Struktur in den meisten Dramen aus der Opposition "Individuum" vs. "Kollektivum" entwickelt. Wie weiter oben ausgefuhrt ${ }^{45}$, betrachtete Witkiewicz in seinen theoretischen Schriften die soziale Entwicklung der Menschheit als einen Weg von einer Gesellschaft der großen, freien Individuen zu einer nivellierten, nur am Gemeinwohl, d.h. an der Gattungserhaltung orientierten Massengesellschaft. Doch sein Kultur-

${ }^{45} \mathrm{Vgl}$. Kapitel 1.2. in dieser Arbeit.

Zur Witkiewicz' Geschichtsphilosophie vgl. Szpakowska, 1968 und 1976. 
pessimismus war kein isoliertes Phänomen - vielmehr stand Witkiewicz dem von $F$. Nietzsche und $H$. Bergson beeinflußten Weltbild seiner Zeitgenossen (etwa den Expressionisten) sehr nahe. Seine geschichtsphilosophischen Theorien spiegeln sich in seinen Dramen weder. Doch es muB in diesem Zusammenhang betont werden, daß Witkiewicz sich stets gegen symbolische Deutungen und weitreichende Interpretationen seiner Dramen wendete und den rein formalen Aspekt seiner Kunst betonte. So schrieb er beispielsweise in einer Polemik mit K. Irzykowski uber das Drama "Neue Befreiung":

\begin{abstract}
"Der Symbolismus als das Ziel der Kunst - das ist naturlich Nonsens. Doch jeder Kunstler, selbst dann, wenn er das wildeste Ding auf der Welt schreiben würde - es sei denn, er stellt aufs Geratewohl etwas Wildes zusammen, indem er z.B. ohne hinzuschauen beschriftete Karten aus einem Sack zieht - befindet sich immer unter der Wirkung seiner Gefuhle, Vorstellungen und Gedanken. Dieser unterbewuBte symbolische Inhalt eines Kunstwerkes ermöglicht es, sogar die wildesten Sachen ideell zu erklären. Doch für einen wahren Kunstler sind diese Elemente ausschließlich das Material seiner kunstlerischen Vision und nicht das Ziel. Ich wiederhole: man kann immer eine kleine Broschüre schreiben, wenn es um dieses Ziel gehen sollte.

<...> Der SchaffensprozeB ist einheitlich, man kann aus ihm verschiedene Momente abstrahieren, aber wenn das Geschaffene Kunst ist, so wirkt es alleine durch seine Form. Ohne diesen AbstraktionsprozeB bekommt das Leben ausschließlich die Funktion, den Komplexen der Erscheinungen in der Zeit auf der Buhne Färbung und dynamische Spannung zu geben.

$\langle\ldots\rangle$ ich muß betonen, daß ich die Buhne nicht als ein Mittel zum Verbreiten meiner Ideen benutze. Diese stelle ich in einer moglichst streng begrifflichen und unsymbolischen Gestalt in gesonderten theoretischen Arbeiten dar. In meinen Dramen ergeben sie sich wider Willen und niemals in einer endgultig präzisen Fassung." (PLsma, II: 330f)
\end{abstract}

Das Zitat wird so ausfuhrlich angefuhrt, weil darin mit expliziter Negation konventioneller symbolischer Interpretationspraxis die formale Rolle der semantischen Strukturen im Sprachkunstwerk thematisiert wird. Im folgenden soll nun die formalistische Funktion der Bedeutungseinheiten in Witkiewicz' Werken untersucht werden.

Die Opposition "Individuum" vs. "Kollektivum" wird in den Dramen von Witkiewicz an verschiedenen sozialen Rollen durchgespielt. Zu nennen waren hier insbesondere die schon in der Literatur der Romantik und der Jahrhundertwende hăufig thematisierten Gegensătze: "Kunstler" vs. "Philister" bzw. "Künstler" vs. "Gesellschaft". In den Dramen "Narr und Nonne" (WiZ), "Beelzebubsonate" (SB), "Die da!" (Oni), "Das namenlose Werk" (BD) u.a. 
entwickelt sich die Geschichte hauptsächlich aus dem Konflikt zwischen dem ins Metaphysische strebenden Kunstler und der (bürgerlichen) Gesellschaft mit ihren Verhaltensregeln und Konventionen. "In unserer Zeit gibt es fur metaphysische Persönlichkeiten nur zwei Plătze: das Gefängnis und die Irrenanstalt" - wie das der Küstler Plazmonik in dem Stuck "Das namenlose Werk" auf den Punkt bringt. (Werke, V: 122). Als Gegenpol und Widersacher des Künstlers fungiert dabei hăufig der selbstzufriedene, die Schranken des Lebens und der Gesellschaft freiwillig akzeptierende Philister.

Der Kunstlertypus wird in anderen Dramen durch soziale Typen ersetzt, die ebenso das Prinzip des Individuellen und Schopferischen verkörpern: das sind beispielsweise geniale Wissenschaftler (etwa der Mathematiker Tumor Mózgowicz), Philosophen, große Herrscher. In diese Reihe gehort auch der Typus der "femme fatale", der dämonischen Frau, die ihren Gefuhlen und sexuellen Bedurfnissen freien Lauf låßt. Die Gemeinsamkeit dieser Figuren besteht in ihrer - um einen Witkiewicz'schen Terminus zu verwenden - "Unersăttlichkeit". Sie alle streben nach metaphysischen Erlebnissen und Gefuhlen, die ihnen die eigene Individualităt und Identităt bestătigen sollen.

Den Individuen in Witkiewicz'schen Dramen steht das Kollektivum, die Volksmasse gegenuber. Die Volksmasse strebt nach der Vernichtung des Individuellen, nach einer allgemeinen Nivellierung der Gesellschaft und nach einer Rationalisierung und Mechanisierung des Lebens, wie das z.B. Girtak im "Namenlosen Werk" zum Ausdruck bringt:

"Wir werden das reine Paradies auf Erden schaffen, ohne Führer und ohne Arbeit! Wir! Die einheitliche, graue, klebrige, stinkende, schreckliche Masse: die neue Einzelexistenz, der ganzen Metaphysik zum Trotz, die sich auf den Begriff des Individuums und der Hierarchie stützt! Es gibt keine Individuen! Fort mit der Persönlichkeit! Es lebe die eine, einheitliche MASSE!!! Hurra!!!" (Werke, v: 120)

Unter anderem war es diese Thematik - Entfremdung des Menschen durch die Zivilisation, allgemeine Nivellierung und Technisierung des Lebens, Gefahren des Totalitarismus -, die Witkiewicz' Popularităt in den 60er Jahren begründete. Die Aktualităt seiner Gedanken - die durch entsprechende Inszenierungen noch unterstrichen wurde - sicherte ihm den Ruf 
eines nahezu visionären Künstlers. Dabei muß man Witkiewicz Weltbild in Relation zu dem seiner Zeitgenossen sehen. Eine ăhnliche Thematik beherrschte auch viele zeitgenossische literarische Werke (z.B. G. Kaisers "Gas" oder K. Capeks "RUR" - beide Werke erschienen Anfang der 20er Jahre).

In einigen Dramen Witkiewicz' ( $K W, W M D, M D C$, Matka) wird die semantische Opposition "Individuum" vs. "Kollektivum" auch innerhalb der kleinsten sozialen Form, der Familie durchgespielt. Dabei werden die familiären Bindungen als zufallig und willkürlich dargestellt und nebenbei die Gattung des naturalistischen Familiendramas à la Ibsen parodiert. Zu den weiteren grundlegenden Bedeutungseinheiten in den Dramen von Witkiewicz gehören die Oppositionen "Natur" vs. "Kultur", "Leben" vs. "Tod", "Endlichkeit" vs. "Unendlichkeit".

Eine genaue Analyse der semantischen Struktur in jedem einzelnen Drama wurde den Umfang dieser Arbeit sprengen ${ }^{46}$. AbschlieBend soll aber die Funktion dieser Bedeutungseinheiten im ganzen Werk beschrieben werden. Wie schon mehrmals in anderen Zusammenhängen festgestellt, findet man in Witkiewicz' Dramen keine monosemen Texte und erst recht keine diskursiven "Meinungen" des Autors vor. Witkiewicz wendet in seinen Dramen eine Reihe von Verfahren an, die die referentielle Leistung des Textes und die konventionelle mimetische Struktur der Geschichte zerstören. Dazu gehören unter anderen: Destruktion konventioneller Motivierungsverfahren in bezug auf die Psychologie und die Handlungen der Figuren; Inkausalităt beim Zusammenfugen von Situationen; Uberlagerung von unterschiedlichen Fiktionsebenen und Kommunlkatlonssystemen. Doch die Montage-Dramen Witkiewicz' sind nicht einfach nur ein Aggregat aus unzusammenhăngenden Situationen, Handlungen und Versatzstucken. Dafur sorgen eine narrative Konfliktstruktur und ein semantisches Gerlist, die in jedem Drama weitgehend erhalten sind. Diese semantische Struktur ist nur rudimentăr, hăufig auch in sich widersprllchlich. Sie wird nicht selten durch parodistische oder ironische Selbstkommentare der Helden ausgehohlt. Ihre Wirkung beruht also nicht auf einer Monosemierung des Textes, sondern auf der Erweite-

${ }^{46}$ Vgl. dazu z.B. Gerould, 1981. 
rung des Assoziationsraumes und auf der Aktivierung der Rezipiententătigkeit. Die semantische Struktur in Witkiewicz' Dramen ist zu rudimentăr, um einen rational-logischen Diskurs wie im konventionellen, realistischen Drama zu ermbglichen. Die Konfliktstruktur und das semantische Gerust in den Dramen von Witkiewicz haben eine ahnliche Funktion wie die von ihm theoretisch erorterten "Richtungsspannungen": sie garantieren eine innere, dynamische Einheit des Werkes, indem sie beim Rezipienten die Spannung auf Fortsetzung und Losung wecken. 


\section{ZUSAMRIENFASSUNG}

Der Xsthetik von St. I. Witkiewicz liegt ein formalistischer Kunstbegriff zugrunde: die Form eines Kunstwerkes wird nicht als Ubertragungsmittel eines kognitiven Gehaltes, sondern als der alleinige Trăger der ăsthetischen Erfahrung betrachtet. Aus dieser Grundthese folgt zum einen die Autonomie der Kunst von jeglicher Nutzlichkeitserwăgung und zum anderen die Irrelevanz der referentiellen Funktion fur die Komposition des Kunstwerks und fur die asthetischen Erfahrungen und Urteile.

Die asthetische Erfahrung, die auf dem Erleben der Form beruht, hat, laut Witkiewicz, metaphysischen Charakter. Diese These stulzt Witkiewicz mit seiner monadologischen Ontologie, und insbesondere mit dem Begriff des "Geheimnisses der Existenz". Die Existenz ist demnach durch die Vielfalt von Monaden (Einzelexistenzen, Qualităten) bedingt. Gleichzeitig aber muß auch eine Einheit in der Vielfalt dieser Monaden bestehen, ein Zusammenhang, der die Identităt und Individualităt des Ganzen garantiert. Diese Einheit betrachtet Witkiewicz als das "Geheimnis der Existenz" und das Erleben dieser Einhelt als ein "metaphysisches Gefuhl". Die Kunst gehore zu den Bereichen, die das Erleben der metaphysischen Gefuhle ermöglichen. Dieses erfolgt auf symbolische Art. Die asthetische form eines Kunstwerkes, die die Vielfalt von kunstlerischen Einzelelementen zu einer Einheit vereint, verweist den Menschen auf die Einheit der eigenen Persönlichkeit. Obwohl er - in Witkiewicz' psychologistischer Sichtweise - nur eine biologische Monade, d.h. eine raum-zeitlich begrenzte Vielfalt an biologisch-psychischen Qualităten ist, empfindet er die Identităt seiner Personlichkeit und die Einmaligkeit seiner Existenz. Das Kunstwerk 18se, sei es bei der Produktion oder bel der Rezeption, dieses metaphysische Gefuhl bei dem Menschen aus. Dabei ist es wichtig, das Witkiewicz fur die Kunstproduktion und -rezeption nicht allein die metaphysischen Gefuhle als grundlegend betrachtet, sondern auch die lebensadăquaten Empfindungen, Erfahrungen und das Denken des Individuums miteinbezieht. Das metaphysische Gefuhl kann nur uber eine Polarisierung in der psychischen Sphăre des Individuums zum Ausdruck gelangen, und die Form des Kunstwerkes ist weitgehend von dieser Sphăre abhăngig. Laut witkiewicz sind daher Kunstproduktion und -rezeption unbewuste und irrationale Handlungen, und die asthetischen Urteile haben einen vollig subjektivistischen Charakter. 
Die Leistung und das Wesen einer formalistischen Ästhetik sind weitgehend von der Definition der Begriffe "Form" und "Inhalt" abhăngig. Wie R. Ingarden festgestellt hat, sind diese Begriffe korrelativ, d.h. sie definieren sich gegenseitig als ein Antonymenpaar. Witkiewicz hat sich in seinen theoretischen Schriften mehrmals zu einer Definition dieser Begriffe geăußert. Er differenziert zwischen der sinnlich-materiellen bzw. äuBeren Form in ihren verschiedenen Arten und der asthetischen bzw. inneren Form. Die ästhetische Form findet ihre Ausprăgung im Artefakt als Komposition oder Konstruktion und im ästhetischen Objekt als die sog. "Reine Form". Der Begriff der "Reinen Form" bei Witkiewicz bezeichnet eine besondere Produktions- und Rezeptionskraft der individuellen Psyche, die ihre Wurzel in dem schon beschriebenen Erleben der Einheit in der Vielfalt hat. "Reine Form" ist aber keine Artefakt-Kategorie. Nur vor diesem Hintergrund bekommt der Begriff "Reine Form" uberhaupt Sinn, denn eine Form ohne Inhalt - und das betonten sowohl die Kritiker Witkiewicz' als auch er selber - ist als realer Gegenstand unmöglich.

Witkiewicz' Auffassung der ästhetischen Form auf der Ebene des Artefakts hat einen strukturalistischen Charakter. Als Inhalt werden von ihm die kunstlerischen Elemente und als Form die funktionalen Wechselbeziehungen zwischen den Elementen betrachtet. Diese Formauffassung findet ihre Entsprechung in der monadologischen Ontologie von Witkiewicz. Wie schon erwahnt, betrachtet er die Dinge und das Sein als unterschiedlich strukturierte Monaden, und das "Geheimnis der Existenz" als "Einheit in der Vielfalt". Ähnlich, wie er die Einzelexistenz, den Menschen, als eine abgeschlossene, individuelle Einheit von biologisch-psychischen Einzelqualităten versteht, ist für ihn auch das Kunstwerk eine unbewußt konstruierte Einheit von küstlerischen Einzelelementen. Die Beziehungen, die zwischen den Elementen eines Kunstwerkes bestehen, haben eine qualitative Entsprechung in der Psyche des Menschen und in der Welt. Aus einem solchen Formbegriff leitet Witkiewicz auch die metaphysische Qualităt der ästhetischen Erfahrung ab.

Bei der Definition des Inhaltsbegriffes unterscheidet Witkiewicz zwischen dem gegenstăndlichen und dem künstlerischen Inhalt. Der kunstlerische, ăsthetisch relevante Inhalt eines Kunstwerkes sind seine rein formalen Elemente: Laute, Farben, Gestalten, Wortbedeutungen (in ihrer evokativen Funktion) und Handlungen (in ihrer evokativ-visuellen Funktion). Diese 
küstlerischen Mittel haben fur Witkiewicz einen autonomen Wert. Ästhetisch irrelevant, obgleich untrennbar mit den rein formalen Elementen verknupft, ist der gegenständliche Inhalt: Wirklichkeitsähnlichkeit in der Darstellung, Gefuhle, Stimmungen, Sinneinheiten und kognitive Gehalte.

Der gegenständliche Inhalt hat zwar - laut Witkiewicz - fü die ästhetische Erfahrung keine Bedeutung, doch er spielt eine wichtige Rolle bei der Komposition des Artefaktes und in der Psychologie des Schaffensprozesses.

Als ein Kompositionsmittel ist der gegenständliche Inhalt notwendig, um dem Stoff die sog. "Richtungsspannungen" (poln.: "napięcia kierunkowe") zu geben. Durch eine gewisse Ẍhnlichkeit der dargestellten Gegenstănde mit der außerkunstlerischen Wirklichkeit werden die Wahrnehmungen und Antizipationen des Rezipienten in einer bestimmter Weise gelenkt: es werden ein Anfang und Ende, oben und unten, rechts und links, etc. im Bilde markiert. In sprachlichen Kunstwerken wird durch das Beibehalten gewisser referentieller Einheiten die Spannung auf eine Fortsetzung und Lösung gehalten. Mit dem Begriff der Richtungsspannung reduziert Witkiewicz also die Bedeutung der Gegenstănde, d.h. der wirklichkeitsbezogenen Elemente in der Kunst, auf eine formal-kompositionelle Funktion.

Eine besondere Ausprägung des gegenständlichen Inhalts ist die Deformation. Sie ist eine Folge der Autonomie kunstlerischer Mittel und der Formdominanz in einem Kunstwerk der Reinen Form: aufgrund kompositioneller Erfordernisse können lebenslogische, realitătsăhnliche Inhalte beliebig verăndert werden. Die Deformation entspringt also nicht etwa einer bestimmten Weltsichtweise des Kunstlers, sondern der kompositionellen Notwendigkeit. Fur die Konstitution des ästhetischen Objektes ist sie unerheblich. Bei der Ausweitung des Gegenstandes seiner Ästhetik auf sprachliche Kunstwerke weist Witkiewicz der Deformation aber auch eine indirekte ästhetische Funktion zu: durch die Destruktion der gegenstănlichen Inhalte werden die kunstlerischen Inhalte eigentlich erst freigesetzt. Diese indirekte assthetische Funktion der Deformation wird an künstlerischen Elementen sichtbar, die nicht rein formal, sondern mit "Lebenslogik" durchsetzt sind, wie beispielsweise die Sprache. In seiner Theorie der küstlerischen Sprache ist die Deformation ein Mittel dazu, Wortbedeutungen als rein formale, d.h. kunstlerische Elemente zu etablie- 
ren. Durch diesen Ansatz bekommt Witkiewicz' Begriff der Deformation eine ăhnliche Bedeutung wie der Begriff der Verfremdung im Russischen Formalismus: er wird als eine Differenzqualităt erfaßt, die den Kunst- vom Lebensbereich abgrenzt.

Mit Hilfe seiner als "maßiger Nominalismus" ironisch bezeichneten Sprachtheorie Ubertrăgt Witkiewicz das Kriterium der Gegenstandslosigkeit von der Malerei auf die Literatur. Er versucht theoretisch zu beweisen, daß analog zu der Malerei auch das sprachliche Kunstwerk als eine formale Einheit jenseits der lebenslogischen Zusammenhănge wirken kann. In seiner Theorie der kunstlerischen Sprache bemüh sich Witkiewicz' um eine theoretische Begrlindung eines formal-ästhetischen Potentials der sprachlichen Bedeutung. Die Arbitrarităt des Zeichens und die Differenzierung innerhalb der Zeichenbedeutung zwischen dem "Privatbedeutungskomplex" und dem außersprachlichen Referenten bzw. Denotaten sind in Witkiewicz' Sprachtheorie die axiomatischen Voraussetzungen fur die Xsthetisierung der Wortbedeutung in formaler und nicht - wie im Realismus oder Naturalismus - in inhaltlicher Hinsicht. Dabei wird der asthetische Wert eines Begriffes Uber seine konnotative Leistung und Uber die von ihm ausgelठste Spannung definiert.

Mit Hilfe eines triadischen Zeichenmodells und des Phanomens des aktuellen und potentiellen Bedeutungsbestandes begr Indet Witkiewicz die Isolierung der sprachlichen Bedeutung aus den referentiellen Sinnstrukturen und ihre Reduktion auf das kleinste Bestandteil, nămlich eine Qualităt in der Vorstellung. Dadurch ist es moglich, die sprachliche Bedeutung theoretisch als ein rein kunstlerisches tlement zu betracnten, das in der Lage ist, abstrakte Formen in der Zeit zu bilden, die durch Spannungen strukturiert und zusammengehalten werden. Die Wortbedeutungen sollen einen Strom von fluchtigen, undeutlichen Vorstellungen und Assoziationen auslossen, die in der Psyche des Rezipienten abstrakte Formen in der Zeit entstehen lassen.

Die Theorie der Reinen Form Ubertrăgt Witkiewicz auf das Theater. Vor dem Hintergrund des formalistischen Kunstbegriffes und der metaphysischen Begrüdung der àsthetischen Erfahrung in Witkiewicz' Ásthetik ist es verstăndlich, daß seine Kritik sich insbesondere gegen die Dominanz des gegenstăndlichen Inhalts in der Kunst in seiner Zeit richtet. Massive Kri- 
tik wird insbesondere an der Ideenbeladenheit und an den sozialpolitischen Diskursen im Bereich der Thematik und Wirkungsintention des Dramas geubbt. Ebenso hăufig und heftig ist die Kritik an einer realitătsbezogenen Rezeptionsweise der Werke. Witkacy wendet sich gegen ein Theater, das lebensnahe Inhalte und psychisch-geistige Gehalte vermitteln oder bestimmte Lebensgefuhle wie z.B. das Nationalgefuhl auslosen will.

Das wichtigste Argument für seine Kritik ist das Wahrheitskriterium der Kunst. Eine mimetische Darstellungskunst ist, laut Witkiewicz, immer mit dem Makel der Luge behaftet. Dabei argumentiert er mit formalistischen und kunstontologischen Kriterien. Demnach ist in der Heterogenităt der beiden Sphären: Kunst und Leben; Fiktion und Realităt; ăsthetische und kognitive Erfahrung ein Wahrheitsanspruch des gegenstăndlichen Gehaltes von vornherein ausgeschlossen bzw. - bei unzulăssiger Vermischung dieser heterogenen Sphăren - das Element der Lüge angelegt. Wenn in der imaginären Welt, die ein Theaterstulck aufbaut, Gegenstände der außerkunstlerischen Wirklichkeit "vorgefuhrt" und "nachgeahmt" werden, und die Erzeugung einer Illusion dieser außerkünstlerischen Wirklichkeit angestrebt wird, so ist ein solches TheaterstUck immer auch mit dem Makel der Unwahrhaftigkeit behaftet. Witkiewicz lehnt jegliche Darstellungs- und Abbildungsästhetik in der Kunst $a b$ und wendet sich dem ăsthetischformalistischen Wert zu. Das Wahrheitskriterium kann demnach in einem autonomen Kunstwerk verwirklicht werden, das ausschlieBlich nach formalen Erfordernissen konstruiert wurde, und seinen Wert und Identităt nur aus der eigenen Struktur bezieht.

Witkiewicz ubertrăgt seine Forderung nach der ästhetisch-formalen Autonomie kunstlerischer Mittel gegenuber einem mimetischen Darstellungskanon von der bildenden auf sprachliche Kunst. Die metaphysisch begrundete assthetische Erfahrung der Reinen Form soll im Theater, ahnlich wie in der abstrakten Malerei, durch eine subjektiv-ăsthetische Konstruktion rein formaler Elemente vermittelt werden. Das Theaterstuck konnte infolge "rein formaler Ziele, d.h. um der Synthese aller Theaterfaktoren willen der Laute, des Buhnenbildes, der Bewegungen auf der Buhne, der gesprochenen Sătze - zu einer unauflösbaren Einheit im allgemeinen Werden in der Zeit $\langle. . .>$ werden." (T, 261). Demnach wirde das Buhnengeschehen durch die Beziehungen zwischen seinen Einzelelementen als eine abstrakte Zeitform ("Werden in der Zeit") wirken, ahnnlich wie die Musik oder deklamierte 


\section{Dichtung.}

Witkiewicz' Theorie der Reinen Form im Theater bewegt sich theatergeschichtlich im Grenzbereich zwischen Symbolismus und der historischen Avantgarde. Mit den Theaterreformen der Jahrhundertwende verbindet den polnischen Kunstler die metaphysisch-rituelle Wirkungsintention und das Ideal einer ăsthetischen Autonomie künstlerischer Mittel. Seine Dramen haben aber nicht den lyrisch-pathetischen Charakter der Stilbuhne: Witkiewicz' Asthetizismus bekommt in seiner literarischen Praxis durch die angewendeten Deformationsverfahren eine groteske Ausprăgung, vergleichbar etwa mit "Ubu-Roi" von A. Jarry. Mit der historischen Avantgarde verbindet Witkiewicz zum großen Teil seine Sprachauffassung: das Wort (und zwar sowohl in seiner Lautgestalt als auch in seiner Bedeutung) wird als ein eigenwertiges, kunstlerisches Element betrachtet, das aus den syntaktischen oder referentiellen Bezligen herausgelost werden muß, damit es seine ästhetische Wirkung voll entfalten kann. Das trennende Moment zu der Xsthetik der Avantgarde bildet Witkiewicz' Asthetizismus. Von dieser Position aus kritisiert er den "programmatischen Unsinn", den die Avantgarde ohne ästhetisch-kompositionelle Rucksichten durchfuhre; ferner die leere Provokationsăsthetik sowie die Inter- und Multimedialităt im Theater, die Kunstgattungs- und Werkautonomie zerstort.

Witkiewicz' intermedialer Denkansatz in der Xsthetik fuhrt unter anderem auch zur Ubertragung des Phänomens der Deformation von der bildenden auf die sprachliche Kunst der Dichtung und des Dramas. wahrend sich die Deformation in der Malerei auf die sinnlich wahrnehmbare äußere Gestalt der dargestellten Gegenstände bezieht, hăngt sie in Sprachkunstwerken mit dem Sinnkriterium und damit mit einer kognitiv-intellektuellen Leistung zusammen. Die Deformation auf der Ebene der Handlungen besteht in der Zerstorrung von kausaler Motivation und raum-zeitlicher Folgerichtigkeit.

Die Funktion der Deformation im Theater besteht, ahnlich wie in der Malerei, in der "Erweiterung der kompositorischen Möglichkeiten durch die Loslosung von lebenslogischen Konsequenzen in der Kunst, nămlich die Phantastik der Psychologie und der Handlung", die "eine völlige Freiheit in der formalen Komposition erlaubt". Die konsequente psychologische und temporal-kausale Motivierung der Handlung sowie logisch-kognitive "Aussagen" des Dramas sind, laut Witkiewicz, nebensăchlich und könnnen aus 
formal-asthetischen Grunden zerstört werden.

Die wichtigsten Attribute der "Reinen Kunst" können also folgendermaßen umrissen werden: In produktionsästhetischer Hinsicht ist das Kunstwerk eine nach dem subjektiv-ăsthetischen Empfinden des Künstlers konstruierte Einheit aus den Elementen des kunstspezifischen Materials (Farbe, Sprache etc.). In rezeptionsăsthetischer Hinsicht ist das "Reine Kunstwerk" ein allein durch seine Form wirkendes Werk. "Reine Form" ist eine Kategorie des asthetischen Objekts. Sie bezeichnet in Witkiewicz' Xsthetik eine besondere psychische Fahigkeit des Individuums, im Erleben der Einheit in der Vielfalt auf die Grundlage der Existenz verwiesen zu werden und dadurch "metaphysische Gefuhle" zu empfinden. Auf der Ebene des Artefaktes entspricht der "Reinen Form" die Struktur des Werkes, d.h. funktionale Beziehungen der künstlerischen Einzelelemente untereinander, die dem Werk Einheit und Geschlossenheit verleihen.

Nach der Theorie der Reinen Form ist der "gegenstandliche Inhalt", d.h. die Âhnlichkeit der dargestellten Gegenstände mit der auBerkünstlerischen Wirklichkeit weder fur die Struktur des Werkes noch fur die asthetische Erfahrung relevant. Er kann, laut Witkiewicz, aus ăsthetischkompositionellen Gründen deformiert werden. Er sollte aber nicht v8llig aus dem Kunstwerk ausgeschlossen werden. Gewisse mimetische Elemente gliedern das Werk und erzeugen Spannung. In Sprachkunstwerken spielt die Deformation eine wichtige Rolle. Sie löst die sprachliche Bedeutung aus den referentiellen Strukturen und setzt damit das asthetisches Potential des Wortes frei.

Fur die Analyse der Dramen von Witklewlcz ergeben slch aus der Theorle der Reinen Form folgende Fragen: Was sind die gegenstăndlichen und was die rein formalen Elemente im Drama?; Durch welche Verfahren wird die Deformation des gegenstăndlichen Gehaltes erreicht?; Worin besteht die rein werkimmanente Struktur des Dramas, d.h. eine Struktur, die auf den Beziehungen der rein formalen Elemente untereinander und nicht auf einer mimetischen Abbildung der außerkünstlerischen Welt beruht?

Das RUlckgrat der Dramenanalyse bildet das Vierschichten-Modell des literarischen Werkes von $R$. Ingarden sowie sein Form- und Inhaltsbegriff. Ingardens Form- und Inhaltsbegriff erscheint fur diese Arbeit aus drei Gründen interessant. Als sehr wichtig erweist sich zunăcht einmal die 
Feststellung der Korrelativităt des Begriffspaars: Form und Inhalt bestimmen sich gegenseitig. Ebenso relevant ist es, daß Ingardens kategorialer Formbegriff, d.h. der Formbegriff, der sich auf das Wesen des literarischen Werkes im allgemeinen bezieht, strukturalistischer Natur ist: das Werk ist eine Einheit, die sich aufgrund von besonderen Beziehungen zwischen seinen vielen Schichten und Phasen einstellt. Dabei billigt Ingarden jeder Schicht und auch jedem Einzelelement des literarischen Kunstwerkes eigene formale und inhaltliche Momente zu. Der dritte, fur die vorliegende Arbeit wichtige Aspekt des Form- und Inhaltsbegriffes von Ingarden besteht darin, daB Ingarden eine Anwendung des Inhaltsbegriffes auf die gegenständliche Schicht des Werkes ablehnte. Die dargestellte Welt in einem literarischen Werk hat einen bestimmten Gehalt an Einzelelementen und eine bestimmte Struktur. Dabei ist ihre Ähnlichkeit mit der außerkünstlerischen Welt nichts weiter als eines der möglichen Strukturelemente. Ingardens Form- und Inhaltsbegriff weist also deutliche Parallelen zur Xsthetik von Witkiewicz auf. Gleichzeitig aber bietet seine Theorie mehr Anhaltspunkte für eine Textanalyse als die hăufig programmatischen oder polemischen Ausfuhrungen Witkiewicz'.

Auf der Ebene der Bedeutungseinheiten in den Dramen von Witkiewicz sind zwei Gruppen von Deformationsverfahren auszumachen. Die erste Gruppe bilden Verfahren, die den durch literarische Konventionen gebildeten Erwartungshorizont des Rezipienten erschuttern. Dazu gehorren beispielsweise die ungeworhnlichen und in bezug auf die Akteinteilung und Spannungsverlauf irrefuhrenden Untertitel ("Drama in zweieinhalb Akten", "Wissenschaftliches Stuck mit Liedchen" etc.). Ferner die verschiedenen intertextuellen Phănomene wie Parodie oder Travestie. In diese Gruppe gehören auch diejenigen Verfahren, die einen ZusammenschluB des außeren und inneren Kommunikationssystems bewirken und daduch antilllusionistische Effekte im Drama ausløsen z.B.: Autothematismen, Vermischung der fiktiven und realen Charakterisierungsmomente innerhalb einer Figurenkonstellation etc. Neben der antilllusionistischen Funktion haben diese Verfahren die Aufgabe, auf die Konstruktion, auf das Gemacht-Sein des Werkes hinzuweisen.

Die zweite Gruppe sind Verfahren, die das Zustandekommen einer Referenz auf die außerkunstlerische Welt verhindern. Dazu gehören auf der Ebenen 
des Wortes und des Satzes semantische Binăroppositionen, Verletzung der Prăsuppositionen, Isotopieverfremdung bis hin zur vollligen Isotopielosigkeit u.a. Die Zusammenfugung der Wortbedeutungen erfolgt nach dem Montageprinzip: es werden hăufig Ausdrücke miteinander verbunden, die keine gemeinsamen semantischen Merkmale besitzen.

Es gibt jedoch auch eine Struktur, d.h. Beziehungen zwischen den Bedeutungseinheiten in den Dramen von Witkiewicz. Mit Hilfe der Begriffe von R. Ingarden kann man feststellen, daß bei einer starken Verfremdung des materialen Inhalts der Bedeutung der formale Inhalt die notwendigen kommunikativen und intergrativen Funktionen Ubernimmt. So kann man 2.B. bei den Figurennamen beobachten, daß selbst bei den "absurdesten" Neologismen gewisse sprachliche Normen, wie z.B. Genus oder eine bestimmte Stilebene, beibehalten werden. Diese formale Struktur ermoglicht dem Rezipienten, Rückschlüsse auf die Figurenkonstellation oder sogar auf die möglichen Konflikte zu ziehen. Durch diese Orientierungshilfe ist es Uberhaupt erst moglich, dramatische Spannung zu erzeugen.

Auf der Ebene der Satzzusammenhänge, bzw. der Dialogfuhrung werden die Elemente des formalen Inhalts durch die Situation der Wechselrede erweitert - semantische Richtungswechsel und das Aufeinanderprallen der Kontexte bis hin zur Stichomythie werden ja im allgemeinen als dialogspezifisch betrachtet. Auf diese Weise bekommen die im äußeren Kommunikationssystem inkohărent wirkenden Repliken durch die Perspektivenvielfalt und die situativen Kontexte eine Struktur. Alle diese pragmatischen bzw. dramenspezifischen Aspekte begrunden zwar keine semantischen, aber doch gewisse formale Satzzusammenhänge. Daruber hinaus wird der Zusammenhang der Rede durch zahlreiche phatische, expressive und appellative Xußerungen hergestellt. Diese Sprachfunktionen Ubernehmen die kommunikative Aufgabe. Allerdings kommt die Kommunikation nicht durch die sprachliche Sinnkonstruktion zustande, sondern durch eine atmosphärische Einstimmung. Seine referentielle Funktion fur das außere Kommunikationssystem erfullt der Text nicht, er bleibt im Ganzen inkohărent, polysemisch.

Die eigentliche Bedeutung des Textes macht seine asthetische Funktion aus, die durch unterschiedliche Kategorien und Effekte zustande kommt. Dazu gehören z.B. die antiillusionistischen Momente, die durch Hinweise auf die fiktionale Seinsweise der entworfenen Gegenstănde und durch Bewußtmachung der Konstruktion entstehen. Ferner das Groteske, das durch 
die Deformation von "lebenslogischen" und literaturkonventionellen Elementen ausgelöst wird. Und schließlich bildet die Spannung (ausgelöst entweder durch die narrativen Strukturen oder durch besondere Wortzusammenstellungen) ein entscheidendes strukturales Element in Witkiewicz' Dramen.

In der Schicht der dargestellten Gegenständlichkeiten in den Dramen von Witkiewicz beziehen sich die Deformationsverfahren auf das "Weltwissen" des Rezipienten. Bestimmte anthropologische und empirische Modelle, die der Rezipient aus der außerkunstlerischen Wirklichkeit in die Kunst Ubertrăgt, werden von Witkiewicz destruiert.

Auf der Ebene der Figurenkonzeption ist beispielsweise die Inkonstanz psychischer und physischer Eigenschaften wohl das auffallendste Deformationsverfahren. Die Figuren in den Dramen von Witkiewicz zeichnen sich nicht nur durch die innere Widersprulchlichkeit ihrer Charaktereigenschaften aus, sondern sie wechseln auch unvermittelt im Laufe des Stückes ihre Identităt oder sogar ihr Geschlecht. Selbst der Tod wird von Witkiewicz als ein reversibles Phănomen behandelt: seine Figuren sterben auf der Buhne, um kurz darauf aufzuerstehen und ganz selbstverständlich am Geschehen teilzunehmen.

Xhnlich wie in der Schicht der Bedeutungseinheiten werden auch bei der Figurenkonzeption durch zahlreiche intra- und intertextuelle Bezüge antiillusionistische Effekte erzeugt, und es wird auf die Konstruktion, auf das Gemacht-Sein des Werkes hingewiesen. In den Dramen von Witkiewicz treten wiederholt Figuren aus anderen bekannten literarischen Werken auf. Dle rigutenkunceptlun stulat slch liaurig auf dramongooohiohtlioh vorgofertigte Typen wie z.B. "femme fatale". Diese Ruckgriffe auf andere Texte und literarische Traditionen haben den Charakter einer Montage: es ist ein spielerisches und scheinbar zuralliges Zusammenfugen von Elementen, die durch die bisherige kulturelle Entwicklung bereitgestellt worden sind.

Die Figurenkonzeption in den Dramen von Witkiewicz ist also weitgehend durch das Deformationsprinzip bestimmt: mit viel Einfallsreichtum zerstört der Autor die biologische, psychologische und soziale "Lebenswahrscheinlichkeit" der Figuren und polemisiert mit den historisch vorgeprägten dramatischen Typen. 
Eine Struktur kann man dagegen in der Figurenkonstellation ausmachen. Damit die alleine auf der Destruktion und Umkehrung des Bestehenden und Gewohnten beruhende Figurenkonzeption nicht in eine vollige Beliebigkeit und Willkurlichkeit fuhrt, wirkt auf der Ebene der Figurenkonstellation ein einheitsstiftendes, auf der Funktion der Einzelfigur im Werkganzen beruhendes Prinzip. Die Figuren sind in eine semantische und aktionale Einheit eingebunden. Witkiewicz' Deformation greift nicht die narrative Struktur des Werkes an, in seinen Dramen kann man sowohl in der Tiefenals auch in der Oberflăchenebene eine einheitliche Struktur feststellen. Sie wird in der Tiefenebene durch semantische Korrespondenzen und Kontrastbezllge und in der Oberflăchenebene durch eine dynamische Interaktionsstruktur gemåß dem Aktantenmodell hergestellt.

Auf der Ebene der Geschichte und der Fabel beziehen sich die Deformationsverfahren auf die kausal-temporale Ordnung von Situationen und Handlungen. Es wird die Motivierung der Handlungen zerstort, die den Schein einer Wahrscheinlichkeit des dramatischen Geschehens heraufbeschwort. Das Verfahren der Demotivierung bzw. der Destruktion von konventioneller Motivierung bezieht sich auf der Ebene der dramatischen Handlungen hauptsăchlich auf die Figurenpsychologie: Witkiewicz destruiert hier das naturalistische Verfahren der psychologischen Motivierung von Handlungen. Auf der Ebene der dramatischen Situationen erscheint das Verfahren der Demotivierung als Abruptheit und Inkausalităt beim Zusammenfugen von Situationen.

Ein weiteres Deformationsverfahren besteht in der Uberlagerung der Fiktionsebenen. Dazu gehbren sowohl die schon mehrmals erwahnten intertextuellen Bezuge in den Dramen von Witkiewicz als auch die Verbindung des außeren und des inneren Kommunikationssystems. Witkiewicz wendet all die Verfahren an, die man aus dem sog. Epischen Theater kennt: Publikumsansprache, Beiseitesprechen, Autothematisierung etc.

Die von Witkiewicz am hăufigsten benutzte Form der Uberlagerung von Fiktionsebenen ist die des "Spiels im Spiel". Dabei wird die primăre Fiktionalitat des Buhnengeschehens mit der sekundăren oder gar tertiăren Fiktionalităt anderer Spielebenen verwoben. Das "Spiel im Spiel" ist konstitutiv fur die Fabel. Ein groBer Teil der Dramen von Witkiewicz kann als selbstzweckhafte Spiele ohne jegliche referentielle Funktion interpre- 
tiert werden.

In Witkiewicz' Dramen erfullt das "Spiel im Spiel" zumeist die Funktion des "obnazenie priema" (dt.: Bloßlegung des Verfahrens) im Sinne von $V$. Sklovskij. Fiktionalităt ist die Existenzform der im Dramentext entworfenen Gegenstăndlichkeiten: sie konstituiert damit also auch die Form des Dramas selbst. Mit der impliziten Thematisierung der Fiktionalităt wird diese dramatische Form sichtbar gemacht und dem Rezipienten eine automatisierte Konkretisierung der dargestellten Gegenständlichkeiten vor dem Hintergrund bekannter Vorgänge in der außerkunstlerischen Wirklichkeit erschwert.

Witkiewicz wendet also in seinen Dramen eine Reihe von Verfahren an, die die referentielle Leistung des Textes und die konventionelle mimetische Struktur der Geschichte zerstören. Dazu gehören unter anderen: Destruktion konventionaler Motivierungsverfahren in bezug auf die Psychologie und die Handlungen der Figuren; Inkausalităt beim Zusammenfugen von Situationen; Uberlagerung von unterschiedlichen Fiktionsebenen und Kommunikationssystemen.

Es stellt sich nun die Frage nach der "Einheit in der Vielfalt" der disparaten dramaturgischen Einzelelemente, die von Witkiewicz scheinbar wahllos zusammengefügt werden. Gibt es ein Moment, das eine Einheit der Fabel, trotz der Deformation der referentiellen Dimension des Stuckes, garantiert? Welche Verfahren und Phänomene fugen die dramatischen Situationen und Handlungen zusammen, wenn das am Weltwissen orientierte kausal-temporale GerUst der Geschichte fehlt?

Die Analyse ergab, daß die Dramen witkiewicz' nicht einfach nur ein Aggregat aus unzusammenhăngenden Situationen, Handlungen und Versatzstucken sind. Fur die Einheit des Ganzen sorgt eine narrative Konfliktstruktur und ein semantisches GerUst, die in jedem Drama weitgehend erhalten sind. Diese semantische Struktur ist nur rudimentăr, hăufig auch in sich widerspruchlich. Sie wird nicht selten durch parodistische oder ironische Selbstkommentare der Helden ausgehbhlt. Ihre Wirkung beruht also nicht auf einer Monosemierung des Textes, sondern auf der Erweiterung des Assoziationsraumes und auf der Aktivierung der Rezipiententătigkeit. Die semantische Struktur in Witkiewicz' Dramen ist zu rudimentår, als das sie einen rational-logischen Diskurs wie im konventionellen Drama zu ermöglichen würden. Die Konfliktstruktur und das semantische Gerulst in 
den Dramen von Witkiewicz haben eine ähnliche Funktion wie die von ihm theoretisch erörterten "Richtungsspannungen": sie garantieren eine innere dynamische Einheit des Werkes, indem sie beim Rezipienten die Spannung auf Fortsetzung und Lösung wecken.

In seinen Dramen wendet Witkiewicz also eine Reihe von Deformationsverfahren an, die die referentielle Funktion des Werkes zerstören und groteske Effekte auslösen. Gleichzeitig kann man aber auch in seinen Stlicken eine Struktur ausmachen, die nicht durch den Bezug auf die außerkunstlerische Wirklichkeit begrundet ist, sondern alleine aus dem sprachlichen Material entsteht. Auf der Ebene der Bedeutungseinheiten wird die "Einheit in der Vielfalt" durch die formalen und pragmatischen Elemente der Bedeutung hergestellt und auf der Ebene der dargestellten Gegenstăndlichkeiten durch die narrative und semantische Struktur. In bezug auf das Artefakt kann man also feststellen, daß Witkiewicz seiner Theorie der Reinen Form treu geblieben ist. Unklar scheint aber, ob diese sehr knappen und modellhaften Aspekte der assthetischen Form die von Witkiewicz geforderte formistische ästhetische Erfahrung hervorrufen können.

In diesem Zusammenhang erhebt sich die Frage, ob Witkiewicz' Ubertragung des Gegenstandslosigkeit-Phănomens von der bildenden auf die sprachliche Kunst gerechtfertigt ist.

In der Malerei kann der Komposition des Materials (Farben, Gestalten) in der Bildflăche tatsächlich ein autonomer Status zugesprochen werden: die ăsthetische Wirkung der Komposition kann von den dargestellten Gegenstăndlichkeiten der ăußeren Welt weitgehend unabhăngig sein.

In der Sprachkunst sieht es jedoch anders aus. Das sprachliche Material ist von Natur aus immer semiotisch: das Phonem hat nicht die Qualităt eines Musiktones, sondern ist ein bedeutungstragendes Element. Nach F. Saussure besteht eine unauflosbare Einheit zwischen Signifikant (Lautform) und Signifikat (Bedeutung). Sprachliche Bedeutung ist aber auch immer in sozial-kommunikative und referentielle Strukturen eingebunden. Ahnlich verhalt es sich mit dem ästhetischen Material des Theaters, mit den Handlungen. Auch sie sind nicht einfach Bewegungen und Bilder im Buhnenraum, sondern haben ihre semiotische Dimension: sie sind innerhalb von Dramenkonventionen und Wirklichkeitsmodellen fest verankert und in raum-zeitliche und kausale Beziehungen eingebunden. Eine Abstraktion von 
diesem semiotischen Potential - und das ist es, was Witkiewicz mit seinem Begriff der Deformation eigentlich fordert - und eine Reduktion auf die primaren "formalen" Gehalte fuhrt notwendigerweise zu neuen und fur die ăsthetische Erfahrung konstitutiven Momenten. Hierbei wăre insbesondere an die ästhetische Kategorie des Grotesken zu denken.

Die Wirkung des Grotesken wird im allgemeinen als eine Aporie von Lachen und Grauen beschrieben'. Sie wird durch die Darstellung einer Wirklichkeit hervorgerufen, in der die Erwartungen des Rezipienten in bezug auf das Normale und Gewohnte enttäuscht werden. In der Forschung hat sich fur diese Darstellung der von W. Kayser ${ }^{2}$ geprägte Begriff "entfremdete Welt" eingeburgert. Das Wesen dieser dargestellten Welt ist die Ambivalenz: es werden Gegenstăndlichkeiten miteinander kombiniert, die in der außerkünstlerischen Wirklichkeit unvereinbar sind: Tod und Geburt; Haßlichkeit und Schönheit; Organisches und Mechanisches; Jugend und Alter; Realistisches und Phantastisches etc.

In bezug auf den rezeptionsästhetischen Aspekt des Grotesken werden die beiden Grundpositionen in der neueren Forschung von W. Kayser und M. Bachtin markiert. W. Kayser betont das Grauenvolle, Abgrundige des Grotesken. Das Groteske erzeuge ein Lachen, das im Halse stecken bleibt. Bei seiner Beurteilung nimmt Kayser die geistige Position der rationalistischen Moderne ein. für die das Ungewohnte und Unerklärbare eine Bedrohung darstellt. M. Bachtin ${ }^{3}$ dagegen geht von einer volkstülichen Karnevalskultur des Mittelalters aus, die im Grotesken antiautoritäre und antiideologische Moglichkeiten sieht. Das Karnevalslachen ist ein fröhliches, befreiendes Lachen uber die Relativierung der durch die offizielle Kultur absolut gesetzten Werte. Die Ambivalenz des Grotesken entspricht, laut Bachtin, einer organischen Weltanschauung des Volkes, in der heterogene Elemente eine dynamische Verbindung mit der stăndigen gegenseitigen Durchdringung und Erneuerung eingehen.

Trotz der leicht unterschiedlichen Beurteilung des rezeptionsästhetischen Aspektes herrscht eine relativ große Ubereinstimmung in bezug auf die

1 Vgl. dazu den Uberblick über die Theorie des Grotesken in: Sandig, 1980 und Best, 1980.

2

Kayser, 1957.

3 Bachtin, 1965. 
Verfahren, mit denen Groteskes erzeugt wird. Auf der Ebene der dargestelIten Gegenstăndlichkeiten wird das schon erwăhnte Zusammenfügen von Gegensătzlichem und Unvereinbarem (M. Bachtin prăgt dafur den Begriff der "Mesalliance") als Strukturmerkmal bezeichnet. Ambivalenz beherrscht auch den Ton des grotesken Werkes: es ist eine Mischung aus Komischem und Tragischem. Zu den Stilmitteln und Kompositionsverfahren des Grotesken gehören ferner Verzerrung und unlogische Akzentverschiebung 4

Alle diese Verfahren haben einen antimimetischen Charakter und entsprechen damit weitgehend Witkiewicz' Deformationsbegriff. In den Dramen von Witkiewicz konnten groteske Stilmittel und Effekte nachgewiesen werden'. Es erhebt sich also die Frage, ob die Wirkung der Dramen von Witkiewicz sie werden oft gespielt und erfreuen sich großer Popularităt - tatsăchlich auf einer formistischen, ästhetischen Erfahrung beruht. Naheliegend wăre auch die Annahme, daß der gegenstăndliche Inhalt bzw. die referentielle Funktion eines sprachlichen Werkes sich grundsătzlich nicht eliminieren lassen, und daß der eigentliche Träger der ästhetischen Erfahrung in den Dramen von Witkiewicz die Deformation ist. Witkiewicz selber bezieht zu dieser Frage folgendermaßen Stellung:

"Irgend jemand meinte, daß ein solches Werk von vornherein eine Groteske sein müste. Wenn wir versuchen, derartige Stllcke in die Kategorien der bisherigen Kunst hineinzupressen, und falls wir sie vom Standpunkt des deformierten Lebens aus betrachten, dann kann es sein, daß wir sie alle, letztendlich doch nicht endgultig, als grotesk bezeichnen mussen. Aber unserer Meinung nach geht es hier um eine vollig neue Kategorie, fur die es bis jetzt keine konkreten, zutreffenden Beispiele gab. Von dem besagten Standpunkt aus betrachtet, muBte man analog dazu die ganze Malerei und Bildhauerei in die Kategorie der Karlkatur hineinpressen. Ob die Begriffe der Karlkatur und des Grotesken den zeitgenössischen Erscheinungen gerecht werden, ist sogar vom lebenslogischen Standpunkt aus zweifelhaft. Trotz ihrer Komik und Tragik unterscheiden sich solche Sachen namlich in ihrem allgemeinen Ton stark von allen anderen. Selbst wenn man einige von ihnen vielleicht als tragische oder komische Grotesken einstufen könnte, so wurde man damit nicht ihr Wesen, d.h. den formalen Inhalt, sondern nur den lebenslogischen Inhalt meinen, der zwar unbedeutend ist, jedoch nicht eliminiert werden kann". (T: 290).

4Vl. dazu: Foster, 1980b: 120.

5 Eine ausfuhrliche Darstellung zu diesem Thema in: Sokoł. 1973. 


\section{LITERATUR VERZEICHNIS}

\subsection{PRIMÄRLITERATUR}

Nienasycenie. Hrsg. v. A. Stawar. Warszawa 1957.

Nowe formy $w$ malarstwie $i$ inne pisma estetyczne. Hrsg. v. J. Leszczynski. Warszawa 1959.

Listy Stanisława Ignacego Witkiewicza do Heleny Czerwijowskiej. Hrsg. v. B. Danek-Wojnowska. In: Twórczosc, 1971, H. 9.

Dramaty. Hrsg. v. K. Puzyna. Warszawa 1962. ${ }^{2} 1972$.

Jedyne wyjscie. Hrsg. v. T. Jodełka-Burzecki. Warszawa $1968 .{ }^{2} 1980$.

Panna Tutli-Putli. Libretto do operetki w trzech aktach w czystawej formie. Hrsg. v. J. Zuławski. In: Dialog (1974), H.2, S. 34-54.

Pisma filozoficzne i estetyczne. Hrsg. v. J. Leszczynski und B. Michalski. 4 Bde. Warszawa 1974-78.

622 upadki Bunga, czyli Demoniczna kobieta. Hrsg. v. A. Micinska. Warszawa 1974.

Stanisław Ignacy Witkiewicz im Briefwechsel mit dem deutschen Philosophen Hans Cornelius. Hrsg. v. H. Kunstmann. In: ZfSIPh 39 (1976), H. 1 S.60-156 und 40 (1978), H. 1. S. 150-213.

Wybór dramatów. Hrsg. v. J. Błonski und M. Kwasny. Wrocław $1974 .{ }^{2} 1983$.

Wybor pism filozoficznych. Hrsg. v. J. Degler und B. Michalski. Wurzburg 1974. (=Analecta Slavica, 7).

Bez kompromisu. Pisma krytyczne i publicystyczne. Hrsg. v. J. Degler. Warapawa 1976

Czysta Forma w teatrze. Hrsg. v. J. Degler. Warszawa 1977, ${ }^{2} 1986$. Narkotyki. Niemyte dusze. Hrsg. v. A. Micinska. Warszawa 1979.

Listy do Bronisława Malinowskiego. Hrsg. v. T. Jodełka-Burzecki und E.C. Martinek. Warszawa 1981.

Nienasycenie. Hrsg. v. M. Misiorny. Warszawa 1982.

Pozegnanie jesieni. Hrsg. v. M. Misiorny. Warszawa 1983.

Wistost tych rzeczy jest nie $z$ swiata tego. Stanisława Ignacego Witkiewicza wiersze i rysunki. Hrsg. v. A. Micinska und Urszula Kenar. Krakow 1984.

Dzieła wybrane. Hrsg. v. T. Jodełka-Burzecki, A. Micinska, K. Puzyna u.a. 5 Bde. Warszawa 1985. 


\subsection{DEUTSCHE UBERSETZUNGEN}

Sammelausgaben:

Stulcke. Ubers.v. H. Bereska. Berlin (Ost) 1982.

Verruckte Lokomotive. Ein Lesebuch mit Bildern des Autors. Hrsg. v. A. Wirth. Frankfurt a.M. 1985

\section{Einzelne Werke:}

Bezimienne dzieło

Das namenlose Werk. Vier Akte eines ziemlich peinlichen Alptraums. Ubers.

v. Ch. Vogel. Berlin (Kiepenheuer) 1972. (Masch. vervielf.)

Dass. ubers. v. H. Bereska. In: Stücke, 1982. S.5-63.

Dramat nie rozpoznany

Das nicht erkannte Drama. Ubers. v. L. Kasajew. Wien 1981.

\section{Gyubal Wahazar}

Gyubal Wahazar oder im Engpaß des Unsinns. Nichteuklidisches Drama in 4 Akten. Ubers. v. I. Boll. Frankfurt a. M. (Suhrkamp) 1974 (Masch. vervielf.)

Gyubal Wahazar oder Auf den Paßhöhen des Unsinns. Ubers. v. H. Bereska. In: Stúcke, 1982. S.63-126.

Janulka, corka FlzdeJkl

Janulka, Tochter des Fizdejko. Tragödie in vier Akten. Ubers. v. G.W. Grzyb und H. Taubmann. Baden-Baden (Hertel) 1987. (Masch. vervielf.)

Jedyne wyjscie

Der einzige Ausweg. (Fragment). Ubers. v. H. Heider und R. Zan. In: Verruckte Lokomotive, 1985. S. 181-196.

\section{Kurka Wodna}

Das Wasserhuhn. Eine sphärische Tragödie in drei Akten. Obers. v. H. Kunstmann. Frankfurt a.M. 1965. 
Dass. ubers. v. N. Dutsch. Munchen (Theater Verlag Desch) 1967. (Masch. vervielf.)

Dass. übers. v. G. Hagenau. Wien (Sessler) 1967. (Masch. vervielf.)

Matka

Die Mutter. Geschmackloses StUlck in zwei Akten mit Epilog. Ubers. v. I. Zimmermann-Göllheim. Baden-Baden (Hertel) 1970. (Masch. vervielf.)

Dass. Ubers. v. H. Bereska. In: Stücke, 1982. S.161-216.

\section{Mątwa czyli Hyrkaniczny swlatopogląd}

Der Tintenfisch oder die Hyrkanische Weltanschaung. Ein Stück in einem Akt. Ubers. v. T. Kantor und H. Taubmann. Baden-Baden (Hertel) 1967. (Masch. vervielf.)

Dass. Ubers. v. H. Bereska. In: Stulcke 1982. S.127-161.

Metaflzyka dwugtowego cielęcla

Die Metaphysik des zweiköpfiges Kalbes. Ein tropisch-australisches Stück in drei Akten. Ubers. v. Ch. Vogel. Berlin (Kiepenheuer) 1970. (Masch. vervielf.)

Nadobnisie 1 koczkodany czyll zielona pigutka

Nixen und Hexen oder Die grüe Pille. Komödie mit Leichen in zwei Akten und drei Bildern. Ubers. v. L. Niesielska. Wien (Sessler) 1974. (Masch. vervielf.)

Niemyte dusze

Ungewaschene Seelen. (Fragment). Ubers. v. K. Dedecius. In: Verruckte Lokomotive, 1985. S. 305-310.

\section{Nienasycenie}

Unersättlichkeit. Ubers. v. W. Tiel. Mit einem Nachwort v. W. Gombrowicz. München 1966.

\section{Nowe wyzwolenie}

Neue Befreiung. Drama in einem Akt. Ubers. v. T. Kantor und H. Taubmann. Baden-Baden (Hertel) 1967. (Masch. vervielf.) 
Ont

Die da. Drama in zweieinhalb Akten. Ubers. v. P. Lachmann. Frankfurt a.M. (Suhrkamp) 1968. (Masch. vervielf.). Abgedruckt in: Theater heute (1986), H. 2. S.34-43.

Jene. Drama in zweieinhalb Akten. Ubers. v. G. W. Grzyb und H. Taubmann. Baden-Baden (Hertel) 1968. (Masch. vervielf.).

Pozegnanie jesient

Abschied vom Herbst (das letzte Kapitel). Ubers. v. H. Heider und R. Zan. In: Verruckte Lokomotive, 1985. S. 85-137.

\section{Pragmatysci}

Die Pragmatiker. Ein Stück in drei Akten. Ubers. v. G.W. Grzyb und H. Taubmann. Baden-Baden (Hertel) 1967. (Masch. vervielf.).

\section{Sonata Belzebuba}

Die Beelzebub-Sonate oder Ein wirklicher Vorfall in Mordovar. Ubers. v. L. Kasajew. Wien (Sessler) 1981.

\section{Szalona Lokomotywa}

Verruckte Lokomotive. Stluck ohne These in zwei Akten mit einem Epilog. Ubers. v. Ch. Vogel. Berlin (Kiepenheuer) 1985. Abgedruckt in: Verrückte Lokomotive. 1985. S.9-40.

\section{Szewcy}

Die Schuster. Ubers. v. Janusz v. Pilecki. Berlin (Klepenheuer) 1967. (Masch. vervielf.). Abgedruckt in: Modernes polnisches Theater $I$. Hrsg. v. A. Wirth. Neuwied und Berlin 1967. S. 7-87. Und in: Verrúckte Lokomotive, 1985. S. 197-297

Dass. Ubers. v. L. Niesielska. Wien (Sessler) 1974. (Masch. vervielf.)

Dass. Ubers. v. H. Bereska. In: Stücke, 1982.

$W$ małym dworku

Im kleinen Landhaus. Stück in drei Akten. Ubers. v. G. W. Grzyb und H. Taubmann. Baden-Baden (Hertel) 1971. (Masch. vervielf.)

dass. Ubers. v. H. Bereska. In: Stücke, 1982. S. 217-262. 
Wariat $i$ zakonnica

Der Narr und die Nonne oder Nichts Schlechtes, das nicht noch schlechter sein könnte. Ein kurzes Stück in drei Akten und vier Vorhăngen. Ubers. v. G. Hagenau. Wien (Deutsch) 1965.

Dass. Ubers. v. H. Kunstmann. Frankfurt a.M. 1965.

Wstep do teorli czystej formy w teatrze

Einfuhrung in die Theorie der Reinen Form des Theaters. Obers. v. F. Griese. In: Verrückte Lokomotive, 1985. S. 41-77.

\subsection{SEKUNDXRLITERATUR ZU WITKIEWICZ}

\subsubsection{BIBLIOGRAPHIEN}

Grzegorczyk, P.: Dzieło pisarskie Stanisława Ignacego Witkiewicza. Próba bibliografii. In: Stanisław Ignacy Witkiewicz. Człowiek i twórca. Księga pamiątkowa. Hrsg. v. T. Kotarbinski und J.E. Płomienski. Warszawa 1957.

Sokót, L.: Stanisław Ignacy Witkiewicz. 1945-1969. Przegląd publikacji. In: Pamiętnik teatralny (1969), H. 3, S. 421-452.

Degler, J.: Twbrczosc Stanisława Ignacego Witkiewicza na swiecie. (Próba bibliografii). In: Przegląd Humanistyczny (1977), H. 10, S. 135-164. und Pamiętnik teatralny (1975) H. 1-4, S. 482-521.

Gasior, A.: Bibliografia podmiotowa i przedmiotowa Stanisława Ignacego Witkiewicza do 1975 r. włącznie. Kartoteka. IBL PAN, Prac Dokumentacji Literatury Współczesnej. Warszawa, Nowy Swiat 72.

Degler, J.: Bibliographie. In: Stanisław Ignacy Witkiewicz. Hrsg. v. H. Dziechcinska. Wrocław u.a. 1986. (=Literary Studies in Poland). S.160-197.

\subsubsection{SAMMELWERKE}

Actes du Colloque international "Witkiewicz" de Bruxelles, Novembre 1981. 
Hrsg. v. A. van Crugten.. In: Cahiers Witkiewicz, H. 4. Lausanne, 1981.

Pamiętnik Teatralny. 1963. H. 3.

Przegląd Humanistyczny. 1977. H. 10.

Russian Literature. 1987. H. 22. Hrsg. v. R. Fieguth.

Spotkanie z Witkacym. Materiały sesji poswięconej tworczosci Stanisława Ignacego Witkiewicza (Jelenia Góra 2-5 Mărz 1978). Hrsg. v. J. Degler. Jelenia Góra 1979.

Stanisław Ignacy Witkiewicz. Człowiek i twórca. Księga pamiątkowa. Hrsg.

v. T. Kotarbinski und J.E. Płomienski. Warszawa 1957.

Stanisław Ignacy Witkiewicz. Katalog zur Ausstellung "Stanisław Ignacy Witkiewicz". Museum Folkwang Essen 1974.

Studia o Stanisławie Ignacym Witkiewiczu. Hrsg. v. M. Głowiński und J. Sławinski. Wrocław u.a. 1972.

Le Theatre en Pologne - The Theatre in Poland, (1975) H. 3.

Le Theatre en Pologne - The Theatre in Poland. (1984) H. 10-12.

Teatr (1975), H. 11.

\subsubsection{EINZELDARSTELLUNGEN}

Birula-Białynicki, Th., 1957: Fragmenty wspomnien o St. Ign. Witkiewiczu. In: Stanisław Ignacy Witkiewicz. Człowiek i twórca. Księga pamiątkowa. Hrsg. v. T. Kotarbinski und J.E. Płomieński. Warszawa. S. $299-307$.

Btonski, J., 1963: Powrot Witkacego. In: Dialog, H. 9, S.71-84.

Błonski, J., 1967a: Teatr Witkiewicza: forma formy. In: Dialog, H. 12 , S.69-83.

Błonski, J., 1967b: Znaczenie i zniekształcenie w "czystej formie" S.I. Witkjewicza. In: Miesięcznik Literacki, H. 8. S. 27-33.

Błonski, J., 1968/69: Faust Witkiewicza. In: Proscenium.

Błonski, J., 1970: U kródeł teatru Witkacego. In: Dialog, H. 5, S.81-90.

Błonski, J., 1972a: Prawodawca sztuki i prorok zagłady - Stanisław Ignacy Witkiewicz. In: Prozaicy dwudziestolecia międzywojennego. Warszawa. S.751-769.

Błonski, J., 1972b: O problematyce dramatów Stanisława Ignacego Witkiewi- 
cza. In: Nurt, H. 5. S.43-46.

Błonski, J., 1973a: Stanisław Ignacy Witkiewicz jako dramaturg. Kraków.

Błonski, J., 1973b: Witkacy a swiat zachodni. In: Texty, H. 3, S.10-41.

Błonski, J., 1976: Trzy apokalipsy w jednej. In: "Twórczosc", H. 10, S.56-78.

Błonski, J., 1983: Wstęp. In: Witkiewicz, St. I.: Wybór dramatów. Wrocław S.I-CXXXV.

Bolecki, W., 1976: Witkacy: fatalne terminy. (Uwagi wstępne). In: Texty, H. 6, S.73-81.

Bolecki, W., 1981: Powiesc worek: Micinski, Jaworski, Witkacy. In: Tworczosc, H. 8, S.92-113.

Crugten, A. van, 1971: S.I. Witkiewicz. Aux sources d'un thectre nouveau. Lausanne.

Czartoryska, U., 1980: Laboratorium "psychologii nieeuklidesowej" czyli o fotografiach Witkacego. In: Odra, H.3., S.55-61.

Danek-Wojnowska, B., 1976: Stanisław Ignacy Witkiewicz a modernizm. Kształtowanie idei katastrophicznych. Wrocław u.a.

Degler, J., 1971: Sztuka teatru w systemie estetycznym Stanisława Ignacego Witkiewicza. In: Littereria, H.3, S.99-129.

Degler, J., 1973: Witkacy w teatrze międzywojennym. Warszawa.

Degler, J., 1985: Dramaty Stanisława Ignacego Witkiewicza na scenach swiata 1971-1983. In: Pamiętnik Teatralny 34, S. 355-424.

Degler, J., 1986: Witkacego teoria teatru. In: St. I. Witkiewicz: Czysta Forma w teatrze. Hrsg. v. J. Degler. Warszawa. 2. Aufl. S. 5-30.

Dort, B., 1980: Die da haben schon die Nachbarsvilla besetzt. Der Pole Wajda und der Franzose Adrien inszenieren Witkiewicz in Frankreich. In: Theater heute, H.8, S.52-54.

Falkiewicz, A., 1960: Witkacy, Artaud, awangarda. In: Dialog, H. 6

Fieguth, R., 1987a: Bemerkungen zur Degradation des Mythos im Drama bei S. Wyspianski und S. I. Witkiewicz. In: Mythos in der slawischen Moderne. Hamburger Kolloquium. Hrsg. v. W. Schmid. Wien. (=Wiener Slawistischer Almanach. Sonderband 20)

Fieguth, R., 1987b: Stanisław Ignacy Witkiewicz. Zum Wechselverhältnis von Theorie und dramatischer Praxis. In: Russian Literature (1987), H.22. $\$ .157-172$

Florynska, H., 1976: Metafizyka czystej formy. 10 tworczosci Stanisława 
Ignacego Witkiewicza). In: Lektury i problemy. Warszawa. S. 285-296.

Gerould, D.Ch., 1981a: Witkacy. St. I. Witkiewicz as an imaginative writer. Seattle, London. Poln. (1981b): Stanisław Ignacy Witkiewicz jako pisarz. Ubers. v. I. Sieradzki. Warszawa.

Gerould, D, Ch., 1990: Witkacy jako postmodernista. In: Dialog, H.6, S.60-63.

Głowinski, M., 1985: Ryszard Ill i Prometeusz. O "Nowym Wyzwoleniu" Stanisława Ignacego Witkiewicza. In: Pamiętnik Literacki, H.4, S.17-27.

Ingarden, R., 1957: Wspomniene o St. I. Witkiewiczu. In: Stanisław Ignacy Witkiewicz. Człowiek i twórca. Księga pamiątkowa. Hrsg. v. T. Kotarbinski und J.E. Płomienskki. Warszawa. S. 169-176.

Irzykowski, K., 1976: Walka o tresc. Kraków 1929. Abgedruckt in: ders.:

Pisma. Hrsg. v. A. Lam. Kraków 1976. S. 87-305.

Iwaszkiewicz, J., 1963: Dramaty Stanisława Ignacego Witkiewicza. In: Twórczosc, H.2, S. 119

Jakimowicz, I., 1974: Malarskie konsekwencje czystej formy. In: Przegląd Humanistyczny, H.7, S.49-67 und H. 8, S. 37-53.

Jakimowicz, I., 1978: Witkacy, Chwistek, Strzeminski. Myśli i obrazy. Warszawa.

Jakimowicz, I., 1985: Witkacy - malarz. Warszawa. Dt.: Witkacy als Maler. Ubers. v. W. Jobhling. Warszawa 1987.

Kiebuzinska, Ch. O., 1988: Revolutionaries in the Theater. Meyerhold, Brecht and Witkiewicz. Ann Arbor u.a.

Kłossowicz, J., 1959: Teoria i dramaturgia Witkacego. In: Dialog, H. 12. S. $81-93$.

Kłossowicz, J., 1964: Konfrontacje: Niespodzianki Witkacego. In: Dialog, H.12.

Kosny, W., 1988: Die Requisiten in S.I. Witkiewicz' "Wariat I zakonnica". In: Ars Philologica Slavica. Festschrift für $H$. Kunstmann. München. S. $248-253$.

Kosny, W., 1989: Zum Nebentext in den Dramen von Stanisław Ignacy Witkiewicz. In: Festschrift für Herta Schmid. Hrsg. v. Jenny Stelleman u. Jan van der Meer. Amsterdam. S.1-19.

Kott, J., 1975: Witkiewicz albo realizm nieoczekiwany. In: Wiadomosci, H.31-32. Dt.: Der unverhoffte Realismus des Witkiewicz. In: Theater heute (1978), H.7, S.32-38. 
Kowalik, K., 1973: Koncepcja procesu twórczego i percepcji dzieła sztuki $w$ estetyce Stanisława Ignacego Witkiewicza. In: Studia Estetyczne, H. 10, S.125.

Kruk, S., 1965: Między Lesmianem a Kantorem. O teorii teatru Stanisława Ignacego Witkiewicza. In: Roczniki Humanistyczne, H. 1, S.109-125.

Kruk, S., 1967: Narodziny polskiej groteski teatralnej. O twórczosci dramatycznej Stanisława Ignacego Witkiewicza. In: Roczniki Humanistyczne, H.1, S.127-143.

Kunstmann, H., 1974: Filozoficzna podróz do Polski. Hans Cornelius i Stanisław Ignacy Witkiewicz. In: Twórczosc, S.72-79.

Kunstmann, H., 1979: Nieznane listy Witkacego. In: Przegląd Humanistyczny, H.6, S.133-136.

Lettenbauer, W., 1973: Zum Stil in zwei Dramen St. I. Witkiewiczs. In: Gedenkschrift fur Alois Schmaus. Munchen. S. 448-454.

Linkowski, R., 1975: Metafizyczny naturalizm estetyki Czystej Formy. In: Studia estetyczne, 12, S.265-277.

Makowiecki, A.Z., 1980: Trzy legendy literackie. Przybyszewski, Witkacy, Gałczyński. Warszawa.

Masłowski, M., 1967: Bohaterowie dramatów Witkacego. In: Dialog, H. 12.

Mencwel, A., 1965: Witkacego jednosc w wielosci. In: Dialog, H. 12.

Michalski, B., 1973: St. I. Witkiewicza monadyzm biologiczny. In: Archiwum Historii Filozofii i Mysli Społecznej, 19.

Michalski, B., 1977: Filozofia ontologicznego pluralizmu S.I. Witkiewicza. In: Schriften, III: 410-447.

Michalski, B., 1978: Miejsce filozofii Witkacego we współczesnej mu filozofii polskiej (Monadyzm biologiczny a reizm und fenomenologıa). In: Studia filozoficzne, H.3, S.79-94.

Michalski, B., 1979: Polemiki filozoficzne Stanisława Ignacego Witkiewicza. Warszawa.

Nierle, M., 1975: Die Darstellung disparater BewuBtseinsebenen in "Nienasycenie" von Stanisław Ignacy Witkiewicz. In: Festschrift für A. Rammelmeyer. München. S.297-316.

Nowotny-Szybistowa, M., 1973: Osobliwoscl leksykalne w jezyku Stanisława Ignacego Witkiewicza. Wrocław.

Piotrowski, P., 1980: Portrety i spoteczenstwo. O Firmie Portretowej S. I. Witkiewicz. In: Problemy interpretacji dzieła sztuki $i$ jego 
funkcji społecznych. Poznan. S. 155-168.

Piotrowski, P., 1985: Metafizyka obrazu. 0 teorii sztuki i postawie artystycznej Stanisława Ignacego Witkiewicza. Poznan.

Pomian, K., 1971: Filozofia Witkacego. In: Pamiętnik Teatralny. 28, H. 3, S.265-280.

Puzyna, K., 1949: Porachunki z Witkacym. In: Twórczosc, H. 7.

Puzyna, K., 19961: Witkacy. In: Dialog, H. 8.

Rogatko, B., 1971: "Walka o tresc" K. Irzykowskiego jako polemika z programen estetycznym S. I. Witkiewicza. In: Pamiętnik Literacki, H.2, S.31- 67 .

Rowinski, C., 1976: Adrian Leverkühn i Joachim Baltazar de Campos de Baleastadar czyli o potędze muzyki. In: Miesięcznik Literacki, H.2, S. $47-54$.

Rudzinska, K., 1973: Artysta wobec kultury. Dwa typy autorefleksji literackiej: ekspresjonisci "Zdroju" i Witkacy. Warszawa.

Rudzinski, R., 1971: Aksjologia Stanisława Ignacego Witkiewicza. In: Etyka, H.9. S.65-90.

Sandauer, A., 1981: Sztuka po koncu sztuki. In: Dialog, H.3, S.100-113.

Sarna, J., 1976: Die geschichtsphilosophischen Ideen von Stanisław Ignac Witkiewicz. In: Deutsche Zeitschrift fur Philosophie, H.12, S.1541.

Sarna, J., 1978: Filosofia St. I. Witkiewicza. Kielce.

Sawrycki, W., 1976: Czysta forma w "Sonacie Belzebuba". In: Dialog, H.2, S.131-138.

Skowronski, J., 1979: O teorii poezji Stanisława Ignacego Witkiewicza. In: Teksty, H.5, S.128-135.

Sokót, L., 1969: Glossa do "Janulki, córki Fizdejki". In: Dialog, H.9. S.110-116.

Sokół, L., 1972: Kształtowanie rzeczywistosci scenicznej w teatrze Stanisława Ignacego Witkiewicza. In: Przegląd Humanistyczny, H.4, S.4371.

Sokół, L., 1973: Groteska w teatrze S.I. Witkiewicza. Wrocław u.a.

Speina, J., 1965: Powiesci Stanisława Ignacego Witkiewicza. Geneza i struktura. Torun 1965.

Szary-Matywiecka, E., 1979: Ksiązka - powiesc - autotematyzm. Od "Pałuby" do "Jedynego wyjscia". Wrocław u.a.

Szpakowska, M., 1968: Witkiewiczowska teoria kultury. In: Dialog, H.10, 
S.104-128.

Szpakowska, M., 1976: Swiatopogląd Stanisława Ignacego Witkiewicza. Wroctaw u.a.

Sztaba, W., 1979: Teatr malarski Witkacego. In: Dialog, H.6, S.134-142.

Sztaba, W., 1982: Gra ze sztuką. O twórczosci Stanisława Ignacego Witkiewicza. Kraków.

Szymanska, B., 1971: Teoria poezji Stanisława Ignacego Witkiewicza. In: Studia Estetyczne, 8, S. 173-187.

Widota, E., 1974: Stylistyczne maski teatru Witkacego. In: Ruch Literacki, H.1, S. 39-48.

Wirth, A., 1985: Nachwort. In: Witkiewicz, St. 1.: Verrulckte Lokomotive. Hrsg. v. A. Wirth. Frankfurt a.M., S.311-320.

Witkiewicz, J.S., 1977: Stanisław Ignacy Witkiewicz w Rosji (w latach 1914-1918). In: Miesięcznik Literacki, H. 8, S.66-74.

Witkiewicz, St., 1969: Listy do syna. Warszawa.

Wojnowska, B., 1972: Sztuka upadła i niech koniec jej będzie lekki. 10 katastrofizmie Stanisława Ignacego Witkiewicza. In: Odra, H.4, S.53-60.

Wolicka, E., 1969: Symbolizm Czystej Formy w pismach estetycznych Stanisława Ignacego Witkiewicza. In: Znak, H. 7-8, S. 932-961.

Zahorska, S., 1945: Stanisław Ignacy Witkiewicz (Witkacy). In: Straty kultury polskiej 1939-1944. Hrsg. v. A. Ordęga und T. Terlecki. Bd. 1. Glasgow. S. 382-396.

Ziomek, J., 1972: Personalne dossier dramatów Witkacego. In: Studia o Stanisławie Ignacym Witkiewiczu. Hrsg. v. M. Głowinski und J. Sławinski. Wrocław u.a., S. 83-105.

\subsection{SONSTIGE SEKUNDXRLITERATUR}

Apollonio, U. (Hrsg.), 1972: Der Futurismus. Manifeste und Dokumente einer künstlerischen Revolution 1909-1918. Koln.

Aristoteles, 1982: Poetik. Ubersetzt und herausgegeben von M. Fuhrmann. Stuttgart.

Asmuth, B., 1984: Einführung in die Dramenanalyse. Stuttgart ${ }^{2} 1984$. 
Bachtin, M., 1965: Trorcestvo Fransua Rable i narodnaja kul'tura srednevekov' ja i Renessansa. Moskva.

Barthes, R., 1970: S/Z. Paris 1970; Dt.: Frankfurt a.M. 1976.

Bauer, S.. 1988: "Gespenster und Propheten". Das moderne polnische Drama auf den Bünnen der Bundesrepublik, Osterreichs und der deutschsprachigen Schweiz. In: Die Rezeption der polnischen Literatur im deutschsprachigen Raum und die der Deutschsprachigen in Polen 19451985. Hrsg. v. H. Kneip und H. Orłowski. Darmstadt. S.128-130.

Bellert, I., 1970: On a condition of the coherence of texts. In: Semiotica, H. 2, S. $335-363$.

Best. O. F. (Hrsg.), 1980: Das Groteske in der Dichtung. Darmstadt.

Borchmeyer, D., Zmegac. V. (Hrsg.), 1987: Moderne Literatur in Grundbegriffen. Frankfurt a.M.

Boy-Zelenski, T., 1957: Pisma. Warszawa

Brauneck, M. (Hrsg.), 1986: Theater im 20. Jahrhundert. Programmschriften, Stilperioden, Reformmodelle. Reinbek b. Hamburg. 2. Aufl.

Broich, U., Pfister, M. (Hrsg.), 1985: Intertextualităt. Formen, Funktionen, anglistische Fallstudien. Tubingen.

Brückner, A., 1974: Słownik etymologiczny języka polskiego. Warszawa. (Nachdruck der Ausgabe von 1927).

Bürger, Ch. und P. (Hrsg.), 1987: Postmoderne: Alltag, Allegorie und Avantgarde. Frankfurt.

Burger, P., 1974: Theorie der Avantgarde. Frankfurt a.M.

Carroll, J.B. (Hrsg.), 1956: Language, Thought, and Reality. Selected Writings of Benjamin Lee Whorf. Cambridge, Mass./New York/London.

Craig, E.G., 1969: Uber die Kunst des Theaters. Hrsg. v. D. Kreidt. Berlin.

Coseriu, E., 1974: Lexikalische Solidarităten. In: Kallmeyer, W. u.a. (Hrsgg.): Lektürekolleg zur Textlinguistik. Bd. 2. Frankfurt a.M., S. $74-86$.

Coseriu, E., 1981: Textlinguistik. Eine Einfuhrung. München.

Civikov, G., 1987: Das ästhetische Objekt. Subjekt und Zeichen in der Literatur wissenschaft anhand einer Kategorie des Prager Strukturalismus. Tubingen.

Culler, J., 1988: Dekonstruktion. Derrida und die poststrukturalistische Literaturtheorie. Aus d. Amerikanischen v. M. Momberger. Reinbek b. 
Hamburg.

Danek, D., 1968: O cytatach struktur (quasi-cytatach) i ich funkcji w wewnętrznej polemice literackiej. In: Prace z poetyki poswięcone VI Międzynaro dowemu Kongresowi Slawistow. Hrsg. v. M.R. Mayenowa und J. Sławinski. Wrocław.

Danek, D., 1972: 0 tytule utworu literackiego. In: Pamiętnik Literacki 63. H.4, S.143-174.

Derrida, J., 1972: Die Schrift und die Differenz. Frankfurt.

Durisin, D., 1968: Die wichtigsten Typen literarischer Beziehungen und Zusammenhănge. In: Aktuelle Probleme der Vergleichenden Literaturforschung. Hrsg. v. G. Ziegengeist. Berlin. S.47-59.

Esslin, M., 1969: The Theatre of the Absurd. New York.

Freytag, G., 1969: Die Technik des Dramas. Darmstadt (Neudruck).

Foster. L.1980a: Gestaltung des Nichtabsoluten. Struktur und Wesen des Grotesken. In: Best, O. (Hrsg.): Das Groteske in der Dichtung. Darmstadt.S. 203-213.

Foster, L., 1980b: Das Groteske. Eine analytische Methode. In: Best, 0.

(Hrsg.): Das Groteske in der Dichtung. Darmstadt. S. 116-123.

Giertz, G., 1975: Kultus ohne Gotter. Emile Jaques-Dalcroze und Adolphe Appia. Versuch einer Theaterreform auf der Grundlage der rhytmischen Gymnastik. München.

Gleizes, A., Metzinger, I., 1912: Vom Kubismus. Berlin.

Goldwater, R., 1967: Primitivism in Modern Art. New York.

Greimas, A.J., 1966: Semantique structurale. Paris. Dt.: Strukturale Semantik. Braunschweig 1971.

Greimas, A.J., 1976: Maupassant. La sémiotique du texte: exercices, pratiques. Paris.

Handbuch philosophischer Grundbegriffe. Hrsg. v. H. Krings, H.M. Baumgartner und Chr. Wild. München 1973-1974.

Hansen-Love, A.A., 1983: Intermedialităt und Intertextualităt. Probleme der Korrelation von Wort- und Bildkunst. Am Beispiel der russischen Moderne. In: Dialog der Texte. Hamburger Kolloquium zu Intertextualităt. Hrsg. v. W. Schmid und W.-D. Stempel. Wien. (Wiener Slawistischer Almanach, Sonderband 11). S.291-360.

Hansen-Love, A.A., 1978: Der russische Formalismus. Wien.

Hegel, G.W.F., 1969ff: Vorlesungen Uber die Asthetik. In: Werke in 20 
Bănden. Frankfurt a.M. Bd. 13-15.

Heilmann, W., 1984: Was ist Form. Zur aktuellen Diskussion in der Religions- und Kunstphilosophie. Munchen.

Hempfer, K.W., 1976: Theorie der Prăsuppositionen und Analyse des Dialogs im absurden Theater (am Beispiel von Ionescos "La Cantatrice chauve"). In: Beihefte zur Zeitschrift fur franzosische Sprache und Literatur, H.4, S.33ff.

Hess, W. (Hrsg.), 1988: Dokumente zum Verstăndnis der modernen Malerei. Reinbek b. Hamburg (Durchgesehene und erweiterte Neuausgabe).

Hubler, A., 1973: Drama in der Vermittlung von Handlung, Sprache und Szene. Bonn.

Ihwe, J. (Hrsg.), 1971: Literaturwissenschaft und Linguistik: Ergebnisse und Perspektiven. 4 Bde. Frankfurt.

Ingarden, R., 1972: Das literarische Kunstwerk. Mit einem Anhang von den Funktionen der Sprache im Theaterschauspiel. Tubingen. 4. Aufl.

Ingarden, R., 1957-58: Studia $z$ estetyki. 3 Bde. Warszawa.

Ingarden, R., 1968: Vom Erkennen des literarischen Kunstwerks. Tubingen 1968.

Jakobson, R., 1971: Linguistik und Poetik. In: Ihwe, J. (Hrsg.): Literaturwissenschaft und Linguistik. Bd. IV/1. Frankfurt. S.142-178.

Jakobson, R., 1981: Uber den Realismus in der Kunst. In: Striedter, J. (Hrsg.): Russischer Formalismus. Texte zur allgemeinen Literaturtheorie und zur Theorie der Prosa. Munchen. 3. Aufl. S.372-391.

Kallmeyer, w. u.a. (Hrsg.), 1974: Lekturekolleg zur Textlinguistik. 2. Bde. Frankfurt a.M.

Kandinskij, V., 1952: Uber das Geistige in der Kunst. Hrsg. v. M. Bill. Bern. 4. Aufl.

Kant, 1., 1974: Kritik der Urteilskraft. In: Werkausgabe. Hrsg. v. W. Weischedel. Bd. 10. Frankfurt a.M.

Kayser, W., 1957: Das Groteske. Seine Gestaltung in Malerei und Dichtung. Oldenburg/Hamburg.

Keller, O., Hafner, H., 1990: Arbeitsbuch zur Textanalyse. Semiotische Strukturen, Modelle, Interpretationen. Müchen. 2. Aufl.

Kemper, P. (Hrsg.), 1988: "Postmoderne" oder Der Kampf um die Zukunft. Frankfurt a.M.

Klotz, V., 1960: Geschlossene und offene Form im Drama. Munchen. 
Knopf, J., 1984: Brecht-Handbuch. Stuttgart.

Kunstmann, H., 1965: Moderne polnische Dramatik. Köln.

Kutschera, F.v., 1988: Ästhetik. Berlin/New York.

Lévi-Strauss, C., 1958/1974: Anthropologie strukturale. 2 Bde. Paris.

Dt.: Strukturale Anthropologie. Frankfurt a.M. 1978 und 1980.

Lewandowski, Th., 1990: Linguistisches wörterbuch. 3 Bde. Heidelberg/Wiesbaden. 5. Aufl.

Link, J., 1985: Literaturwissenschaftliche Grundbegriffe. Munchen. 3.Aufl.

Lotman, Ju., 1989: Die Struktur literarischer Texte. MUnchen. 3. Aufl.

Lyotard, J.-F., 1984: Das Erhabene und die Avantgarde. In: Merkur, 38, S.151-164.

Lyotard, J.F., 1986: Das postmoderne Wissen. Aus d. Französischen v. O.Pfersmann. Vollst. Uberarb. Fassung. Graz u.a.

Malevix, K., 1989: Suprematismus. Die gegenstandslose Welt. (Aus d. Russ. v. Hans v. Riesen). Hrsg. v. W. Haftmann. Köln. 2. Aufl.

Marczak-Oborski, S. (Hrsg.), 1973: Mysl teatralna polskiej awantgardy 1919-1939. Antologia. Warszawa.

Markov, V.: (Hrsg.), 1967: Manifesty i programmy russkich futuristov (Die Manifeste und Programmschriften der russischen Futuristen). MUnchen.

Mukarovsky, J., 1967: Kapitel aus der Poetik. Ubers. v. W. Schamschula. Frankfurt a.M.

Mukałovsky, J., 1974: Studien zur strukturalistischen $\lambda$ sthetik und Poetik. Munchen 1974.

Nietzsche, F.W., 1987: Die Geburt der Tragodie aus dem Geiste der Musik. Hrsg. v. P. Sloterdijk. Frankfurt a.M.

Petofi, J.S., Franck, D.: (Hrsg.), 1973: Prăsuppositionen in Philosophie und Linguistik. Frankfurt.

Pfister, M., 1988: Das Drama. Theorie und Analyse. Munchen. 5. Aufl.

Portner, P. (Hrsg.), 1960: Literaturrevolution 1910-1925. Dokumente Manifeste - Programme. 2 Bde.

Propp, V., 1975: Morphologie des Mărchens. Frankfurt a. M. 1975. Russ.: Morfologia skazki. Leningrad 1928.

Putz, P., 1970: Die Zeit im Drama. Gottingen 1970.

Sandig, H., 1980: Deutsche Dramaturgie des Grotesken um die Jahrhundertwende. München. 
Sauerbier, S.D., 1976: Gegendarstellung. Ästhetische Handlungen und Demonstrationen. Die zur Schau gestellte Wirklichkeit in den zeitgenössischen Künsten. Köln.

Schlemmer, O. U.a., 1965: Die Buhne im Bauhaus. Hrsg. v. W. Gropius. Mainz/Berlin.

Schmeling, M., 1977: Das Spiel im Spiel. Ein Beitrag zur Vergleichenden Literaturkritik. Rheinfelden.

Schulte-Sasse, J., Werner, R., 1977: Einfuhrung in die Literaturwissenschaft. Munchen.

Sklovskij, V., 1925: Teorija prozy. Moskva, Leningrad.

Sklovskij, V., 1981: Die Kunst als Verfahren. In: Striedter, J. (Hrsg.): Russischer Formalismus. Texte zur allgemeinen Literaturtheorie und zur Theorie der Prosa. Munchen. 3. Aufl., S. 3-35.

Souriau, E., 1950: Les deux cent mille situations dramatiques. Paris.

Strelka, J., 1978: Methodologie der Literaturwissenschaft. Tubingen.

Strelka, J., 1989: Einfuhrung in die literarische Textanalyse. Tubingen.

Striedter, J. (Hrsg.), 1981: Russischer Formalismus. Texte zur allgemeinen Literaturtheorie und zur Theorie der Prosa. München. 3. Aufl.

Striedter, J., 1981: Zur formalistischen Theorie der Prosa und der literarischen Evolution. In: Striedter, J. (Hrsg.): Russischer Formalismus. Texte zur allgemeinen Literaturtheorie und zur Theorie der Prosa. Munchen ${ }^{3} 1981$. S.IX-LXXXIII.

Tesnière, L., 1953: Esquisse de Syntaxe Strukturale. Paris 1953. Dt. (Auszuge): Entwurf einer strukturalen Syntax. Ubersetzt v. Wolfgang Klein. Saarbrücken 1969.

Todorov, T., 1969: Grammaire du Decamtrone. Paris.

Todorov, T., 1972: Poetik der Prosa. Frankfurt a.M.

Todorov, T., 1972: Die strukturelle Analyse der Erzahlung. Ubersetzt von G. Köhler. In: Ihwe, J. (Hrsg.): Literaturwissenschaft und Linguistik. Bd. 3/II. S. 265-275.

Tomaševskij, B., 1985: Theorie der Literatur. Poetik. Nach dem Text der 6. Auflage (Moskau-leningrad 1931) herausgegeben und eigeleitet von Klaus-Dieter Seemann. Aus dem Russischen ubersetzt von Ulrich Werner. Wiesbaden.

Voigt, J., 1954: Das Spiel im Spiel. Gottingen.

Weiss, P., 1979: Kandinsky in Munich. The Formative Jugendstil Years. 
Princeton.

Werlen, I., 1989: Sprache, Mensch und Welt. Geschichte und Bedeutung des Prinzips der sprachlichen Relativität. Darmstadt.

Werner, J.M., 1986: Erkenntnis und Wahrheit. Nietzsches Destruktion der Erkenntnistheorie als Konsequenz des Verlustes verbindlicher Wahrheit. Frankfurt u.a.

Worringer, W., 1987: Abstraktion und Einfuhlung. Munchen. 14. Aufl.

Zelinsky, B., 1983: Der Primitivismus und die Anfänge der avantgardistischen Malerei und Literatur in RuBland. In: ders.: (Hrsg.): Russische Avantgarde 1907-1921. Bonn. S. 5-25.

Zelinsky, B. (Hrsg.), 1983: Russische Avantgarde 1907-1921. Vom Primitivismus zum Konstruktivismus. Bonn.

Zima, P.V., 1991: Literarische Xsthetik: Methoden und Modelle der Literaturwissenschaft. Tubingen. 


\section{ABKURZUNGSVERZEICHNIS}

Werkausgaben

Schriften

Pisma filozoficzne i estetyczne (Philosophische und asthetische Schriften). Hrsg. v. J. Leszczynski und B. Michalski. 4 Bde. Warszawa $1974-78$.

Werke

Dzieła wybrane (Ausgewahlte Werke). Hrsg. v. T. Jodełka-Burzecki, A. Micinska, K. Puzyna u.a. 5 Bde. Warszawa 1985.

Theoretische Schriften:

CzF O Czystej Formie (Uber die Reine Form). Erstdruck: Zet (1932), H.7, S.2; H.9, S.3; H.10, S.3; H.11, S.2; H.12, S.4. Entstanden vermutlich 1921 oder 1925. Zitiert nach: Schriften, II: 31-53.

NFM Nowe formy $w$ malarstwie i wynikajace stąd nieporozumienia (Neue Formen in der Malerei und die daraus entstehenden MiBverstăndnisse). Erstdruck: Warszawa 1919. Zitiert nach: Schriften, I: 3152.

SzE Szkice estetyczne (Ästhetische Skizzen). Erstdruck: Kraków 1922. Zitiert nach: Schriften, I: 153-240.

$T$ Teatr. (Theater). Erstdruck: Krakow 1923. Eln Sammelband mit theoretischen Aufsätzen und Kritiken, die zwischen 1920 und 1923 in verschiedenen Zeitschriften publiziert wurden. Zitiert nach: Schriften, I: 241-394.

Dramen

(Alle bis auf "Panna Tutli-Putli" zitiert nach: Werke, Bd. IV und V)

$B D$ Bezimienne dzieło. Cztery akty dost przykrego koszmaru (Das namenlose Werk. Vier Akte eines ziemlich peinlichen Alptraums). 1921. 
GW Gyubal Wahazar, czyli Na przełęczach bezsensu. Nieeuklidesowy dramat w czterech aktach (Gyubal Wahazar oder Auf den Paßhöhen des Unsinns. Nichteuklidisches Drama in vier Akten). 1921.

JCF Janulka, córka Fizdejki. Tragedia w czterech aktach. (Janulka, die Tochter von Fizdejko. Tragödie in vier Akten). 1923.

JMKW Jan Maciej Karol Wscieklica. Dramat w trzech aktach bez trupów. (Jan Maciej Karol Wuterich. Drama in drei Akten ohne Leichen). 1922.

KW Kurka Wodna. Tragedia sferyczna w trzech aktach (Das Wasserhuhn. Spharische Tragðdie in drei Akten). 1921

M Mątwa czyli Hyrkaniczny swiatopogląd. Sztuka w jednym akcie (Der Tintenfisch oder die Hyrkanische Weltanschaung. Ein Stuck in einem Akt). 1922

Matka Matka. Niesmaczna sztuka w dwoch aktach z epilogiem. (Die Mutter. Geschmackloses Stuck in zwei Akten mit Epilog). 1924

MDC Metafizyka dwugłowego cielęcia. Tropikalno-australijska sztuka w trzech aktach. (Die Metaphysik eines zweikbpfiges Kalbes. Ein tropisch-australisches Stuck in drei Akten). 1921.

MKIB Maciej Korbowa i Bellatrix. Tragedia $w$ pięciu aktach $z$ prologiem. (Maciej Korbowa und Bellatrix. Tragödie in funf Akten mit Prolog). 1918.

MP Mister Price czyli Bzik tropikalny. Dramacik w trzech aktach napisany na wspótkę z pania Eugenią Dunin-Borkowska (Mister Price oder der Tropenkoller. Ein kleines Drama in drei Akten geschrieben zusammen mit Frau Eugenia Dunin-Borkowska). 1920.

NIK Nadobnisie i koczkodany czyli zielona pigułka. Komedia z trupami w dwóch aktach $i$ trzech odsłonach (Grazien und Vogelscheuchen oder Die grune Pille. Komodie mit Leichen in zwei Akten und drei AufzUgen). 1922.

NT Niepodległose trójkątów. Sztuka w czterech aktach. (Die Unabhăngigkeit der Dreiecke. Stuck in vier Akten). 1921.

NW Nowe wyzwolenie. Dramat w jednym akcie (Neue Befreiung. Drama in einem Akt). 1920.

Oni Oni. Dramat w dwoch i poł aktach (Die da. Drama in zweieinhalb Akten). 1920.

PTP Panna Tutli-Putli. Libretto do operetki $w$ trzech aktach $w$ czysta- 
wej formie. (Frăulein Tutli-Putli. Libretto zu einer Operette in reinlicher Form in drei Akten). 1920. Erstdruck von erhaltenen Fragmenten in: Dialog (1974), H.2, S. 34-54.

P Pragmatyści. Sztuka w trzech aktach (Die Pragmatiker. Stuck in drei Akten). 1919.

SB Sonata Belzebuba czyli Prawdziwe zdarzenie w Mordowarze (Die Beelzebubsonate oder Ein wahrer Vorfall in Mordosud). 1925.

SL Szalona lokomotywa. Sztuka bez tezy $w$ dwoch aktach $z$ epilogiem (Verruckte Lokomotive. Stuck ohne These in zwei Akten mit einem Epilog). 1923.

Sz Szewcy. Naukowa sztuka ze "spiewkami" w trzech aktach (Die Schuster. Wissenschaftliches Stück mit "Liedchen" in drei Akten). 1934.

TM Tumor Mózgowicz. Dramat w trzech aktach z prologiem. (Tumor Hirnmann. Drama in drei Akten mit einem Prolog). 1920.

WiZ Wariat i zakonnica czyli nie ma złego co by na jeszcze gorsze nie wyszło. Krótka sztuka w trzech aktach i czterech odsłonach. (Narr und Nonne oder Es gibt nichts Schlimmes, was sich nicht zum Schlimmeren wenden würde. Kurzes Stück in drei Akten und vier Aufzulgen). 1923.

WMD W małym dworku. Sztuka w trzech aktach. (Im kleinen Landhaus. St(lick in drei Akten). 1921. 